\title{
Trace elements in New Zealand ferromanganese nodules: implications for deep sea environments
}

Andrea Mary Lola Davies

A thesis submitted to Victoria University of Wellington in partial fulfilment of requirements for the degree of Master of Geology, October 2017.

School of Geography, Environment and Earth Sciences

Victoria University of Wellington 



\section{Contents}

Contents

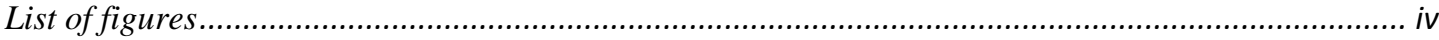

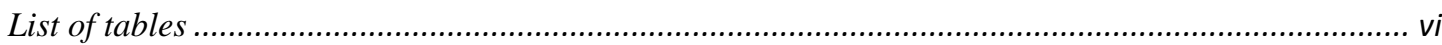

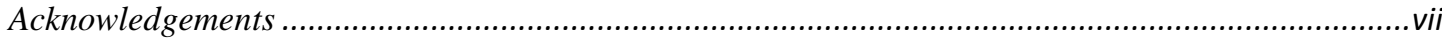

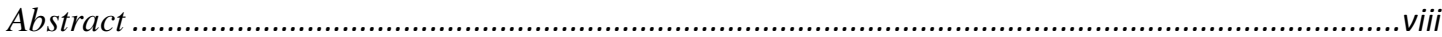

\section{Chapter 1 Introduction ................................................................................ 1}

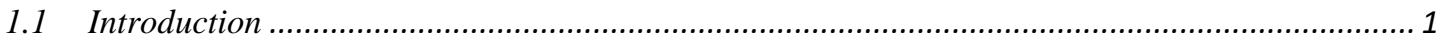

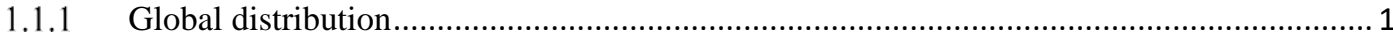

1.1.2 New Zealand nodule fields ......................................................................................... 3

1.2 Thesis aims

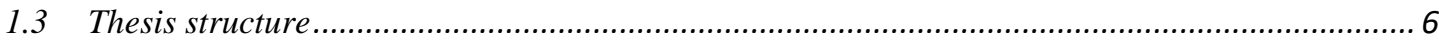

\section{Chapter 2 Oceanography ..................................................................................... 9}

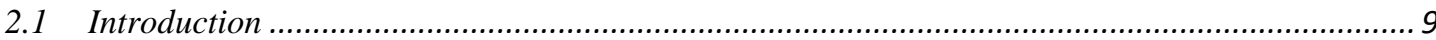

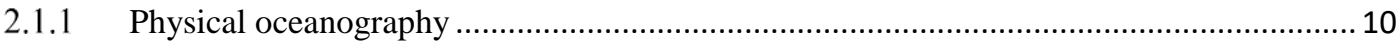

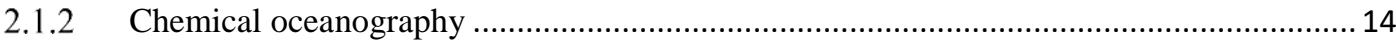

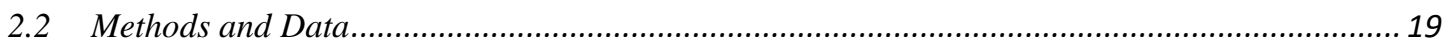

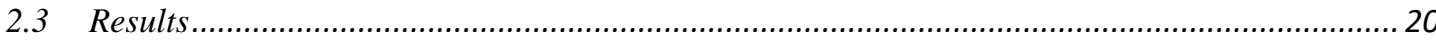

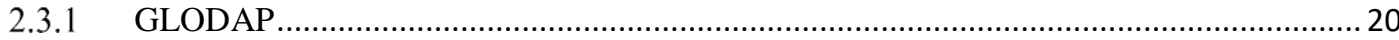

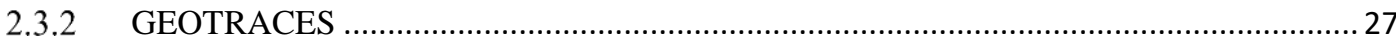

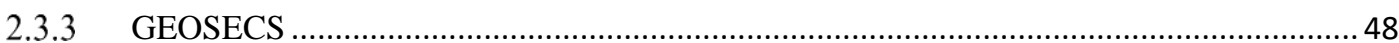

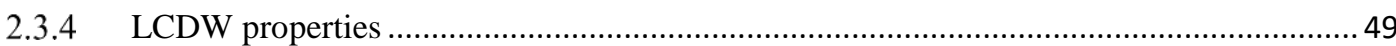

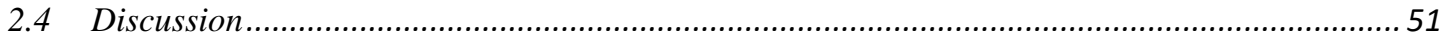

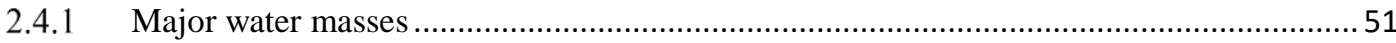

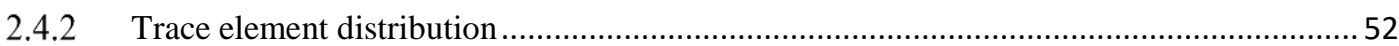

2.4.3 South West Pacific Ocean trace elements ...................................................................... 59

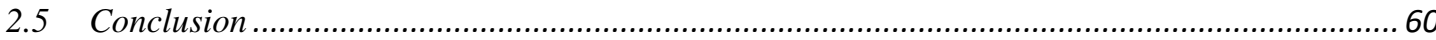

\section{Chapter 3 Deep-sea sedimentology ................................................................. 61}

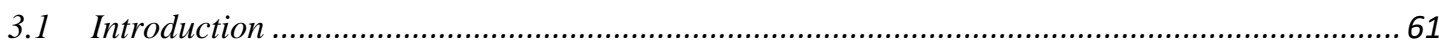

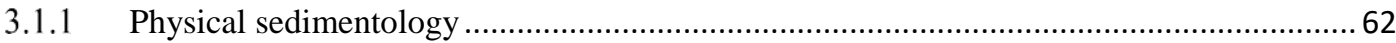

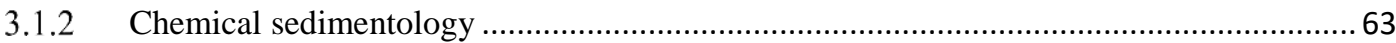




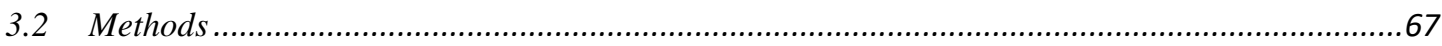

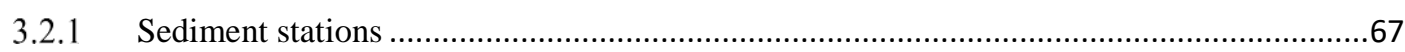

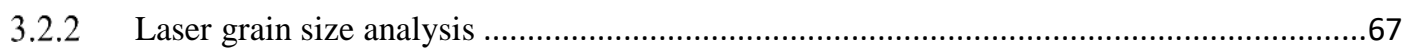

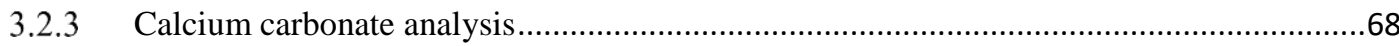

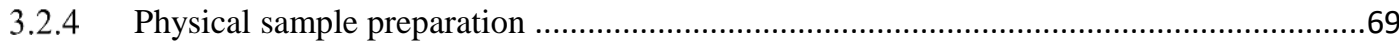

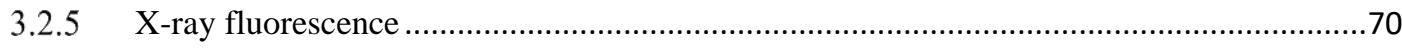

3.2.6 Electron probe microanalyser Energy-dispersive X-ray spectroscopy ............................70

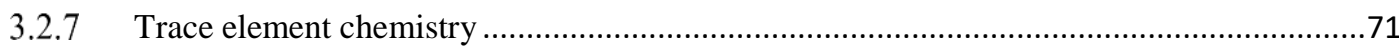

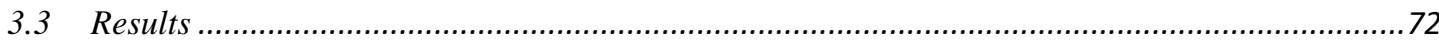

3.3.1 Grain size and calcium carbonate content............................................................. 72

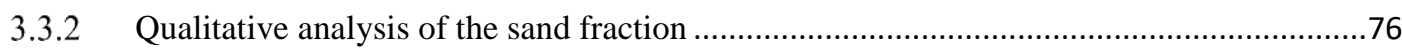

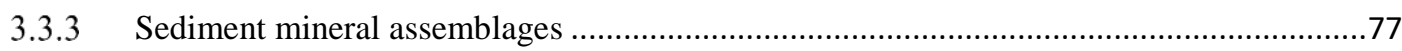

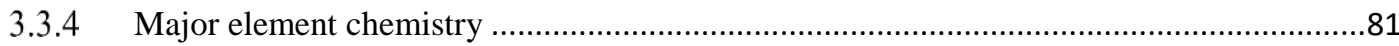

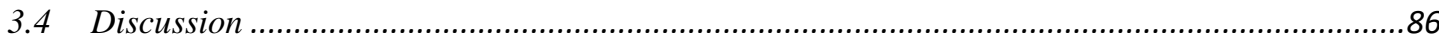

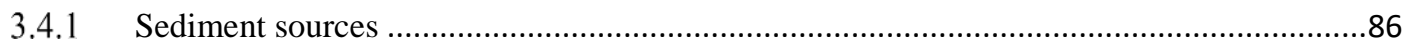

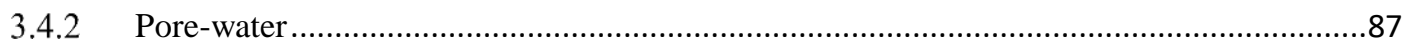

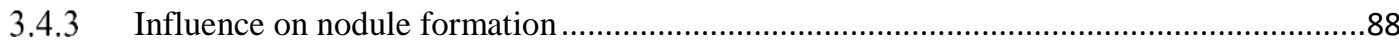

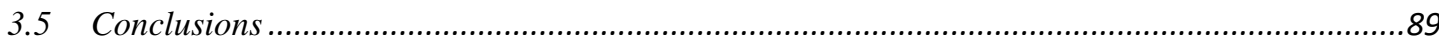

Chapter 4 Ferromanganese nodules...................................................91

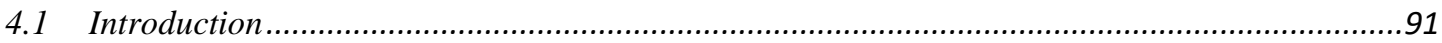

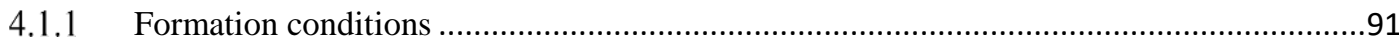

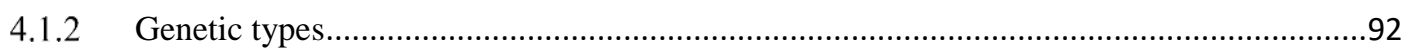

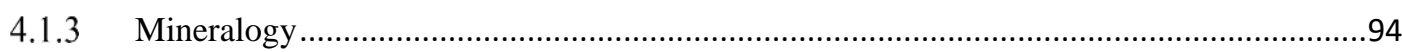

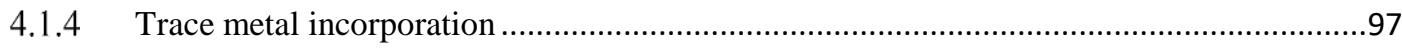

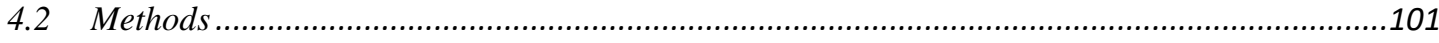

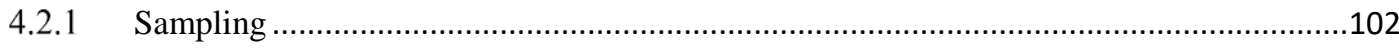

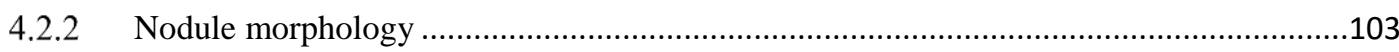

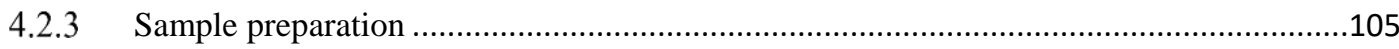

4.2.4 Inductively coupled plasma mass spectrometry .................................................106

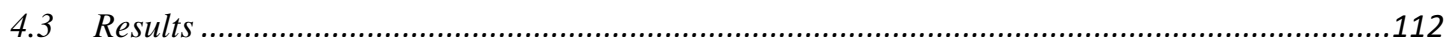

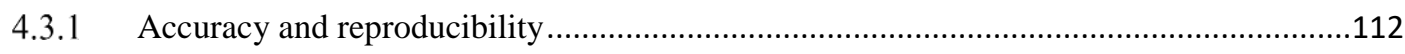

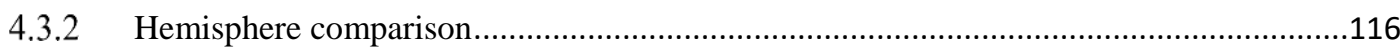

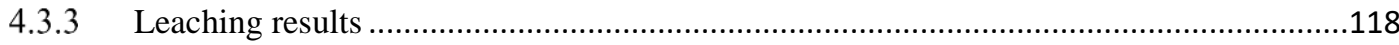

4.3.4 New Zealand nodule fields ...........................................................................120

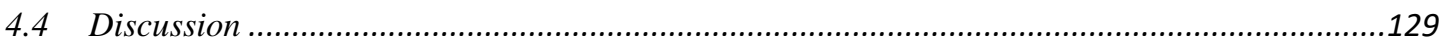

4.4.1 Influence of the detrital component on bulk compositions. .........................................129 


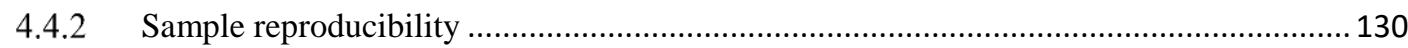

4.4.3 Geochemistry of the New Zealand nodule fields ..................................................... 132

4.5 Conclusions

Chapter 5 Synthesis ................................................................................... 137

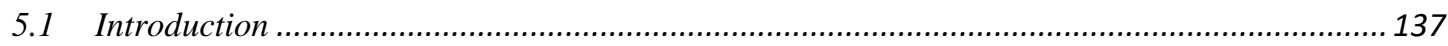

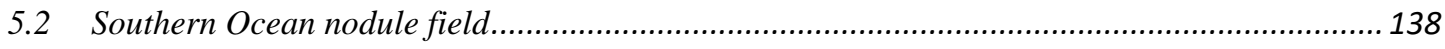

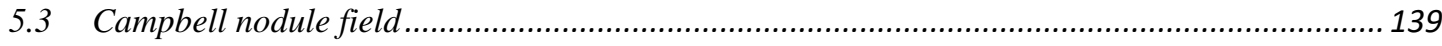

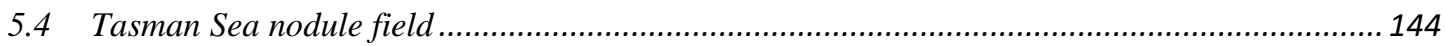

Chapter 6 Conclusions and future work ................................................. 147

6.1 Conclusions

6.2 Future work

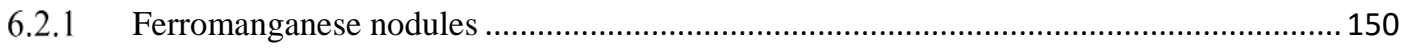

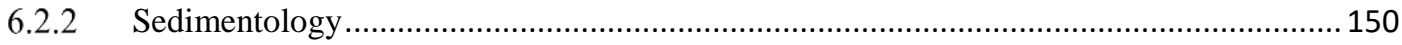

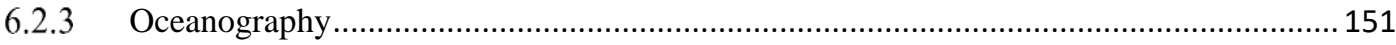

Appendix A Oceanography figures ......................................................... 153

Appendix B Sedimentary data ........................................................................ 159

Appendix C Ferromanganese nodule characteristics............................. 161

Appendix D Major, minor and trace elements - ICP-MS ................... 201

Appendix E JMn-1 (GSJ SRM) data from ICP-MS runs.................... 219

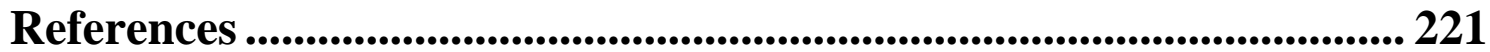




\section{List of figures}

Figure 1.1: The approximate global distribution of known major ferromanganese nodule fields.__ 2

Figure 1.2: Ferromanganese nodule and deep ocean sediment sample locations on a bathymetric map of New Zealand.

Figure 2.1: Deep water currents found in the New Zealand region. 11

Figure 2.2: Interpreted nepheloid layer and the Campbell Plateau.__ 12

Figure 2.3: Topas screenshot from the TAN1702 voyage. _ 13

Figure 2.4: Map of the New Zealand transects visualised from the GLODAP dataset.__ 20

Figure 2.5: Temperature, salinity, and oxygen profiles along the P15 transect. __ 22

Figure 2.6: Phosphate and silicate profiles along the P15 transect. 23

Figure 2.7: Temperature, salinity, and oxygen profiles along the P11 transect. _ 25

Figure 2.8: Phosphate and silicate profiles along the P11 transect. 26

Figure 2.9: Map of transects GIPY4 (South Atlantic), SR3 (Tasman Sea), and GP13 (Southwest Pacific Ocean). 27

Figure 2.10: Temperature, salinity, and oxygen profiles for the GIPY4 GEOTRACES transect. _ 29

Figure 2.11: Phosphate and silicate profiles for the GIPY4 GEOTRACES transect. __ 30

Figure 2.12: Dissolved Mn and Fe profiles for the GIPY4 GEOTRACES transect. ___ 32

Figure 2.13: Dissolved Ce and La profiles for the GIPY4 GEOTRACES transect. __ 33

Figure 2.14: Dissolved Pb, Al, and Ti profiles for the GIPY4 GEOTRACES transect. ___ 35

Figure 2.15: Dissolved Cu, Zn, and Cd profiles for the GIPY4 GEOTRACES transect. __ 36

Figure 2.16: Temperature, salinity, and oxygen profiles for the SR3 GEOTRACES transect. _ 38

Figure 2.17: Phosphate and silicate profiles for the SR3 GEOTRACES transect. __ 39

Figure 2.18: Dissolved Fe, Al, and Ni profiles for the SR3 GEOTRACES transect. __ 40

Figure 2.19: Dissolved $\mathrm{Cu}, \mathrm{Zn}$, and Cd profiles for the SR3 GEOTRACES transect. __ 41

Figure 2.20: Temperature, salinity, and oxygen profiles for the GP13 GEOTRACES longitudinal transect.

Figure 2.21: Phosphate and silicate profiles for the GP13 GEOTRACES transect.___ 44

Figure 2.22: Dissolved Mn, Fe, and Ni profiles for the GP13 GEOTRACES transect. __ 45

Figure 2.23: Dissolved Pb profile for the GP13 GEOTRACES transect.__ 46

Figure 2.24: Dissolved Cu, Zn, and Cd profiles for the GP13 GEOTRACES transect.___ 47

Figure 2.25: Dissolved $\mathrm{Mn}$ at $178^{\circ} \mathrm{E}, \mathrm{52}^{\circ} \mathrm{S}$ and 5,454 $\mathrm{m}$ bottom depth. ___ 48

Figure 3.1: Map of the sediments sample locations analysed in this study.

Figure 3.2: Example of sedimentary clasts in a surficial sediment. _— 63

Figure 3.3: A typical redox reaction sequence in the sedimentary column. __ 65

Figure 3.4: The percentage sand, silt, and clay for each sediment. $\_74$

Figure 3.5: Sand distribution. 15

Figure 3.6: Sand percentage versus calcium carbonate percentage.__ 75

Figure 3.7: Particle distribution from grainsize analysis and GRADISTAT. _ 76

Figure 3.8: Discrimination diagram of Bhatia (1983) for terrigenous components. __ 81 
Figure 3.9: Major oxide ratios on Campbell Slope to identify source variations.

Figure 3.10: Major element oxide ratios for Campbell Slope sediments to identify potential redox variations in the sediment.

Figure 4.1: Ferromanganese nodule types and the sedimentary environment in which they form. 92

Figure 4.2: Polyhedral representations of phyllomanganate and tectomanganate mineral structures. 96

Figure: 4.3: Simplified electrochemical model showing adsorption of dissolved trace metal species onto oppositely charged Fe and Mn oxyhydr(oxide) colloids. 98

Figure 4.4: Hyperbolic regression curves for $\mathrm{Ni}+\mathrm{Cu}$ and $\mathrm{Mn} / \mathrm{Fe}$ for nodule samples from the Clarion Clipperton Zone (CCZ) and Peru Basin. 98

Figure 4.5: Locations where the ferromanganese nodules were sampled. 101

Figure 4.6: Sample U1398-1-D, showing concentric growth layers typical of nodule growth. 103

Figure 4.7: Ferromanganese nodule morphotypes. 104

Figure 4.8: The outermost $1 \mathrm{~mm}$ of each nodule. 105

Figure 4.9: The weights measured for sample U1399-1-A-Z are plotted to show the method used to determine dry weights for the sample aliquots. 108

Figure 4.10: Hemisphere comparison. 117

Figure 4.11: Authigenic ( $\mathrm{L}$ - leached) and alumino-silicate ( $\mathrm{D}$ - detrital-residue) phase associations for samples. 119

Figure 4.12: Ternary diagram with $\mathrm{Fe}-\mathrm{Mn}-(\mathrm{Ni}+\mathrm{Cu}) * 10$. 121

Figure 4.13: $\mathrm{Cu}+\mathrm{Ni}(\mathrm{ppm})$ concentrations against $\mathrm{Mn} / \mathrm{Fe}$ for samples analysed in this study. 122

Figure 4.14: Multi-element diagram. 126

Figure 4.15: Shale (PAAS) normalised REE concentrations of ferromanganese nodules. 129

Figure 5.1: Model velocity at the seafloor. 139 


\section{List of tables}

Table 1.1: Location of ferromanganese nodules, and sediments analysed in this study. __ 5

Table 2.1: Latitude, longitude, and depth for each ferromanganese nodule location. 9

Table 2.2: Common mineral and their associated formula. 14

Table 2.3 LCDW hydrographic and nutrient properties. 49

Table 2.4: Dissolved trace elements in LCDW. 50

Table 3.1: Texture, grain size and calcium carbonate content of each sediment sample. 73

Table 3.2: Qualitative analysis of the sand fraction. 78

Table 3.3: Mineral groups identified in the sediments from EDS analyses. 80

Table 3.4: Element oxide ratios. 85

Table 4.1: Sample counts for each location. 102

Table 4.2: Elements and isotopes measured on the ICP-MS. 111

Table 4.3: Summary of replicate analyses of GSJ SRM JMn-1. 113

Table 4.4: Summary of replicate analyses of USGS SRM NOD-A-1 114

Table 4.5: Summary of replicate analyses of sample U1413-1-B. 115 


\section{Acknowledgements}

First and foremost I would like to thank my supervisors: Monica Handler, Richard Wysoczanski and Helen Bostock. The experience I have gained throughout this thesis is invaluable, and I have learned so much from each of you. Monica, I appreciate being able to knock on your door for any question, big or small. Richard, thanks for kicking the project off, and assisting me throughout my thesis. Helen, I was astounded by your remarkably quick turn around with edits. I sincerely appreciate the vast amount of assistance I received from all of my supervisors, and their continual support throughout all the setbacks.

I would like to thank those who provided technical and analytical assistance through the (significant) laboratory work required in this thesis. In particular I would like to acknowledge Bruce Charlier and Luisa Ashworth for their assistance in the Geochemistry laboratory, Jane Chewings in the sedimentary laboratory, and Lisa Northcote at NIWA for your laboratory help. I would like to thank Elliot Swallow for showing me the ropes around multiple laboratories at SGEES. I would also like to thank Jenni Hopkins for your help with the EPMA.

The funding for this thesis was provided by NIWA through the Enabling the Management of Offshore Mining (EMOM) project from the Ministry of Business, Innovation and Employment.

I would like to thank my friends and family for their continual support. To my "academic sister" Gracie Frontin-Rollet, your help is greatly appreciated, and I enjoyed our academic and non-academic discussions. Thanks to my flatmates, both past and present: Hannah, Ella, and Tom. I would also like to thank fellow masters students; Hamish, Aiden, Tom, Lauren, and Alex. Lastly, but definitely not least, I would like to thank my parents Shona and Philip Davies for your love and support throughout my thesis. 


\begin{abstract}
Ferromanganese nodules are authigenic marine sediments that form over millions of years from the precipitation of Fe oxyhydroxides and Mn oxides from seawater (hydrogenetictype growth) and sediment pore-water (diagenetic-type growth). Fe-Mn (oxyhydr)oxides grow in layers about nuclei, effectively scavenging minor metals such as $\mathrm{Ni}, \mathrm{Cu}$ and $\mathrm{Co}$ from the waters they grow in. The uptake of different elements into the ferromanganese nodules reflects their environment and mechanism of growth, and these deposits are of interest both as a potential source of metals of economic interest, and as records of changing ocean conditions.
\end{abstract}

This study investigates the composition of 77 ferromanganese nodules from the seafloor around New Zealand. Samples analysed come from locations several thousand kilometres apart under the same water mass (Lower Circumpolar Deep Water - LCDW), but with varying depth, current velocity, and sediment type. The outermost $1 \mathrm{~mm}$ rim of each nodule, representing near-modern growth, was sampled to compare with modern environmental parameters including substrate sediment composition and chemical and physical oceanography. Major, minor, and trace element analysis of nodule rims were undertaken, and the authigenic and detrital components examined via leaching experiments to evaluate their relative influence on growth mechanisms.

Overall, New Zealand ferromanganese nodules are hydrogenetic in origin. However, there are systematic variations in composition that reflect variable diagenetic influence. Hydrogenetic endmember compositions are defined by samples from two localities in the Southern Ocean that have no evidence for diagenetic influence. Diagenetic influence on nodule composition is exemplified by samples from the two locations in the Tasman Sea, but also include nodules from the Campbell nodule field. Nodules from the Campbell nodule field come from two transects perpendicular to the Campbell Plateau, and the Deep Western Boundary Current (DWBC). Both sediment composition and nodule rim chemistry vary systematically across both transects. Areas closest to the slope have sediment profiles indicating high energy, erosive environments, continental-sourced sand components, and are dominated by nodules with hydrogenetic chemical characteristics similar to those of the Southern Ocean. Further from the slope, the sediment profiles indicate silt dominated sediments of a more oceanic crustal provenance, lower energy environment, and increased influence of oxic diagenetic processes on the major, minor 
and trace element profiles of the nodules. No hydrothermal contribution was identified in the chemistry of any of the nodules analysed.

The physical and chemical properties of the sediment, along with current velocities, were found to be the key influences in diagenetic enrichment in the nodules. The influence of seawater chemistry was difficult to determine due to the lack of direct analyses in the area. Ferromanganese nodule chemistry is a function of the nodule environment, including water body, sediment composition and depth. The authigenic components of nodules can therefore be used to investigate the deep-sea environment.

The redox conditions of sediments and the productivity of the overlying water will affect the trace metal constituents of the pore-waters of a sediment (Kuhn et al., 2017). Sediments with a larger fraction of labile organic matter may result in trace element enrichment of the pore-water. Sediments below the CCD will be higher in trace elements than sediments below the CCD (U1413, U1406B, U1402, U1398, U1398, and U1378) due to carbonate matter acting as a dilutant that can limit the supply of trace elements mobilised in the pore-water during diagenesis (Glasby, 2006). Terrigenous clasts such as quartz (Chester, 1990), will also reduce trace element enrichment in the pore-water due to their low reactivity, e.g. for the sediment U1406B, which has a high lithic component (Table 3.2). Sediments with a higher biogenic silica component (such as U1373, U1374, and U1378) (Table 3.2, Table 3.4) are predicted to produce nodules with higher trace element contents (ISA, 2010).

In contrast to both the CCZ and Indian Ocean nodules, the Campbell nodule field samples formed above the CCD, and hence in sediments that include a significant carbonate component. This minimises the trace element pore-water enrichment and can account for the lower $\mathrm{Cu}+\mathrm{Ni}+\mathrm{Co}$ contents observed in the Campbell nodule field nodules compared with those that formed below the CCD (CCZ and Indian Ocean). 



\section{Chapter 1 Introduction}

\subsection{Introduction}

Ferromanganese nodules are deep-water polymetallic concretions formed by the precipitation of Fe-Mn (oxyhydr)oxide layers around a nucleus. In the marine environment $\mathrm{Fe}$ and $\mathrm{Mn}$ are redox sensitive and upon oxidisation they precipitate from seawater or pore-water in the sediments, forming hydrogenetic and diagenetic type nodules respectively. Both $\mathrm{Fe}$ and $\mathrm{Mn}$ (oxyhdr)oxides are effective scavengers of minor elements such as $\mathrm{Ni}, \mathrm{Cu}$, and $\mathrm{Co}$, with the hydrogenetic-diagenetic ratio causing variations in the enrichment of these metals. Ferromanganese nodules are also potentially valuable economic resources that are becoming increasingly of interest due to their association with metals used in the rapidly growing green technology sector. These are base elements such as $\mathrm{Mn}, \mathrm{Co}, \mathrm{Ni}, \mathrm{Cu}$ and other associated metals such as $\mathrm{Li}$, and the rare earth elements (REE). As an example, the green technology sector uses these metals for applications such as smartphones and cars (Hein et al., 2013). China currently holds a monopoly on the production of REE, and finding additional sources of these resources is desirable (Ragnarsdóttir, 2008; Kato et al., 2011).

Ferromanganese nodule growth is one of the slowest processes on earth (ISA, 2008), with Fe-Mn oxyhydroxides precipitating in layers around a central nucleus at rates of 1250 mm/m.yr. (von Stackelberg, 2000; Hein and Koschinsky, 2014). As such, nodule micro-layers provide records of changing environmental conditions and seawater chemistry over time (m.yr.). In this study only the outermost rims $(<1 \mathrm{~mm})$ of ferromanganese nodules from the oceans around New Zealand have been analysed to determine their chemical composition and the influence of the oceanography and sedimentology on their formation in the (near) modern day environment.

\subsubsection{Global distribution}

Ferromanganese nodules have been found in ocean basins worldwide (Hein et al., 2013) (Figure 1.1). There are three main regions within ocean basins where nodules form; abyssal plains, mountainous seafloor regions, and the siliceous circumpolar belt (Glasby, 
1976). The Pacific Ocean in particular contains many ferromanganese deposits (Mero, 1965).

The most widely studied nodule fields are the Clarion-Clipperton Zone (CCZ), the Peru basin nodule field, the central Indian Ocean nodule field, and the Cook Islands nodule field (Figure 1.1).

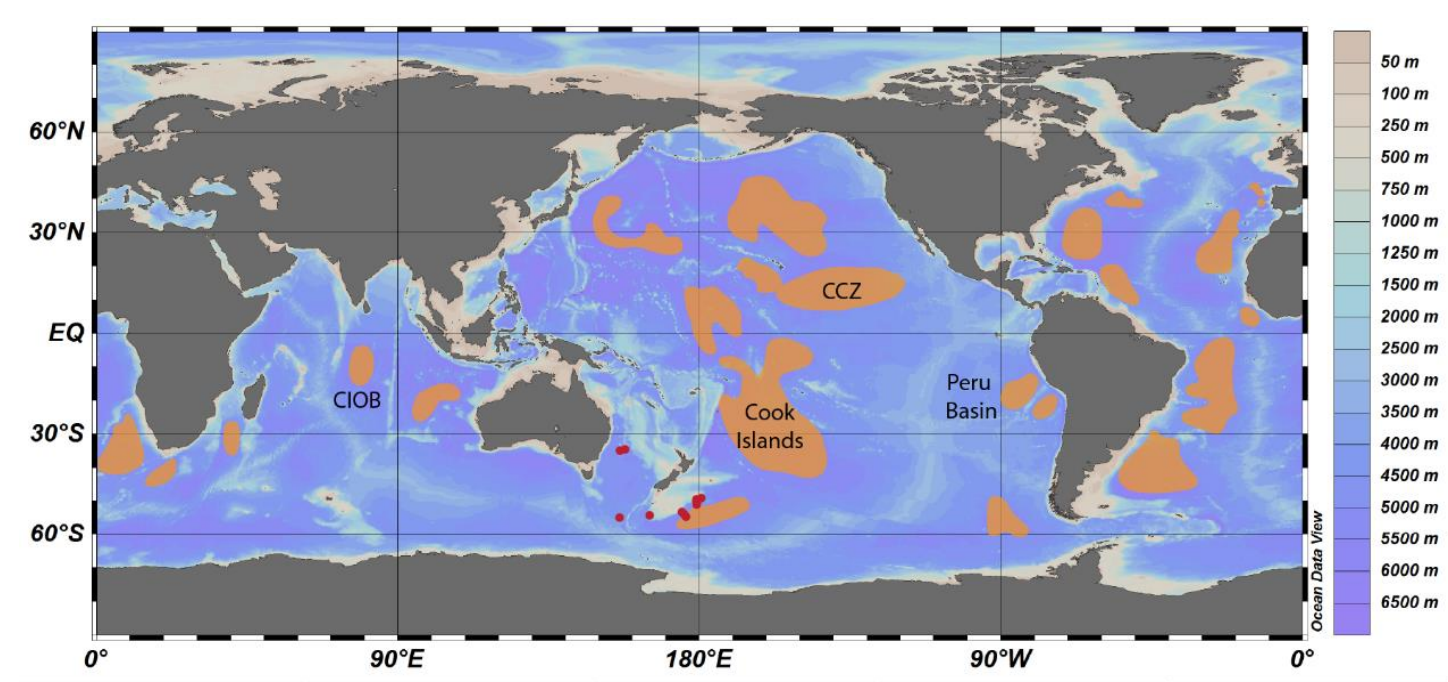

Figure 1.1: The approximate global distribution of known major ferromanganese nodule fields are marked in orange. Sample locations analysed in this thesis are indicated with red dots. Key areas of economic interest are labelled; Cook Islands, Peru basin, CIOB - central Indian Ocean basin, CCZ - Clarion Clipperton Zone. Figure adapted after Hein et al. (2013), with a base map from Ocean Data View (Schlitzer, 2015).

The CCZ covers 4,000,000 $\mathrm{km}^{2}$ (ISA, 2010) and displays only minor compositional variation compared to nodule abundance, with the western CCZ to eastern CCZ changing from hydrogenetic to increasingly diagenetic in origin (Kuhn et al., 2017). The CCZ has been widely studied due to its high concentration of trace elements such as $\mathrm{Cu}$ and $\mathrm{Ni}$.

The Peru Basin is approximately half the size of the CCZ, and the environment is characterised by a high organic flux to the sediment and thus a shallow suboxic zone in the sediment (Koschinsky et al., 2001). This area has nodules above the calcium compensation depth (CCD). The Peru nodule field is lower in elements such as $\mathrm{Cu}, \mathrm{Co}$, REE and Y ( $\mathrm{REYY}$ ), but is higher in Li and Ni than the CCZ (Kuhn et al., 2017).

The Indian Ocean covers an area of $\sim 700,000 \mathrm{~km}^{2}$ and has more variable abundances of nodules with compositions showing more variability than other areas (Mukhopadhyay et al., 2008). Ni, $\mathrm{Cu}$ and Co contents are similar to nodules from the CCZ, but Indian Ocean nodules typically have higher $\mathrm{Pb}$ and REE contents (Kuhn et al., 2017).

The Cook Island nodule field covers $\sim 2,000,000 \mathrm{~km}^{2}$ (Hein et al., 2015). Low sedimentation rates, a strong erosional environment, and a lot of material for nodules to 
nucleate on, have led to a high density of nodules in this area. The Cook Island nodules are characterised by high Co, Ti, $\Sigma$ REY, and low $\mathrm{Cu}$ and Ni (Kuhn et al., 2017). With prices of high tech metals and REE increasing (Ragnarsdóttir, 2008), this nodule field is economically comparable to the CCZ (Hein et al., 2015).

\subsubsection{New Zealand nodule fields}

Ferromanganese nodules have previously been identified on Campbell Plateau (Summerhayes, 1967a; Glasby and Summerhayes, 1975; Carter and McCave, 1997), Macquarie Ridge (Summerhayes, 1967a), and in the Tasman Sea (Glasby and Summerhayes, 1975; Glasby et al., 1986).

Analyses of Campbell Plateau nodules have been previously reported. Chang et al. (2003a) and Wright et al. (2005) described nodule morphology based on dredged samples, and the density of the nodule field and the substrate was characterised using seafloor photographs. The mineralogy, and major and trace element chemistry for bulk nodule samples, and sequential samples of some nodules from rim to core in 1-5 g subsamples, have been reported by Chang et al. (2003b). Combining nodule morphology and main seafloor substrate, Chang et al. (2003a) defined several nodule facies within the Campbell nodule field moving broadly from the Campbell Plateau slope outwards: hydrogenous, abyssal hydrogenous/diagenetic, and abyssal diagenetic nodule facies. Graham et al. (2003) reports a growth rate of 4-11 mm/Ma in nodules from the Campbell nodule field.

The major element chemistry of the Tasman Sea nodule field has previously been described by Glasby et al. (1986), who specifically concentrated on elements of economic interest at the time. Sediment from this region was also analysed for major element content and grain-size. The chemical composition of nodules near Macquarie Ridge were reported by Summerhayes (1967b). That study, however, used "standard wet chemical techniques" to determine iron and manganese concentrations and reported that "accuracy is probably around $\pm 50 \%$ ".

This study builds on this earlier work. In particular, advances in analytical techniques since these previous studies were conducted has allowed a more precise array of compositional data on a greater number of elements than reported in these previous studies.

The samples analysed are from locations several thousand kilometres apart in essentially the same water mass, but with different environmental characteristics (e.g. depth, CCD, 
sediment source). This is a unique sample set world-wide, as it spans a large spatial range, and has co-existing sediment samples, that allows nodule formation processes to be evaluated from one water mass and in highly varying local conditions over a large distance. The samples are from the main nodule collection from New Zealand waters, collected from multiple research voyages.

A multitude of ferromanganese nodules from various locations (Figure 1.2) of New Zealand's deep-sea floor have been (re-)analysed as part of this study, making it possible to interpret variations in nodule composition change relative to location, depth and their relative proximity to the deep ocean currents. By focussing on the outermost $1 \mathrm{~mm}$ of the nodules, rather than the bulk samples (or large incremental rim to core subsamples) that average many million years of growth, it is possible to examine their compositional relationship to the coeval sediments and water masses that they are growing in. This allows evaluation of whether they reflect the modern seawater chemistry of the Lower Circumpolar Deep Water (LCDW) as the water mass moves up the eastern and western boundaries of New Zealand (Figure 2.1).

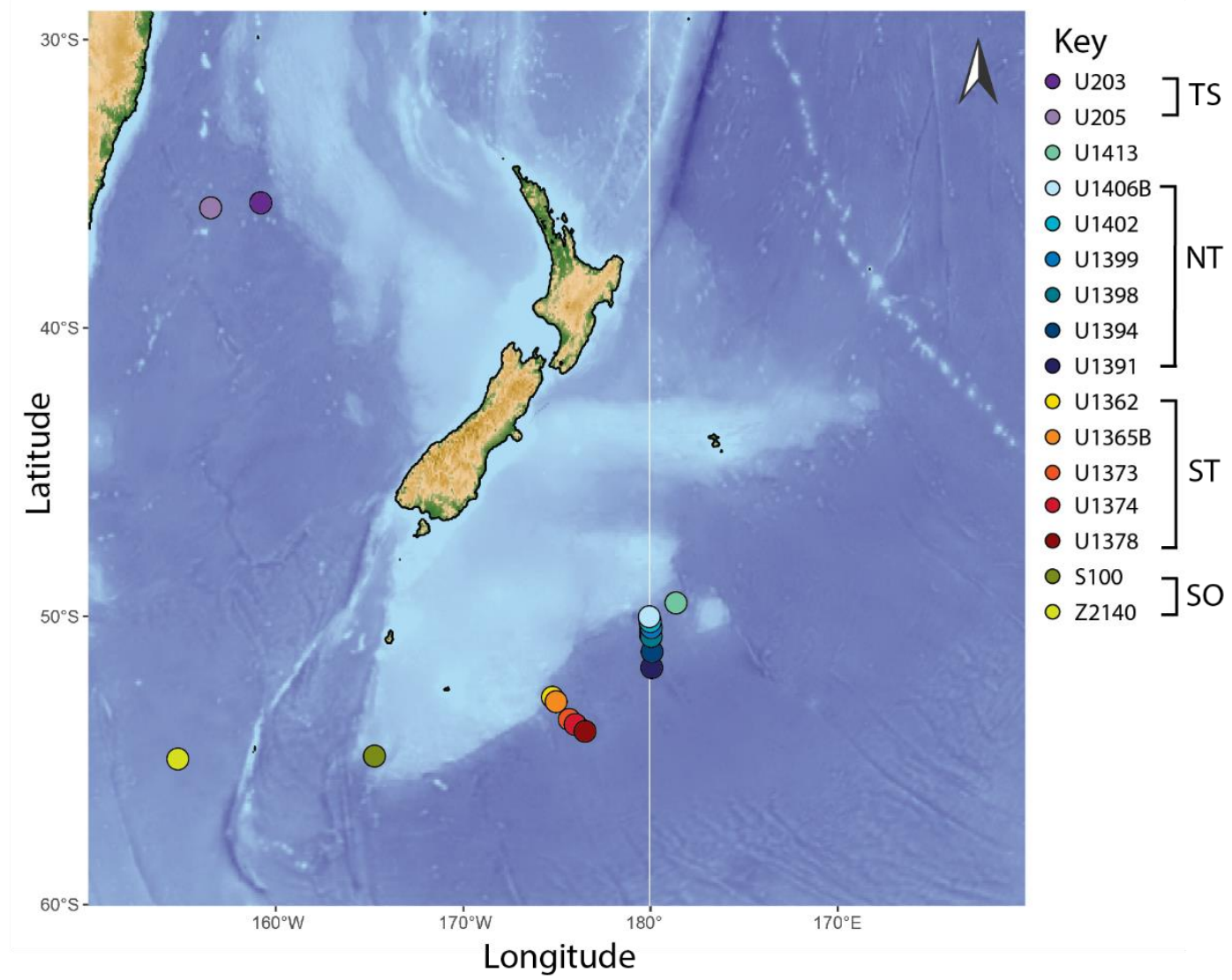

Figure 1.2: Ferromanganese nodule and deep ocean sediment sample locations on a bathymetric map of New Zealand. TS - Tasman Sea, NT - Northern transect of the Campbell Plateau, ST - Southern transect of the Campbell Plateau, SO - Southern Ocean. The base map was created using the marmap package developed by Pante \& Simon-Bouhet (2013), using bathymetric data from NOAA (Amante and Eakins, 2009), and applies to all such maps used in the thesis. 
A large collection of ferromanganese nodules and their associated sediments have been obtained from numerous voyages in the Southwest Pacific Ocean (Table 1.1) and stored at NIWA, Greta Point, Wellington. A total of 77 nodules and 13 sediment samples (Table 1.1) were obtained for analysis in this study, from a range of locations and depths.

Table 1.1: Location of ferromanganese nodules, and sediments analysed in this study.

\begin{tabular}{c|c|c|c|c} 
Sample & Latitude & Longitude & Depth & Sample type \\
\hline \hline $\mathbf{U 2 0 3}$ & $35.632^{\circ} \mathrm{S}$ & $159.167^{\circ} \mathrm{E}$ & $4,919 \mathrm{~m}$ & Nodule and sediment \\
\hline $\mathbf{U 2 0 5}$ & $35.810^{\circ} \mathrm{S}$ & $156.530^{\circ} \mathrm{E}$ & $4,714 \mathrm{~m}$ & Nodule \\
\hline $\mathbf{U 1 4 1 3}$ & $49.519^{\circ} \mathrm{S}$ & $178.654^{\circ} \mathrm{W}$ & $4,375 \mathrm{~m}$ & Nodule and sediment \\
\hline $\mathbf{U 1 4 0 6 B}$ & $49.949^{\circ} \mathrm{S}$ & $179.923^{\circ} \mathrm{E}$ & $4,475 \mathrm{~m}$ & Nodule and sediment \\
\hline $\mathbf{U 1 4 0 2}$ & $50.202^{\circ} \mathrm{S}$ & $179.933^{\circ} \mathrm{E}$ & $4,445 \mathrm{~m}$ & Nodule and sediment \\
\hline $\mathbf{U 1 3 9 9}$ & $50.387^{\circ} \mathrm{S}$ & $179.962^{\circ} \mathrm{E}$ & $4,494 \mathrm{~m}$ & Nodule and sediment \\
\hline $\mathbf{U 1 3 9 8}$ & $50.625^{\circ} \mathrm{S}$ & $179.986^{\circ} \mathrm{E}$ & $4,495 \mathrm{~m}$ & Nodule and sediment \\
\hline $\mathbf{U 1 3 9 4}$ & $51.168^{\circ} \mathrm{S}$ & $179.942^{\circ} \mathrm{E}$ & $4,862 \mathrm{~m}$ & Sediment \\
\hline $\mathbf{U 1 3 9 1}$ & $51.709^{\circ} \mathrm{S}$ & $179.999^{\circ} \mathrm{E}$ & $4,810 \mathrm{~m}$ & Sediment \\
\hline $\mathbf{U 1 3 6 2}$ & $52.837^{\circ} \mathrm{S}$ & $174.843^{\circ} \mathrm{E}$ & $4463 \mathrm{~m}$ & Sediment \\
\hline $\mathbf{U 1 3 6 5 B}$ & $53.032^{\circ} \mathrm{S}$ & $175.014^{\circ} \mathrm{E}$ & $4684 \mathrm{~m}$ & Sediment \\
\hline $\mathbf{U 1 3 7 3}$ & $53.583^{\circ} \mathrm{S}$ & $175.695^{\circ} \mathrm{E}$ & $4,941 \mathrm{~m}$ & Nodule and sediment \\
\hline $\mathbf{U 1 3 7 4}$ & $53.759^{\circ} \mathrm{S}$ & $176.046^{\circ} \mathrm{E}$ & $4,958 \mathrm{~m}$ & Nodule and sediment \\
\hline $\mathbf{U 1 3 7 8}$ & $53.978^{\circ} \mathrm{S}$ & $176.450^{\circ} \mathrm{E}$ & $4,915 \mathrm{~m}$ & Nodule and sediment \\
\hline $\mathbf{S 1 0 0}$ & $54.857^{\circ} \mathrm{S}$ & $165.225^{\circ} \mathrm{E}$ & $2,370 \mathrm{~m}$ & Nodule \\
\hline $\mathbf{Z 2 1 4 0}$ & $54.933^{\circ} \mathrm{S}$ & $154.767^{\circ} \mathrm{E}$ & $4,058 \mathrm{~m}$ & Nodule
\end{tabular}

\subsection{Thesis aims}

The objective of this research is to investigate the composition and incorporation of metals into ferromanganese nodules in the (near) modern environment, and to evaluate chemical variations based on localised environmental parameters, such as depth, location with respect to bottom currents, and associated detrital sediment.

This study will complete this objective by:

- Identifying the major and trace element geochemistry of ferromanganese nodules.

- Analysing physical and chemical aspects of the substrate the ferromanganese nodules lie in to understand the relationship between the deep-sea sedimentology and nodule formation.

- Investigating the physical properties of the seawater overlying nodules to identify the water mass, and examine the chemical oceanography of comparable water masses to estimate trace element concentrations of the deep ocean environment around New Zealand. 


\subsection{Thesis structure}

This thesis is composed of 6 chapters, with additional data and results not presented in the main text listed in the appendices.

Chapter 1. Introduction: This chapter gives an overview of the importance of ferromanganese nodules, previous work on New Zealand nodule fields, and the aims of the thesis.

Chapter 2. Oceanography: This chapter introduces aspects of physical and chemical oceanography. Data from the Global Ocean Data Analysis Project (GLODAP) is used to identify the water masses overlying the ferromanganese nodules. GEOTRACES data is then analysed to estimate the trace element concentrations overlying these ferromanganese nodule fields and potential effects on ferromanganese nodule composition.

Chapter 3. Deep-sea sedimentology: This chapter explores physical and chemical sedimentology in the deep-sea environment. Sediments were analysed to determine grainsize, calcium carbonate content, mineral composition, and major element concentrations. These data are then interpreted to understand the sedimentary environment in the regions where the ferromanganese nodules occur.

Chapter 4. Ferromanganese nodules: This chapter discusses formation conditions and their effect on the mineralogy and incorporation of trace metals into nodules. Major and trace element compositions of ferromanganese nodules are presented and results used to identify regional variations and trends.

Chapter 5. Synthesis: This chapter brings together the findings of Chapter 2, Chapter 3, and Chapter 4 to interpret the geochemistry of the ferromanganese nodules relative to the oceanography and sedimentology of the marine environment.

Chapter 6. Conclusions and future work: This chapter summarises the findings of this thesis and makes recommendations for future research. 
Appendices: Supplementary information that includes data and results not presented in the main manuscript.
A. Additional oceanography data for Chapter 2.
B. Additional sedimentology data for Chapter 3.
C. Ferromanganese nodule characteristics.
D. Major, minor and trace elements by ICP-MS.
E. JMn-1 (GSJ SRM) data from multiple ICP-MS runs 


\section{Chapter 2 Oceanography}

\subsection{Introduction}

In this chapter the physical and chemical oceanography is discussed in order to determine the potential chemistry of the waters overlying the nodules. Unfortunately, there is little geochemical data for the Southwest Pacific region. Data from GEOTRACES voyages conducted in the South Atlantic, South Tasman Sea/Southern Ocean and the South Pacific Ocean northeast of New Zealand have been examined. These transects are used to describe the potential relationship between trace element geochemistry and the physical oceanography. These relationships have been used to infer the potential geochemistry of the water masses in the New Zealand region, particularly in the areas where the ferromanganese nodules analysed in this thesis come from in the north Tasman Sea and along the base of the slope of the Campbell Plateau in the South Pacific Basin.

The majority of the ferromanganese nodules examined in this study are located at depths below 4,000 $\mathrm{m}$ (Table 2.1). The exception to this is nodule $\mathrm{S} 100$, which is found at 2,340 m depth; however, due to deep water shoaling in the Southern Ocean, it is still located in “deep waters". For this reason this section focusses only on deep water masses.

Table 2.1: Latitude, longitude, and depth for each ferromanganese nodule location, and their corresponding water mass. LCDW - Lower Circumpolar Deep Water, AABW - Antarctic Bottom Water.

\begin{tabular}{c|c|c|c|c} 
Sample & Latitude & Longitude & Depth & Water mass \\
\hline \hline $\mathbf{U 2 0 3}$ & $35.632^{\circ} \mathrm{S}$ & $159.167^{\circ} \mathrm{E}$ & $4,919 \mathrm{~m}$ & LCDW \\
\hline $\mathbf{U 2 0 5}$ & $35.810^{\circ} \mathrm{S}$ & $156.530^{\circ} \mathrm{E}$ & $4,714 \mathrm{~m}$ & LCDW \\
\hline $\mathbf{U 1 4 1 3}$ & $49.519^{\circ} \mathrm{S}$ & $178.654^{\circ} \mathrm{W}$ & $4,375 \mathrm{~m}$ & LCDW \\
\hline $\mathbf{U 1 4 0 6 B}$ & $49.949^{\circ} \mathrm{S}$ & $179.923^{\circ} \mathrm{E}$ & $4,475 \mathrm{~m}$ & LCDW \\
\hline $\mathbf{U 1 4 0 2}$ & $50.202^{\circ} \mathrm{S}$ & $179.933^{\circ} \mathrm{E}$ & $4,445 \mathrm{~m}$ & LCDW \\
\hline $\mathbf{U 1 3 9 9}$ & $50.387^{\circ} \mathrm{S}$ & $179.962^{\circ} \mathrm{E}$ & $4,494 \mathrm{~m}$ & LCDW \\
\hline $\mathbf{U 1 3 9 8}$ & $50.625^{\circ} \mathrm{S}$ & $179.986^{\circ} \mathrm{E}$ & $4,495 \mathrm{~m}$ & LCDW \\
\hline $\mathbf{U 1 3 7 3}$ & $53.583^{\circ} \mathrm{S}$ & $175.695^{\circ} \mathrm{E}$ & $4,941 \mathrm{~m}$ & LCDW/AABW \\
\hline $\mathbf{U 1 3 7 4}$ & $53.759^{\circ} \mathrm{S}$ & $176.046^{\circ} \mathrm{E}$ & $4,958 \mathrm{~m}$ & LCDW/AABW \\
\hline $\mathbf{U 1 3 7 8}$ & $53.978^{\circ} \mathrm{S}$ & $176.450^{\circ} \mathrm{E}$ & $4,915 \mathrm{~m}$ & LCDW/AABW \\
\hline $\mathbf{S 1 0 0}$ & $54.857^{\circ} \mathrm{S}$ & $165.225^{\circ} \mathrm{E}$ & $2,370 \mathrm{~m}$ & LCDW/AABW \\
\hline $\mathbf{Z 2 1 4 0}$ & $54.933^{\circ} \mathrm{S}$ & $154.767^{\circ} \mathrm{E}$ & $4,058 \mathrm{~m}$ & LCDW/AABW
\end{tabular}




\subsubsection{Physical oceanography}

The main deep waters in this region are the Circumpolar Deep Waters (CDW) (Chiswell et al., 2015) (Figure 2.1). These are a mixture of water masses that flow into the Southern Ocean from the adjacent basins, such as the Antarctic Bottom Water (AABW) flowing in from the Antarctic Margin, the North Atlantic Deep Water (NADW), the Indian Deep Water (IDW) and the Pacific Deep Water (PDW) (Bostock et al., 2013). Due to the different properties of these deep water masses flowing into the Southern Ocean and mixing to form the $\mathrm{CDW}$, the $\mathrm{CDW}$ varies and can be separated into the Upper Circumpolar Deep Water (UCDW) and the Lower Circumpolar Deep Water (LCDW) (Mantyla and Reid, 1983). The UCDW in the South Pacific basin is found at $~ 1450$ $2500 \mathrm{~m}$ depth, and is primarily contributed to by the PDW and IDW, its temperature ranges from $\sim 3-4{ }^{\circ} \mathrm{C}$, it has oxygen concentration in the range of $175-200 \mu \mathrm{mol} / \mathrm{kg}$, and its salinity is 34.3-34.7 (Chiswell et al., 2015). The LCDW is located below $\sim 2500 \mathrm{~m}$ depth and is contributed to by the NADW, and mixes with the AABW (Chiswell et al., 2015). It has a temperature ranging from $1-3{ }^{\circ} \mathrm{C}$, oxygen content of $175-225 \mu \mathrm{mol} / \mathrm{kg}$, and salinity of 34.7-34.75 (Chiswell et al., 2015). Pure Antarctic Bottom Water is present close to Antarctica and is deeper than 4,000 $\mathrm{m}$ and has a temperature $-0.8-2{ }^{\circ} \mathrm{C}$, oxygen concentration of $\sim 225-250 \mu \mathrm{mol} / \mathrm{kg}$, and a salinity of $\sim 34.60-34.70$; however, this AABW quickly mixes with the LCDW and so its distinctive signature has not been identified north of $55^{\circ} \mathrm{S}$ (Chiswell et al., 2015). 


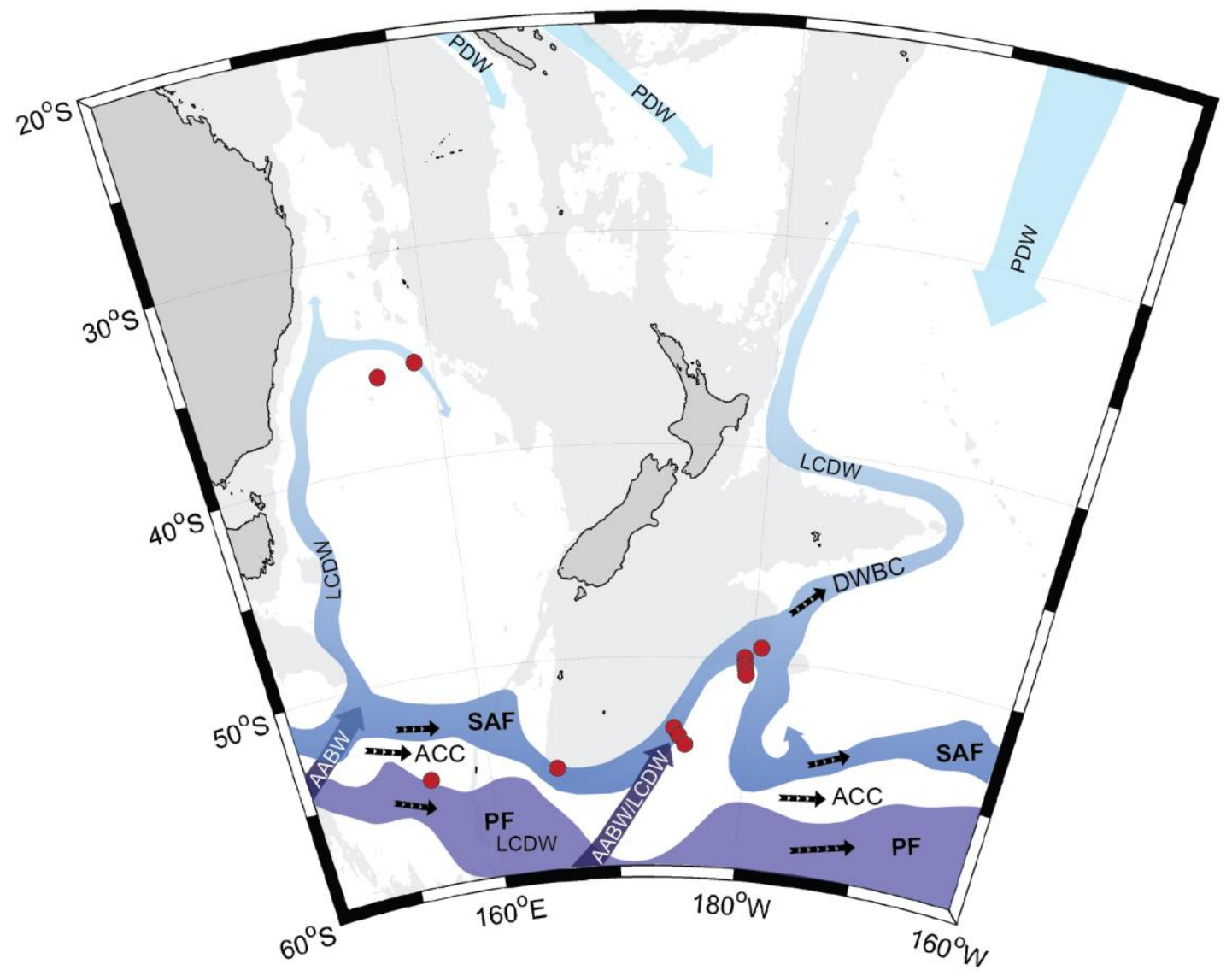

Figure 2.1: Deep water currents found in the New Zealand region with bathymetry shallower than 3,000 $\mathrm{m}$ shaded in grey. Adapted from Chiswell et al. (2015). The red dots indicate locations of the ferromanganese nodules analysed in this study (locations in Table 2.1). PDW - Pacific Deep Water, LCDW - Lower Circumpolar Deep Water, AABW Antarctic Bottom Water, DWBC - Deep Water Boundary Current, SAF - Subantarctic Front, PF - Polar Front.

The LCDW and AABW flow north into the Southwest Pacific Ocean along the edge of the Campbell Plateau as part of the Deep Western Boundary Current (DWBC) (Orsi et al., 1995; Carter \& McCave, 1997), and into the Tasman Sea along the east Australian continental slope by a weaker deep western boundary current (Sokolov and Rintoul, 2000) (Figure 2.1). The Campbell Plateau nodule field at $48-59^{\circ} \mathrm{S}$ (Wright et al., 2005) sits at the base of the Subantarctic Slope and is located under the fast flowing Antarctic Circumpolar Current (ACC) (48-68 Sv) (Stanton and Morris, 2004). North of Campbell Plateau the ACC branches off to the east at $49^{\circ} \mathrm{S}$ (Carter and McCave, 1997; Carter and Wilkin, 1999), and the DWBC slows down to $16.0 \pm 11.9 \mathrm{~Sv}$ at $32^{\circ} \mathrm{S}$ (Whitworth et al., 1999). As the LCDW flows northward it becomes warmer, less oxygen rich, and increasingly saline due to mixing with the PDW (Carter and McCave, 1997; Chiswell et al., 2015). 
A particular feature of the DWBC that flows along the edge of the Campbell Plateau is the presence of a nepheloid layer found immediately above the seafloor (Carter and McCave, 1997). Nepheloid layers are associated with substantial quantities of suspended matter caused by fast bottom currents stripping the very fine sediment from the seafloor. The thickness of the layer is related to the velocity of the water current (McCave, 1986). Eddies form approximately nine times a year long the Subantarctic Slope (Stanton and Morris, 2004) and may reach the seafloor (Carter and McCave, 1997; Carter and Wilkin, 1999) contributing to the stirring up of the very fine sediment and formation of the nepheloid layer. Carter \& McCave (1997) reports a nepheloid layer of $370 \mathrm{~m}$ thickness and 0.8 turbidity from the Emerald Basin to the base of the Campbell Plateau $\left(53-57^{\circ} \mathrm{S}\right.$, $160-165^{\circ} \mathrm{E}$ ), and $170 \mathrm{~m}$ and turbidity of 0.5 as the water mass travels north.

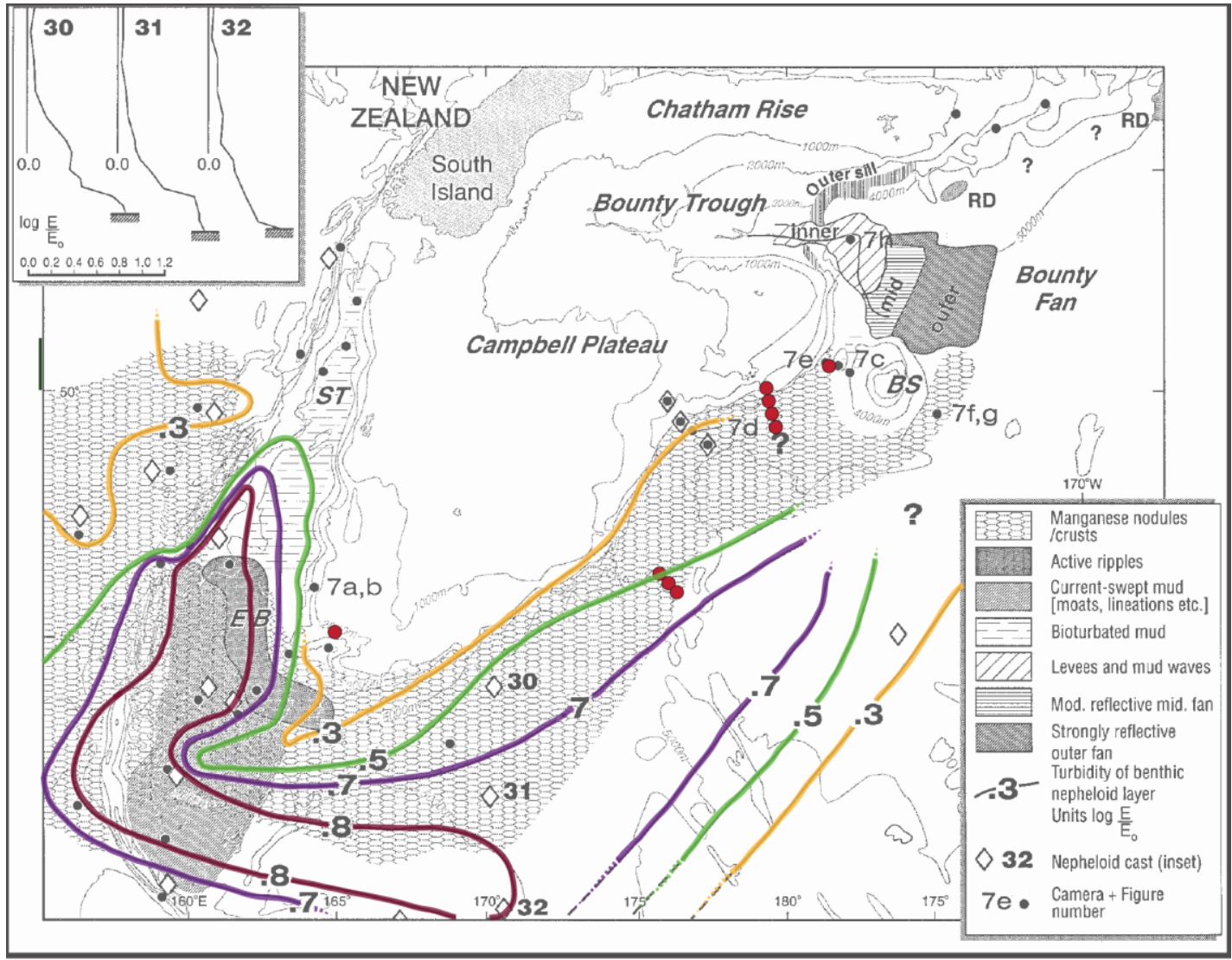

Figure 2.2: Interpreted nepheloid layer and the Campbell Plateau, adapted from Carter and McCave (1997). The ferromanganese nodules analysed in this study displayed as red dots. Sample locations U203, U205, and Z2140 are not pictured as they are outside the scope of this map. The coloured lines highlight the interpreted nepheloid layer, the yellow, green, purple, and maroon lines represent $0.3,0.5,0.7$ and 0.8 turbidity in units $\log \frac{E}{E_{o}}$. The interpreted turbidity of the nepheloid layer likely extends north of the given line, as indicated with dashed lines. 
The presence of the nepheloid layer was evident from indirect observations during a recent voyage on the RV Tangaroa (TAN1702). CTD altimeter readings showed a false bottom about $50-100 \mathrm{~m}$ above the seafloor, and in the Topas sub-bottom profiler data as a thin reflection above the main sea floor (Figure 2.3).

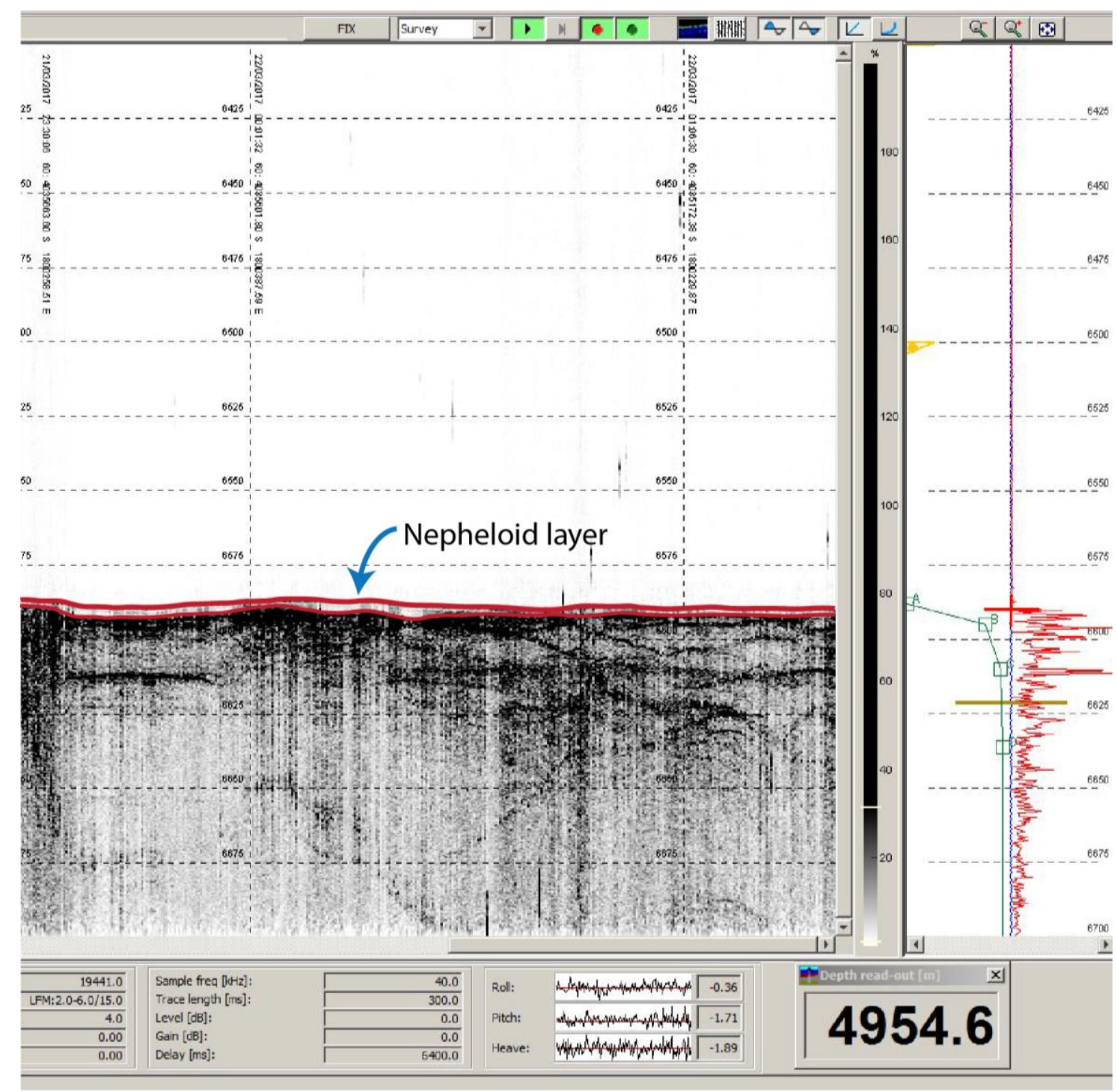

Figure 2.3: Topas screenshot from the TAN1702 voyage at $53.8^{\circ} \mathrm{S}, 176.0^{\circ} \mathrm{E}$. 


\subsubsection{Chemical oceanography}

The ocean chemistry of an area is related to both the large-scale movement of water bodies from ocean circulation, and more regionalised factors such as the composition of the underlying seafloor, volcanology/hydrothermal fluxes, local terrigenous influx from rivers and atmospheric deposition (dust) as well as the overlying biological productivity of the region (Bruland et al., 2014). Such environmental aspects likely alter the characteristic trace element chemical signatures that are measured in ferromanganese nodule deposits. These authigenic deposits may therefore provide a further understanding of the chemistry of the deep-sea environment.

\subsubsection{Elemental inputs}

The composition of riverine material is derived from the rock types of the catchment (Martin and Whitfield, 1983). Thus the majority of riverine material has a similar composition to the upper continental crust (UCC). Typical detrital riverine minerals and their associated formulas are described in Table 2.2. It is worth noting that many of these minerals may settle out or be scavenged in estuaries before making it to the open ocean (Orians and Bruland, 1986).

Table 2.2: Common riverine minerals and their associated formulas ( $\mathrm{Li}$ and Schoonmaker, 2003; Rudnick and Gao, 2003)

\begin{tabular}{|c|c|}
\hline Minerals & Elements \\
\hline Quartz & $\mathrm{SiO}_{2}$ \\
\hline Orthoclase & $\mathrm{KAlSi}_{3} \mathrm{O}_{8}$ \\
\hline Plagioclase & $(\mathrm{Ca}, \mathrm{Na})(\mathrm{Al}, \mathrm{Si}) \mathrm{AlSi}_{2} \mathrm{O}_{8}$ \\
\hline Amphiboles & $\mathrm{Ca}_{2}(\mathrm{Mg}, \mathrm{Fe})_{5} \mathrm{Si}_{8} \mathrm{O}_{22}(\mathrm{OH})_{2}$ \\
\hline Pyroxene & $(\mathrm{Mg}, \mathrm{Fe})_{2} \mathrm{Si}_{2} \mathrm{O}_{6}$ \\
\hline Olivine & $(\mathrm{Mg}, \mathrm{Fe})_{2} \mathrm{SiO}_{4}$ \\
\hline Biotite & $\mathrm{K}(\mathrm{Mg}, \mathrm{Fe})_{3}\left(\mathrm{AlSi}_{3} \mathrm{O}_{10}\right)(\mathrm{F}, \mathrm{OH})_{2}$ \\
\hline Muscovite & $\mathrm{KAl}_{2}\left(\mathrm{AlSi}_{3} \mathrm{O}_{10}\right)(\mathrm{F}, \mathrm{OH})_{2}$ \\
\hline Illite & $\mathrm{K}_{\mathrm{x}} \mathrm{Al}_{2}\left(\mathrm{Si}_{4-\mathrm{x}} \mathrm{Al}_{\mathrm{x}}\right) \mathrm{O}_{10}(\mathrm{OH})_{2}$ \\
\hline Chlorite & $(\mathrm{Mg}, \mathrm{Fe})_{5}(\mathrm{Al}, \mathrm{Fe})_{2} \mathrm{Si}_{3} \mathrm{O}_{10}(\mathrm{OH})_{8}$ \\
\hline Kaolinite & $\mathrm{Al}_{2} \mathrm{Si}_{2} \mathrm{O}_{5}(\mathrm{OH})_{4}$ \\
\hline Smectite & $(\mathrm{M})_{\mathrm{x}-\mathrm{y}}\left(\mathrm{R}^{3+}{ }_{2-\mathrm{y}} \mathrm{R}^{2+}{ }_{\mathrm{y}}\right)\left(\mathrm{Si}_{4-\mathrm{x}} \mathrm{Al}_{\mathrm{x}}\right) \mathrm{O}_{10}(\mathrm{OH})_{2}$ \\
\hline
\end{tabular}

Atmospheric inputs are produced by processes such as crustal weathering, dust storms, and volcanic particulates. These particles are wind driven and deposited directly into surface waters (Bruland et al., 1994) and can travel far from the continental source. Minerals associated with aeolian deposition are similar to those river-transported detrital 
minerals listed in Table 2.2, but also tend to provide an additional anthropogenic input for elements Fe, Cd, and Zn (Buat-Menard and Chesselet, 1979; Duce et al., 1991).

Hydrothermal fluids are produced by seawater interactions with recently extruded basalt, i.e. at seafloor spreading at mid-ocean ridges (Elderfield and Schultz, 1996; German and Seyfried, 2014). Metals in hydrothermal fluids may migrate from the source, or be scavenged by siderophilic metallic deposits (Resing et al., 2015). As mid-ocean ridges tend to exist at intermediate and deep water depths the elements may be scavenged before they can make their way to the surface waters. Elements commonly associated with hydrothermal vents include Fe, Mn, Zn, and Cu (Sander and Koschinsky, 2011).

Resuspension, and subsequent dissolution of particles from the sediment-seawater interface is an additional input of elements into the water column (Koschinsky et al., 2001). Baker and Feely (1978) found the chemistry of suspended matter in nepheloid layers was closely related with the underlying seafloor sediment chemistry.

\subsubsection{Speciation}

To understand the chemistry of the ocean it is necessary to understand the speciation of elements in seawater. The speciation of these trace metals depends on their physical form (i.e. dissolved, colloidal, particulate), chemical form (i.e. ionic, inorganic and organic complexation, and organometallic compounds) and oxidation state (Millero, 1990; Sander and Koschinsky, 2011). The physicochemical properties of elements directly affects their behaviour in the ocean environment ( $\mathrm{Li}, 1991)$.

Oceanic matter exists in particulate $(>0.2 \mu \mathrm{m})$, colloidal $(0.2 \mu \mathrm{m}-1 \mathrm{~nm})$, and dissolved/aqueous $(<1 \mathrm{~nm})$ forms (Bruland et al., 2014). Fine grained particulate material may be suspended in the water column. Small particles tend to be mobile in the environment, very fine particulates tend to aggregate into larger particles, and large particles may sink to the sea-floor (Anderson, 2014). Colloids are suspended in seawater, and have high complexation capacities (Guo and Santschi, 1997). Aqueous species exist as molecules or ions and they may form chemical species such as organic and inorganic ligands. Once in the marine environment a particle or compound may be recycled before making it to the seafloor (Martin et al., 1987). 


\subsubsection{Elemental distribution profiles}

The residence time, i.e. the time elements spend as dissolved species in the oceanic water column, controls their large-scale distribution pattern. Elements can subsequently be divided into specific distribution profiles based on their behaviour in the water column. The distribution profiles are divided into: scavenged-type, nutrient-type, conservativetype, and hybrid-type profiles (Li, 1991; Bruland et al., 2014).

\section{Scavenged-type trace metal profiles}

Scavenged-type trace metals have short $(\sim 100-1,000$ year) residence times in the ocean (Steele et al., 2009). Scavenged-type are readily adsorbed onto the surfaces of downwelling particles, or at the seawater-sediment boundary (Turekian, 1977). They typically are highest in concentration close to their source, and decrease with increasing distance (Bruland et al., 2014). The distribution of $\mathrm{Mn}$ and $\mathrm{Ce}$ (two elements important to ferromanganese nodule chemistry) are discussed. Other scavenged-type elements are $\mathrm{Pb}$, and Al.

Dissolved Mn is typically high in concentration in surface and (potentially) intermediate waters and low in deep waters. In the surface waters particulate $\mathrm{Mn}$ is deposited by aeolian, riverine, and resuspension processes and subsequently undergoes photoreduction from $\mathrm{Mn}(\mathrm{IV})$ to $\mathrm{Mn}(\mathrm{II})$ (Elderfield, 1976; Wu et al., 2014; Homoky et al., 2016). Dissolved Mn is consumed in surface waters by phytoplankton (Raven, 1990). At intermediate depths dissolved Mn enters the ocean environment through hydrothermal vents and reworking of sediments (Hein et al., 1997). Mn is mobile in the ocean and it moves to more oxidising environments, e.g. (Klinkhammer and Hudson, 1986) found evidence of lateral movement of $\mathrm{Mn} \sim 2,000 \mathrm{~km}$ from the hydrothermal source vent. In deep waters dissolved $\mathrm{Mn}$ is typically low in concentration due to the oxidation of $\mathrm{Mn}$ (II) to $\mathrm{Mn}(\mathrm{IV})$ in seawater, which is potentially bacterially mediated (Tebo et al., 2004, 2005). This process forms Mn oxide minerals (Koschinsky and Hein, 2003), such as the ferromanganese nodules analysed in this study. Dissolved Mn is typically at it maxima in the water column where there is low oxygen concentrations $(<100 \mu \mathrm{mol} / \mathrm{kg})$ (Klinkhammer and Bender, 1980).

$\mathrm{Ce}$ enters the marine environment through rivers. In oxygenated seawater $\mathrm{Ce}$ (III) is oxidised to $\mathrm{Ce}(\mathrm{IV})$ as the insoluble $\mathrm{CeO}_{2}$ (Elderfield et al., 1988) and is scavenged by FeMn (oxyhydr)oxide particles. 


\section{Nutrient-type trace metal profiles}

Nutrient-type trace metals have moderately long residence times (1,000-100,000 years in the water column) and are intimately linked to the biogeochemical cycle (Bruland et al., 1994). In surface waters they are consumed by organisms, which sink and are regenerated in deep waters releasing them back to the water column. The depth in which they undergo regeneration is dependent on the biological process the nutrient is associated with, i.e. species critical for the formation of soft-tissue such as phosphate and nitrate undergo regeneration at shallower depths than species that are associated with the formation of hard-shells such as silicate (Bruland, 1980). In deep water they tend to undergo minimal scavenging. Thus these elements are typically depleted in surface waters and enriched in the deep ocean. As they accumulate over time they tend to increase in concentration as the deep-water currents travel away from their source regions. Nutrient-type elements include $\mathrm{Zn}, \mathrm{Ni}, \mathrm{Cd}$, and all REE except $\mathrm{Ce}$ (Steele et al., 2009). $\mathrm{Zn}$ has a residence time of 3,000 \pm 600 years, entering the ocean by riverine and hydrothermal processes (Roshan et al., 2016), and undergoing regeneration in deep water (Morel et al., 2003). Zn occurs primarily as the $\mathrm{Zn}^{2+}$ (Koschinsky and Hein, 2003), $\mathrm{Zn}$ is found in the ocean primarily as the $\mathrm{Zn}^{2+}$ cation (Koschinsky and Hein, 2003), and is likely complexed by organic ligands (Sander and Koschinsky, 2011). Zn is essential for the skeletal growth of organisms such as phytoplankton, and for metabolic processes (Morel et al., 2003).

Oxygen is an example of an element with a non-conservative distribution and is inversely related to nutrients (Steele et al., 2009). The vertical and lateral distributions of dissolved oxygen are determined by factors such as the sea-air interface, biological productivity, and physical transport. At the sea surface dissolved oxygen is determined by the solubility of oxygen in sea water, with oxygen being more soluble in colder water (Talley et al., 2011a). Dissolved oxygen is high at this interface and decreases with depth as it is consumed through the respiration and decomposition of organisms in the photosynthetic zone. Below this the photosynthetic zone dissolved oxygen gradually increases due to reduced biological activity. At depths, deep water currents transport water rich in dissolved oxygen, and due to little organic matter reaches the seafloor, only minor amounts of dissolved oxygen are consumed by processes such as diagenesis. This results in deep water currents being increasingly depleted in oxygen the further from its source it travels (Talley et al., 2011a). 


\section{Hybrid-type trace metal profiles}

Elements that display both nutrient and scavenged-type properties are called hybrid or mixed-types elements $(\mathrm{Li}, 1991)$. These elements are consumed in surface waters and then regenerated and scavenged in deep waters. $\mathrm{Fe}, \mathrm{Cu}$, and $\mathrm{Ti}$ are examples of hybridtype elements.

It has a residence time of $\sim 50-100$ years in the ocean (Steele et al., 2009). Fe enters the oceans by detrital, aeolian, and hydrothermal mechanisms (Boyd and Ellwood, 2010; Resing et al., 2015). In surface waters Fe can be considered a limiting nutrient, with areas of the ocean being high-nutrient, low-chlorophyll (HNLC) areas due to lack of Fe (de Baar, 2005). Fe(II) oxidises to Fe(III) in normal seawater conditions, and dissolved Fe(III) hydrolyses in seawater to form $\mathrm{Fe}(\mathrm{OH})_{3}$ and $\mathrm{Fe}(\mathrm{OH})_{2}{ }^{+}$(Steele et al., 2009). Dissolved $\mathrm{Fe}$ in seawater can be bound to ligands, which diminishes the scavenging of $\mathrm{Fe}$. Hydrothermal originated dissolved Fe fluxes may be rapidly bound to a sulphide phase and oxidised to $\mathrm{Fe}$ oxyhydroxides, or oxidised from $\mathrm{Fe}(\mathrm{II})$ to particulate $\mathrm{Fe}$ (III) (Feely et al., 1996). However, (Sander and Koschinsky, 2011) found some dissolved Fe underwent organic complexation and thus migrated further from source than the insoluble $\mathrm{Fe}$. Fe is scavenged in deep-water environments by particulates (Broecker and Peng, 1982; Boyd and Ellwood, 2010).

\section{Conservative-type trace metal profiles}

Conservative-type distributions have long residence times in the ocean i.e. $\geq 100,000$ years (Bruland et al., 2014), and have a low reactivity in seawater. They may undergo some biological processes whereby upon degradation they re-enter the water column, but these reactions are negligible in comparison to their long residence time and concentration in the ocean environment. Elements with a conservative distribution are relatively homogenously distributed throughout the deep ocean, and correlate with the salinity of a water mass, as their residence time is much longer than $\sim 1,000$ year global ocean circulation (Steele et al., 2009).

Mo, $\mathrm{W}$, and $\mathrm{U}$ are examples of conservative-type trace metals. The main species is $\mathrm{MoO}_{4}{ }^{2-}$ (Koschinsky and Hein, 2003), and it has a residence time of $\sim 800,000$ years (Emerson and Huested, 1991). Mo is only a minor species used by biological reactions (Bruland et al., 2014). Conservative-type trace metals will not be discussed further in this 
chapter due to the lack of available chemical data, but may be of interest when discussing the chemical composition of the ferromanganese nodules.

\subsection{Methods and Data}

The majority of the chemistry data used in this chapter was from the Global Data Analysis Project (GLODAP) and GEOTRACES voyages, with one GEOSECS station. Unfortunately, the trace element data were not available for the same transects as the GLODAP (P11 and P15), so data from GEOTRACES transects upstream and downstream of the ferromanganese nodule sites was examined to understand the potential trace elements in the LCDW overlying the nodules.

The GLODAP data is combined from a variety of ocean cruises that were undertaken in the 1990s such as World Ocean Circulation Experiment (WOCE), the Joint Global Ocean Flux Study (JGOFS), and the Ocean Atmosphere Carbon Exchange Study (OACES). These data was then converted to comparable formats and quality control procedures were ensured (Key et al., 2004).

GEOTRACES is an international collaboration that aims to chemically characterise trace elements in global oceans. Due to the extreme difficulties in measuring trace elements in the oceans as a result of contamination during sampling there are some strict protocols that have been developed and rigorous inter-laboratory comparison exercises to ensure that there is consistency of results between voyages and institutions. The methods can be found in the GEOTRACES Cookbook of Francois (2014).

GEOSECS the first large scale, global collective to study the distribution of elements in the ocean, and was undertaken in the 1970s (Craig and Turekian, 1976).

The quality controlled GLODAP and GEOTRACES datasets were downloaded from their website in Ocean Data View (ODV) format (Key et al., 2004). Unpublished GEOTRACES data of the GP13 transect north of New Zealand was obtained from Dr Michael Ellwood in .xslx format, and imported into ODV. GEOSECS data was taken from (Klinkhammer and Bender, 1980), manually entered into excel, and imported into ODV. All data was plotted and visualised in ODV (Schlitzer, 2015). 


\subsection{Results}

\subsubsection{GLODAP}

This section discusses the main hydrographic and nutrient properties of the water masses in the New Zealand region. Two latitudinal transects are discussed. The P11 transect is in the Tasman Sea along $155^{\circ} \mathrm{E}$ and $\mathrm{P} 15$ is primarily along $170^{\circ} \mathrm{W}$ (Figure 2.4). These two transects span the nodules analysed in this project and provide information about the water masses overlying the nodules.

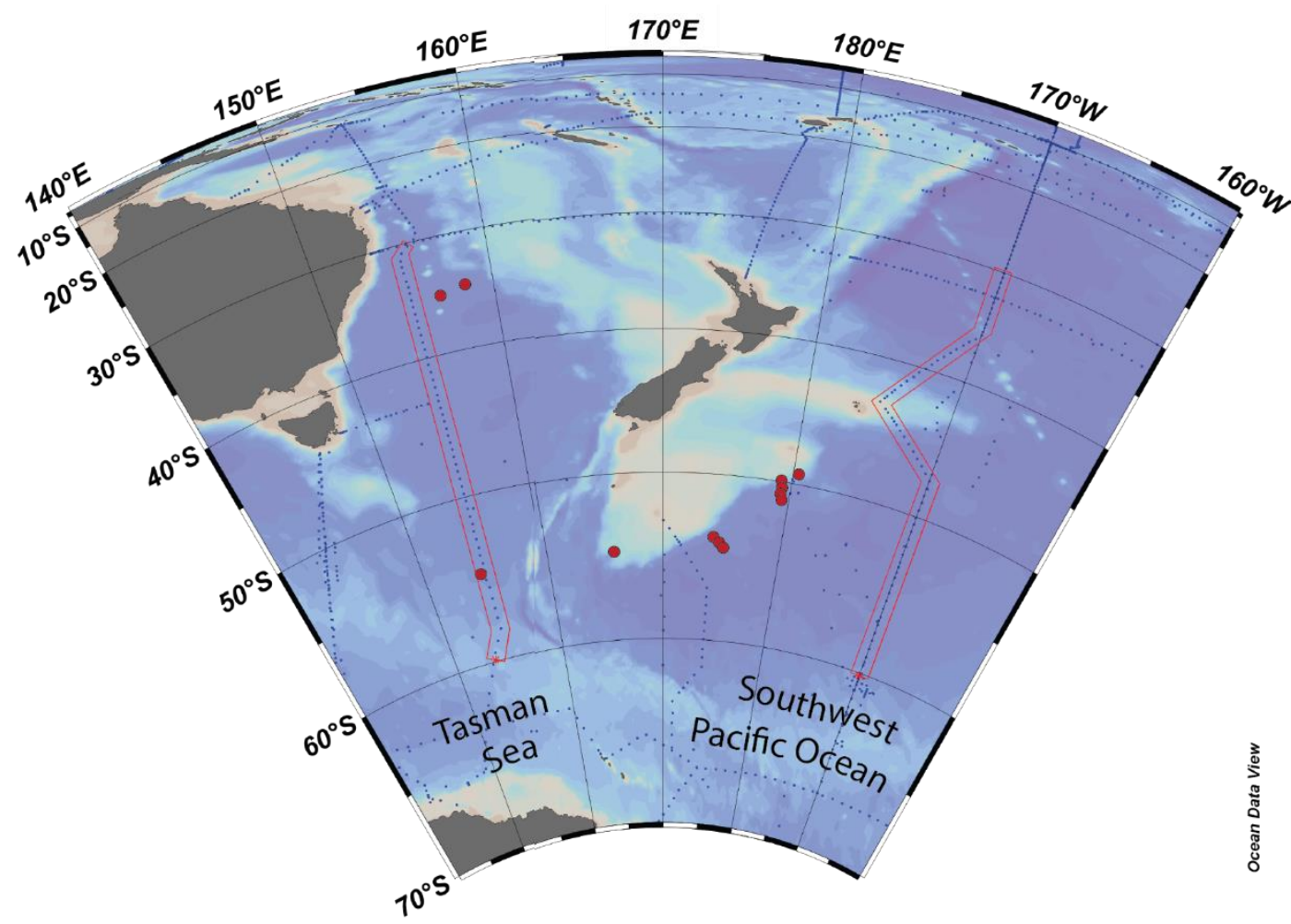

Figure 2.4: Map of the New Zealand transects visualised from the GLODAP dataset (Key et al., 2004). West of New Zealand is the Tasman Sea transect, and east of New Zealand is the Southwest Pacific Ocean transect. Both transects were visualised from $30-60^{\circ} \mathrm{S}$. Red dots mark the location of the ferromanganese nodules sampled for this study. 


\subsubsection{P15 $\left(\mathbf{1 7 0}^{\circ} \mathbf{W}\right)$ Southwest Pacific Ocean}

AABW are identified in this area based on the cold $\left(<1{ }^{\circ} \mathrm{C}\right)$ temperature. The LCDW is identified by the slightly higher temperature, and lower oxygen content relative to AABW. The UCDW exhibits a characteristic oxygen depletion at 500-2,500 m between $60-45^{\circ} \mathrm{S}$. The PDW was observed between $1,000-3,500 \mathrm{~m}$, at $45-30^{\circ} \mathrm{S}$, also based on the characteristic dissolved oxygen depletion $(175->150 \mu \mathrm{mol} / \mathrm{kg})$.

Seawater temperature tends to decrease with increasing depth (Figure 2.5). A stream of cold AABW mixing with the LCDW is apparent south of $\sim 55^{\circ} \mathrm{S}$. The LCDW becomes less oxygen rich as it travels northward and is no longer underlain by the AABW, bottom water oxygen levels at the nodule locations $\left(50-55^{\circ} \mathrm{S}\right)$ range from $\sim 175-\sim 225 \mu \mathrm{mol} / \mathrm{kg}$.

South of the Chatham Rise in the LCDW and AABW the phosphate concentration is lower $(2.25 \mu \mathrm{mol} / \mathrm{kg})$ and decreases with increasing latitude (Figure 2.6). Nitrate (Figure A.1; Appendix A) show a similar profiles to phosphate. The AABW and the PDW also display enriched silicate concentrations $>120 \mu \mathrm{mol} / \mathrm{kg}$ (Figure 2.6).

In summary, the water mass interpreted to overly the Campbell nodule field (49.5$53.5^{\circ} \mathrm{S}$ ) is the LCDW, mixed with the AABW. It has a temperature of $\sim 1{ }^{\circ} \mathrm{C}$, salinity of $\sim 35$, and dissolved elemental concentrations of $\sim 212 \mu \mathrm{mol} / \mathrm{kg}$ oxygen, $\sim 2.2 \mu \mathrm{mol} / \mathrm{kg}$ phosphate, $\sim 24 \mu \mathrm{mol} / \mathrm{kg}$ silicate, and $\sim 32 \mu \mathrm{mol} / \mathrm{kg}$ nitrate (Table 2.3). 

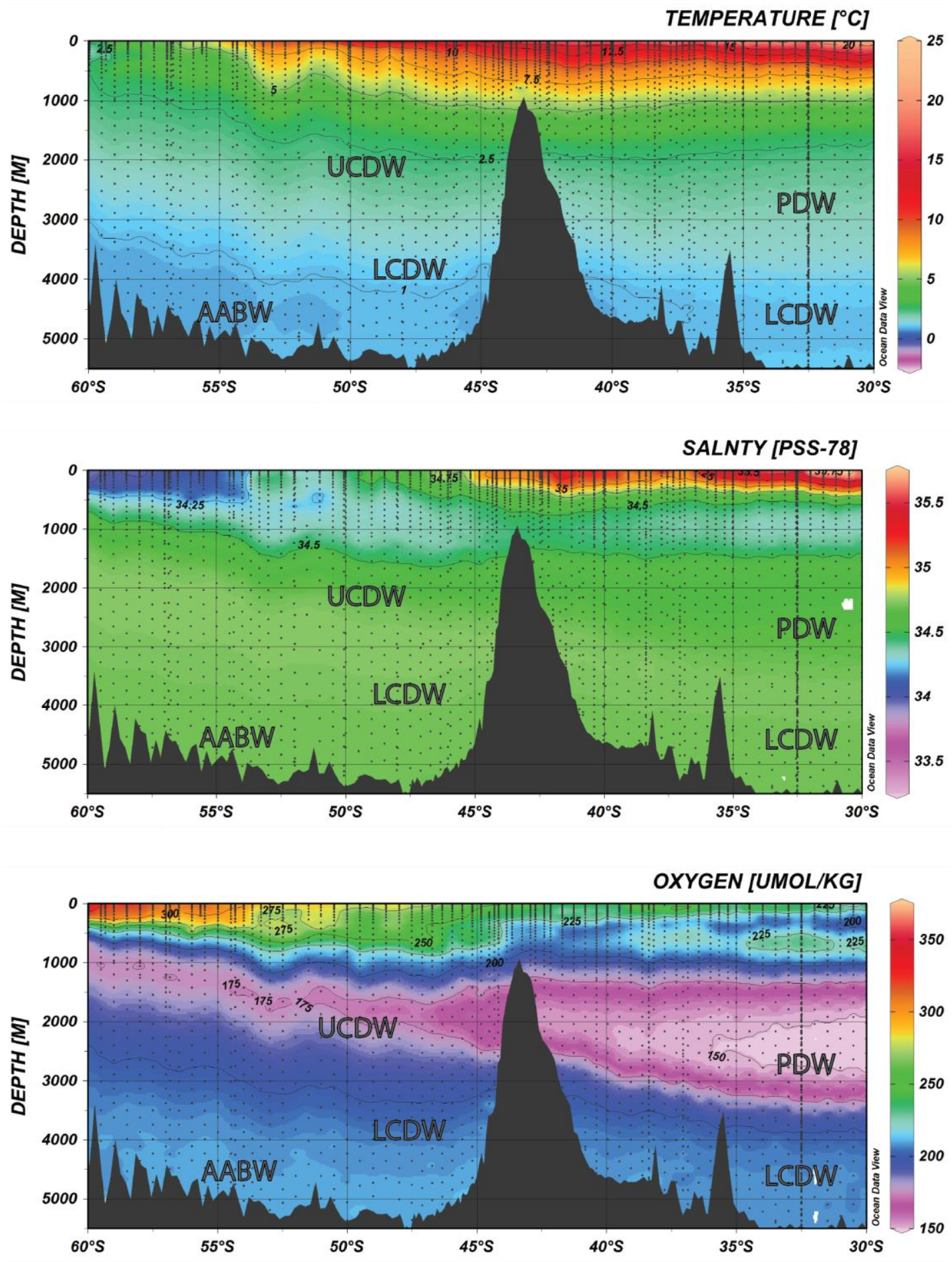

Figure 2.5: Temperature, salinity, and dissolved oxygen profiles along the P15 (Southwest Pacific Ocean) transect. The deep water masses; AABW - Antarctic Bottom Water, LCDW - Lower Circumpolar Deep Water, UCDW - Upper Circumpolar Deep Water, and PDW - Pacific Deep Water, have been identified and labelled. The bathymetric high from $\sim 40-45^{\circ} \mathrm{S}$ is the Chatham Rise. The Campbell nodule field is located at $\sim 50-54^{\circ} \mathrm{S}$. 

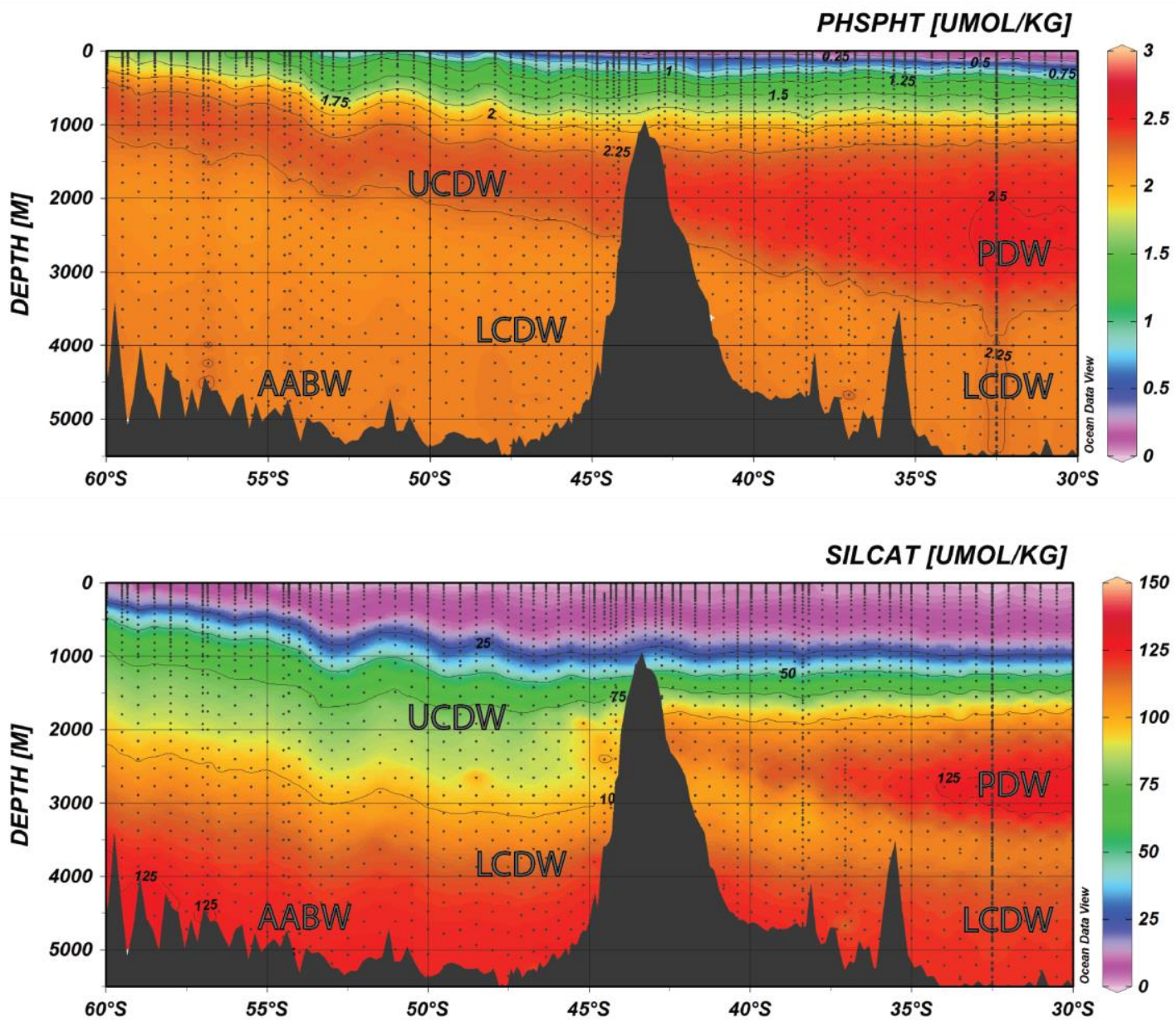

Figure 2.6: Phosphate and silicate profiles along the P15 (Southwest Pacific Ocean) transect. The deep water masses: AABW, LCDW, UCDW, and PDW have been identified and labelled. Acronyms as for Figure 2.5. The Campbell nodule field is located at $\sim 50-54^{\circ} \mathrm{S}$. 


\subsubsection{P11 $\left(\mathbf{1 5 5}^{\circ} \mathbf{E}\right)$ Tasman Sea}

AABW, the LCDW, and UCDW were identified on the basis of temperature and dissolved oxygen concentrations, as per the P15 transect. The cold $\left(>1{ }^{\circ} \mathrm{C}\right)$ AABW mixes with the overlying LCDW and is not seen north of $45^{\circ} \mathrm{S}$ (Figure 2.7). In the AABW, LCDW, and UCDW, salinity is uniform. The oxygen rich (> $200 \mu \mathrm{mol} / \mathrm{kg}$ ) AABW is visible between $45-60^{\circ} \mathrm{S}$ (Figure 2.7 ).

In the AABW and the LCDW it has a consistent phosphate content of $2-2.25 \mu \mathrm{mol} / \mathrm{kg}$, with a poleward shoaling (rising) apparent (Figure 2.8). Nitrate (Figure A.1; Appendix A) shows a similar profile to phosphate. Silicate concentrations increase with depth in the UCDW, LCDW, and AABW (Figure 2.8).

The water mass overlying the Tasman nodules $\left(35.6-35.8^{\circ} \mathrm{S}\right)$ is the LCDW. The LCDW in this region is characterised by a temperature of $1.17^{\circ} \mathrm{C}$, salinity of 34.7 , and dissolved oxygen concentration of $194 \mu \mathrm{mol} / \mathrm{kg}$, phosphate concentrations of $2.21 \mu \mathrm{mol} / \mathrm{kg}$, silicate concentrations of $120.2 \mu \mathrm{mol} / \mathrm{kg}$, and nitrate concentrations of $33.3 \mu \mathrm{mol} / \mathrm{kg}$ (Table 2.3 ). 

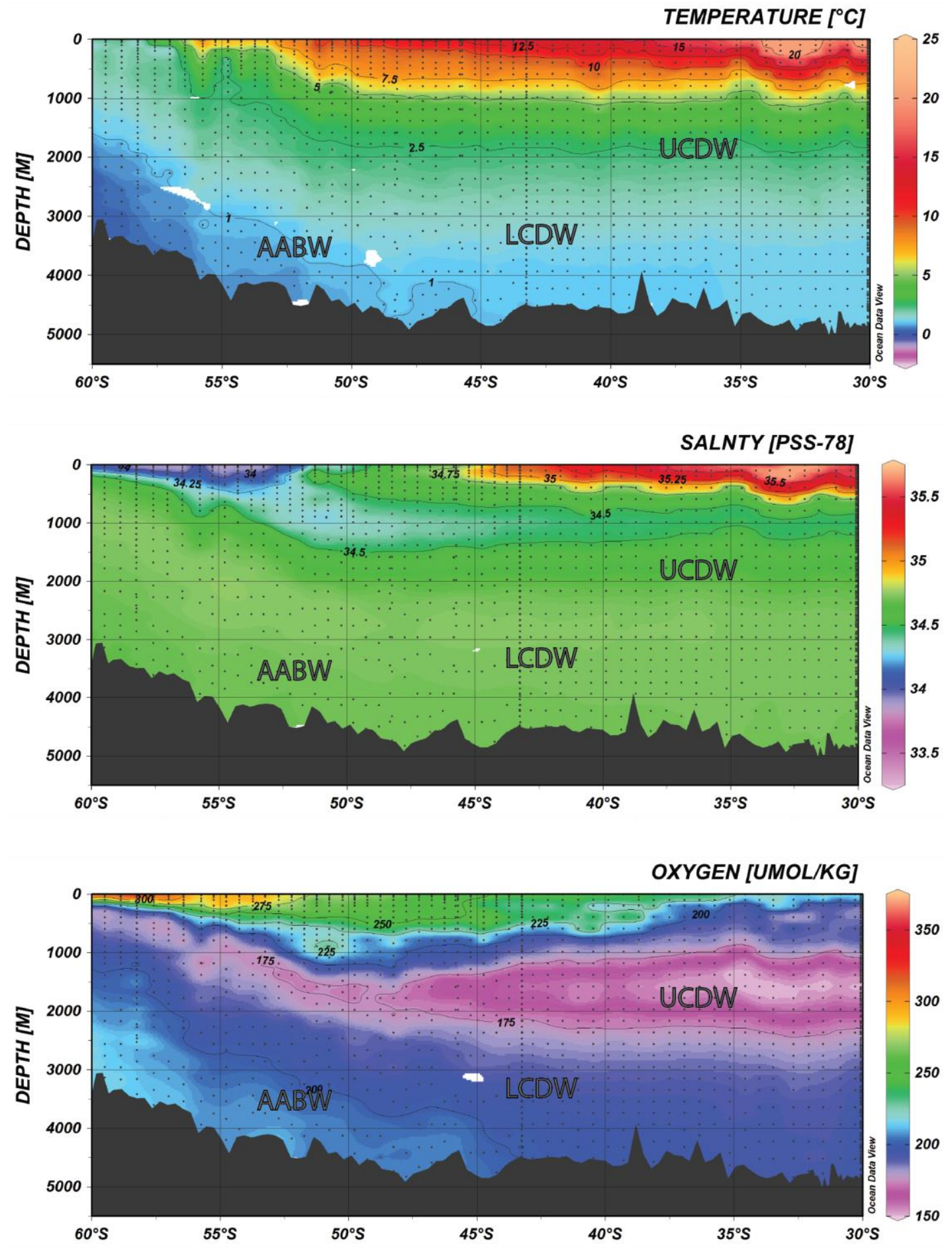

Figure 2.7: Temperature, salinity, and dissolved oxygen profiles along the P11 (Tasman Sea) transect. The deep water masses: AABW - Antarctic Bottom Water, LCDW - Lower Circumpolar Deep Water, UCDW - Upper Circumpolar Deep Water, and PDW - Pacific Deep Water, have been identified and labelled. The Tasman nodule field is located at $\sim 35.6-35.8^{\circ} \mathrm{S}$. 

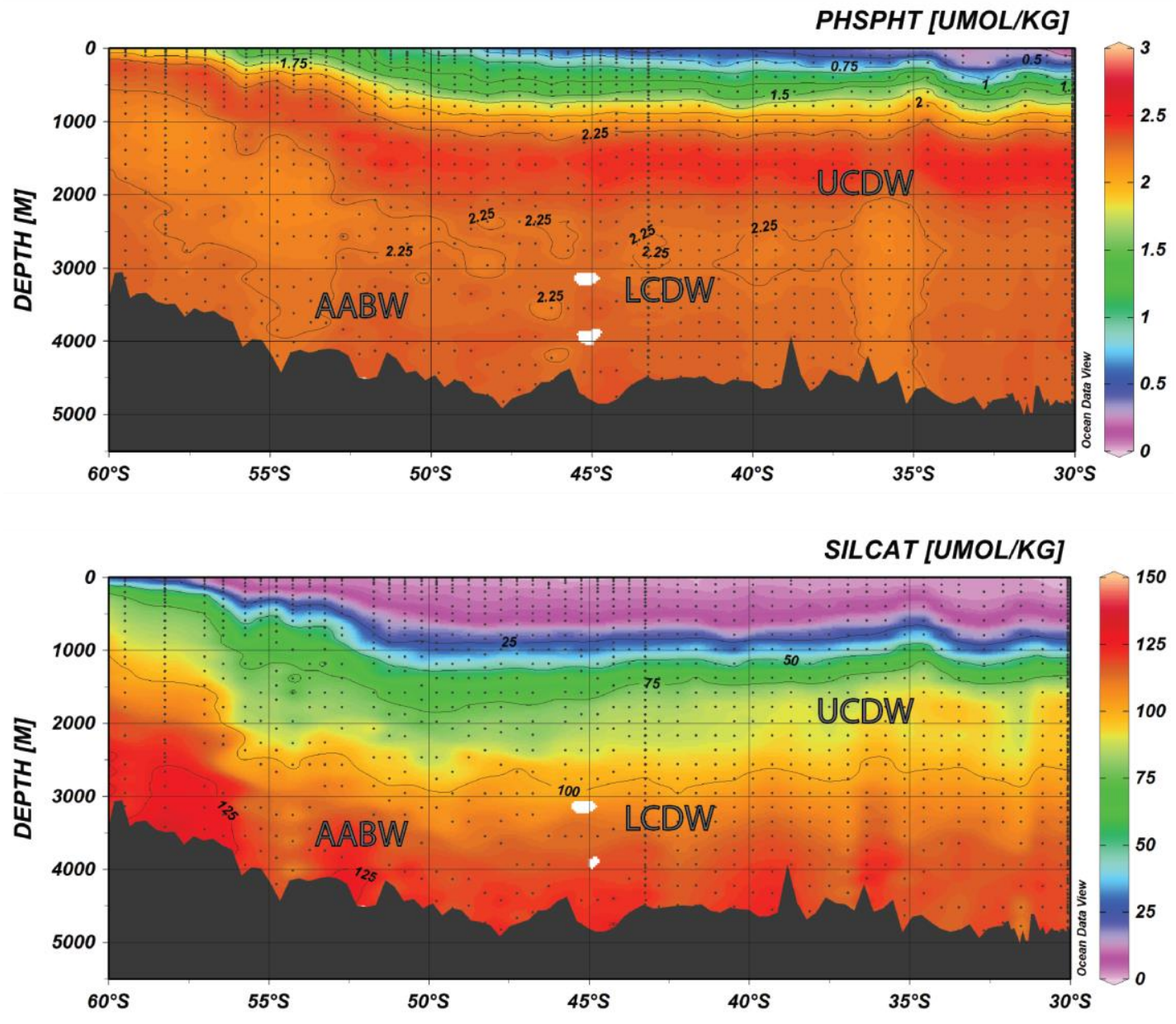

Figure 2.8: Phosphate and silicate profiles along the P11 (Tasman Sea) transect. The deep water masses: AABW, LCDW, UCDW, and PDW have been identified and labelled. Acronyms as for Figure 2.7. The Tasman nodule field is located at $\sim 35.6-35.8^{\circ} \mathrm{S}$. 


\subsubsection{GEOTRACES}

Unfortunately trace elements have not been analysed on the P11 and P15 transects. In this section the trace elements will be described from two latitudinal sections; GIPY4 (0$\left.18^{\circ} \mathrm{E}\right)$ from the South Atlantic and SR3 $\left(145^{\circ} \mathrm{E}\right)$ from South of Tasmania to Antarctica (Figure 2.9). One longitudinal section from the South Pacific, GP13 (30 $\left.{ }^{\circ} \mathrm{S}\right)$ is also described (Figure 2.9). These three sections were chosen as they sample similar water masses (LCDW) to those present in the New Zealand region and may provide some insight into the trace element concentrations we might find present in the waters overlying the nodules analysed in this project. The hydrographic and nutrient properties will be briefly described along each section, followed by a description of the trace elements that were analysed along the transect.

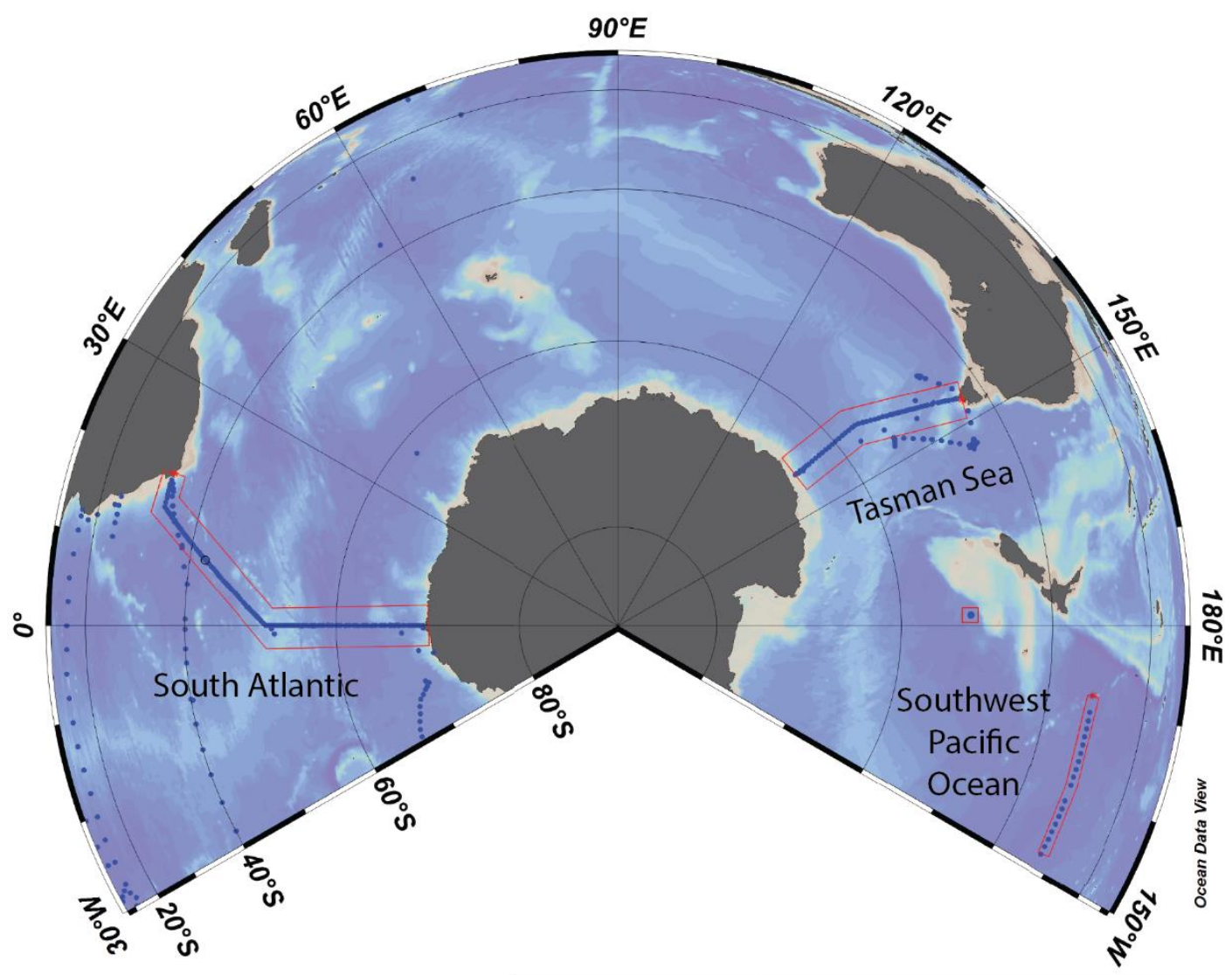

Figure 2.9: Map of transects GIPY4 (South Atlantic Ocean), SR3 (Tasman Sea), and GP13 (Southwest Pacific Ocean), visualised from the GEOTRACES dataset (Mawji et al., 2015) by Ocean Data View (Schlitzer, 2015). The GEOSECS location just east of the Campbell Plateau (small red box) discussed in the next section is also shown. 


\subsubsection{GIPY4 South Atlantic/Southern Ocean}

The LCDW are identified in this transect at 1,500-5,000 $\mathrm{m}$ from $55-45^{\circ} \mathrm{S}$, and $\geq 4,000 \mathrm{~m}$ depth north of $45^{\circ} \mathrm{S}$ based on the temperature $\left(\sim 1^{\circ} \mathrm{C}\right)$ and dissolved oxygen content (200-225 $\mu \mathrm{mol} / \mathrm{kg}$ ) (Figure 2.10). AABW are evident south of $\sim 55^{\circ} \mathrm{S}$ from the cold $(\leq$ $\left.0{ }^{\circ} \mathrm{C}\right)$, oxygen rich $(225-250 \mu \mathrm{mol} / \mathrm{kg})$ deep water characteristics displayed. The UCDW are identified at $500-2,000 \mathrm{~m}$ from $55-34^{\circ} \mathrm{S}$ by its $\sim 2.5-3{ }^{\circ} \mathrm{C}$ temperature, and oxygen content (175-200 $\mu \mathrm{mol} / \mathrm{kg})$. The NADW are recognised between 2,000-4,000 m north of $43^{\circ} \mathrm{S}$ due to their higher salinity (> 34.75) and oxygen content of $\sim 225 \mu \mathrm{mol} / \mathrm{kg}$ (Figure 2.10). The LCDW overlies the AABW south of $\sim 55^{\circ} \mathrm{S}$.

The LCDW has a higher dissolved oxygen concentration than the UCDW ( 220 vs. $\sim 210 \mu \mathrm{mol} / \mathrm{kg}$ ) when it is below the NADW (Figure 2.10). The hydrographic characteristics of the LCDW are summarised in Table 2.3.

The phosphate concentration in the LCDW and AABW is relatively homogenous ( $\geq 2-\leq 2.3 \mu \mathrm{mol} / \mathrm{kg}$ ) (Figure 2.11). The NADW is comparatively depleted in phosphate. Nitrate has a profile similar to phosphate (Appendix A). Silicate is displays a greater enrichment in the AABW than the LCDW (Figure 2.11). 


\section{Hydrographic and nutrient properties}
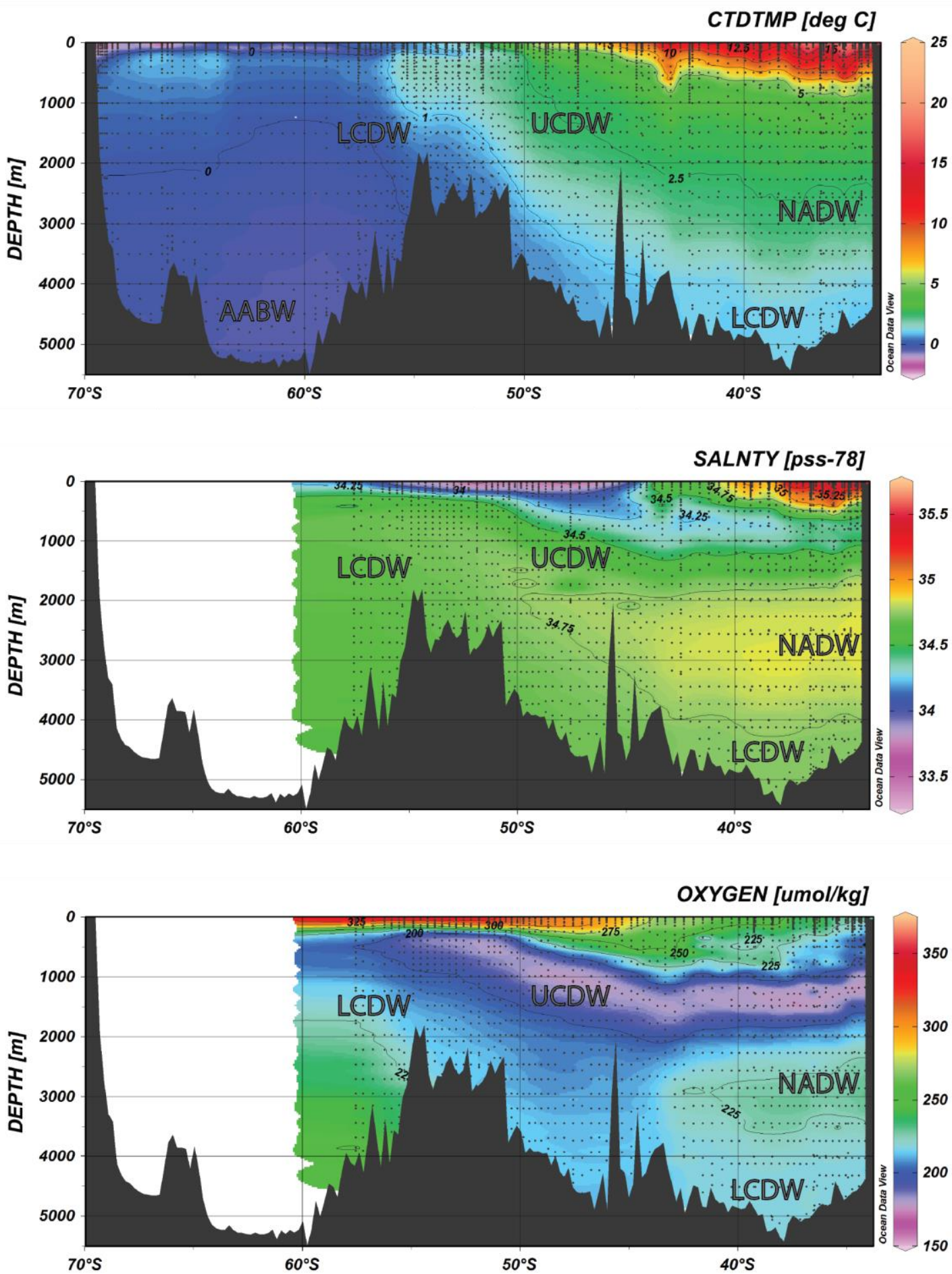

Figure 2.10: Temperature, salinity, and dissolved oxygen profiles for the GIPY4 GEOTRACES transect in the South Atlantic Ocean. The deep water masses: AABW - Antarctic Bottom Water, LCDW - Lower Circumpolar Deep Water, UCDW - Upper Circumpolar Deep Water, and NADW - North Atlantic Deep Water, have been identified and labelled. The Mid-Atlantic Ridge is located at $\sim 50-56^{\circ} \mathrm{S}$. The Antarctic continental shelf is located at $70^{\circ} \mathrm{S}$, and the profile ends at the African continental shelf. 

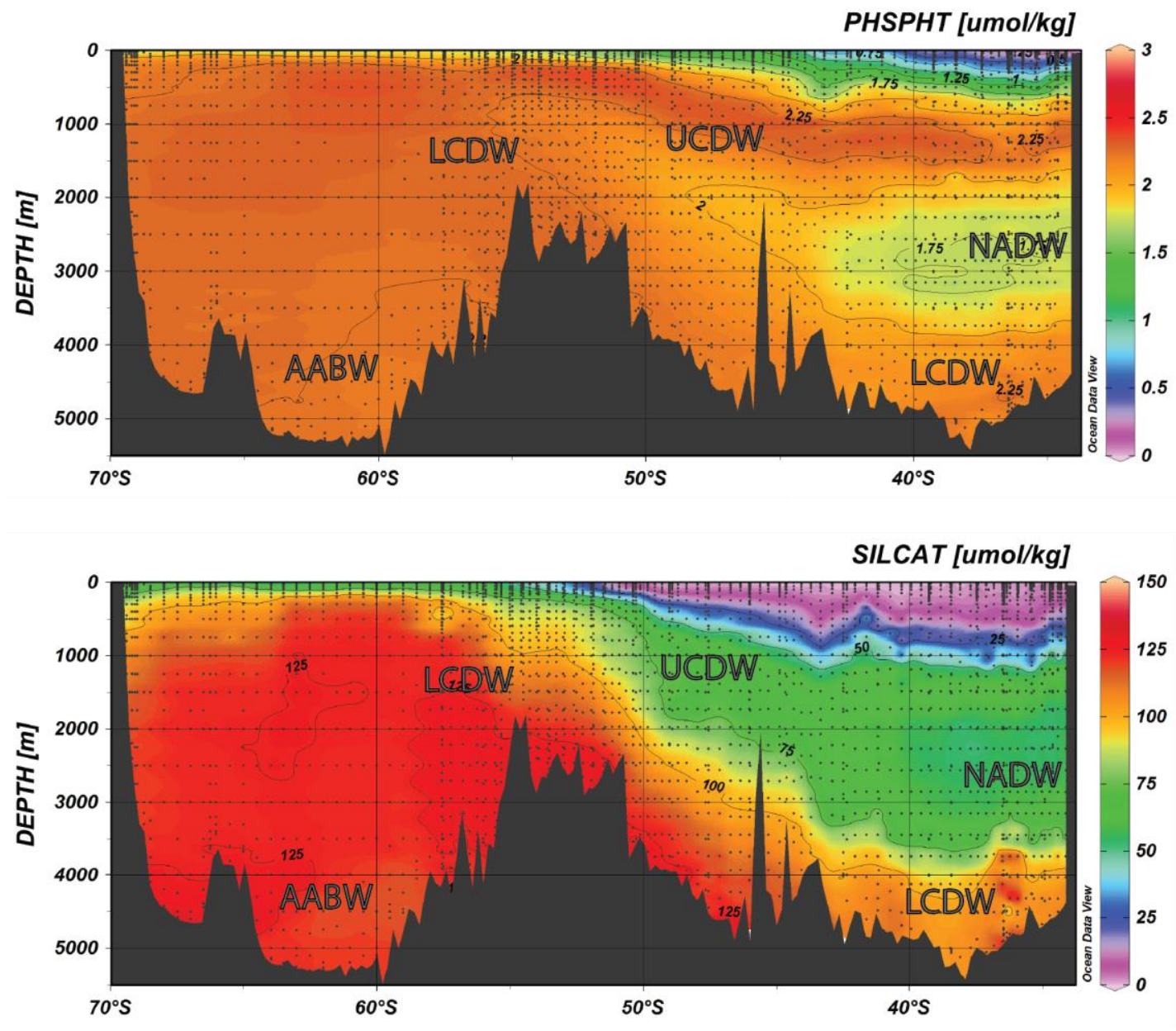

Figure 2.11: Phosphate and silicate profiles for the GIPY4 GEOTRACES transect in the South Atlantic Ocean. The deep water masses: AABW, LCDW, UCDW, and NADW have been identified and labelled. Acronyms as for Figure 2.10 . 
Figure 2.12 displays a large flux of $\mathrm{Mn}$ visible at $\sim 55^{\circ} \mathrm{S}$ and 2,000 $\mathrm{m}$ depth at the midocean ridge, with $\mathrm{Mn}$ concentrations reaching $\geq 0.75 \mathrm{nmol} / \mathrm{kg}$. Between $40-50^{\circ} \mathrm{S}$ at 4,000 $\mathrm{m}$ depth in the LCDW there is a band with a relatively higher concentration of Mn than the surrounding seawater. Below this band, closer to the seafloor there is lower concentrations of Mn. The underlying NADW also displays an enrichment. Mn tends to be depleted in the AABW south of the mid ocean ridge, with the exception of two enriched haloes near the seafloor at $60^{\circ} \mathrm{S}$ and $66^{\circ} \mathrm{S}$.

$\mathrm{Fe}$ in the $\mathrm{AABW}$ is relatively homogenous, with the exception of an area from $\sim 57-65^{\circ} \mathrm{S}$, 3,000-4,500 $\mathrm{m}$ (Figure 2.12). A flux of dissolved Fe is visible in the LCDW at the midocean ridge at $1,500-3,500 \mathrm{~m}$ depth, and at $\sim 36^{\circ} \mathrm{S}$ at 3,500-4,500 $\mathrm{m}$ depth. Similarly to the Mn profile dissolved Fe is depleted in the LCDW between $40-50^{\circ} \mathrm{S}$ at $\geq 4,000 \mathrm{~m}$ depth. The NADW is relatively enriched in Fe, with concentrations ranging from $0.5-\geq 0.75 \mathrm{nmol} / \mathrm{kg}$. The UCDW becomes more enriched in Fe with closer proximity to the African continent at $35^{\circ} \mathrm{S}$.

The LCDW has low (Figure 2.13) concentrations of Ce with the exception of $\sim 45-35^{\circ} \mathrm{S}$ at $\geq 3,500 \mathrm{~m}$ depth. At $47.6^{\circ} \mathrm{S}, \sim 4,300 \mathrm{~m}$ there is a very low $(2.31 \mathrm{pmol} / \mathrm{kg}) \mathrm{Ce}$ concentration. In contrast, La is enriched in the AABW and the LCDW; with the exception of the $47.6^{\circ} \mathrm{S} \sim 4,300 \mathrm{~m}$ station mentioned in the Ce transect above, and at 35$40^{\circ} \mathrm{S}$ at $\geq 4,000 \mathrm{~m}$ depth which is enriched with a concentration of $49 \mathrm{pmol} / \mathrm{kg}$ (Figure 2.13). La concentrations above this area decrease with decreasing depth, with the UCDW having less than the NADW and the LCDW in turn. Other REE (Pr, Nd, Sm, Eu, Gd, Tb, Dy, Ho, Er, Tm, Yb, and Lu) show similar profiles to La (Appendix A) and are not discussed due to the similarity with La. 


\section{Trace element properties}
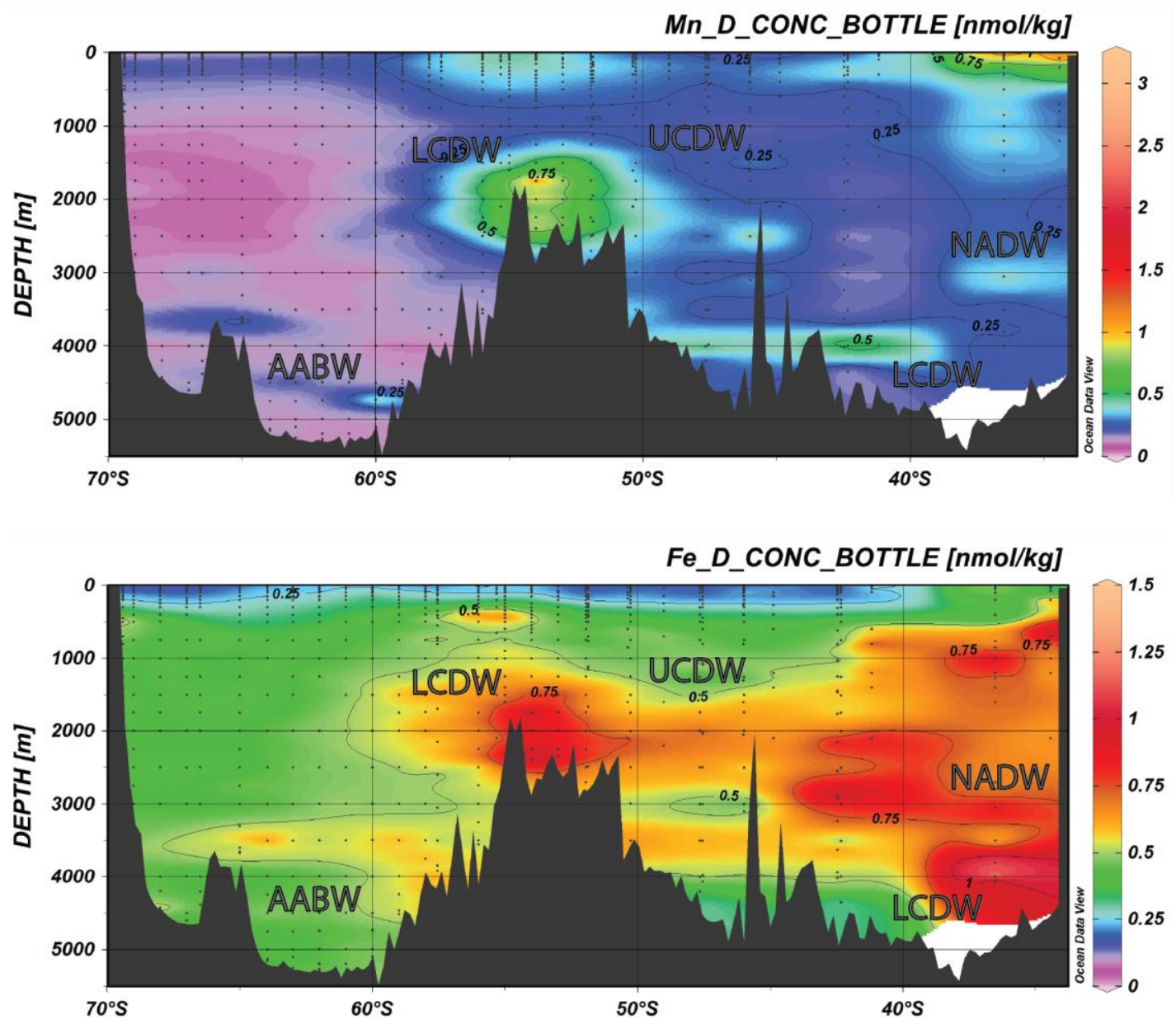

Figure 2.12: Dissolved Mn and Fe profiles for the GIPY4 GEOTRACES transect in the South Atlantic Ocean. The deep water masses: AABW, LCDW, UCDW, and NADW identified in the hydrographic data are labelled. Acronyms as for Figure 2.10. 

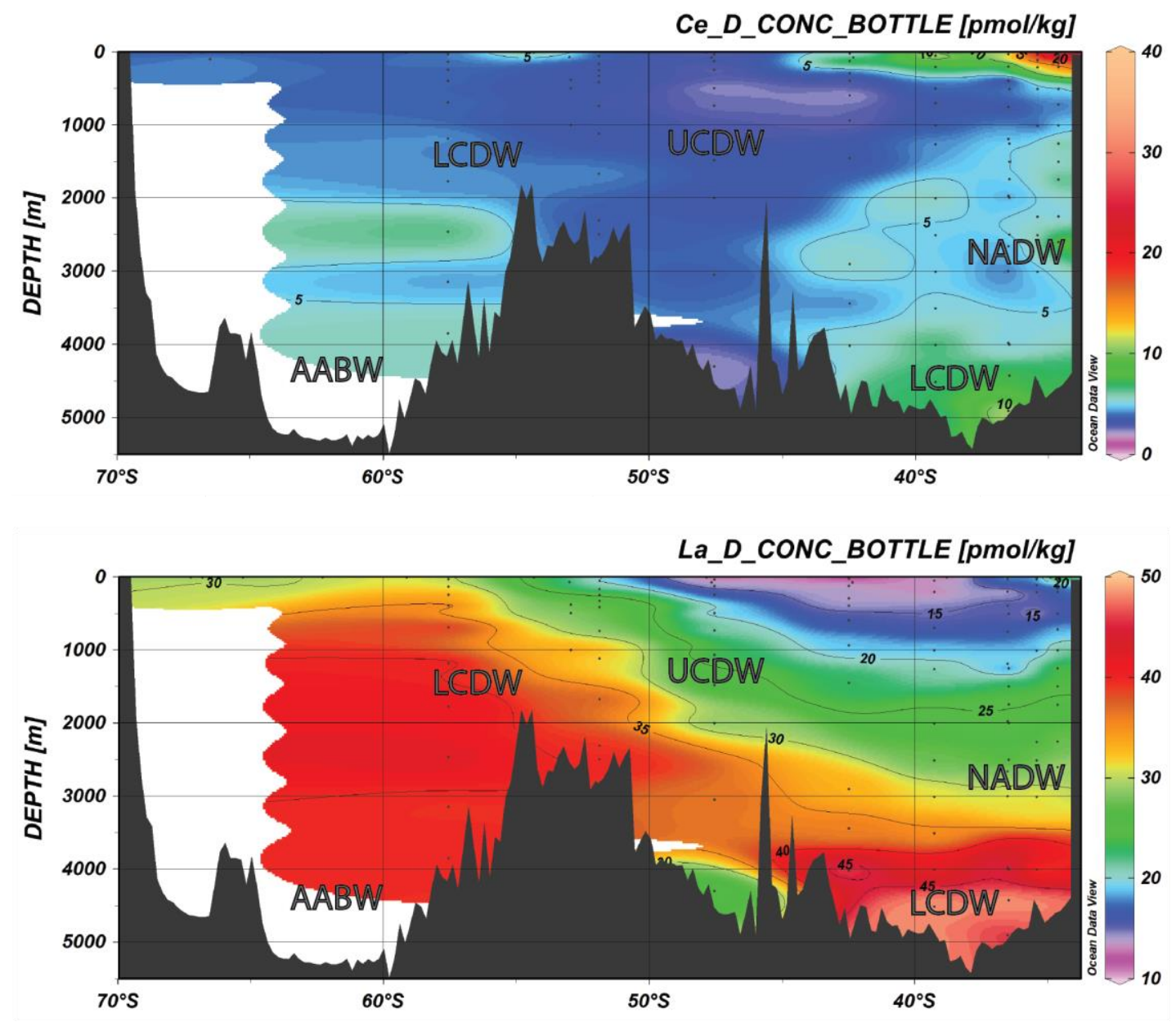

Figure 2.13: Dissolved Ce and La profiles for the GIPY4 GEOTRACES transect in the South Atlantic Ocean. The deep water masses: AABW, LCDW, UCDW, and NADW identified in the hydrographic data are labelled Note the smaller number of measurements for these elements (shown by the black dots in the transect). Acronyms as for Figure 2.10. 
The concentration of $\mathrm{Pb}$ does not seem to correlate with variations in water masses (Figure 2.14). There is a depletion in the LCDW adjacent to the mid-ocean ridge complex at $\sim 55^{\circ} \mathrm{S}$ from $1,000-3,000 \mathrm{~m}$, and at $\sim 45^{\circ} \mathrm{S}$ from $2,000-3,500 \mathrm{~m}$. Surface waters adjacent to the African continent are enriched in $\mathrm{Pb}$. Al concentrations in seawater also do not appear to correspond with water masses (Figure 2.14). Seawater south of $50^{\circ} \mathrm{S}$ is depleted in $\mathrm{Al}$. An enriched halo is apparent at $47.6^{\circ} \mathrm{S}$ at $800 \mathrm{~m}$ depth, but this may be an erroneous measurement and has been flagged in the GEOTRACES database. The concentration of $\mathrm{Ti}$ appears to be moderately related to water mass variability, with the AABW displaying relatively uniform concentrations of Ti. The UCDW and the LCDW are significantly more enriched in $\mathrm{Ti}$ at the northernmost $44.7^{\circ} \mathrm{S}$ station.

$\mathrm{Cu}$ displays a profile similar to silicate, with the exception of two enriched areas in the LCDW near the seafloor at $50^{\circ} \mathrm{S}$ and $48^{\circ} \mathrm{S}$, and an enriched halo the bottom waters of the $\mathrm{AABW}$ at $\sim 68^{\circ} \mathrm{S}$ (Figure 2.15). $\mathrm{Zn}$ also displays a profile similar to that of silicate, however there is an enrichment similar to that seen in the La profile at $\sim 45-35^{\circ} \mathrm{S}$ and $\geq 3,500 \mathrm{~m}$ depth. Cd displays a profile similar to that of phosphate and nitrate. The trace element concentrations for the LCDW in this transect are located in Table 2.4. They will be compared to the LCDW trace element concentrations from other regions. 

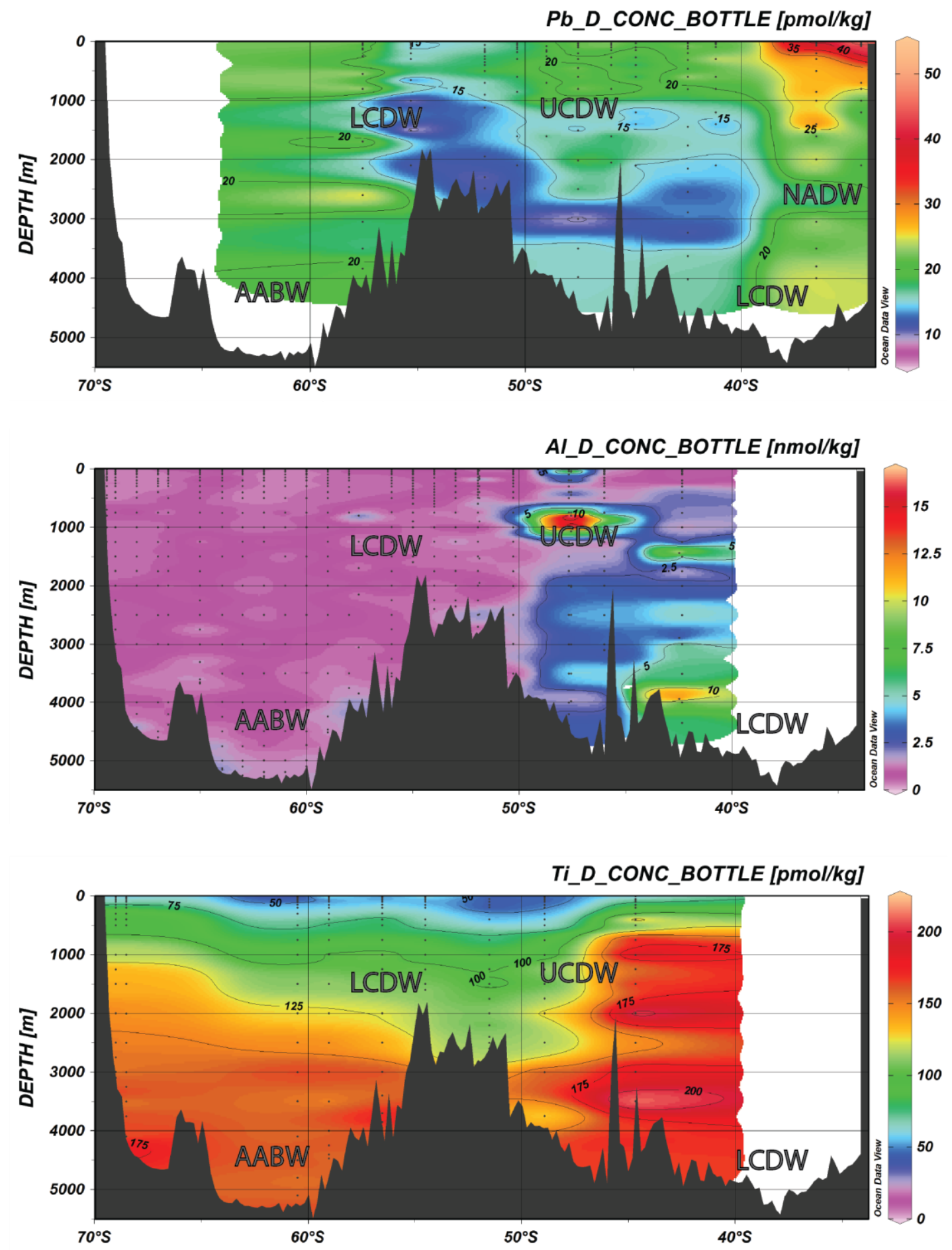

Figure 2.14: Dissolved Pb, Al, and Ti profiles for the GIPY4 GEOTRACES transect in the South Atlantic Ocean. The deep water masses: AABW, LCDW, UCDW, and NADW identified in the hydrographic data are labelled. Acronyms as for Figure 2.10. 

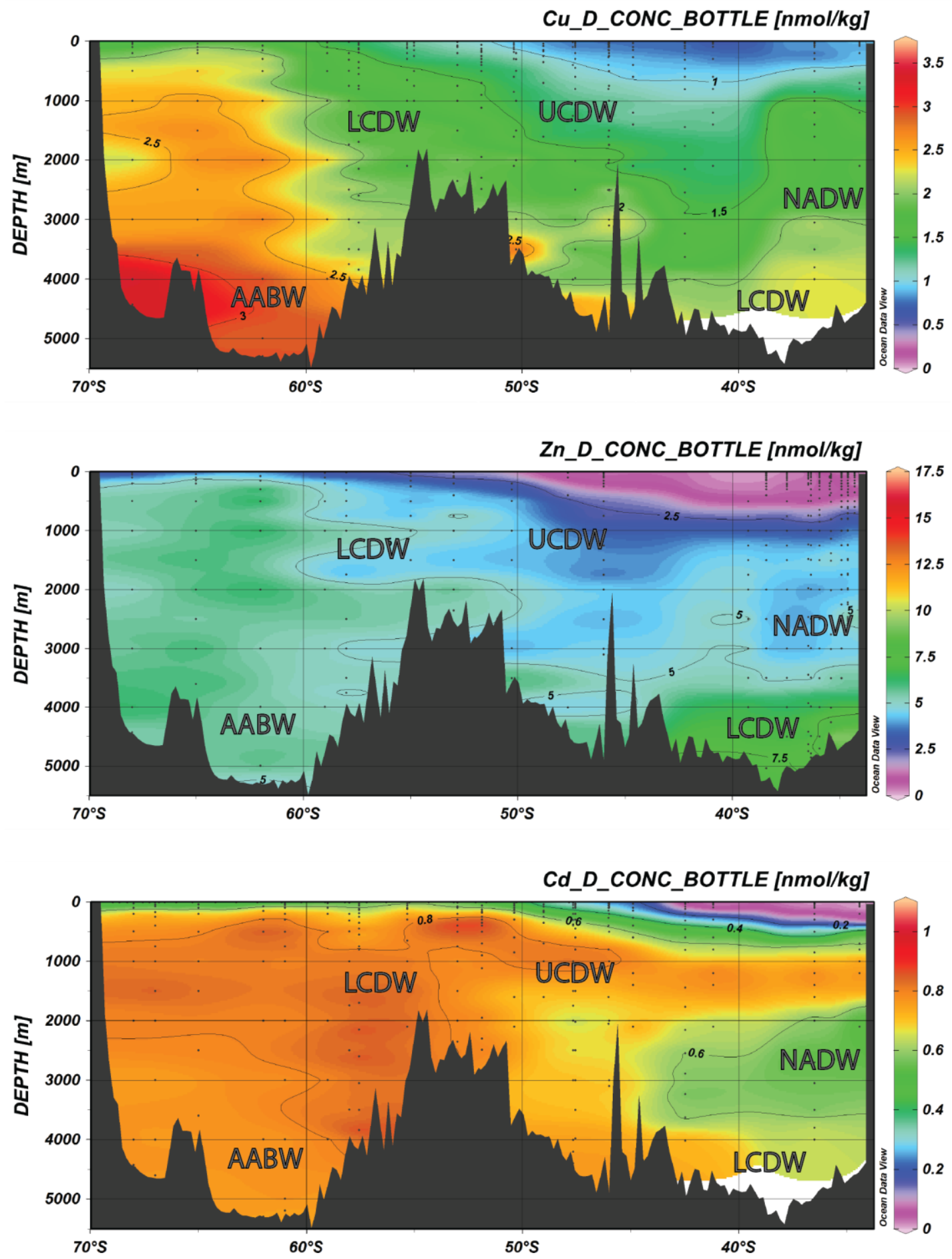

Figure 2.15: Dissolved $\mathrm{Cu}, \mathrm{Zn}$, and Cd profiles for the GIPY4 GEOTRACES transect in the South Atlantic Ocean. The deep water masses: AABW, LCDW, UCDW, and NADW identified in the hydrographic data are labelled. Acronyms as for Figure 2.10. 


\subsubsection{2 $\quad$ SR3 $\left(\mathbf{1 4 5}^{\circ} \mathbf{E}\right)$ Tasman Sea - Southern Ocean}

The LCDW is recognised in this transect at $500-4,500 \mathrm{~m}$ from $65-45^{\circ} \mathrm{S}$, based on the temperature $\left(\sim 1-1.75^{\circ} \mathrm{C}\right)$ and dissolved oxygen content $(200-225 \mu \mathrm{mol} / \mathrm{kg}$ ) (Figure 2.16; Table 2.3). AABW are identified south of $\sim 60^{\circ} \mathrm{S}$ by its cold $\left(\leq 0{ }^{\circ} \mathrm{C}\right)$ and oxygen rich $(225-250 \mu \mathrm{mol} / \mathrm{kg})$ properties. The UCDW are evident at 500-3,000 m from 64$44^{\circ} \mathrm{S}$ by the low oxygen concentrations of $160-180 \mu \mathrm{mol} / \mathrm{kg}$.

The presence of $\mathrm{AABW}$ diminishes north of $55^{\circ} \mathrm{S}$ (Figure 2.16). Salinity is homogenous in deep waters such as the UCDW, LCDW and AABW. Figure 2.16 displays that the underlying LCDW and AABW are increasingly oxygen rich with depth and closer proximity to Antarctica.

The phosphate concentration in the LCDW and AABW is relatively homogenous at $>2$ $2.3 \mu \mathrm{mol} / \mathrm{kg}$ (Figure 2.17). AABW display a greater enrichment in silicate than the LCDW, except near the seafloor south of $\sim 63^{\circ} \mathrm{S}$. 


\section{Hydrographic and nutrient properties}
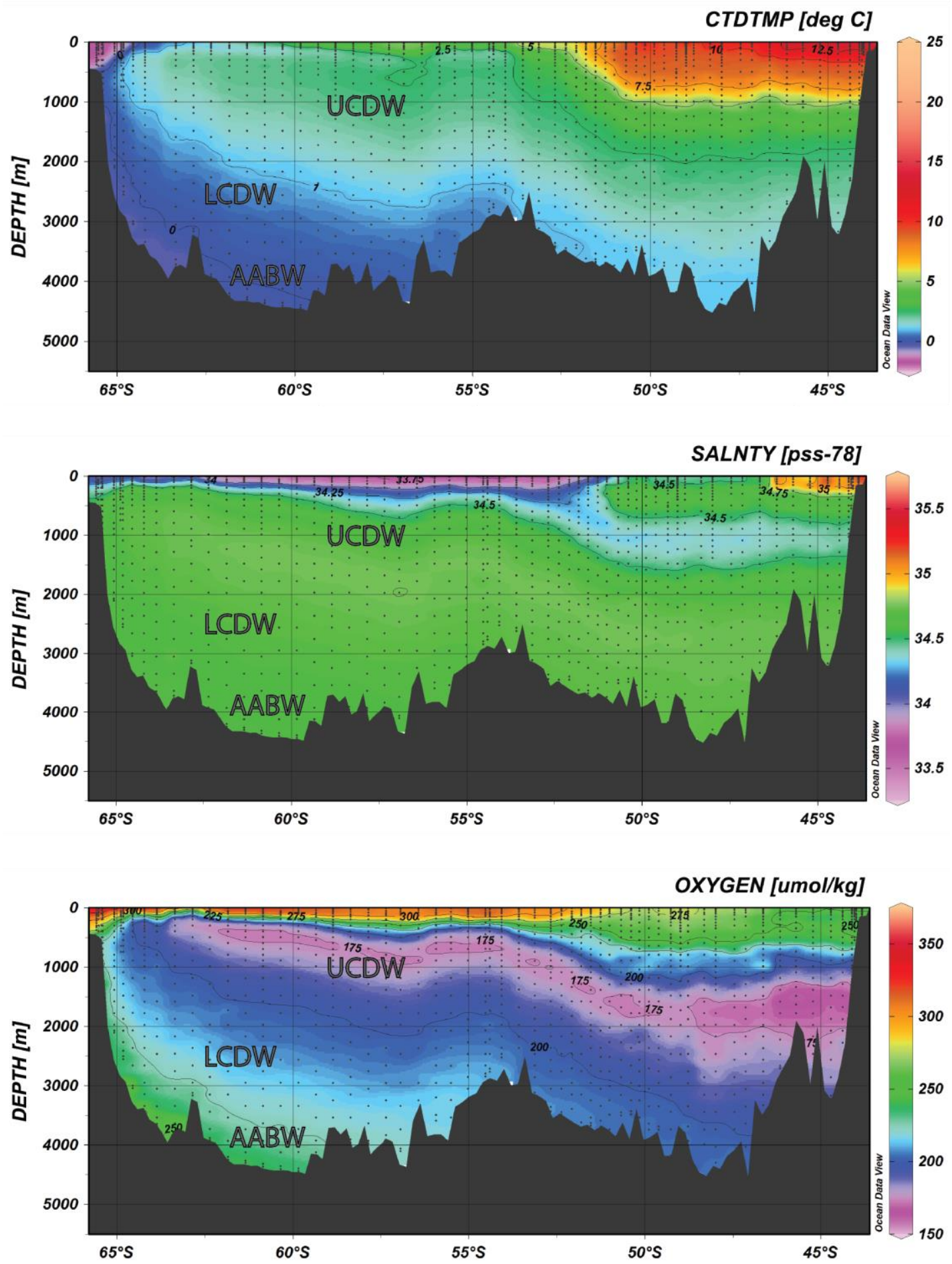

Figure 2.16: Temperature, salinity, and dissolved oxygen profiles for the SR3 GEOTRACES transect in the Tasman Sea - Southern Ocean. The deep water masses: AABW, LCDW, and UCDW have been identified and labelled. Acronyms as for Figure 2.7. The Southeast Indian Ridge is located at $\sim 54^{\circ} \mathrm{S}$. 

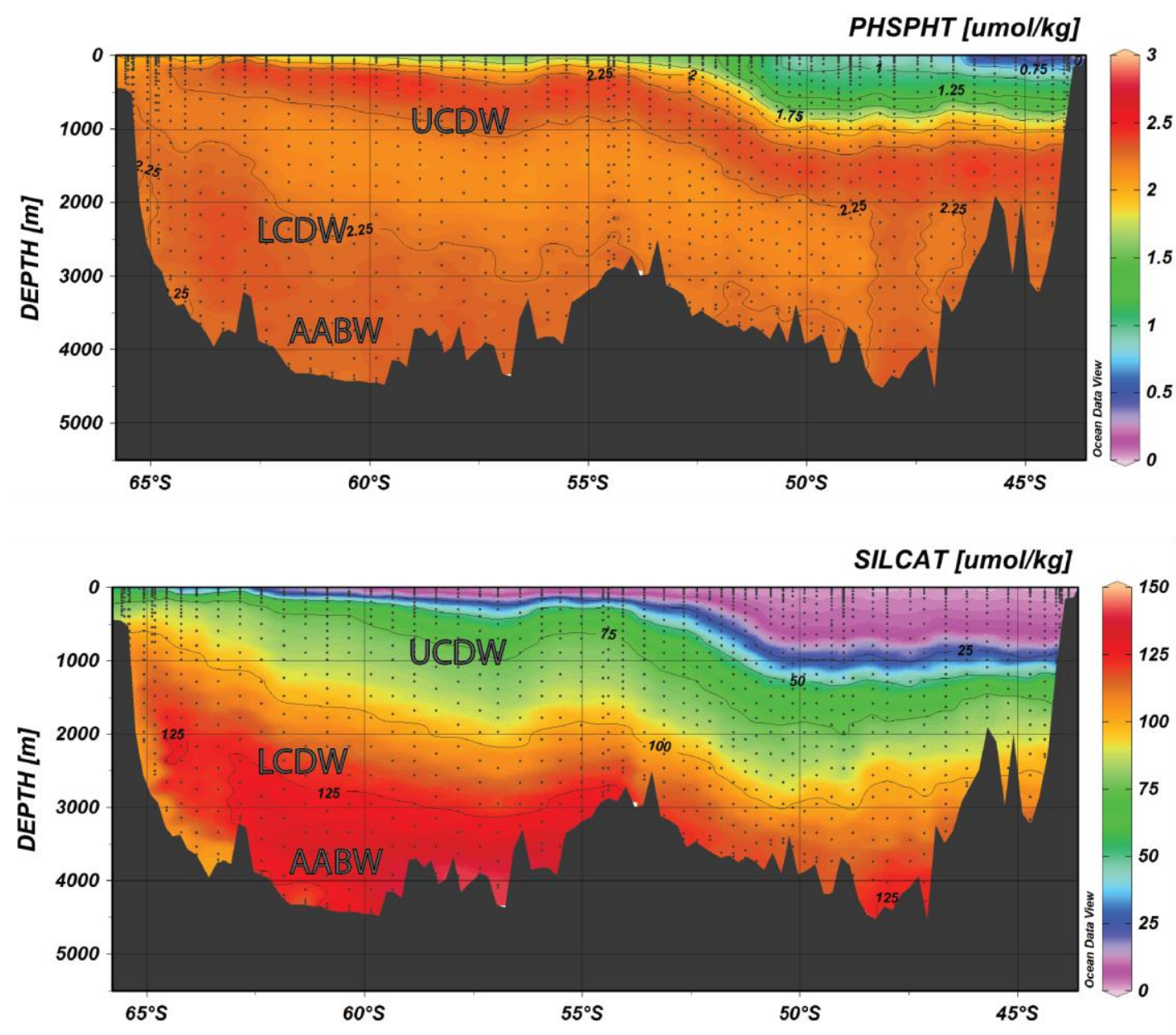

Figure 2.17: Phosphate and silicate profiles for the SR3 GEOTRACES transect in the Tasman Sea - Southern Ocean. The deep water masses: AABW, LCDW, and UCDW have been identified and labelled. Acronyms as for Figure 2.7.

Dissolved $\mathrm{Fe}$ concentration is independent of water masses in this transect and are enriched north of $\sim 56^{\circ} \mathrm{S}$ at $\geq 2000 \mathrm{~m}$ depth, with fluxes in proximity to particular bathymetric peaks (Figure 2.18). The station at $60.85^{\circ} \mathrm{S}$ appears to be particularly depleted compared to the surrounding water column (Figure 2.18). Al is depleted in the deep water masses in this transect, with the exception of an enrichment haloes located at the $60.85^{\circ} \mathrm{S}$ station at $4,325 \mathrm{~m}$ depth. In contrast $\mathrm{Ni}$ displays a profile similar to silicate in the LCDW.

$\mathrm{Cu}$ and $\mathrm{Zn}$ display profiles similar to silicate, with the exception of a flux of dissolved $\mathrm{Zn}$ at $65^{\circ} \mathrm{S}, 3,000 \mathrm{~m}$ depth (Figure 2.19). Cd displays a profile similar to phosphate. The trace element concentrations for the LCDW are displayed in Table 2.4. 


\section{Trace element properties}
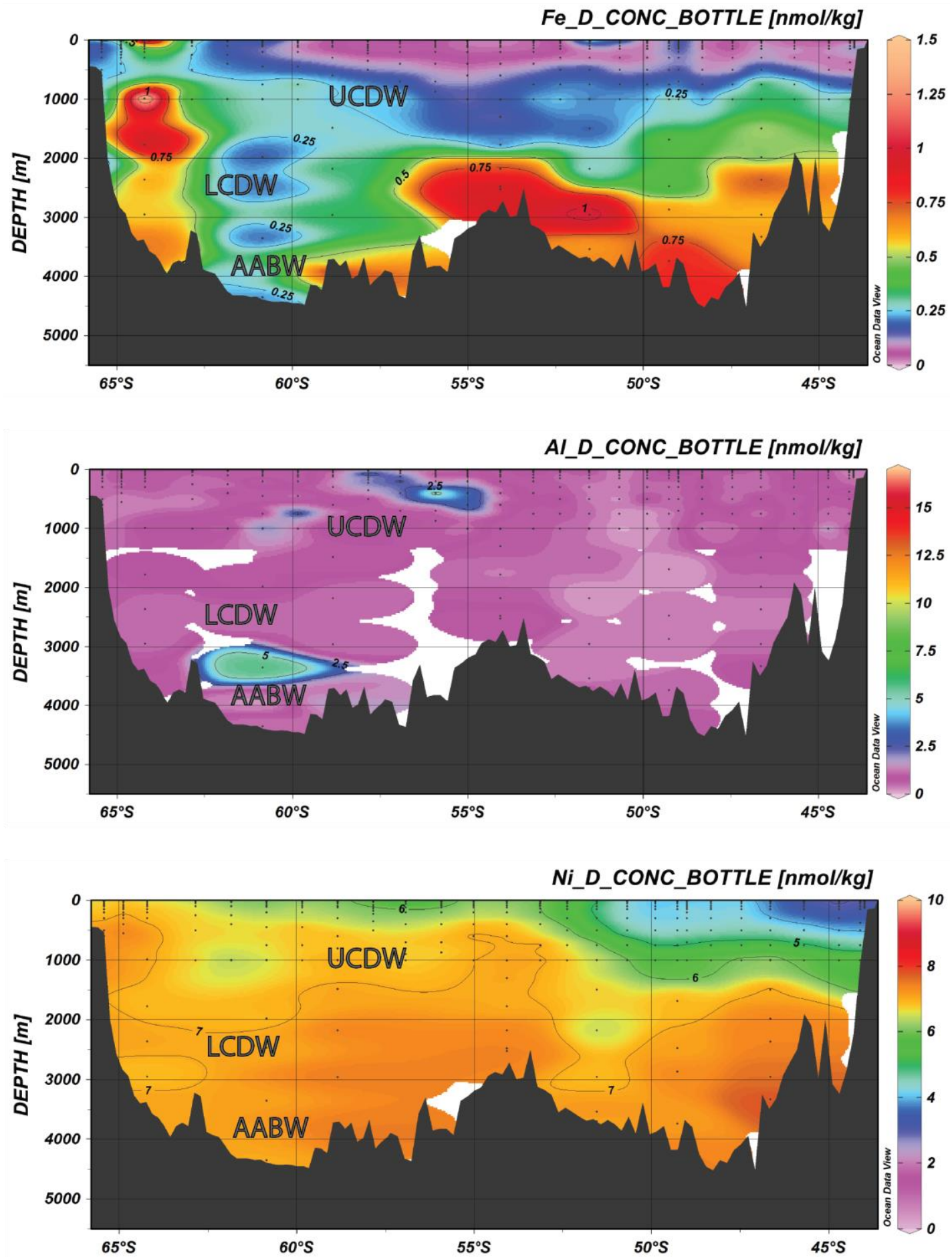

Figure 2.18: Dissolved Fe, Al, and Ni profiles for the SR3 GEOTRACES transect in the Tasman Sea - Southern Ocean. The deep water masses: AABW, LCDW, and UCDW have been identified in the hydrographic data are labelled. Acronyms as for Figure 2.7. 

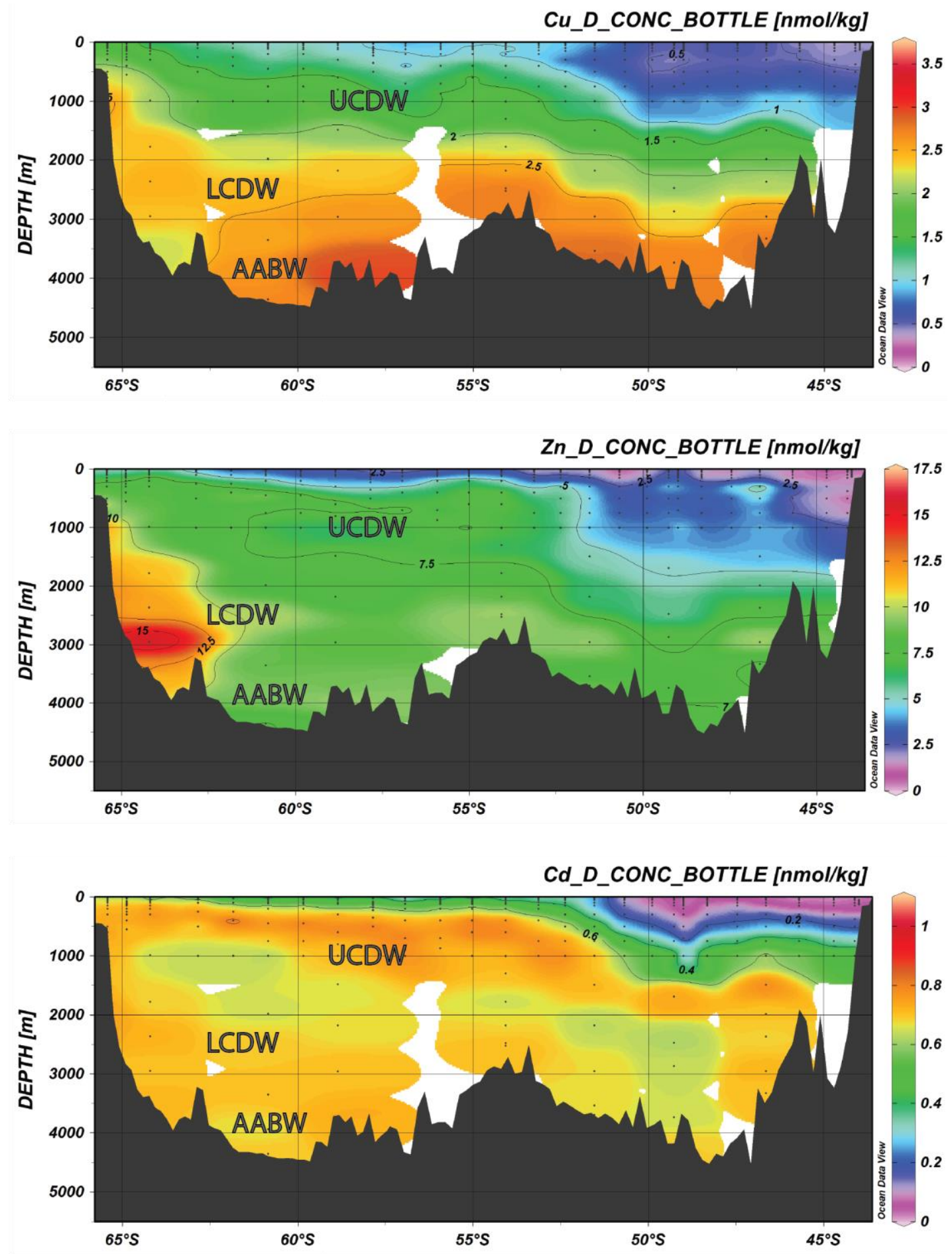

Figure 2.19: Dissolved Cu, Zn, and Cd profiles for the SR3 GEOTRACES transect in the Tasman Sea - Southern Ocean. The deep water masses: AABW, LCDW, and UCDW have been identified in the hydrographic data are labelled. Acronyms as for Figure 2.7. 


\subsubsection{GP13 $\left(3^{\circ}{ }^{\circ} \mathbf{S}\right)$ Tasman Sea - Southwest Pacific Ocean}

The LCDW are identified by the temperature $\left(1-1.6^{\circ} \mathrm{C}\right)$ and dissolved oxygen content (> 175- $\leq 200 \mu \mathrm{mol} / \mathrm{kg}$ ) of the water mass (Figure 2.20; Table 2.3). The PDW - Pacific Deep Waters, are identified based on the low oxygen concentrations (175$>150 \mu \mathrm{mol} / \mathrm{kg})$. 

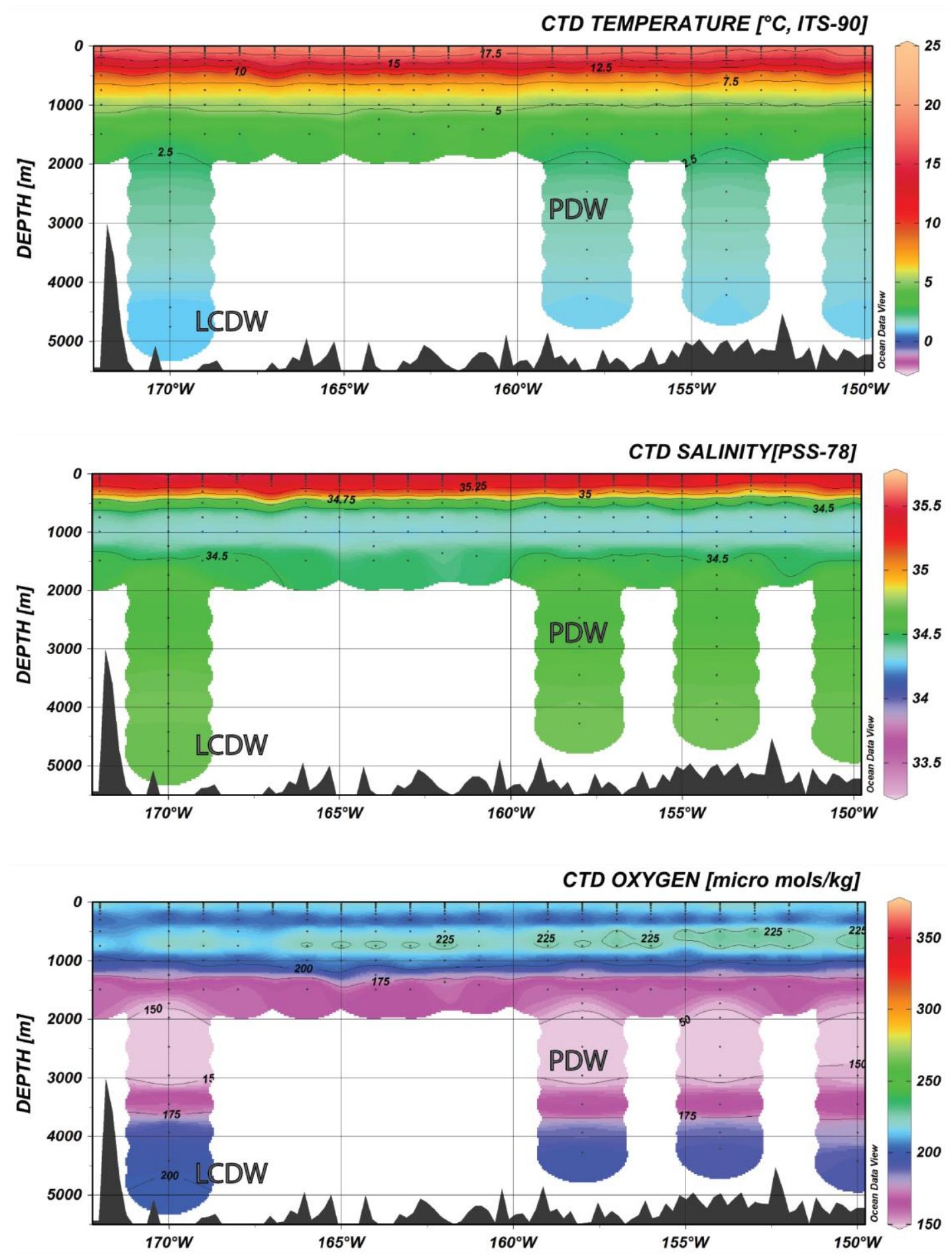

Figure 2.20: Temperature, salinity, and dissolved oxygen profiles for the GP13 GEOTRACES longitudinal transect in the Tasman Sea - Southwest Pacific Ocean. The deep water masses: LCDW - Lower Circumpolar Deep Water and PDW - Pacific Deep Water have been labelled. 

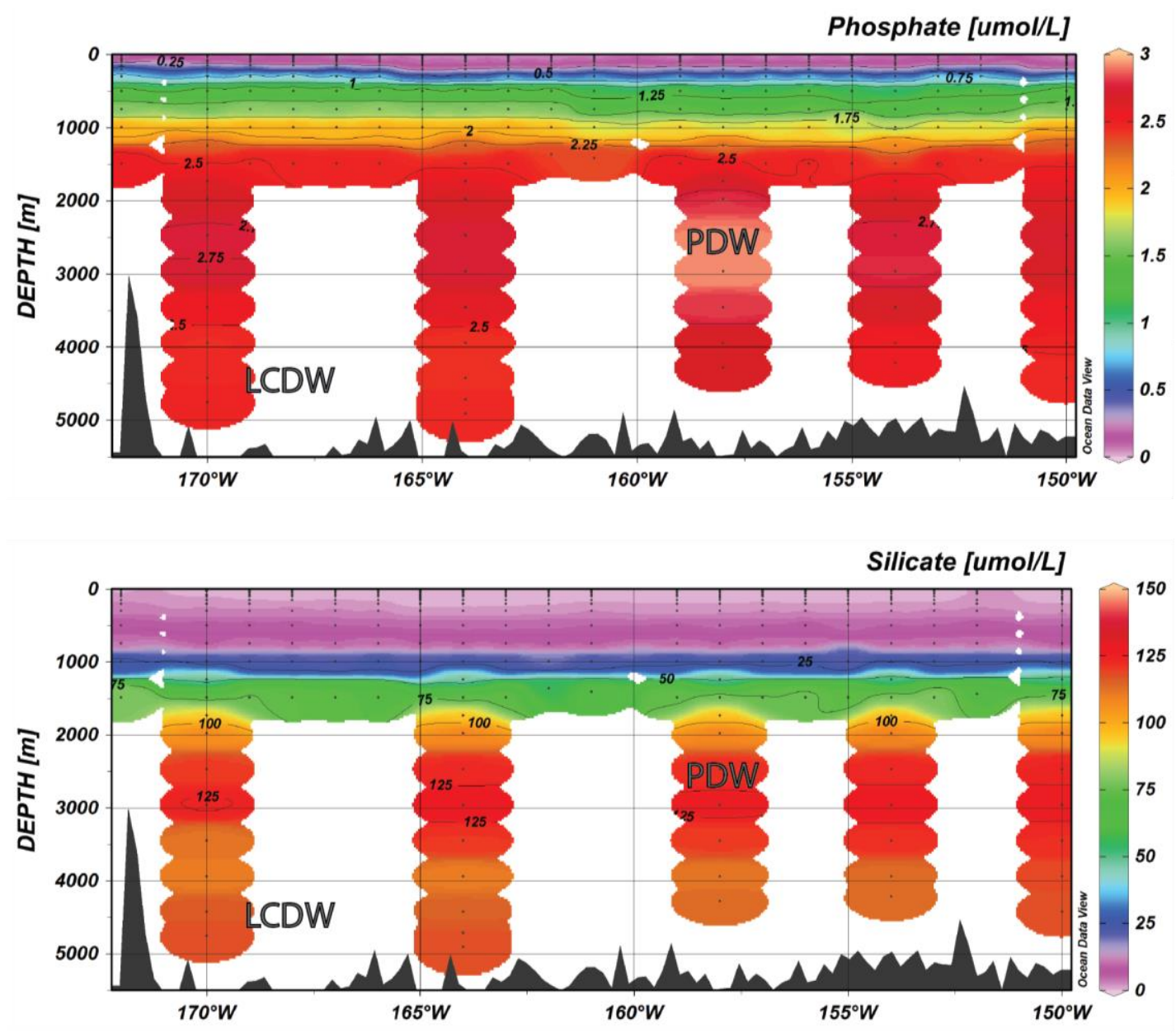

Figure 2.21: Phosphate and silicate profiles for the GP13 GEOTRACES transect in the Tasman Sea - Southwest Pacific Ocean. The deep water masses: LCDW and PDW have been labelled. Acronyms as for Figure 2.20.

The LCDW is relatively depleted in Mn, as in the GIPY4 transect (Figure 2.12), with the PDW showing slightly higher Mn concentrations (Figure 2.22). Fe exhibits a highly variable data in the PDW and LCDW in this transect and the PDW is enriched in Fe, especially at the $164^{\circ} \mathrm{W}$ station and in the LCDW there is one enriched area at $164^{\circ} \mathrm{W}$ $\sim$ 4,000 m depth. Ni behaves similarly to silicate, whereas $\mathrm{Pb}$ is depleted in the LCDW and PDW. 

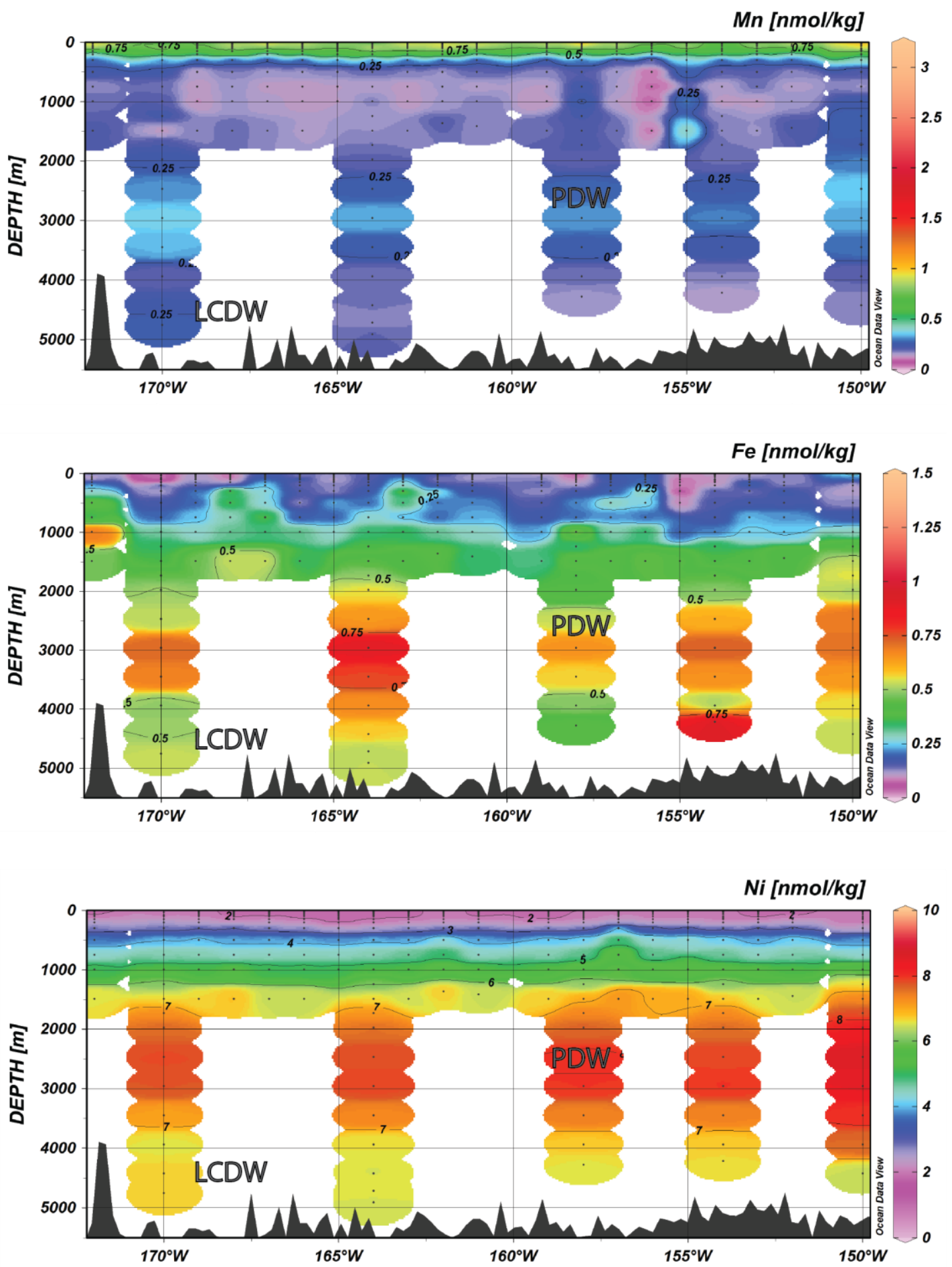

Figure 2.22: Dissolved Mn, Fe, and Ni profiles for the GP13 GEOTRACES transect in the Tasman Sea - Southwest Pacific Ocean. The deep water masses: LCDW and PDW have been identified in the hydrographic data are labelled. Acronyms as for Figure 2.20. 


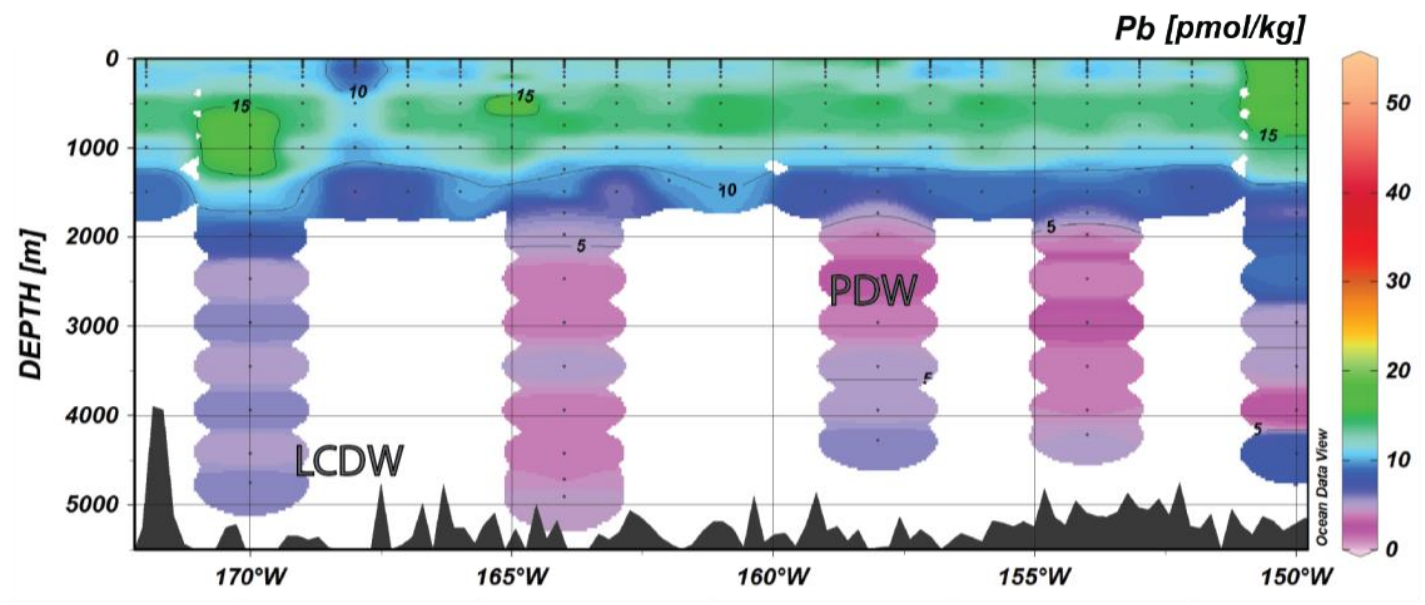

Figure 2.23: Dissolved Pb profile for the GP13 GEOTRACES transect in the Tasman Sea - Southwest Pacific Ocean. The deep water masses: LCDW and PDW have been identified in the hydrographic data are labelled. Acronyms as for Figure 2.20.

$\mathrm{Cu}$ and $\mathrm{Zn}$ display profiles comparable to the silicate profile. $\mathrm{Cd}$ has a profile similar to the phosphate profile (Figure 2.24). Table 2.4 displays the trace element concentrations for the seawater in this section. 

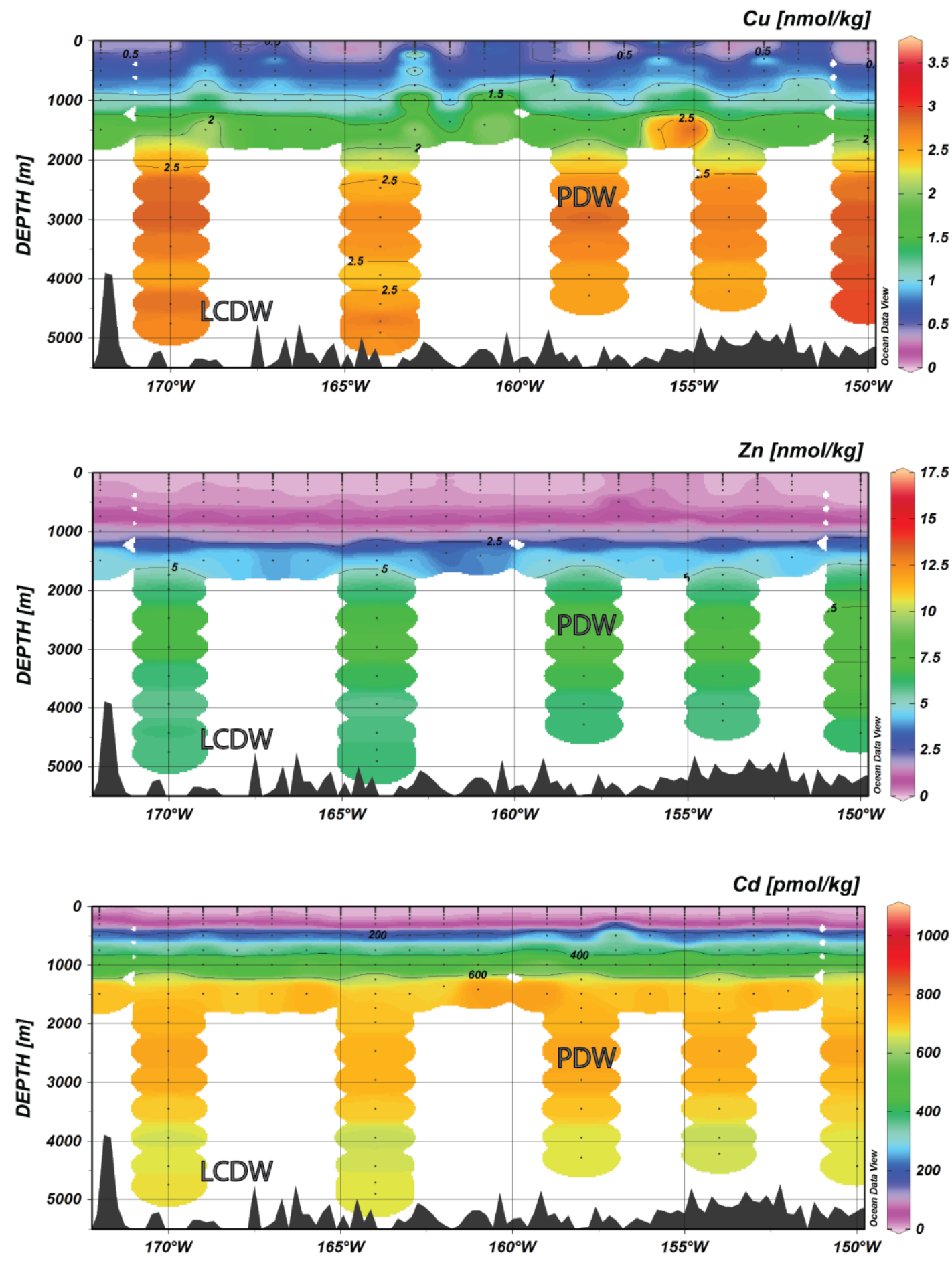

Figure 2.24: Dissolved Cu, Zn, and Cd profiles for the GP13 GEOTRACES transect in the Tasman Sea - Southwest Pacific Ocean. The deep water masses: LCDW and PDW have been identified in the hydrographic data are labelled. Acronyms as for Figure 2.20. 


\subsubsection{GEOSECS}

GEOSECS was the first attempt to analyse geochemical data in the world's ocean. Only a small number of stations were sampled in the South Pacific and analysed for dissolved Mn concentrations. One of these stations (G293) was in close vicinity to the Campbell Plateau nodules at $178^{\circ} \mathrm{E}, 52^{\circ} \mathrm{S}$ (Figure 2.9).

$\mathrm{Mn}$ is highest in the bottom depths with the greatest concentration of $2.91 \mathrm{nmol} / \mathrm{kg}$ at 5,271 $\mathrm{m}$ depth (Figure 2.25). This information is also shown in Table 2.4

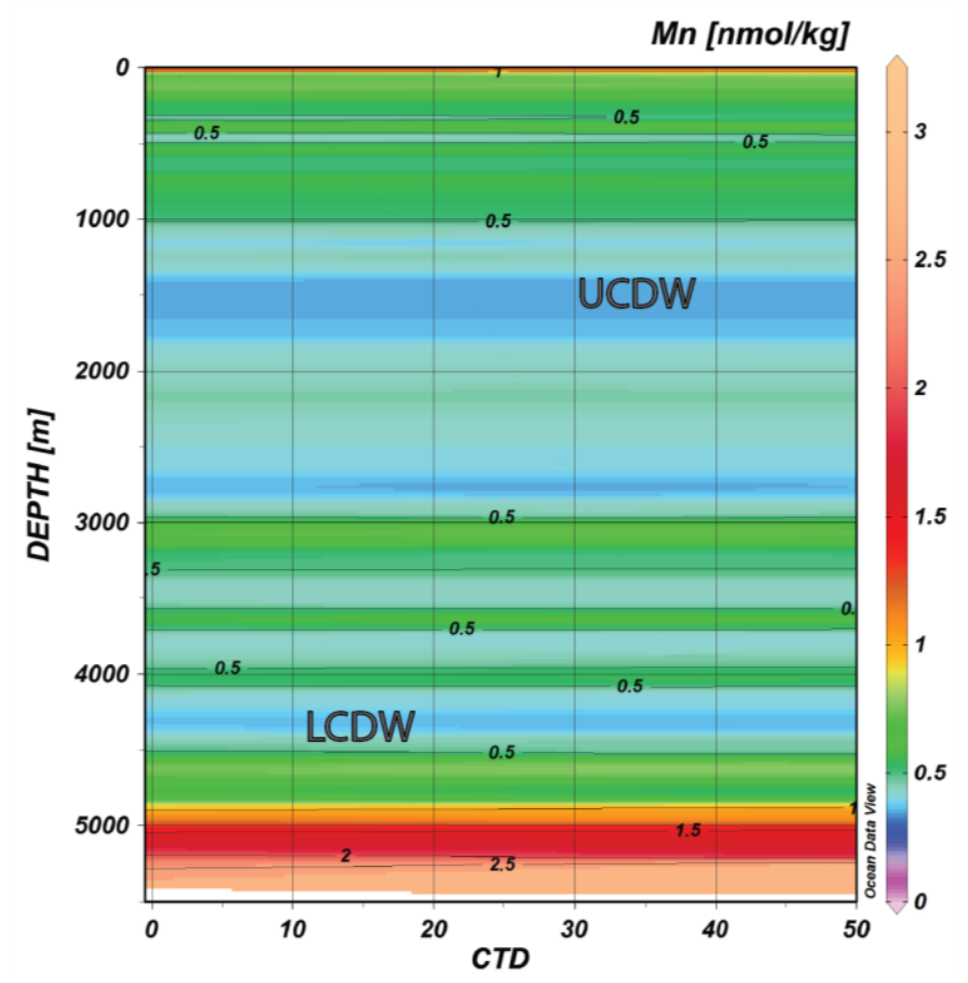

Figure 2.25: Dissolved $\mathrm{Mn}$ at $178^{\circ} \mathrm{E}, 52^{\circ} \mathrm{S}$ and $5,454 \mathrm{~m}$ bottom depth. The deep water masses: LCDW - Lower Circumpolar Deep Water and UCDW - Upper Circumpolar Deep Water, have been identified in the hydrographic data in Figure 2.5 and are labelled. 


\subsubsection{LCDW properties}

Table 2.3 LCDW hydrographic and nutrient properties from the GLODAP transects; P15 and P11, and the GEOTRACES transects; GIPY4, SR3, and GP13.

\begin{tabular}{l|l|l|l|l|l} 
LCDW properties & P15 & P11 & GIPY4 & SR3 & GP13 \\
\hline \hline Temperature $\left({ }^{\circ} \mathbf{C}\right)$ & $\geq 1-<2.5$ & $\geq 1-<2.5$ & $\sim 1-1.5$ & $1-1.75$ \\
\hline Salinity & $>34.5-<34.75$ & $>34.5-<34.75$ & $>34.5-\leq 34.75$ & $>34.5-<34.75$ & $>34.5-<34.75$ \\
\hline Oxygen $(\boldsymbol{\mu m o l} / \mathbf{k g})$ & $\geq 175-<225$ & $\geq 175-<225$ & $>200-\leq 225$ & $\geq 200-<225$ & $>175-\leq 200$ \\
\hline Phosphate $(\boldsymbol{\mu m o l} / \mathbf{k g})$ & $\geq 2-\leq 2.5$ & $\geq 2-<2.5$ & $\geq 2-\leq 2.3$ & $>2-2.3$ & $\sim 2.5$ \\
\hline Silicate $(\boldsymbol{\mu m o l} / \mathbf{k g})$ & $\geq 100-\leq 125$ & $\geq 100-\leq 125$ & $\geq 95-\leq 125$ & $\geq 100-\sim 130$ & $115-125$ \\
\hline Nitrate $(\boldsymbol{\mu m o l} / \mathbf{k g})$ & $>30-<35$ & $>30-<35$ & $\geq 30-<35$ & $\geq 30-<35^{*}$ & $>30-\leq 35^{*}$
\end{tabular}

Note: *In SR3 and GP13 nitrate is measured as $\mathrm{NO}_{2}+\mathrm{NO}_{3}$. 


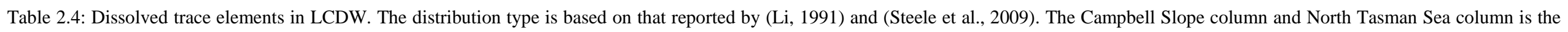
interpreted values of the LCDW overlying the Campbell nodule field and Tasman Sea nodule field.

\begin{tabular}{|c|c|c|c|c|c|c|c|}
\hline Elements & $\begin{array}{c}\text { Distribution } \\
\text { type }\end{array}$ & LCDW GIPY4 & LCDW SR3 & LCDW GP13 & GEOSECS & Campbell Slope & $\begin{array}{c}\text { North } \\
\text { Tasman Sea }\end{array}$ \\
\hline "Manganese (nmol/kg) & Scavenged & $\sim 0-\geq 0.75$ & & $\sim 0.1-0.3$ & $>0.25->3$ & $>0.25->3$ & $?$ \\
\hline Iron $(\mathrm{nmol} / \mathrm{kg})$ & Hybrid & $>0.25-\geq 1$ & $\sim 0.2-1$ & $0.4-<1$ & & $?$ & $?$ \\
\hline Cerium $(\mathrm{pmol} / \mathrm{kg})$ & Scavenged & $2-10$ & & & & $?$ & $?$ \\
\hline Lanthanum (pmol/kg) & Nutrient & $25-\leq 50$ & & & & $25-50$ & $25-50$ \\
\hline Lead $(\mathrm{pmol} / \mathrm{kg})$ & Scavenged & $\sim 10-\geq 20$ & & $3-8$ & & $?$ & $?$ \\
\hline Aluminium $(\mathrm{nmol} / \mathrm{kg})$ & Scavenged & $\sim 0-\geq 15$ & $\sim 0.2-5.7$ & & & $?$ & $?$ \\
\hline Nickel (pmol/kg) & Nutrient & & $\sim 7$ & $\sim 7$ & & $\sim 7$ & $\sim 7$ \\
\hline Titanium (pmol/kg) & Hybrid & $100->200$ & & & & $?$ & $?$ \\
\hline Copper $(\mathrm{nmol} / \mathrm{kg})$ & Hybrid & $1.5->2.5$ & $2-2.8$ & $2.5-3$ & & $?$ & $?$ \\
\hline Zinc $(\mathrm{nmol} / \mathrm{kg})$ & Nutrient & $>2.5-\geq 7.5$ & $5-\leq 12.5$ & $\sim 6$ & & $5-10$ & $5-10$ \\
\hline Cadmium (nmol/kg) & Nutrient & $0.6-\geq 0.8$ & $0.6-<0.8$ & $\sim 0.6$ & & $\sim 0.6$ & $\sim 0.6$ \\
\hline Praseodymium (pmol/kg) & Nutrient & $3.7-7.6$ & & & & $3.7-7.6$ & $3.7-7.6$ \\
\hline Neodymium $(\mathrm{pmol} / \mathrm{kg})$ & Nutrient & $\sim 16-33$ & & & & $\sim 16-33$ & $\sim 16-33$ \\
\hline Samarium (pmol/kg) & Nutrient & $2.9-6.0$ & & & & $2.9-6.0$ & $2.9-6.0$ \\
\hline Europium (pmol/kg) & Nutrient & $0.7-1.5$ & & & & $0.7-1.5$ & $0.7-1.5$ \\
\hline Gadolinium (pmol/kg) & Nutrient & $4.6-7.8$ & & & & $4.6-7.8$ & $4.6-7.8$ \\
\hline Terbium $(\mathrm{pmol} / \mathrm{kg})$ & Nutrient & $0.7-1.2$ & & & & $0.7-1.2$ & $0.7-1.2$ \\
\hline Dysprosium (pmol/kg) & Nutrient & $5.6-8.9$ & & & & $5.6-8.9$ & $5.6-8.9$ \\
\hline Holmium (pmol/kg) & Nutrient & $1.6-2.3$ & & & & $1.6-2.3$ & $1.6-2.3$ \\
\hline Erbium (pmol/kg) & Nutrient & $5.6-7.8$ & & & & $5.6-7.8$ & $5.6-7.8$ \\
\hline Thulium (pmol/kg) & Nutrient & $0.9-1.2$ & & & & $0.9-1.2$ & $0.9-1.2$ \\
\hline Ytterbium (pmol/kg) & Nutrient & $5.7-8.2$ & & & & $5.7-8.2$ & $5.7-8.2$ \\
\hline Lutetium (pmol/kg) & Nutrient & $1.0-1.4$ & & & & $1.0-1.4$ & $1.0-1.4$ \\
\hline
\end{tabular}




\subsection{Discussion}

\subsubsection{Major water masses}

Profiles of New Zealand oceans displayed water masses AABW, LCDW, UCDW on the $155^{\circ}$ E, Tasman Sea transect (Figure 2.7), and the on the $170^{\circ}$ E Southwest Pacific Ocean transect (Figure 2.5) there is an additional influence of the PDW (Talley et al., 2011a). Similar water masses in the South Atlantic Ocean, South Tasman Sea, and South Pacific Ocean transects were identified using the temperature, salinity, and oxygen profiles based on previous work (Talley et al., 2011b). The water masses identified in the South Atlantic Ocean are AABW, LCDW, UCDW, and NADW (Figure 2.10). In the Tasman Sea/Southern Ocean the water masses recognised are the AABW, LCDW, and UCDW (Figure 2.16). In the Tasman Sea/Pacific Ocean longitudinal transect the water masses identified were the LCDW and the PDW (Figure 2.20).

Table 2.3 shows the temperature of the LCDW between the latitudinal transects P15, P11, GIPY4, and SR3 is comparable $\left(\sim 1-<2.5^{\circ} \mathrm{C}\right)$ at similar latitudes and exhibits equatorward sinking and warming. The northernmost longitudinal transect GP13 exhibits a marginally warmer LCDW. Salinity and oxygen are consistent in the LCDW in each transect (Table 2.3), with oxygen displaying a decrease with increasing distance from Antarctica. The longitudinal section GP13 is lower in oxygen as it is furthest from Antarctica and has started to mix with low oxygen waters of the PDW. Phosphate, nitrate and silicate are comparable between the GIPY4, SR3, and GP13 transects (Table 2.3), with GP13 displaying a slight increase in these nutrient concentration (Table 2.3). GIPY4 has slightly lower silicate concentrations when it is underlain by the NADW. GP13 displays a higher concentration of silicate as the water mass has started mixing with high silicate PDW.

These results are consistent with the LCDW warming, becoming less oxygen rich, and increasingly nutrient rich as the water mass travels northward away from the Antarctic Margin. 


\subsubsection{Trace element distribution}

\subsubsection{Scavenged-type}

Mn: GIPY4, GP13, GEOSECS.

Dissolved Mn is high in concentration in surface waters offshore of continents, as seen in Figure 2.12, Figure 2.22, and Figure 2.25. $\mathrm{Mn}$ in surface waters is likely sourced from aeolian and riverine sources, which undergoes photo-reduction to dissolved $\mathrm{Mn}^{2+}$ (Wu et al., 2014). Figure 2.12 in the South Atlantic exhibits a large dissolved Mn flux from a hydrothermal vent at a mid ocean ridge. The Mn flux appears to migrate north in the LCDW down the ridge to an oxidative environment (Resing et al., 2015; van Hulten et al., 2017). Measurements close to the seafloor show a depletion of Mn that may be indicative of scavenging, and a potential ferromanganese pavement offshore of South Africa and Antarctica (Cronan (1975) confirms the occurrence of ferromanganese nodules in the deep waters off South Africa). Smaller fluxes near the seafloor may indicate hydrothermal sources or reworking of the seafloor in a nepheloid type environment; however, the input of Fe in similar locations points to a hydrothermal origin. The NADW has higher concentrations of Mn, this may be due to the downward movement of Mn from enriched surface waters (van Hulten et al., 2017).

The South Pacific Ocean is relatively depleted in dissolved Mn (Figure 2.22) compared with the South Atlantic Ocean (Figure 2.12), with no intermediate and deep-water inputs apparent. Dissolved Mn is higher in the PDW than the LCDW. This is possibly because the LCDW has a higher oxygen content and an increased potential to oxidise Mn(II) to insoluble $\mathrm{Mn}(\mathrm{IV})$.

The GEOSECS data (Figure 2.25) displays a Mn flux of $2.91 \mathrm{nmol} / \mathrm{kg}$ in bottom waters, this is anomalously high relative to other regions in the world's oceans and is in contrast to the expected scavenged trace-metal profile of Mn. This irregularity could be explained analytically. Klinkhammer and Bender (1980) do not mention filtering the seawater prior to analysis, but do mention acidifying the sample for an undefined period of time. Thus, during this interval the dissolvable $\mathrm{Mn}$ fraction could have gone into solution, yielding higher Mn concentrations that represent both the aqueous $\mathrm{Mn}$ in the seawater and dissolvable $\mathrm{Mn}$ from any suspended matter. The chemistry of the suspended particulates (i.e. the nepheloid layer in Figure 2.3) has not been analysed; however it is apparent that if the Mn flux is due to the lack of filtering, then Mn must be a component in the suspended matter. The suspended matter could be particles that have scavenged Mn oxide 
colloids onto their surface. Baker and Feely (1978) indicate that nepheloid layers have similar composition to the underlying seafloor. This could indicate the possibility is the Mn nodule pavement may effectively be eroded by high velocity sediment laden currents. This idea would imply Fe-Mn (oxyhydr)oxide minerals eroded from ferromanganese nodules are a fraction of the suspended material in the nepheloid layer. Micronodules in the substrate (discussed in Chapter 3) could be from such erosion. This could mean that the outer rims of ferromanganese nodules in this study do not accurately reflect the modern ocean chemistry.

It is also possible that the Mn flux observed off the Campbell Plateau may not be caused solely by suspended particles, and may actually represent a flux of aqueous $\mathrm{Mn}$ in the seawater. The high Mn concentrations could be due to agitation from fast currents regularly disturbing the seawater-sediment interface. Sediments undergo diagenesis (discussed further in Chapter 3) where the solid Mn(IV) species is reduced to the aqueous $\mathrm{Mn}$ (II) species, and thus $\mathrm{Mn}^{2+}$ is higher in concentration in pore-water relative to seawater. (Koschinsky et al., 2001) report that upon repeated disturbances of a sedimentseawater interface (filtered) dissolved Mn increases. Such repeated disturbances occur in the region as eddies have been reported to occur approximately nine times a year along the Subantarctic Slope (Stanton and Morris, 2004). However, the experiment of Koschinsky et al. (2001) also suggests that the dissolved Mn flux rapidly adsorbs onto a particulate surface. In the deep sea environment adsorption could be onto a suspended particulate, or a Fe-Mn (oxyhydr)oxide surface.

There appears to be no distinct relationship between the LCDW and dissolved Mn concentrations (Table 2.4). Dissolved Mn is heterogeneously distributed in the LCDW and variability in concentration is dependent on the proximity of the hydrothermal or terrigenous source. Sources of dissolved Mn in New Zealand deep waters could be from small hydrothermal inputs due to localised volcanism south of New Zealand along the Macquarie Ridge, with dissolved Mn concentrations decreasing as the seawater travels further from the source (van Hulten et al., 2017); however, it is not apparent that these hydrothermal systems are still active as this is no longer an active spreading centre. The GEOTRACES profiles also indicate a strong scavenging effect close to the seafloor which is especially apparent close to ferromanganese nodule fields. The GP13 profile also indicates a Mn depleted water mass north of New Zealand. 
Thus it is most likely that the high Mn content over the Campbell Slope nodules is probably a recycling effect from the presence of the nepheloid layer in this region. This does not occur in the in the water mass overlying the Tasman Sea nodules due to the more quiescent water currents.

\section{Ce: GIPY4.}

Figure 2.13 shows dissolved Ce is highest in surface waters off the African continent, consistent with a riverine input of Ce (Figure 2.13). Ce has a negative correlation when compared to the Mn profile seen in Figure 2.12 in the deep water environment. Ce is typically depleted in the marine environment due to its affinity to Fe-Mn oxyhydr(oxide) minerals. The relatively high Ce concentration in the LCDW above the seafloor off South Africa seems anomalous for a scavenged-type element, which are typically depleted in bottom waters. This area does correlate with a seemingly lower region of dissolved Mn, or there may be a localised source in the area.

Dissolved Ce in the LCDW appears to be correlated to dissolved Mn rather than the water mass. Additional GEOTRACES stations would be required to better interpret trends in dissolved Ce. Dissolved Ce in the LCDW overlying the Campbell Slope and Tasman Sea ferromanganese fields is likely low due to the scavenging by ferromanganese nodules.

Pb: GIPY4, GP13.

Figure 2.14 demonstrates higher concentrations of dissolved $\mathrm{Pb}$ concentrations are higher in surface waters, particularly those offshore of South Africa (Figure 2.14), possibly indicating an anthropogenic source (Buat-Menard and Chesselet, 1979). Seawater around the Mid-Atlantic Ridge is relatively depleted in $\mathrm{Pb}$. This depletion, and the chalcophilic tendency of $\mathrm{Pb}$ (McLennan, 1989) point towards sorption onto particulate matter, such as Fe sulphides and/or Fe oxyhyrdoxides, associated with hydrothermal activity. The South Pacific Ocean profile (Figure 2.23) shows a greater depletion in the LCDW than the South Atlantic Ocean profile (Figure 2.14)

Dissolved $\mathrm{Pb}$ displays a scavenging profile, and the concentration in seawater is influenced by the proximity to a source and suspended particles in the water column. Estimations of the dissolved $\mathrm{Pb}$ concentration in the LCDW around New Zealand are difficult to make, judging by the large variation in concentrations in the LCDW in the GIPY4 and GP13 transects (Table 2.4), but are likely to be low, due to minimal anthropogenic input. The presence of a nepheloid layer in the LCDW overlying the 
Campbell ferromanganese nodule field could indicate lower concentrations of dissolved $\mathrm{Pb}$ in the LCDW in the Southwest Pacific Ocean compared with the Tasman Sea, due to scavenging by suspended particulates.

\section{Al: GIPY4, SR3.}

At latitudes north of $45^{\circ} \mathrm{S}$ in the South Atlantic Ocean (Figure 2.14) and the South Tasman Sea (Figure 2.18) Al is relatively depleted, with the exception of localised enrichments in deep waters near the seafloor, and intermediate waters at 500-1,000 m. Dissolved Al in the ocean is low due to the $\mathrm{Al}(\mathrm{III})$ undergoing hydrolysis to species $\left(\mathrm{Al}(\mathrm{OH}){ }_{3}{ }^{0}\right.$ and $\mathrm{Al}(\mathrm{OH})_{4}^{-}$) that is highly reactive to suspended matter (Orians and Bruland, 1985). $\mathrm{Al}$ is deposited by aeolian processes, and is indicative of a continental source. Deposition of off-continental dust could be the source of the enriched areas at intermediate depths. However, higher surface water concentrations would have been expected. The enriched areas near the seafloor could be caused by the dissolution of suspended particles of sediment.

There are no stations north of $42.3^{\circ} \mathrm{S}$ in the South Atlantic Ocean profile for dissolved Al (Figure 2.14). However, to the south at $40-50^{\circ} \mathrm{S}$, surface waters above $500 \mathrm{~m}$ are relatively depleted in $\mathrm{Al}$. This may be due to riverine $\mathrm{Al}$ tending to be trapped in estuarine environments due to its reactive nature (Orians and Bruland, 1986). Al is usually at a minimum at mid-depths (Orians and Bruland, 1986), this is contrary to the profile seen in the South Atlantic Ocean. The fluxes at depths $>500 \mathrm{~m}$ at the $43.4^{\circ} \mathrm{S}$ station were measured two weeks before the eddy apparent in Figure 2.14 at $42.3^{\circ} \mathrm{S}$ was measured (Speich, 2008). The eddy may have disturbed the seafloor causing sediment particles to become suspended and dissolve in the seawater.

Dissolved Al concentrations vary greatly in the same water mass (Table 2.4). This makes it impossible to estimate the dissolved $\mathrm{Al}$ content in the LCDW in the Southwest Pacific Ocean. It is possible that the presence of the nepheloid layer produces elevated concentrations of dissolved Al in the LCDW southeast of New Zealand that would not occur in the Tasman Sea. 


\subsubsection{Nutrient-type}

La (and REE excluding Ce): GIPY4.

Dissolved La concentrations are relatively consistent within the water masses (Figure 2.13). This profile is in agreement with the other REE measured ( $\mathrm{Pr}, \mathrm{Nd}, \mathrm{Sm}, \mathrm{Eu}$, Gd, Tb, Dy, Ho, Er, Tm, Yb, and Lu; Figures A3-A6). La has higher concentrations in deep waters such as the AABW, and the LCDW where it is at its maximum south of South Africa. REEs enter the ocean predominantly through the riverine pathway (Elderfield et al., 1988) and form carbonate complexes ( $\mathrm{Li}, 1991)$. It is expected $\mathrm{La}$ and other REE (excluding Ce) to have similar concentrations in the LCDW around New Zealand. However, these elements were only measured on the GIPY4 cruise, so it is difficult to make accurate comparisons as there may be regional differences due to localised riverine input.

Zn: GIPY4, SR3, GP13.

The nutrient-type trace element $\mathrm{Zn}$ is extracted from seawater during soft-tissue formation in diatoms (Vance et al., 2017). Dissolved Zn concentrations in the South Atlantic Ocean (Figure 2.15) and the South Pacific Ocean (Figure 2.24) show consistent profiles with respect to the water masses (Table 2.4), similar to those for silicate, perhaps reflecting a detrital influence. The South Tasman Sea profile (Figure 2.19) shows a generally less uniform depletion in surface waters north of $50^{\circ} \mathrm{S}$, and localised enrichments in the deep waters offshore of South Africa and Antarctica, the latter possibly originating from hydrothermal activity (cf. the Fe concentration profile). Concentration highs in the South Atlantic Ocean (Figure 2.15) may reflect a riverine source. Such variations in concentration due to localised fluxes do not migrate far, and there is a uniformity in $\mathrm{Zn}$ concentration in deep waters. This provides some confidence that dissolved $\mathrm{Zn}$ concentrations in the LCDW overlying the nodule fields around New Zealand are comparable.

Dissolved $\mathrm{Zn}$ tends to correlate well with water masses (Table 2.4), but is potentially influenced by localised sources, however the flux does not migrate far and $\mathrm{Zn}$ is relatively uniform in deep waters. This implies that comparable dissolved concentrations in the LCDW overlying the nodule fields around New Zealand to the GEOTRACES transects (GIPY4, SR3, and GP13). 
Cd concentration profiles (Figure 2.15, Figure 2.19, and Figure 2.24) all display consistent variations within individual water masses, similar to the phosphate profiles (Figure 2.11, Figure 2.17, and Figure 2.21). These profiles relate to soft-tissue regeneration in shallow waters (Morel et al., 2003). Thus, Cd concentrations in the LCDW tend to be uniformly distributed around global ocean basins (Table 2.4), including those in the Southwest Pacific Ocean containing ferromanganese nodule fields.

Ni: SR3, GP13.

Figure 2.18 and Figure 2.22 show a dissolved Ni profile comparable to silicate in deep waters. Dissolved Ni is used in both skeletal and soft-tissue formation in phytoplankton, thus it may display both shallow water and a deep water regeneration profiles (Sclater et al., 1976). Dissolved Ni is consistent in concentration in the LCDW in the transects from SR3 and GP13 (Table 2.4), so the LCDW around New Zealand likely has similar concentrations to those seen in these transects.

\subsubsection{Hybrid-type}

Fe: GIPY4, SR3, GP13.

Dissolved Fe concentrations in surface waters of the South Tasman Sea-Southern Ocean (Figure 2.18) and the South Pacific Ocean (Figure 2.22) are relatively low. The South Atlantic Ocean (Figure 2.12) is, by comparison, less depleted, especially offshore of South Africa. Higher concentrations at the Mid-Atlantic Ridge are likely to relate to hydrothermal venting; there, the flux decreases away from the ridge, which may indicate settling out of Fe sulphide and/or Fe oxyhydroxide particles. The Fe that does not settle out could be due to Fe complexation. The depletion of dissolved Fe close to the seafloor at $40-50^{\circ} \mathrm{S}$ is consistent with dissolved $\mathrm{Mn}$, and is likely due to a ferromanganese nodule field in the region (Cronan, 1975). The highest concentration of Fe occurs in the LCDW at $36.5^{\circ} \mathrm{S}$. This NADW is also relatively enriched in Fe. These enrichment could be due to riverine input and/or down welling of aeolian material of the African continent.

Figure 2.18 in the South Tasman Sea exhibits a dissolved Fe profile that displays some consistency with silicate, particularly in surface and intermediate waters. In the AABW a flux is apparent at $\sim 64^{\circ} \mathrm{S}$. A similar feature is also seen in the $\mathrm{Zn}$ profile at similar latitudes, but different depths. Both elements are associated with hydrothermal activity. The Southeast Indian ridge also exhibits an enriched halo of dissolved Fe. This is likely 
due to seawater-interactions with basalt i.e. basaltic weathering or hydrothermal activity. Figure 2.22 in the Pacific Ocean displays irregular enrichments in the PDW and LCDW that do not correspond across the stations at different latitudes at the same depth. It is unclear what could cause this as they are not seen in other GP13 profiles. Fe in the LCDW varies greatly (Table 2.4) depending on its proximity to a source.

The distance Fe travels depends on the speciation and if it is scavenged. Dissolved Fe in New Zealand waters is indeterminate due to these factors and is discussed in Section 2.4.3.

Cu: GIPY4, SR3, GP13.

Dissolved $\mathrm{Cu}$ is essential for the growth of phytoplankton (Morel et al., 2003). There appears to be little scavenging occurring in the deep water environment, however this could be caused by a lack of samples near the bottom depths. Both Figure 2.15 and Figure 2.19 show local highs in the LCDW adjacent to mid-ocean ridges, but not at what appears to be the main vent. These areas display some consistency with moderate influxes in dissolved Fe. This could indicate a hydrothermal input of $\mathrm{Cu}$, or currents disturbing sediments causing the release of dissolved $\mathrm{Cu}$ from pore-water (Koschinsky et al., 2001). The enriched area in the AABW at $65-68^{\circ} \mathrm{S}$ in Figure 2.15 is also adjacent to a regional bathymetric high, however only Ti displays a high concentration in this area, so the source is unlikely to be associated with submarine volcanic activity.

Dissolved $\mathrm{Cu}$ concentrations display some consistency in the LCDW in each transect (Table 2.4). Any irregularities could be caused by local sources such as hydrothermal processes and sediment disturbance. This may imply that dissolved $\mathrm{Cu}$ is higher in concentration in the LCDW in the Southwest Pacific Ocean compared to the Tasman Sea.

\section{Ti: GIPY4.}

Dissolved Ti displays a profile in Figure 2.14 that has some similarity with silicate in waters south of $44.7^{\circ} \mathrm{S}$. North of this station intermediate and deep waters are enriched in $\mathrm{Ti}$, similar to the $\mathrm{Fe}$ and $\mathrm{Al}$ profiles. This indicates a detrital source from the African continent (Orians et al., 1990). This source may be riverine or aeolian in origin. Ti displays a hybrid-type profile, and forms hydroxide complexes in seawater ( $\mathrm{Li}, 1991)$.

There is only one Ti profile, so inferences of its chemistry in the LCDW are limited. It is possible that $\mathrm{Ti}$ concentrations are low in the LCDW until the water travels north of 
$44.7^{\circ} \mathrm{S}$ where there is an input of continental derived matter from Australia or New Zealand.

\subsubsection{South West Pacific Ocean trace elements}

The behaviour of elements in seawater can be described as scavenged-type, nutrient-type, hybrid-type, and conservative-type distributions. The concentration of scavenged-type elements is highly dependent on local sources, whereas nutrient-type profiles tend to be uniform in the deep-ocean, and hybrid-type profiles have elements of each type. Table 2.4 lists the predicted concentrations of nutrients in the LCDW overlying the Campbell Slope and Tasman Sea based on the nutrient concentrations in LCDW in other regions. To estimate concentrations of scavenged-type elements in the LCDW around New Zealand it is necessary to identify potential inputs of trace elements from local sources.

There is little riverine material transported to the LCDW southeast and northwest of New Zealand during interglacial periods. During glacial periods more sediment is transported off the New Zealand continent (Carter et al., 2000). The Campbell Plateau and Macquarie Ridge have previously undergone periods of volcanism and there may be recent volcanism to the east of Macquarie Ridge area at $\sim 60^{\circ} \mathrm{S}$ (Conway et al., 2012). Erosion of volcanic rocks when fast currents go through gaps in the Macquarie Ridge (Schuur et al., 1998) could be a source of trace elements. Any influence due to this would not be observed in the ferromanganese nodules located in the Tasman Sea or Z2140 which is located west of the Macquarie Ridge, and any effect would decrease as the water mass journeyed further north. This means comparing samples from the Tasman nodule field and Z2140 to samples from the Campbell nodule field could give indications to any volcanic influence from the Macquarie Ridge.

The Australian continent is the major modern dust source in the Southern Hemisphere (Lamy et al., 2014). This implies that the LCDW overlying the Tasman Sea nodules which is closer to an Australian dust source, should have a greater contribution from aeolian processes compared to the LCDW in the southwest Pacific Ocean.

Rintoul and Bullister (1999) and Figure 2.1 show that the LCDW which is relatively enriched in dissolved Fe in the SR3 transect could travel northward to the nodule fields, but depending on the speciation of $\mathrm{Fe}$ in the seawater it may be scavenged before it reaches the nodules in the northern Tasman Sea. Assuming a hydrothermal origin for the 
dissolved Fe, this indicates potentially elevated dissolved Mn concentrations in this water mass (Figure 2.12).

Reworked sediments are the main probable source (and sink) of elements in the LCDW located southeast of New Zealand, due to the nepheloid layer there (Carter and McCave, 1997). This is likely a major input of $\mathrm{Mn}, \mathrm{Al}, \mathrm{Cu}, \mathrm{Ti}$ and potentially $\mathrm{Fe}$ into the water mass overlying the Campbell nodule field. Dissolved $\mathrm{Pb}$ is likely scavenged by the suspended particles. The intermittent re-working of sediments in the deep sea environment could cause fluxes of Mn (Koschinsky et al., 2001), which may facilitate the authigenic precipitation of ferromanganese nodules in the area. This mechanism will be discussed further in the following chapters.

\subsection{Conclusion}

The physical and chemical oceanography of the deep waters of the SW Pacific have been discussed. The nodules in the Tasman Sea and the Campbell slope are bathed in LCDW with cold temperature and high oxygen waters. From the distribution of trace elements along transects upstream in the Southern Ocean (GIPY4 and SR3) and downstream in the subtropical South Pacific Ocean (GP13) it is possible to estimate what trace element concentrations may be found in the LCDW overlying the Campbell Slope and Tasman Sea nodules (Table 2.4). We would expect elements with a nutrienttype distribution to be uniform throughout the LCDW, and elements with a scavenged or hybrid-type distribution to be variable depending on the proximity to local inputs. In the following chapters the chemistry of the LCDW will be compared with the chemistry of the sediments surrounding the nodules and the chemistry of the outer rim of the nodules. 


\section{Chapter 3 Deep-sea sedimentology}

\subsection{Introduction}

This chapter discusses deep-sea sedimentology from the Campbell and Tasman nodule fields (Figure 3.1). These sediments are located in deep water environments (Chapter 2), so the processes specifically relating to deep-sea physical and chemical sedimentology will be discussed, with particular focus on the terrigenous and biogenic components of the sediment. Ferromanganese nodules are authigenic and this component will be discussed in the next chapter. The formation, and trace metal incorporation of ferromanganese nodules is influenced by the surrounding sedimentary environment (Manceau et al., 2014; Wegorzewski and Kuhn, 2014).

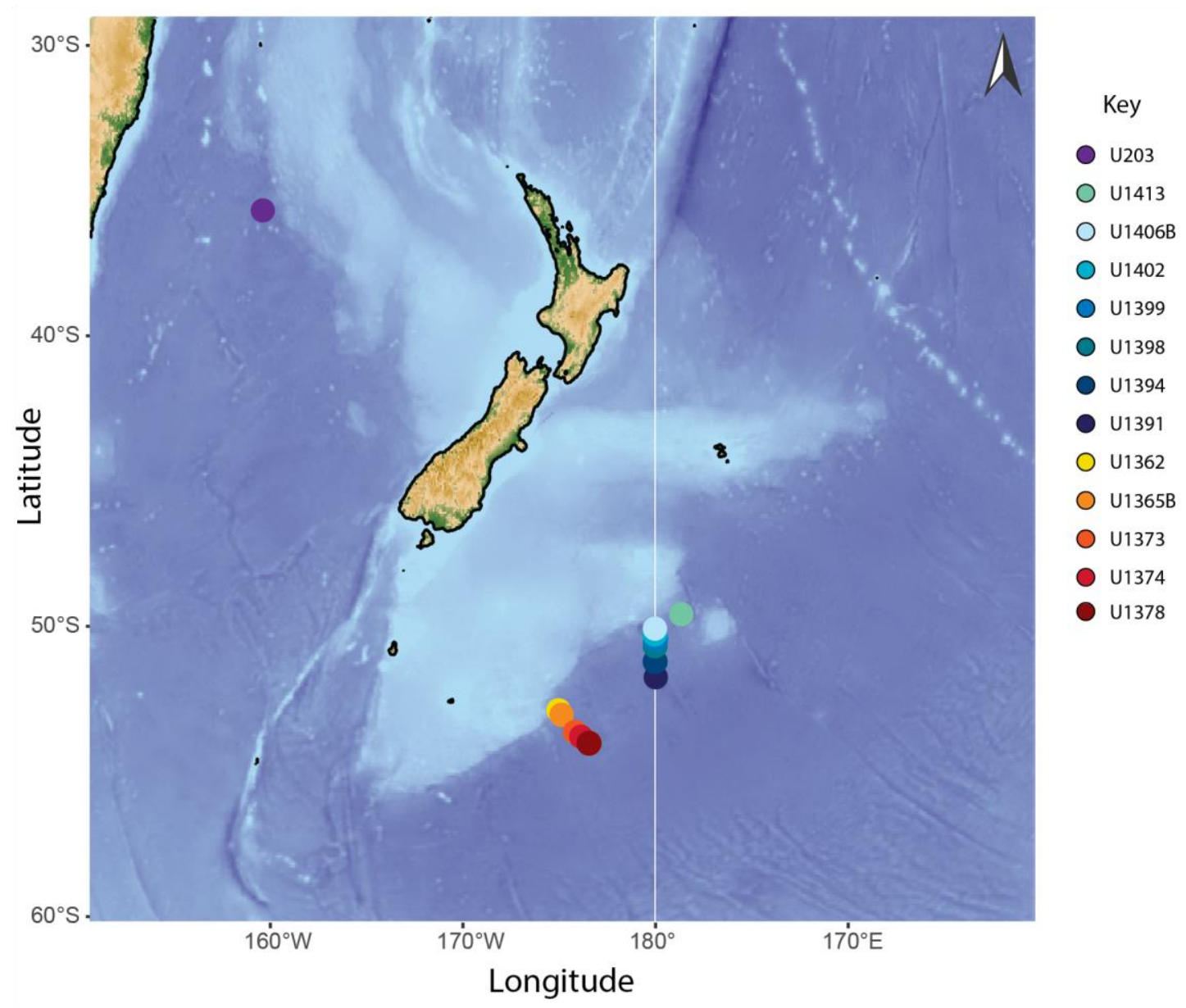

Figure 3.1: Map of the sediments sample locations and ferromanganese nodule locations analysed in this study. 


\subsubsection{Physical sedimentology}

Deep-sea sediments are composed of mixtures of detrital, biogenic, and authigenic material, with each component having distinctive chemical compositions (Sageman and Lyons, 2003). The composition of marine sediments is dependent on the proximity to continental or volcanic inputs, biological productivity, depth, and regional oceanographic currents.

Detrital matter is mainly composed of terrigenous, volcanic, and cosmogenic material. Terrigenous matter is sourced from continental weathering and erosion (inputs have been discussed in Chapter 2). Volcanic particles cause a short-term pulse in material and tend to be introduced at active boundaries, such as mid-ocean ridges and subduction zones, or at sites of intra-plate volcanism.

Biogenic sediments are formed by the accumulation of the skeletal remains of organisms (typically calcium carbonate or silicate) that settle to the seafloor.

Authigenic sediments form in situ on the seafloor by processes such as adsorption from seawater (Scott, 2008). Ferromanganese nodules are an example of an authigenic sedimentary deposit, and as the main focus of this study are discussed in detail in Chapter 4. Examples of other authigenic deposits are clays, phosphate nodules, glauconite and pyrite (Fütterer, 2000). Each of these authigenic deposits require specific environmental conditions to form, for example phosphate nodules form in suboxic conditions (Jarvis et al., 1994) and pyrite formation requires a reducing environment (Froelich et al., 1979; Froelich, 1988).

The continual accumulation of sediments in the marine environment is dependent on the supply of material and the energy of the environment. The major currents in the region such as the ACC and DWBC were described in Chapter 2. Potential sources of sediment at the Campbell nodule field include: sediment transported along the flow path of these currents including; terrigenous mud and foraminiferal ooze from the Solander Channel, volcanic sediment from the Macquarie Ridge, and erosion of sediments along the Subantarctic Slope of the Campbell Plateau (Carter and McCave, 1997).

Grains at the surface of the seawater-sediment interface tend to be unconsolidated, but with continual accumulation and subsequent burial, grains become increasingly packed, causing a reduction in pore space (Breitzke, 2006; Boudreau, 2013) (Figure 3.2). Claysized particles have negative surface charges that are repulsed in unconsolidated 
sediments, but these particles become more aligned when compacted (Bennett et al., 1991). Larger clasts (e.g. sand) undergo less compaction and thus tend to have greater porosity even once they are buried (Berner, 1980). Poorly sorted sediments may have reduced porosity due to the potential for small clasts to accumulate in the interstitial pores. The pore space between these grains contains seawater that can migrate through the sediment column depending on the permeability of a sediment. Coarse-grained material tends to have a higher permeability, and thus may have more opportunity for pore fluid migration (Huettel and Webster, 2001). Post-depositional processes such as erosion and bioturbation can also effect the permeability and porosity of the sediment.

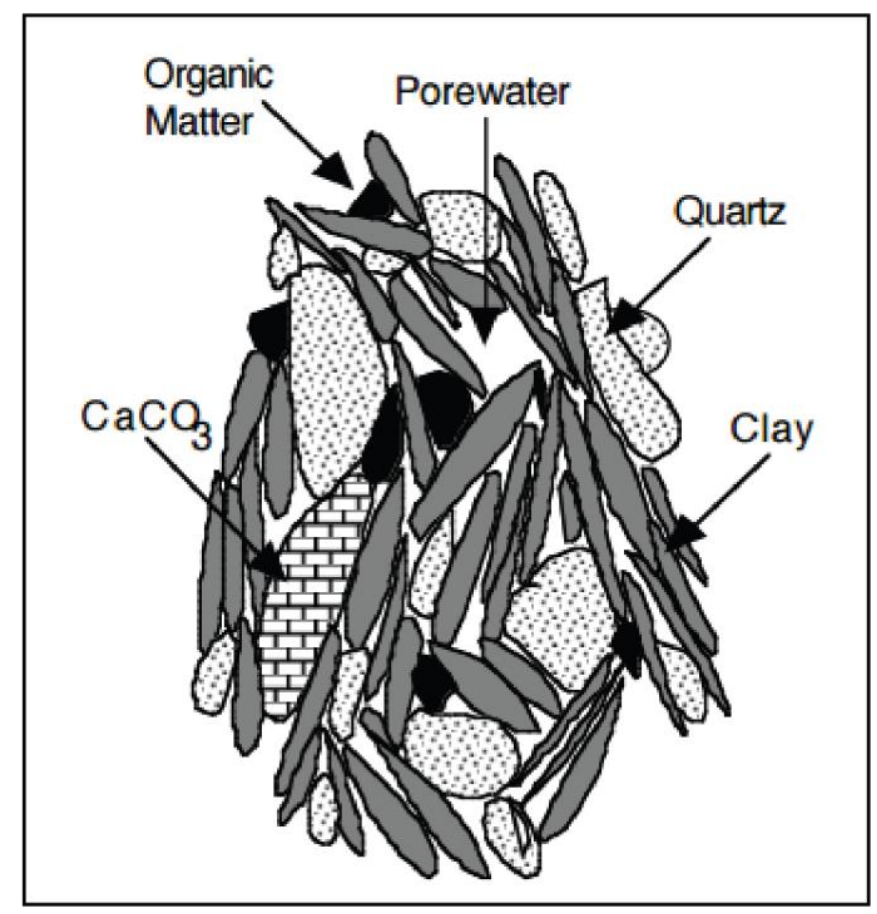

Figure 3.2: Example of sedimentary clasts in a surficial sediment. This figure displays an example of grain size, shape, and sorting on the porosity of a sediment. From Boudreau (2013).

\subsubsection{Chemical sedimentology}

\subsubsection{Sediment chemistry}

The chemical composition of a sediment is based on its source components and any secondary processes that occur such as weathering and diagenesis. Sediment composition has an effect on pore-water composition in the sediments (Breitzke, 2006), which in turn can influence the composition of ferromanganese nodules.

Terrigenous sediments have a chemical composition similar to that of the upper continental crust, as previously discussed (Table 2.2, pg. 14). 
The predominant mineralogy of biogenic sediments is calcium carbonate and opaline silica, derived from organisms such as foraminifera and diatoms, respectively. The amount of carbonate present in deep marine sediment is related to both supply and calcite solubility. In the southwest Pacific Ocean around New Zealand, the lysocline (the depth in the ocean at which calcite dissolution rapidly increases) ranges from 3,100-3,500 mbsl, and the carbonate compensation depth southeast of New Zealand (or CCD: the depth at which there is very little carbonate is left in the sediments due to dissolution) is 4,600 mbsl (Bostock et al., 2011).

Authigenic sediments have a varied composition e.g. clays are associated with aluminosilicate mineralogy, phosphorites are associated with carbonate fluoroapatite (CFA), and sulphide deposits are associated with chalcophilic elements. Ferromanganese nodule chemistry will be discussed in the following chapter.

\subsubsection{Early Diagenesis}

Early diagenesis is the process whereby minerals in the upper sedimentary column undergo dissolution and transformation under low temperature conditions (Berner, 1980). Bacteria within the sedimentary column metabolise and decompose organic matter using oxidants as electron acceptors (Figure 3.3). Oxidants are preferentially consumed based on the resultant energy produced per mole of organic carbon oxidised, and reactions with higher free energy values are preferred (Froelich et al., 1979; Stumm and Morgan, 1996). Oxygen is preferentially consumed to degrade organic matter; however, below the first few centimetres of the sediment-seawater interface oxygen is increasingly depleted. With increasing depth the sedimentary column progresses from oxic to suboxic to anoxic (Froelich et al., 1979; Goloway and Bender, 1982). In a suboxic environment organic matter can no longer undergo oxic decomposition so other chemical compounds act as oxidising agents and are thus reduced (Figure 3.3).

In a suboxic environment solid-phase $\mathrm{MnO}_{2}$ is reduced to its dissolved $\mathrm{Mn}^{2+}$ form in sediment pore-water (Froelich et al., 1979). The $\mathrm{Mn}^{2+}$ species can then migrate up the sediment column by molecular diffusion processes (Boudreau and Scott, 1978). As $\mathrm{Mn}^{2+}$ travels to the sediment-ocean interface it may precipitate in this more oxic environment and be recycled in the sedimentary column, adsorb onto a Mn oxide or ferromanganese surface, or re-enter the water column (Calvert and Pedersen, 1993) (Figure 3.3). Solid phase $\mathrm{Fe}(\mathrm{OH})_{3}$ is reduced to its dissolved form, $\mathrm{Fe}^{2+}$, under reducing conditions (Froelich 
et al., 1979). However in the anoxic/suboxic environment the iron species preferentially reacts with the reduced $\mathrm{H}_{2} \mathrm{~S}$ species to form $\mathrm{FeS}_{2}$ (pyrite).

Deep marine sediments typically have low levels of organic matter and are located in oxygen-rich water. Thus, oxygen is the primary oxidant in the deep ocean, with $90 \%$ of deep-sea organic matter being oxidised by oxygen, with the remainder oxidised by $\mathrm{NO}_{3}{ }^{-}, \mathrm{MnO}_{2}, \mathrm{FeO}_{3}$, and $\mathrm{SO}_{4}{ }^{2-}$ (Bender and Heggie, 1984).

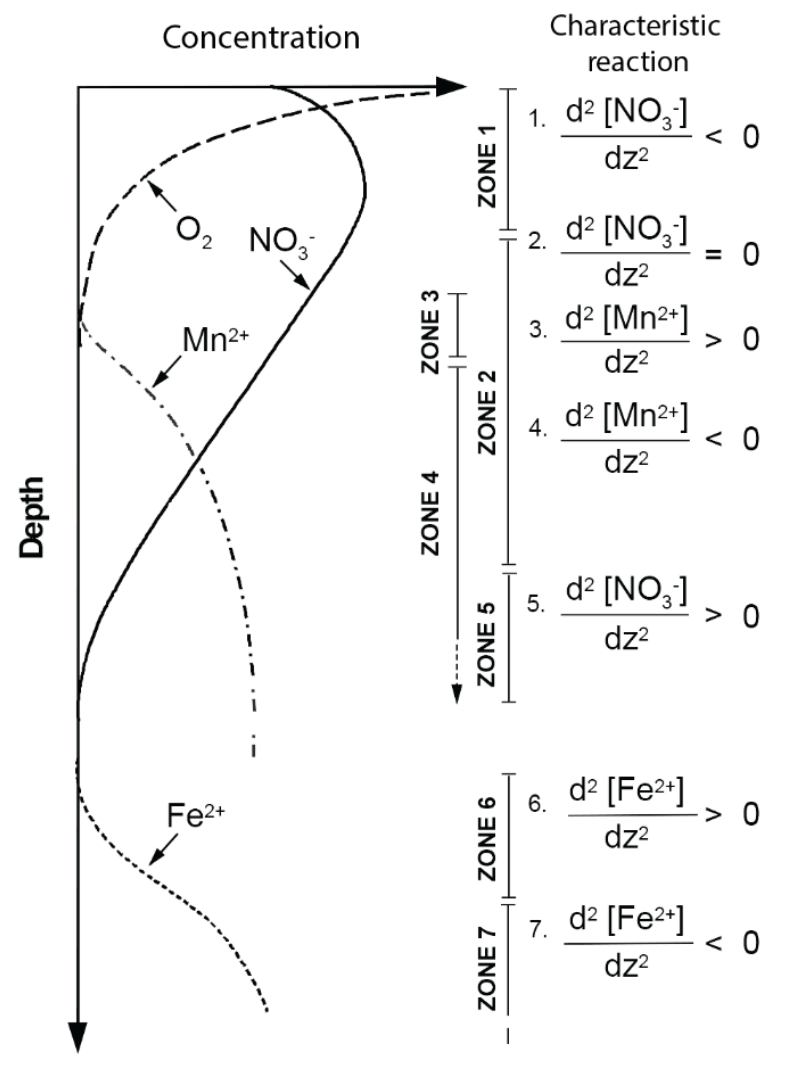

Figure 3.3: A typical redox reaction sequence in the sedimentary column. The zones represent the oxidant of organic carbon in the sediment. In zone 1 oxygen is the main electron acceptor. In zones $2-5 \mathrm{NO}_{3}{ }^{-}$and $\mathrm{MnO}_{2}$ act as the oxidants. $\mathrm{MnO}_{2}$ is reduced to its' $\mathrm{Mn}^{2+}$ state. Zones 6-7 have $\mathrm{Fe}_{2} \mathrm{O}_{3}$ as the oxidant where upon reduction it exists as the $\mathrm{Fe}^{2+}$ ion. The resultant cations from the reduction reaction in the sediment column go into the pore-water where they may undergo upward diffusion and then oxidise in the presence of oxygen (i.e. zone 3). From Froelich et al. (1979).

The more permeable a sediment the deeper the penetration of oxygenated seawater into the sediment column. This can affect the recycling of Mn and Fe in the sedimentary column. A shallow redox zone could cause $\mathrm{Mn}^{2+}$ ions to migrate into the overlying seawater before they precipitate (Boudreau and Scott, 1978), whereas a deep redox boundary will lead to internal recycling of Mn oxides (Burdige, 1993), with dissolved Mn not being able to form nodules before being oxidised. Thus a greater diagenetic influence is expected on ferromanganese nodules in sediments with a moderate-shallow redox zone. 
The above conditions assume steady-state diagenesis where sediments are continuously accumulating. Processes such as erosion and bioturbation disrupt the redox profile of the sediment by inputting oxic seawater into suboxic or anoxic zones and inputting Fe and Mn oxides into the sedimentary column (Aller, 1990; Thamdrup, 2000). Thus, erosion and bioturbation may encourage authigenic minerals such as ferromanganese nodules to form (Aller, 1990).

\subsubsection{Pore-water chemistry}

Interstitial water chemistry is a function of the original composition of the trapped seawater, the composition of the sediment grains, processes such as diagenesis and adsorption, and a possible influence from the underlying basement rock (Chester, 1990). Enrichment of trace metals in pore-waters requires the trace metal to be in a dissolved form and to be affected by the redox conditions in the sediment. There is also an input of trace metals associated with biology (discussed in Chapter 2) into the pore-waters. Sediments with a high biogenic silica component are considered to enrich pore-water in trace metals during early diagenesis (Wegorzewski and Kuhn, 2014). Ferromanganese nodules have been reported to have high concentrations of trace elements when located just below the CCD under productive waters (Cronan and Hodkinson, 1994). Elements associated with terrigenous matter such as $\mathrm{Ti}, \mathrm{Al}$, and $\mathrm{K}$ are not associated with organic diagenetic processes and their reactivity in interstitial waters in the upper sedimentary column is associated with the formation of clays (Chester, 1990).

Sediments with a deep oxic zone do not show a surface enrichment in $\mathrm{Mn}, \mathrm{Fe}$, $\mathrm{Ni}$ or $\mathrm{Cd}$ in interstitial waters (Klinkhammer et al., 1982). Dissolved $\mathrm{Cu}$ is higher in interstitial waters near the surface and may be released into the seawater (Callender and Bowser, 1980). Sediments with a shallow oxic zone overlying a suboxic zone display a large concentration gradient in $\mathrm{Mn}, \mathrm{Ni}$ and $\mathrm{Cu}$ in their interstitial waters (Halbach et al., 1981). Other elements that are associated with redox processes within the sedimentary profile include V, Cr, Co, U and Th (Sageman and Lyons, 2003). 


\subsection{Methods}

Bulk sediments samples were obtained from thirteen locations and analysed for grainsize distribution, calcium carbonate content, and bulk major element chemistry.

\subsubsection{Sediment stations}

Sediment from a single station in the Tasman Sea, U203, was collected (Figure 3.1). The Campbell Plateau slope stations are located along two transects (referred to here as southern and northern transects). The southern transect (with samples listed with increasing distance from the Campbell slope) includes; U1362, U1365B, U1373, U1374 and U1378. The northern transect includes; U1413 (offset from main transect, located between Antipodes Island and Bollons Gap), U1406B, U1402, U1399, U1398, U1394, and U1391.

Sediments samples were collected at the same time as the nodules using a PVC tube inside the dredge (Chang et al., 2003a). This should account for the top $\sim 0-20 \mathrm{~cm}$ of the surficial sediment.

\subsubsection{Laser grain size analysis}

Laser grain size analysis was undertaken in the sediment laboratory at Greta Point, NIWA using a Beckman Coulter LS 13320 Laser Diffraction Particle Size Analyser with an Aqueous Liquid Module. This technique uses the optical properties of different size particles to equate grain size to the diffraction angle of light.

A representative sediment sub-sample of $\sim 0.3 \mathrm{~g}$ was placed into a $60 \mathrm{~mL}$ polypropylene (PPE) specimen container with $45 \mathrm{~mL}$ of washing solution $\left(1: 4, \mathrm{NaHCO}_{3}: \mathrm{NaCO}_{3}\right)$. The samples were shaken and left for ten minutes to break up and allow the clay particles to deflocculate. The containers were swirled and suspended in an ultrasonicator for ten seconds at a time to avoid disintegrating any foraminifera present. This process was repeated as necessary until no clay flocculates remained.

The solution was then poured into the Aqueous Liquid Module of the laser grain size analyser, and rinsed with ultra-pure water. The obscuration of the sample was checked (ideally it was in the range of 15-25\%). The run settings were 180 seconds, and an auto rinse occurred between each sample until there was no measurable obscuration. The grainsize data was then entered into GRADISTAT (Blott and Pye 2001; Blott 2010), a particle size analysis software. The results are presented in Appendix B. 


\subsubsection{Calcium carbonate analysis}

Calcium carbonate analysis was also undertaken at Greta Point, NIWA. The calcium carbonate content of each sediment sample was measured using the vacuum gasometric method of Muller and Gastner (1971) and Dunn (1980). The carbonate bomb method quantifies the calcium carbonate content of the sediment by comparing the pressure in the bomb under vacuum before and after acid is added to the sample. $\mathrm{A} \mathrm{CaCO}_{3}$ standard was run alongside the sediment samples, and three samples were duplicated.

Sediment samples were placed in foil boats and dried overnight in an oven set to $100{ }^{\circ} \mathrm{C}$. Sub-samples were taken and ground using a ceramic mortar and pestle and placed into a desiccator. Approximately $0.33 \mathrm{~g}$ of powdered sample was weighed out onto paper. This was then transferred into a carbonate bomb. Five drops of ultra-pure water were added to each sample, and $5 \mathrm{~mL}$ of concentrated $\mathrm{H}_{3} \mathrm{PO}_{4}$ were added to the side arm of each bomb using a syringe. Greased O-rings followed by a lid were placed on each bomb. The bomb lid and body were secured with a clamp and the bomb was then attached to the carbonate line.

The bomb lid was then opened to give the pressure inside the vessel. The vacuumed cylinder (of which the volume is known) was then opened to obtain a second pressure. The volume of the bomb could then be calculated using Equation 3.1.

$$
V_{1}=\frac{P_{2} \cdot V_{2}}{\left(P_{1}-P_{2}\right)}
$$

Equation 3.1: The volume of the bomb used in the calcium carbonate analysis. V1 - initial volume, V2 - final volume, $\mathrm{P} 1$ - initial pressure, $\mathrm{P} 2$ - final pressure.

The bomb was then pumped out to remove the air and create a vacuum, and the pressure recorded. The $\mathrm{H}_{3} \mathrm{PO}_{4}$ in the side arm of the bomb was added to the sediment, and any carbonate in the sample reacted to form $\mathrm{CO}_{2}$, thus changing the pressure in the bomb. The samples were left for 90 minutes to ensure all $\mathrm{CaCO}_{3}$ in the sample had reacted. The bomb was then reattached to the carbonate line and the final pressure recorded.

The ideal gas law $(P V=n R T)$ was used to determine the amount of $\mathrm{CaCO}_{3}$ in the sample by rearranging the equation to get Equation 3.2. 


$$
n=\frac{P_{3}-\left(P_{2}-P_{1}\right) \cdot\left(\frac{V_{1}}{1000}\right)}{R \cdot T}
$$

Equation 3.2: Calculation to find the amount of $\mathrm{CaCO}_{3}$ in a sediment sample. $\mathrm{P}_{3}$ is the pressure of the bomb after the $\mathrm{H}_{3} \mathrm{PO}_{4}$ was added, $\mathrm{R}$ - ideal gas constant equal to $8.314 \mathrm{~J} / \mathrm{mol}, \mathrm{n}-$ the number of moles of $\mathrm{CO}_{2}, \mathrm{~T}-$ the average temperature (in Celsius) measured throughout the experiment.

The mass of $\mathrm{CaCO}_{3}$ was then calculated using; $\mathrm{m}=\frac{\mathrm{n}}{\mathrm{M}}$, where $\mathrm{m}-$ mass, and $\mathrm{M}-$ molar mass of $\mathrm{CaCO}_{3}$. The percentage of $\mathrm{CaCO}_{3}$ was then calculated by dividing the mass of $\mathrm{CaCO}_{3}$ by the initial sample weight added to the bomb.

The accuracy and precision was found to be excellent, with the pure $\mathrm{CaCO}_{3}$ standard reporting $97.2 \% \mathrm{CaCO}_{3}$, and the replicate samples $<1 \%$ difference (Appendix B).

\subsubsection{Physical sample preparation}

\subsubsection{Sieving}

Approximately $10 \mathrm{~g}$ of sediment was added to a specimen container with washing solution $\left(1: 4, \mathrm{NaHCO}_{3}: \mathrm{NaCO}_{3}\right)$, and agitated to deflocculate the clay particles. The sample solution was then emptied into a $63 \mu \mathrm{m}$ sieve and spray bottles of distilled water were used to wash mud particles through the sieve. When the water was clear the samples were rinsed onto filter paper. Once drained the filter paper was placed on foil boats and oven dried overnight at $50{ }^{\circ} \mathrm{C}$. The mud sized filtrate was left to settle.

The sand fraction samples were sieved into > 355 $\mu \mathrm{m}, 355-250 \mu \mathrm{m}$, and 250-63 $\mu \mathrm{m}$ fractions. Each grain size fraction for all sites was examined under a microscope and qualitatively described.

\subsubsection{Mineral grains}

Mineral grains were hand-picked under a Leica binocular microscope using a super-fine paint brush from the sieved $>355 \mu \mathrm{m}$ fraction. They were placed into weighed microcentrifuge tubes.

\subsubsection{Bulk sediment grinding}

An agate mortar and pestle were used to grind bulk sediment samples. Prior to grinding each sample, silica sand was ground in the mortar and pestle, which was then cleaned using ethanol and Kimwipes, to ensure minimal cross contamination. After grinding, the sample powders were stored in PPE sample containers. 


\subsubsection{X-ray fluorescence}

Glass disks were prepared by weighing out $1 \mathrm{~g}$ of sample powder with $10 \mathrm{~g}$ of flux (1.2:2.2, $\left.\mathrm{Li}_{2} \mathrm{~B}_{4} \mathrm{O}_{7}: \mathrm{LiBO}_{2}\right)$, and a $\mathrm{NH}_{4} \mathrm{I}$ tablet into a platinum crucible. This mixture was then mixed with a stirring rod and the crucible placed in a Claisse LeNeo Fluxer at $1075{ }^{\circ} \mathrm{C}$ and heated for 25 minutes to make a fused glass disk.

Analysis of the disks was conducted at NIWA on a Panalytical MiniPal-4 energy dispersive XRF spectrometer. Samples were run five times, and the average values taken. The calibration curve was based on 12 silicate standards obtained from United States Geological Survey (USGS), National Institute of Standards and Technology (NIST) and Geological Survey of Japan (GSJ). The USGS standard reference materials (SRM) SCO1 and SDC-1 were analysed along with the sediment samples to monitor accuracy and precision. The standards are in agreement with the certified values of SCO-1 within $\pm 5 \%$ and reproducibility was $<1 \%$ RSD for all elements with the exception of $\mathrm{P}_{2} \mathrm{O}_{5}(2.1 \%$ $\mathrm{RSD})$ and $\mathrm{Na}_{2} \mathrm{O}(6.2 \% \mathrm{RSD})$.

\subsubsection{Electron probe microanalyser Energy-dispersive X-ray spectroscopy}

Mineral and rock grains for each sediment were made into epoxy mounts for electronprobe microanalysis at Victoria University using energy-dispersive X-ray spectroscopy on a JEOL JXA-8230 SuperProbe Electron Probe Microanalyser.

Grains were placed onto sticky tape in distinctive patterns. Plastic moulds were then placed onto the tape and epoxy (16 g EpoFix resin and $2 \mathrm{~g}$ EpoFix hardener, well-mixed) was poured in. The epoxy was left to set overnight. The mounts were then polished by using progressively finer (600-2000 grit) silicon carbide sandpaper until the grains were exposed at the surface. The mounts were then polished on a polishing lap using $3 \mu \mathrm{m}$, and then $1 \mu \mathrm{m}$ liquid diamond, followed by colloidal silica to produce a fine polish. Prior to analysis a carbon coating was applied to make the mount surface conductive. Analysis of mineral grains was conducted using an energy dispersive X-ray spectrometer, with a typical run time of $\sim 1$ minute and a $1 \mu \mathrm{m}$ spot size. This method produced fast, semiquantitative analyses suitable for identifying mineral and rock fragment assemblages in each sediment. 


\subsubsection{Trace element chemistry}

Attempts were made to analyse the trace element chemistry of the sediments by solution inductively coupled plasma mass spectrometry (ICP-MS) at Victoria University, using a modified method from $\mathrm{Hu}$ et al. (2013). This method, utilising $\mathrm{NH}_{4} \mathrm{~F}$, has the ability to dissolved refractory minerals, commonly present in sediments and difficult to dissolve using standard hydrofluoric acid dissolution methods. However, this method is still new and has not previously been applied to marine sediments. Modifications to this method required for the carbonate-rich marine sediments proved to be time consuming and more difficult than expected. Reliable results were not able to be obtained in time to be included in this thesis. 


\subsection{Results}

\subsubsection{Grain size and calcium carbonate content}

Texture, grain size distribution, and calcium carbonate content for the sediment samples are summarised in Table 3.1. Sample U203 from the Tasman Sea has the lowest sand content of all the samples analysed (Table 3.1, Figure 3.4). The particle distribution (Figure 3.7) displays a peak in the medium clay fraction. This sample also has a very low calcium carbonate content of $3.9 \%$ (Table 3.1).

The percentage sand is greatest $(79.4 \%)$ in U1365B, followed by U1362 with $68.8 \%$ (Table 3.1, Figure 3.5), both in the southern Campbell Plateau slope transect. The three outer locations along this transect (U1373, U1374, and U1378) have much lower (<20\%) sand components that decrease with distance from the shelf (Table 3.1, Figure 3.5). The particle distribution diagram (Figure 3.7) further indicates peaks in the sand fraction for both U1362 and U1365B, and U1406B displays another peak in the very coarse sand fraction. By contrast, the U1373, U1374 and U1378 all plot mainly in the silt-size range. The calcium carbonate content for all samples generally decreases with increasing depth (Figure 3.4), with the exception of the sediment from U1378, which has calcium carbonate content of $25.1 \%$ (Table 3.1), despite being located $4,915 \mathrm{mbsl}$. There is no apparent correlation between the calcium carbonate and sand contents in a sediment (Figure 3.6). This indicates that some of the sand grains are not carbonate, and are thus detrital in origin, indicating there is some terrigenous material in the sand fraction.

In the northern transect, the sediment from U1406B has the greatest sand fraction (72.3\%), followed by U1413 (22.0\%), with the remaining locations along the transect having sand fractions of 8.6-15.7\% (Table 3.1, Figure 3.5). As with the southern transect, silt and sand were negatively correlated (Figure 3.4). U1406B displays similar grain size trends to U1362 and U1365B from the southern transect (Figure 3.7). They contain larger proportions of coarse grained material (very fine to very coarse sand), with peaks at the medium sand size $(\sim 0.2 \mathrm{~mm})$ (Figure 3.7). The deeper sediments (U1402, U1399, U1398, U1394, and U1391) exhibit similar grainsize trends to the deeper locations in the southern transect (U1373, U1374, and U1378). This transect shows decreasing calcium carbonate further from the continental slope (Figure 3.4), with the exception of U1406B, with only sediments U1391 and U1394 being below the CCD (20\% calcium carbonate threshold) (Table 3.1, Figure 3.4). As with the southern transect there is no correlation observed between the calcium carbonate and sand contents in a sediment (Figure 3.6). 
Table 3.1: Texture, grain size and calcium carbonate content of each sediment sample.

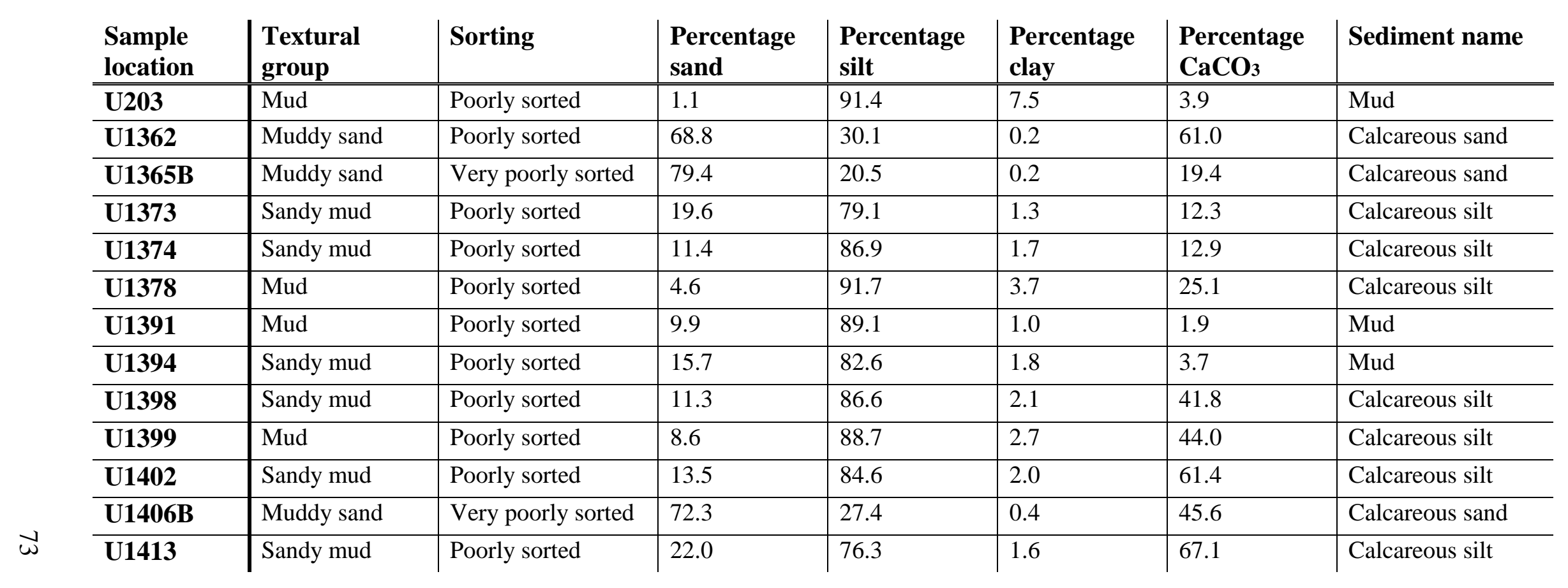



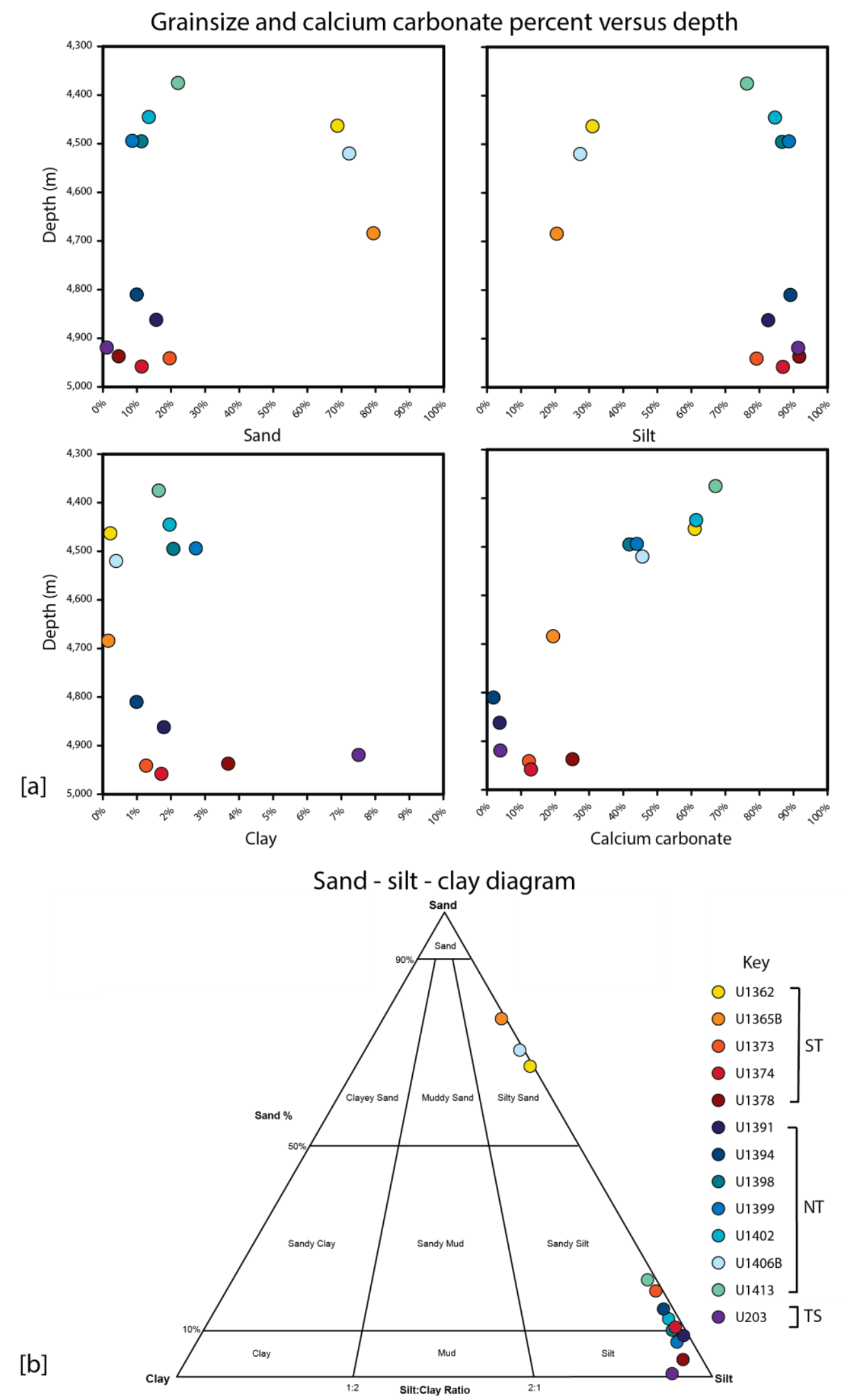

Figure 3.4: The percentage sand, silt, and clay for each sediment shown (a) versus the depth the sediment is located in, and (b) in a sand-silt-clay ternary diagram, from (Folk, 1980). 


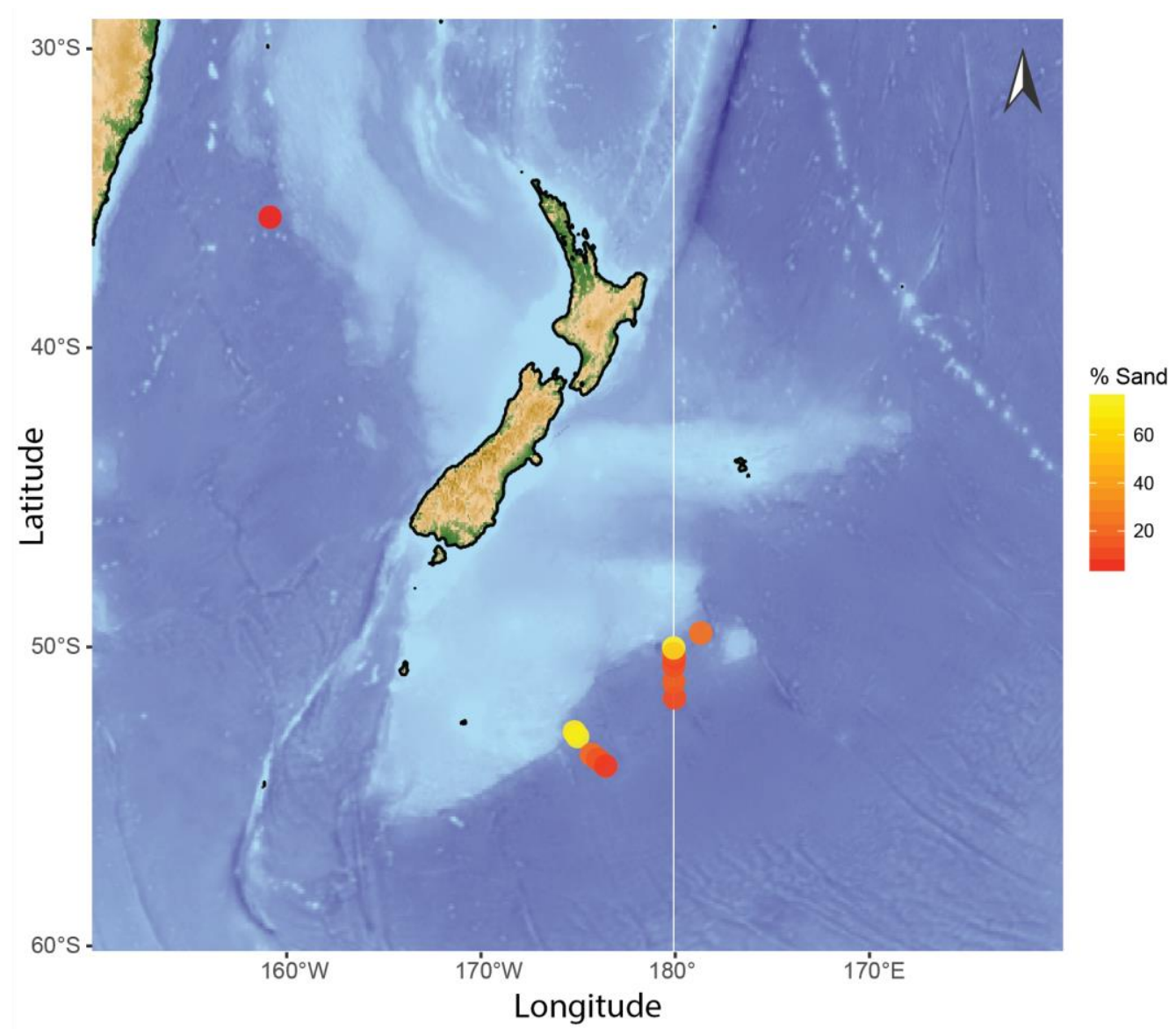

Figure 3.5: Sand distribution using the RStudio Marmap package (Pante and Simon-Bouhet, 2013).

Sand versus calcium carbonate

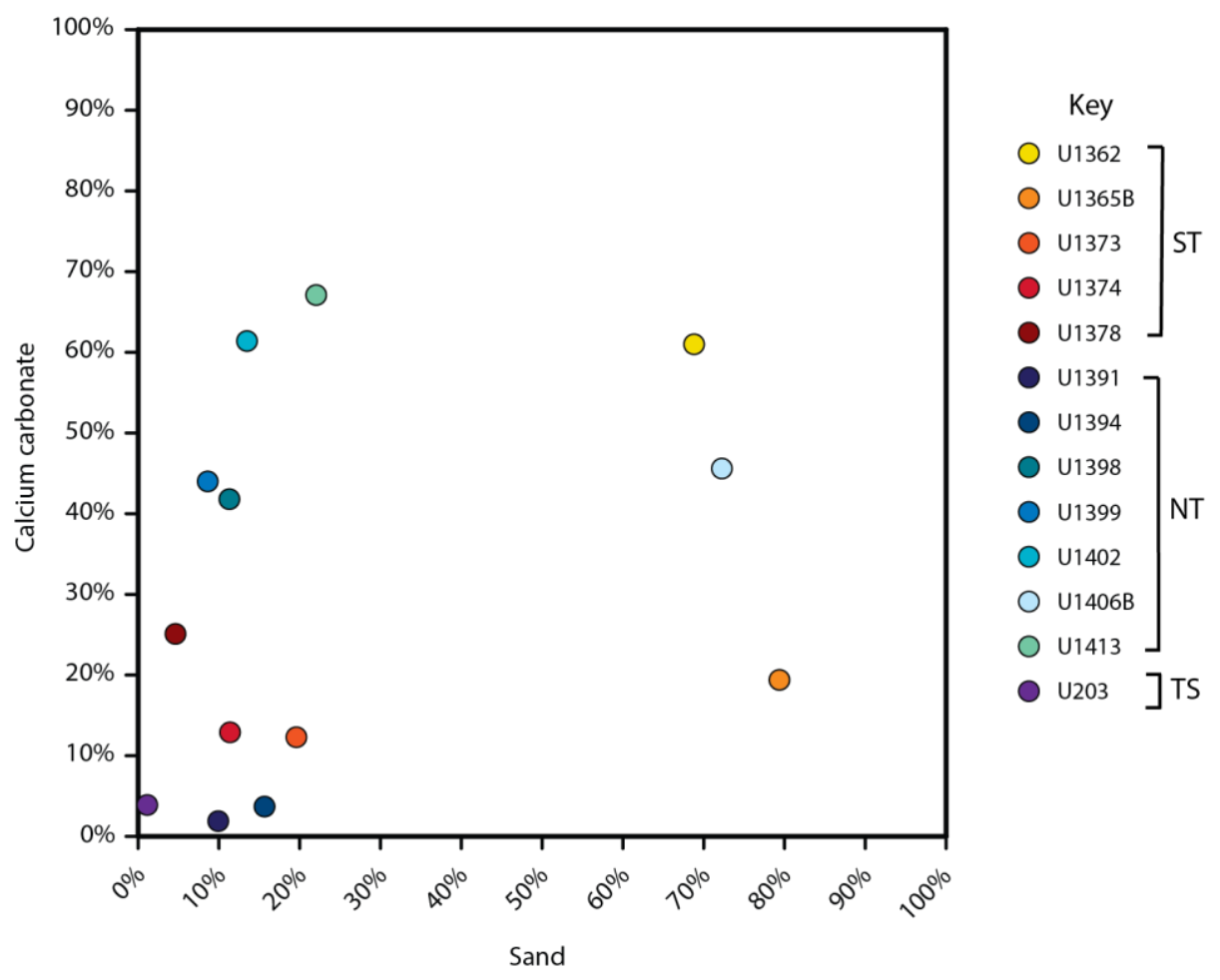

Figure 3.6: Sand percentage versus calcium carbonate percentage. 


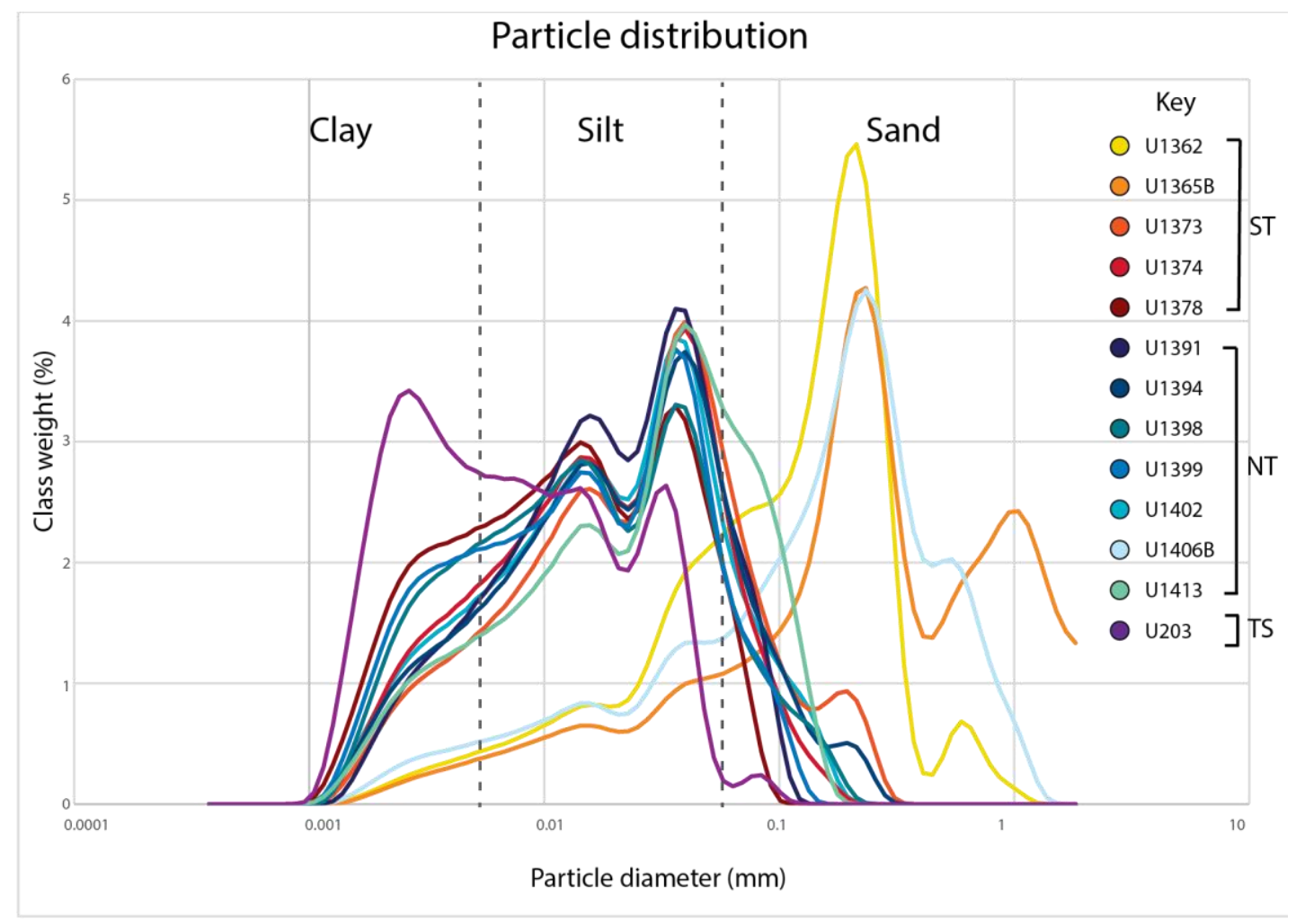

Figure 3.7: Particle distribution from grainsize analysis and GRADISTAT (Blott and Pye, 2001).

\subsubsection{Qualitative analysis of the sand fraction}

Sample U203 is sand poor (1.1\%) (Table 3.1). The > $355 \mu \mathrm{m}$ fraction contained one benthic foraminifera specimens, and the smaller sand fractions contained micronodules, biogenic material and lithic fragments.

The southern transect sand fractions have low micronodule contents in the two sediments closest to the slope (U1362 and U1365B), higher in U1373 and U1374, and lower in U1378 (Table 3.2). U1365B has the highest concentration of lithics (mineral/rock fragments), and a relatively low foraminifera content, except in the fines. U1362 has the highest foraminifera content. Both lithic and foraminifera content generally decrease with increasing distance from the continent. There was no siliceous matter identified in U1365B and U1362, and no clear trends in siliceous matter content across the transect.

In the northern transect, the largest faction of micronodules is found in the two sediments closest to the shelf (U1413 and U1406B). The sediment samples display a general decrease in lithic fragment content with increasing distance from the Subantarctic Slope, with the exception of U1391 which is higher (e.g. $30 \%$ in the $>355 \mu \mathrm{m}$ fraction) than the sample from U1406B (15\% in the > $355 \mu \mathrm{m}$ fraction). Similarly to the southern transect, foraminifera content generally decreases and siliceous species increase with depth and distance away from slope. 


\subsubsection{Sediment mineral assemblages}

Felsic minerals (quartz and alkali feldspar) are present in all sediments, with the exception of quartz in U1378 and alkali feldspar in U1399 (Table 3.3). Plagioclase was identified in all samples from the northern transect, except sample U1394, and present in only U1378 in the southern transect. Minerals associated with mafic rocks (e.g. olivine, pyroxene, and amphibole) are only present in three samples (Table 3.3). Pyroxene occurs in samples U1363 and U1365B from the southern transect, with amphibole also present in sample U1365B. Olivine was only found in U1413 from near Bollons Gap. Garnet, a metamorphic mineral, is present in the sediment from U1373. 
Table 3.2: Qualitative analysis of the sand fraction. The percentage of different fractions are visual estimates.

\begin{tabular}{|c|c|c|c|c|c|c|c|c|c|c|}
\hline \multirow[t]{2}{*}{$\begin{array}{c}\text { Sample } \\
\text { name }\end{array}$} & & \multirow[t]{2}{*}{$\begin{array}{c}\text { Micro } \\
\text {-nodule }\end{array}$} & \multicolumn{2}{|c|}{ Detrital } & \multicolumn{2}{|c|}{ Calcareous } & \multicolumn{2}{|c|}{ Siliceous } & \multicolumn{2}{|c|}{ Other } \\
\hline & & & Quartz & $\begin{array}{l}\text { Mineral/rock } \\
\text { fragments }\end{array}$ & Foraminifera & $\begin{array}{l}\text { Agglutinated } \\
\text { foraminifera }\end{array}$ & Diatoms & Radiolaria & Bioclast & Spicules \\
\hline U203 & $\begin{array}{c}>355 \mu \mathrm{m} \\
250-355 \mu \mathrm{m} \\
>63-250 \mu \mathrm{m}\end{array}$ & $\begin{array}{c}- \\
- \\
15 \%\end{array}$ & $\begin{array}{c}- \\
10 \% \\
30 \%\end{array}$ & $\begin{array}{c}- \\
20 \% \\
10 \%\end{array}$ & $\begin{array}{c}100 \% \\
- \\
-\end{array}$ & $\begin{array}{c}- \\
10 \% \\
3 \%\end{array}$ & $\begin{array}{l}- \\
- \\
-\end{array}$ & $\begin{array}{c}- \\
30 \% \\
10 \%\end{array}$ & $\begin{array}{c}- \\
30 \% \\
20 \%\end{array}$ & $\begin{array}{c}- \\
- \\
12 \%\end{array}$ \\
\hline U1362 & $\begin{array}{c}>355 \mu \mathrm{m} \\
250-355 \mu \mathrm{m} \\
>63-250 \mu \mathrm{m}\end{array}$ & $\begin{array}{l}1 \% \\
1 \% \\
1 \%\end{array}$ & $\begin{array}{l}25 \% \\
30 \% \\
30 \%\end{array}$ & $\begin{array}{l}13 \% \\
10 \% \\
10 \%\end{array}$ & $\begin{array}{l}50 \% \\
45 \% \\
55 \%\end{array}$ & $\begin{array}{l}2 \% \\
2 \% \\
2 \%\end{array}$ & $\begin{array}{l}- \\
- \\
-\end{array}$ & $\begin{array}{l}- \\
- \\
-\end{array}$ & $\begin{array}{c}7 \% \\
7 \% \\
-\end{array}$ & $\begin{array}{l}2 \% \\
5 \% \\
2 \%\end{array}$ \\
\hline U1365B & $\begin{array}{c}>355 \mu \mathrm{m} \\
250-355 \mu \mathrm{m} \\
>63-250 \mu \mathrm{m}\end{array}$ & $\begin{array}{l}- \\
- \\
-\end{array}$ & $\begin{array}{l}50 \% \\
50 \% \\
30 \%\end{array}$ & $\begin{array}{l}45 \% \\
35 \% \\
20 \%\end{array}$ & $\begin{array}{c}1 \% \\
12 \% \\
45 \%\end{array}$ & $\begin{array}{c}2 \% \\
1 \% \\
2.5 \%\end{array}$ & $\begin{array}{l}- \\
- \\
-\end{array}$ & $\begin{array}{l}- \\
- \\
-\end{array}$ & $\begin{array}{l}2 \% \\
2 \% \\
2 \%\end{array}$ & $\begin{array}{c}- \\
>0.1 \% \\
0.5 \%\end{array}$ \\
\hline U1373 & $\begin{array}{c}>355 \mu \mathrm{m} \\
250-355 \mu \mathrm{m} \\
>63-250 \mu \mathrm{m}\end{array}$ & $\begin{array}{c}25 \% \\
7 \% \\
7 \%\end{array}$ & $\begin{array}{l}15 \% \\
20 \% \\
12 \%\end{array}$ & $\begin{array}{l}25 \% \\
15 \% \\
10 \%\end{array}$ & $\begin{array}{l}10 \% \\
20 \% \\
40 \%\end{array}$ & $\begin{array}{l}5 \% \\
3 \% \\
3 \%\end{array}$ & $\begin{array}{l}12 \% \\
16 \% \\
15 \%\end{array}$ & $\begin{array}{l}3 \% \\
5 \% \\
5 \%\end{array}$ & $\begin{array}{l}5 \% \\
7 \% \\
3 \%\end{array}$ & $\begin{array}{c}- \\
7 \% \\
5 \%\end{array}$ \\
\hline U1374 & $\begin{array}{c}>355 \mu \mathrm{m} \\
250-355 \mu \mathrm{m} \\
>63-250 \mu \mathrm{m}\end{array}$ & $\begin{array}{c}17 \% \\
3 \% \\
2 \%\end{array}$ & $\begin{array}{l}12 \% \\
3 \% \\
3 \%\end{array}$ & $\begin{array}{l}5 \% \\
2 \% \\
5 \%\end{array}$ & $\begin{array}{l}44 \% \\
40 \% \\
35 \%\end{array}$ & $\begin{array}{l}7 \% \\
7 \% \\
3 \%\end{array}$ & $\begin{array}{l}10 \% \\
30 \% \\
35 \%\end{array}$ & $\begin{array}{c}1 \% \\
10 \% \\
10 \%\end{array}$ & $\begin{array}{l}3 \% \\
3 \% \\
5 \%\end{array}$ & $\begin{array}{l}1 \% \\
2 \% \\
2 \%\end{array}$ \\
\hline U1378 & $\begin{array}{c}>355 \mu \mathrm{m} \\
250-355 \mu \mathrm{m} \\
>63-250 \mu \mathrm{m}\end{array}$ & $\begin{array}{c}3 \% \\
1.5 \% \\
1 \%\end{array}$ & $\begin{array}{c}5 \% \\
1 \% \\
-\end{array}$ & $\begin{array}{l}2 \% \\
1 \% \\
1 \%\end{array}$ & $\begin{array}{l}80 \% \\
70 \% \\
85 \%\end{array}$ & $\begin{array}{c}3 \% \\
2 \% \\
-\end{array}$ & $\begin{array}{c}- \\
20 \% \\
7 \%\end{array}$ & $\begin{array}{c}- \\
2 \% \\
3 \%\end{array}$ & $\begin{array}{c}6 \% \\
2 \% \\
-\end{array}$ & $\begin{array}{c}1 \% \\
0.5 \% \\
3 \%\end{array}$ \\
\hline U1391 & $\begin{array}{c}>355 \mu \mathrm{m} \\
250-355 \mu \mathrm{m} \\
>63-250 \mu \mathrm{m}\end{array}$ & $\begin{array}{c}- \\
1 \% \\
1 \%\end{array}$ & $\begin{array}{c}25 \% \\
5 \% \\
3 \%\end{array}$ & $\begin{array}{c}30 \% \\
2 \% \\
7 \%\end{array}$ & $\begin{array}{c}15 \% \\
10 \% \\
7 \%\end{array}$ & $\begin{array}{l}7 \% \\
7 \% \\
3 \%\end{array}$ & $\begin{array}{l}13 \% \\
50 \% \\
70 \%\end{array}$ & $\begin{array}{c}3 \% \\
15 \% \\
7 \%\end{array}$ & $\begin{array}{c}7 \% \\
10 \% \\
1 \%\end{array}$ & $\begin{array}{c}- \\
>0.1 \% \\
1 \%\end{array}$ \\
\hline
\end{tabular}




\begin{tabular}{|c|c|c|c|c|c|c|c|c|c|c|}
\hline U1394 & $\begin{array}{c}>355 \mu \mathrm{m} \\
250-355 \mu \mathrm{m} \\
>63-250 \mu \mathrm{m}\end{array}$ & $\begin{array}{c}2 \% \\
>0.1 \% \\
-\end{array}$ & $\begin{array}{c}3 \% \\
0.5 \% \\
10 \%\end{array}$ & $\begin{array}{c}3 \% \\
0.5 \% \\
-\end{array}$ & $\begin{array}{l}20 \% \\
10 \% \\
25 \%\end{array}$ & $\begin{array}{l}10 \% \\
2 \% \\
5 \%\end{array}$ & $\begin{array}{l}45 \% \\
75 \% \\
35 \%\end{array}$ & $\begin{array}{c}- \\
10 \% \\
3 \%\end{array}$ & $\begin{array}{c}15 \% \\
2 \% \\
15 \%\end{array}$ & $\begin{array}{c}2 \% \\
- \\
7 \%\end{array}$ \\
\hline U1398 & $\begin{array}{c}>355 \mu \mathrm{m} \\
250-355 \mu \mathrm{m} \\
>63-250 \mu \mathrm{m}\end{array}$ & $\begin{array}{l}1 \% \\
1 \% \\
1 \%\end{array}$ & $\begin{array}{l}5 \% \\
2 \% \\
1 \%\end{array}$ & $\begin{array}{c}5 \% \\
2 \% \\
0.5 \%\end{array}$ & $\begin{array}{l}86 \% \\
90 \% \\
97 \%\end{array}$ & $\begin{array}{c}1 \% \\
1 \% \\
0.5 \%\end{array}$ & $\begin{array}{c}- \\
1 \% \\
-\end{array}$ & $\begin{array}{c}- \\
>0.1 \% \\
-\end{array}$ & $\begin{array}{l}2 \% \\
2 \% \\
-\end{array}$ & $\begin{aligned}> & 0.1 \% \\
& 1 \% \\
> & 0.1 \%\end{aligned}$ \\
\hline U1399 & $\begin{array}{c}>355 \mu \mathrm{m} \\
250-355 \mu \mathrm{m} \\
>63-250 \mu \mathrm{m}\end{array}$ & $\begin{array}{c}2 \% \\
1 \% \\
0.5 \% \\
\end{array}$ & $\begin{array}{c}3 \% \\
2 \% \\
0.5 \% \\
\end{array}$ & $\begin{array}{c}2 \% \\
2 \% \\
0.5 \% \\
\end{array}$ & $\begin{array}{l}85 \% \\
85 \% \\
90 \% \\
\end{array}$ & $\begin{array}{l}5 \% \\
2 \% \\
2 \% \\
\end{array}$ & $\begin{array}{c}- \\
7 \% \\
4 \%\end{array}$ & $\begin{array}{c}- \\
>0.1 \% \\
2 \%\end{array}$ & $\begin{array}{c}2 \% \\
0.5 \% \\
- \\
\end{array}$ & $\begin{array}{c}1 \% \\
0.5 \% \\
0.5 \% \\
\end{array}$ \\
\hline U1402 & $\begin{array}{c}>355 \mu \mathrm{m} \\
250-355 \mu \mathrm{m} \\
>63-250 \mu \mathrm{m}\end{array}$ & $\begin{array}{c}2 \% \\
0.5 \% \\
>0.1 \%\end{array}$ & $\begin{array}{l}5 \% \\
1 \% \\
2 \%\end{array}$ & $\begin{array}{l}3 \% \\
2 \% \\
3 \%\end{array}$ & $\begin{array}{l}80 \% \\
95 \% \\
90 \%\end{array}$ & $\begin{array}{l}7 \% \\
1 \% \\
2 \%\end{array}$ & $\begin{array}{l}- \\
- \\
-\end{array}$ & $\begin{array}{c}- \\
- \\
3 \%\end{array}$ & $\begin{array}{c}2 \% \\
0.5 \% \\
-\end{array}$ & $\begin{aligned} & 1 \% \\
> & 0.1 \% \\
> & 0.1 \%\end{aligned}$ \\
\hline U1406B & $\begin{array}{c}>355 \mu \mathrm{m} \\
250-355 \mu \mathrm{m} \\
>63-250 \mu \mathrm{m}\end{array}$ & $\begin{array}{l}5 \% \\
5 \% \\
7 \%\end{array}$ & $\begin{array}{c}50 \% \\
15 \% \\
7 \%\end{array}$ & $\begin{array}{c}15 \% \\
5 \% \\
3 \%\end{array}$ & $\begin{array}{l}23 \% \\
70 \% \\
80 \%\end{array}$ & $\begin{array}{l}3 \% \\
3 \% \\
2 \%\end{array}$ & $\begin{array}{l}- \\
- \\
-\end{array}$ & $\begin{array}{l}- \\
- \\
-\end{array}$ & $\begin{array}{l}3 \% \\
2 \% \\
1 \%\end{array}$ & $\begin{array}{c}1 \% \\
>0.1 \% \\
>0.1 \%\end{array}$ \\
\hline U1413 & $\begin{array}{c}>355 \mu \mathrm{m} \\
250-355 \mu \mathrm{m} \\
>63-250 \mu \mathrm{m}\end{array}$ & $\begin{array}{l}2 \% \\
2 \% \\
1 \%\end{array}$ & $\begin{array}{l}3 \% \\
7 \% \\
1 \%\end{array}$ & $\begin{array}{l}2 \% \\
5 \% \\
1 \%\end{array}$ & $\begin{array}{l}85 \% \\
83 \% \\
90 \%\end{array}$ & $\begin{array}{l}3 \% \\
2 \% \\
2 \%\end{array}$ & $\begin{array}{c}0.5 \% \\
- \\
2 \%\end{array}$ & $\begin{array}{c}- \\
0.5 \% \\
1 \%\end{array}$ & $\begin{array}{c}3 \% \\
- \\
-\end{array}$ & $\begin{array}{c}1.5 \% \\
0.5 \% \\
2 \%\end{array}$ \\
\hline
\end{tabular}

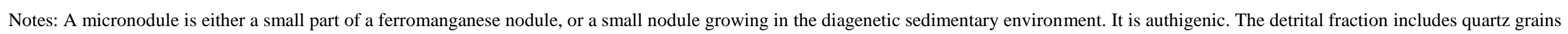

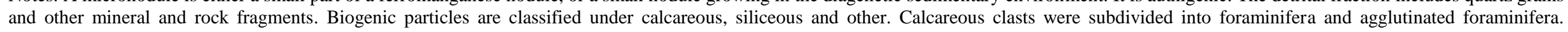

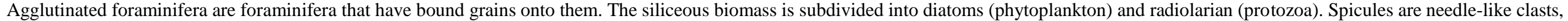

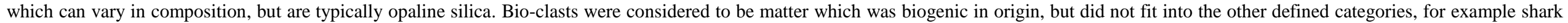
teeth. 
Table 3.3: Mineral groups identified in the sediments from EDS analyses. An X denotes the occurrence of the mineral phase in the sediment.

\begin{tabular}{|c|c|c|c|c|c|c|c|c|c|c|c|}
\hline & U1413 & U1406B & U1399 & U1398 & U1394 & U1391 & U1362 & U1365B & U1373 & U1374 & U1378 \\
\hline Quartz & $\mathrm{X}$ & $\mathrm{X}$ & $\mathrm{X}$ & $\mathrm{X}$ & $\mathrm{X}$ & $\mathrm{X}$ & $\mathrm{X}$ & $\mathrm{X}$ & $\mathrm{X}$ & $\mathrm{X}$ & - \\
\hline Alkali feldspar & $\mathrm{X}$ & $\mathrm{X}$ & - & $\mathrm{X}$ & $\mathrm{X}$ & $\mathrm{X}$ & $\mathrm{X}$ & $\mathrm{X}$ & $\mathrm{X}$ & $\mathrm{X}$ & $\mathrm{X}$ \\
\hline Silicic glass & - & - & - & - & $\mathrm{X}$ & $\mathrm{X}$ & - & - & - & - & - \\
\hline Micas & - & $\mathrm{X}$ & - & - & - & - & - & - & $\mathrm{X}$ & - & - \\
\hline Olivine & $\mathrm{X}$ & - & - & - & - & - & - & - & - & - & - \\
\hline Pyroxene & - & - & - & - & - & - & $\mathrm{X}$ & $\mathrm{X}$ & - & - & - \\
\hline Plagioclase & $\mathrm{X}$ & $\mathrm{X}$ & $\mathrm{X}$ & $\mathrm{X}$ & - & $\mathrm{X}$ & - & - & - & - & $\mathrm{X}$ \\
\hline Amphibole & - & - & - & - & - & - & - & $\mathrm{X}$ & - & - & - \\
\hline Garnet & - & - & - & - & - & - & - & - & $\mathrm{X}$ & - & - \\
\hline Rock fragments & - & $\mathrm{X}$ & - & - & - & $\mathrm{X}$ & - & $\mathrm{X}$ & $X$ & $\mathrm{X}$ & $\mathrm{X}$ \\
\hline Oxides & - & - & - & - & - & $\mathrm{X}$ & - & - & - & - & - \\
\hline
\end{tabular}




\subsubsection{Major element chemistry}

Sediments from U1362 and U1365B have major element chemistry compatible with a terrigenous source (Figure 3.8). This is in contrast to all other sediments analysed, which have an ocean arc signature (Figure 3.8).

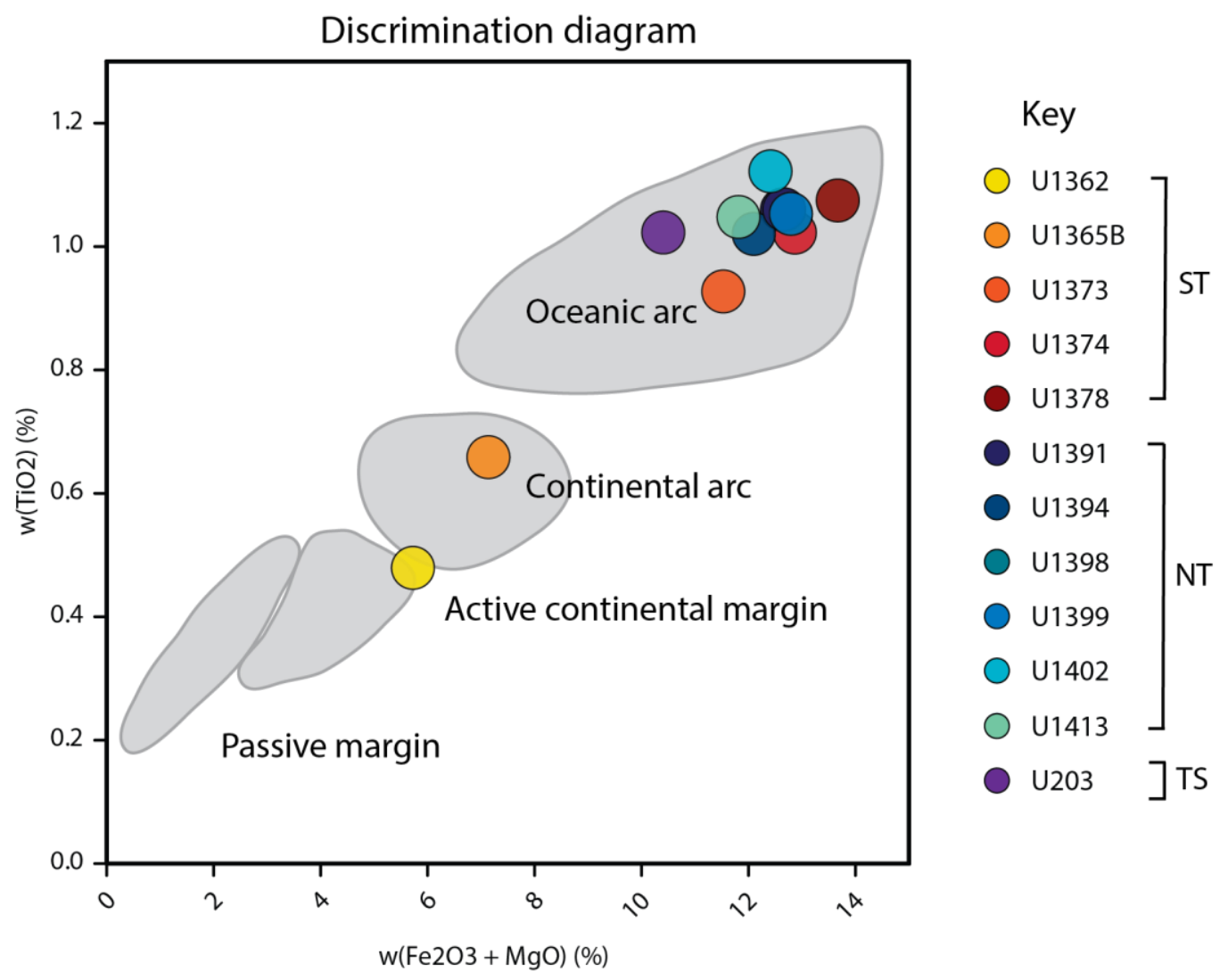

Figure 3.8: Discrimination diagram of Bhatia (1983) for terrigenous components. The compositional data was normalised to $\mathrm{CaO}$ to remove the biogenic calcium signal. The grey shaded areas are from Bhatia (1983) and are used to distinguish the sources of sediments, e.g. passive margin, active continental margin, continental arc, and ocean arc. ST - southern transect of the Campbell Plateau, NT - northern transect of the Campbell Plateau, TS - Tasman Sea.

Major element data is plotted on 4D diagrams to identify patterns in Campbell Plateau slope sediment provenance. Figure 3.9 uses element oxide ratios to determine variation in the source, i.e. biogenic silica and carbonate, and potential variations in the lithogenic source. Proxies for environmental conditions are explored in Figure 3.10 to identify potential redox variations in the sediments. The sediment from Tasman Sea was not plotted on the 4D diagrams due to its distance from the Campbell Plateau slope samples, however the XRF results and the ratios for this sediment are presented in Table 3.4. The sample from U1406B did not have enough material for XRF analysis.

$\mathrm{SiO}_{2} / \mathrm{TiO}_{2}$ (Figure 3.9) is a proxy for biogenic silica. U203 in the Tasman Sea (Table 3.4) has a lower $\mathrm{SiO}_{2} / \mathrm{TiO}_{2}$ ratio than $\mathrm{U} 1413, \mathrm{U} 1402$, U1398, and $\mathrm{U} 1399$, and is more comparable to U1373, U1374, U1378, U1394, and U1391. $\mathrm{CaO} / \mathrm{Al}_{2} \mathrm{O}_{3}$ (a proxy for 
biogenic carbonate) is also much lower (0.04) than in all other sediments, and $\mathrm{TiO}_{2} / \mathrm{K}_{2} \mathrm{O}$ is comparable to the deeper locations from the Campbell Plateau slope. $\mathrm{MnO} / \mathrm{Al}_{2} \mathrm{O}_{3}$ is very low in this sample (0.02) (Table 3.4).

In the southern transect, $\mathrm{U} 1365 \mathrm{~B}$ has significantly higher $\mathrm{MnO} / \mathrm{Al} 2 \mathrm{O} 3$ and $\mathrm{MnO} / \mathrm{Fe} 2 \mathrm{O} 3$, and $\mathrm{U} 1362$ lower $\mathrm{MnO} / \mathrm{Al} 2 \mathrm{O} 3$ and $\mathrm{MnO} / \mathrm{Fe} 2 \mathrm{O} 3$ than the other sediments analysed (Table 3.4; Figure 3.10). The deepest samples from the northern transect (U1394 and U1391) have higher $\mathrm{SiO} 2 / \mathrm{TiO} 2$ than the shallower samples. As with the southern transect, $\mathrm{CaO} / \mathrm{Al} 2 \mathrm{O} 3$ decreases with increasing depth (Table 3.4; Figure 3.9). Sediments from the northern transect have generally lower $\mathrm{MnO} / \mathrm{Fe} 2 \mathrm{O} 3$ and $\mathrm{Fe} 2 \mathrm{O} 3 / \mathrm{TiO} 2$ than those from the southern transect. 


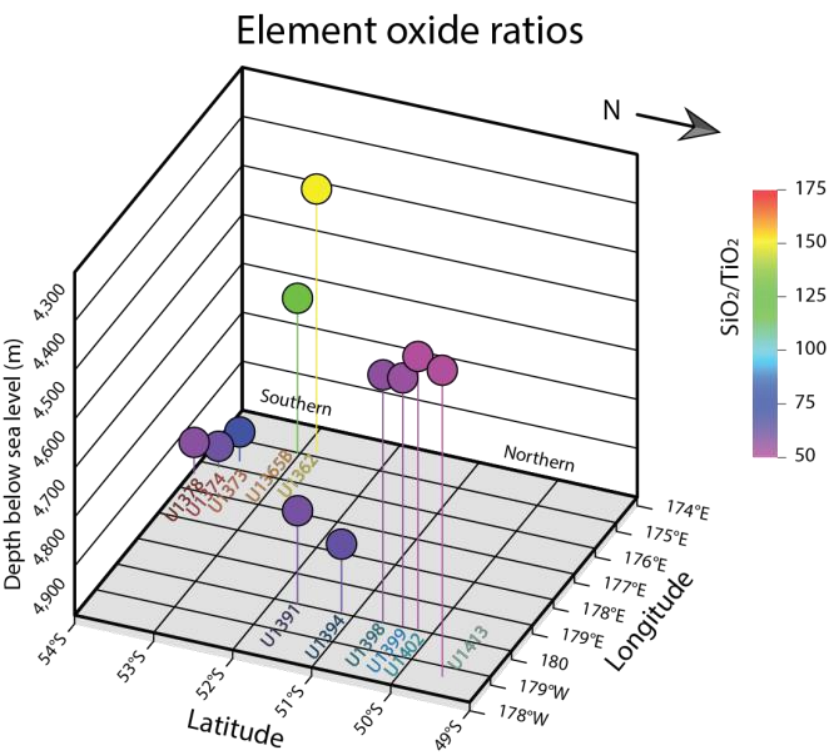

[a]

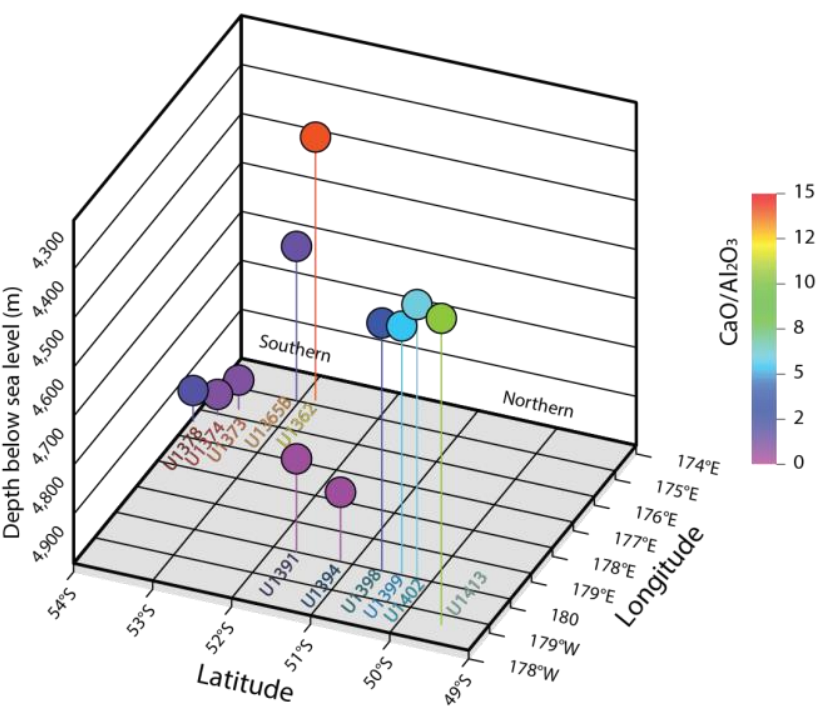

[b]

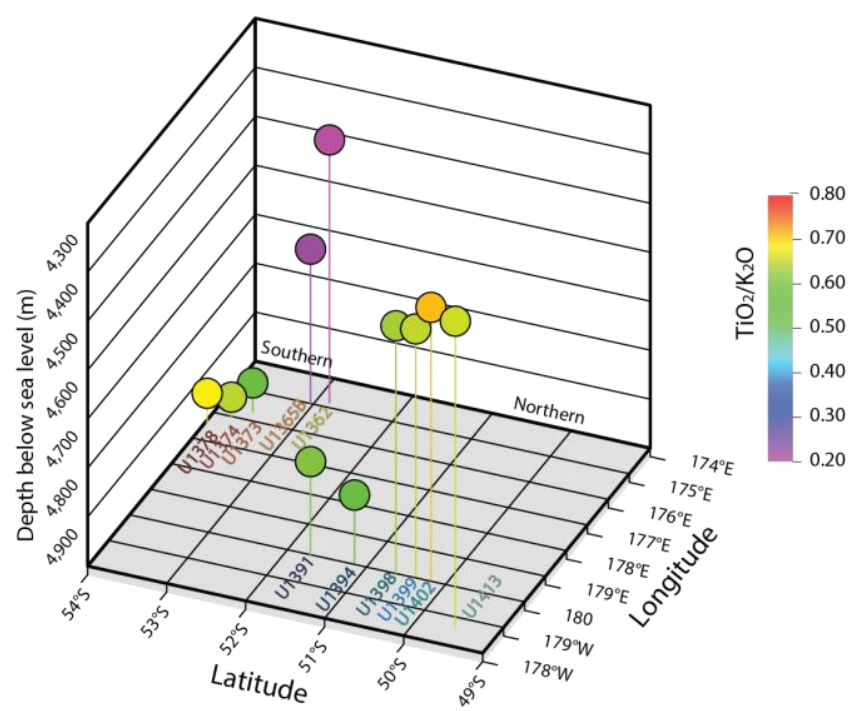

Figure 3.9: Major oxide ratios on Campbell Slope to identify source variations. The map displays a 4D picture of the latitude, longitude and depth, and elemental ratios differing in colour relative to their value. The northern transect is in the forefront, the southern transect is in the back. a. - the $\mathrm{SiO}_{2} / \mathrm{TiO}_{2}$ ratio; a proxy for biogenic silica. $\mathrm{b}$. $-\mathrm{the} \mathrm{CaO} / \mathrm{Al}_{2} \mathrm{O}_{3}$ ratio; a proxy for biogenic carbonate. c. - the $\mathrm{TiO}_{2} / \mathrm{K}_{2} \mathrm{O}$ ratio; a proxy for variations in sediment source (Rothwell and Croudace, 2015). 


\section{Element oxide ratios}

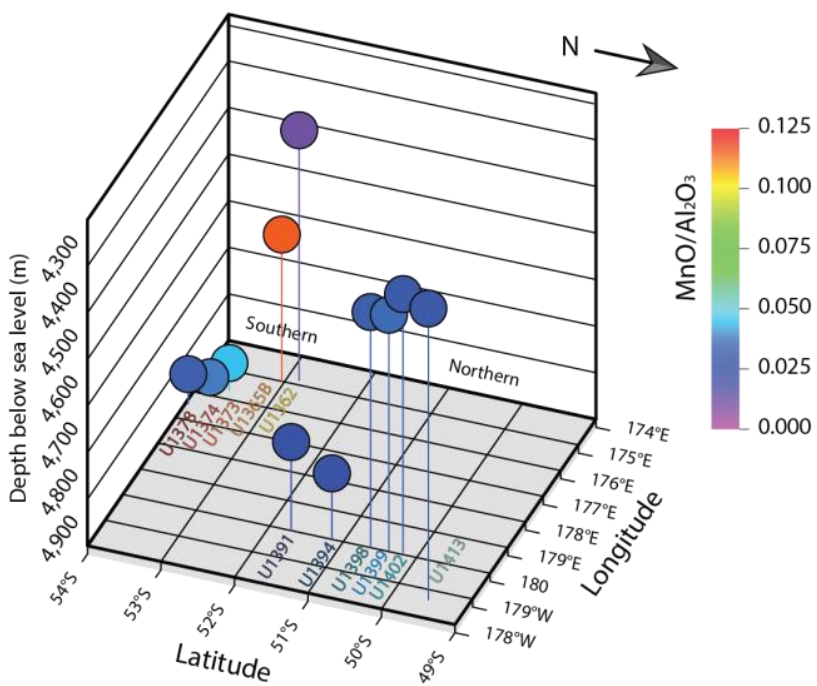

[a]

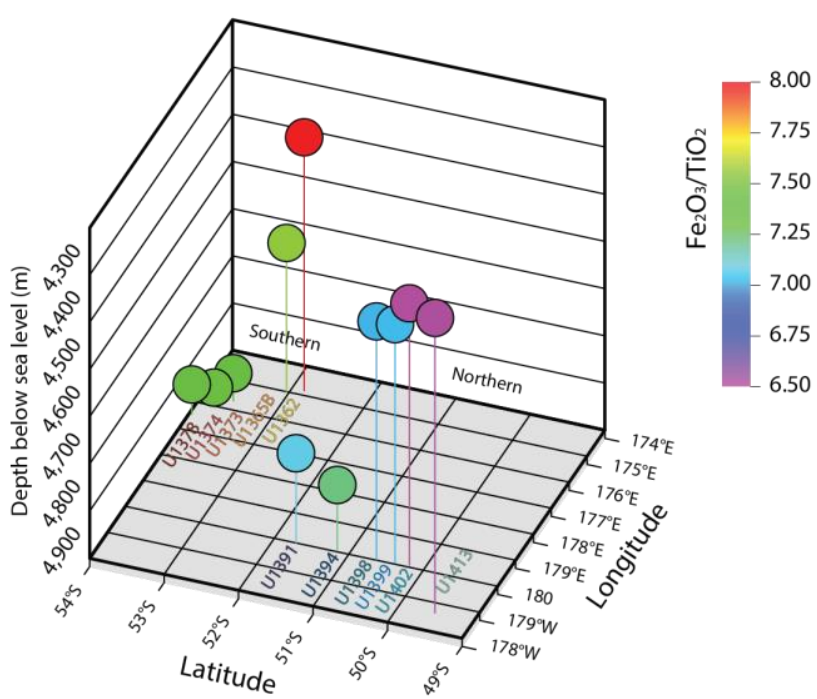

[b]

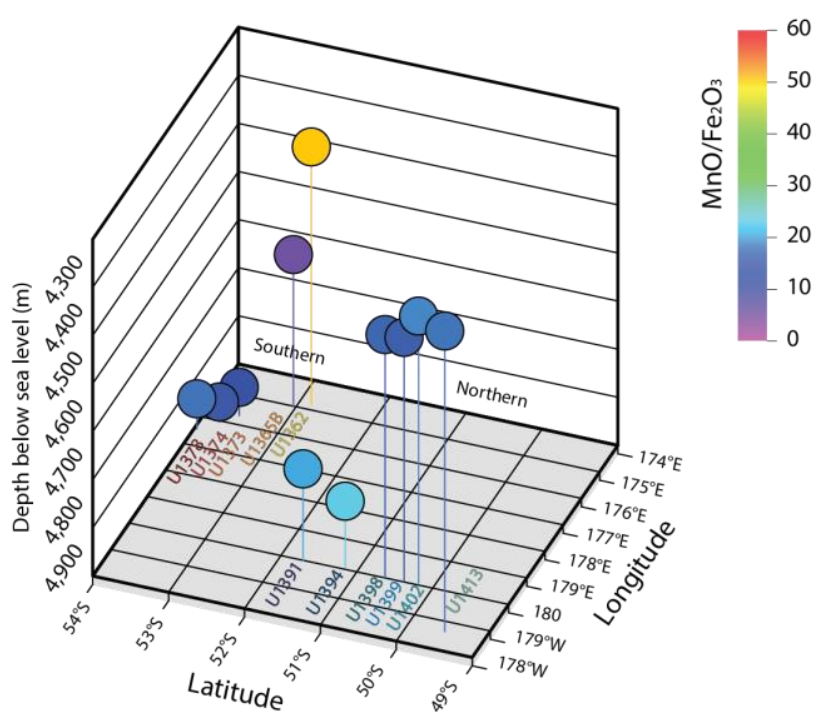

Figure 3.10: Major element oxide ratios for Campbell Slope sediments to identify potential redox variations in the sediment. The map displays a 4D picture of the latitude, longitude and depth, and elemental ratios differing in colour relative to their value. The northern transect is in the forefront, the southern transect is in the back. a. - the $\mathrm{MnO} / \mathrm{Al}_{2} \mathrm{O}_{3}$ ratio; a proxy for periodic oxygenation. $\mathrm{b}$. - the $\mathrm{Fe}_{2} \mathrm{O}_{3} / \mathrm{TiO}_{2}$ ratio; a proxy for the diagenetic remobilisation of $\mathrm{Fe}$. c. - the $\mathrm{MnO} / \mathrm{Fe}_{2} \mathrm{O}_{3}$ ratio; a proxy for discriminating oxic and suboxic conditions (Rothwell and Croudace, 2015). 
Table 3.4: Element oxide ratios.

\begin{tabular}{|c|c|c|c|c|c|c|}
\hline \multirow[b]{2}{*}{ Location } & \multicolumn{6}{|c|}{ Element oxide ratios } \\
\hline & $\mathrm{SiO}_{2} / \mathrm{TiO}_{2}$ & $\mathrm{CaO} / \mathrm{Al}_{2} \mathrm{O}_{3}$ & $\mathrm{TiO}_{2} / \mathrm{K}_{2} \mathrm{O}$ & $\mathrm{MnO} / \mathrm{Al}_{2} \mathrm{O}_{3}$ & $\mathrm{Fe}_{2} \mathrm{O}_{3} / \mathrm{TiO}_{2}$ & $\mathrm{MnO} / \mathrm{Fe}_{2} \mathrm{O}_{3}$ \\
\hline $\mathbf{U} 203$ & 57.41 & 0.04 & 0.40 & 0.020 & 7.65 & 0.05 \\
\hline U1413 & 51.18 & 10.44 & 0.66 & 0.031 & 6.52 & 0.06 \\
\hline $\mathrm{U} 1402$ & 50.86 & 6.02 & 0.71 & 0.031 & 6.51 & 0.05 \\
\hline U1399 & 54.98 & 5.39 & 0.65 & 0.036 & 7.02 & 0.06 \\
\hline U1398 & 56.40 & 3.60 & 0.63 & 0.033 & 7.02 & 0.06 \\
\hline U1394 & 63.29 & 0.45 & 0.54 & 0.023 & 7.22 & 0.04 \\
\hline U1391 & 60.46 & 0.45 & 0.61 & 0.026 & 7.08 & 0.05 \\
\hline $\mathrm{U} 1362$ & 150.63 & 14.04 & 0.20 & 0.012 & 8.00 & 0.02 \\
\hline U1365B & 116.24 & 1.54 & 0.22 & 0.116 & 7.55 & 0.18 \\
\hline U1373 & 70.23 & 1.05 & 0.53 & 0.044 & 7.41 & 0.08 \\
\hline U1374 & 61.94 & 1.07 & 0.65 & 0.038 & 7.33 & 0.07 \\
\hline U1378 & 57.58 & 2.01 & 0.69 & 0.033 & 7.42 & 0.06 \\
\hline
\end{tabular}




\subsection{Discussion}

\subsubsection{Sediment sources}

\section{Tasman Sea}

Sediment sample U203 from the Tasman Sea has a finer grain size than the other sediments analysed, indicating a low energy environment consistent with that discussed in Chapter 2. The discrimination diagram in Figure 3.8 suggests the detrital source is oceanic crustal material, and is similar in composition to the deeper sediment samples from the southern and northern transect, indicating that the detrital fraction was most likely transported by water currents, as an aeolian source would display a continental signature. The low calcium carbonate content (Table 3.1) and $\mathrm{SiO}_{2} / \mathrm{TiO}_{2}$ (Table 3.4, Figure 3.9) comparable to the deeper Campbell Plateau slope locations are indicative of low biogenic carbonate source (as it is below the CCD) and moderate biogenic silica relative to other locations.

\section{Campbell nodule field}

The sand contents of sediments in the southern transect in the Campbell Plateau slope indicates a highly erosive environment close to the Subantarctic Slope, and while the sediments further afield (U1373, U1374, and U1378) are finer grained, they are coarser than expected in a deep marine environment (c.f. the sediment from U203 in the Tasman Sea) (Figure 3.7). This indicates an environment with strong currents, consistent with interpretations discussed in the oceanography chapter, with the source for this detrital matter likely from erosion and scouring by the strong currents along the Subantarctic Slope of the Campbell Plateau (Beggs et al., 1990). The coarse grained material in U1362 and U1365B is identified to be sourced from continental-derived material (Figure 3.8) and is likely a "current moat" from erosion of the DWBC along the slope (Carter and McCave, 1997; Carter and Wilkin, 1999). Since there is no local continental source the local variation represent winnowing as opposed to terrestrial input. The deeper sediments (U1373, U1374, and U1378) indicate an oceanic arc source, and may have been transported from a volcanic source such as erosion of the Macquarie Ridge by the ACC and DWBC (Carter and McCave, 1997). The biogenic component of the sediments indicates an input from biogenic silica in U1373 and U1374, and less in U1378. The calcium carbonate content in U1378 is anomalously high for the depth $(4,915 \mathrm{mbsl}$, with the CCD at 4,600 m (Bostock et al., 2011). These biogenic clasts may have settled from 
the overlying ocean or been transported by ocean currents (Northcote and Neil, 2005; Stickley et al., 2013).

The northern transect displays a similar erosional trend in locations near to slope as observed in the southern transect, and the broad sediment characteristics of this transect are interpreted to result from the same erosional processes. The U1406B sediment exhibits the same grainsize patterns as U1362 and U1365B, indicative of erosion (Figure 3.7). The terrigenous component in the U1406B sediment may be interpreted to be sourced from similar mechanisms. The sediments further from the slope (U1402, U1399, U1398, U1391, and U1394) are similarly interpreted to have comparable sources to the deeper locations in the southern transect (i.e. the volcanic Macquarie Ridge). The terrigenous component of U1413 (e.g. the presence of olivine minerals) is not comparable to $\mathrm{U} 1406 \mathrm{~B}$ (the closest location in proximity), is likely due to erosion of the nearby Antipodes Island, which is volcanic in composition. There is less biogenic silica in sediment from this transect as compared to the southern transect, as indicated by the biogenic silica proxy, and qualitative analysis of the sand fraction (Figure 3.9, Table 3.2).

\subsubsection{Pore-water}

Based on the grainsize and sorting of the sediments it is possible to estimate the potential porosity and permeability of the sediments, which will affect diagenetic processes that may influence ferromanganese nodule growth. Coarse, well sorted sediments are more porous than fine grained, poorly sorted sediments.

The sediment analysed from the Tasman Sea is poorly sorted with the highest clay and silt fractions, and the lowest sand content measured in this study, (Table 3.1). This indicates that it may have a low porosity below the surficial sediment, and high porosity at the surface due to the surface repulsion of clays (Burdige, 2006).

High sand contents in the sediments closest to the slope in the Campbell nodule field (U1362, U1365B and U1406B) suggest high porosity in the sediment. Grainsize data in locations further afield from the slope in the southern transect (U1373, U1374, and U1378) and northern transect (U1402, U1399, U1398, U1391, and U1394) indicate potentially lower porosity than those near the slope, but higher than U203 in the Tasman Sea.

The sediment from $\mathrm{U} 1362$ has a low $\mathrm{MnO} / \mathrm{Fe}_{2} \mathrm{O}_{3}$ ratio and $\mathrm{U} 1365 \mathrm{~B}$ has a high $\mathrm{MnO} / \mathrm{Fe}_{2} \mathrm{O}_{3}$ ratio (Figure 3.10). The remaining sediments analysed display similar 
$\mathrm{MnO} / \mathrm{Fe}_{2} \mathrm{O}_{3}$ ratios, with a slight decrease $(0.05-0.06)$ in the northern transect compared to the southern transect (0.06-0.08) (Figure 3.10, Table 3.4). This suggest the sediment locations, excluding U1362, have an oxic sediment column, with the sediment from $\mathrm{U} 1365 \mathrm{~B}$ being the most oxygen-rich. This is further supported by the high $\mathrm{Fe}_{2} \mathrm{O}_{3} / \mathrm{TiO}_{2}$ ratio of $\mathrm{U} 1362$, compatible with diagenetic $\mathrm{Fe}^{2+}$ remobilisation in a shallow suboxic sedimentary column, with (Rothwell and Croudace, 2015). The assumption that high $\mathrm{Fe}_{2} \mathrm{O}_{3} / \mathrm{TiO}_{2}$ is due to iron reduction indicates that sediments from U1402 and U1413 have deeper oxic zones in the sedimentary column, however this is not seen in the $\mathrm{MnO} / \mathrm{Fe}_{2} \mathrm{O}_{3}$ ratio of these sediments.

Micronodules in a sediment column form after $\mathrm{Mn}^{2+}$ ions migrate upwards and oxidise in the oxic zone and may be recycled in the sedimentary column (Stoffers et al., 1984; Glasby, 2006). The presence of micronodules in the sediments from U1373, U1374, U1378, U1398, and U1394 (Table 3.2, Table 3.3) may indicate a suboxic-oxic zone boundary within the surficial sedimentary column that was obtained in the dredge sampling. This assumption however, is not corroborated by high $\mathrm{MnO} / \mathrm{Fe}_{2} \mathrm{O}_{3}$ and $\mathrm{Fe}_{2} \mathrm{O}_{3} / \mathrm{TiO}_{2}$ in these sediments, but could explain the low $\mathrm{Fe}_{2} \mathrm{O}_{3} / \mathrm{TiO}_{2}$ ratio for sediments from U1402 and U1413 and the lower amount of micronodules observed in those sediments (Table 3.2).

Carter and McCave (1997) noted that ferromanganese nodules from U1413 near Bollons Gap, where the DWBC diverts to the east, had a muddy coating, indicating only periodic erosion, needed to ensure the nodules are maintained at the surface.

\subsubsection{Influence on nodule formation}

The redox conditions in the sedimentary column will affect the precipitation of Fe and Mn (oxyhydr)oxide minerals onto a ferromanganese surface from the pore-water. A large oxic zone could lead to recycling of Mn below the surficial sediments, causing a reduced $\mathrm{Mn}^{2+}$ flux, and little contribution of Mn to nodule formation through diagenetic processes. A shallow oxic layer could lead to $\mathrm{Mn}^{2+}$ ions escaping the sedimentary column into the overlying waters prior to precipitation. Micronodules may then indicate the oxic-suboxic boundary in a sedimentary column.

The porosity and permeability of the sediments is difficult to interpret, however well sorted, sand-sized clasts are considered to have greater porosity. A sediment with greater porosity and permeability would allow a greater migration of $\mathrm{Mn}^{2+}$ ions, and thus 
potentially a larger diagenetic contribution to nodule growth. This suggests that nodules in a muddy substrate (e.g. U203) will have less influence from diagenetic processes.

Continual erosion effects the redox profile of a sedimentary column, and means that a diagenetic profile within the sediment can not be established and maintained (Aller, 1990). Intermittent eddies would also disturb the sedimentary column and interrupt the redox profile. This would have the effect of inputting oxygen and mixing Fe and $\mathrm{Mn}$ oxides, which could promote authigenic nodule formation (Jung and Lee, 1999). The chemistry of nodules from an erosional environment such as U1406B may therefore be expected to exhibit some differences in composition compared to nodules located in a calmer environment.

\subsection{Conclusions}

The sediment from the Tasman Sea exhibits physical and chemical characteristics consistent with a quiescent environment, whereas the Campbell Slope sediments are consistent with a dynamic environment related to the proximity to the slope and the DWBC. Locations close to the slope display particle distributions consistent with erosion, which may influence diagenetic processes in the sedimentary column by inputting oxic water into reducing conditions. This process would release a flux of $\mathrm{Mn}^{2+}$ ions into seawater which may sorb to ferromanganese (oxyhydr)oxide surfaces, thus promoting ferromanganese nodule formation. This may be an intermittent event caused by periodic eddy activity.

The sediments were found to have varying terrigenous and biogenic components that are predicted to affect nodule composition. Sediments close to the slope (U1362, U1365B, and U1406B) have higher contents of detrital grains consistent with a continental source (i.e. quartz, alkali feldspar), whereas the locations further from slope have greater contributions of oceanic volcanic mineralogy. Biogenic carbonate decreases with depth, whereas biogenic silica tended to increase with depth, with sediments from the southern Campbell Slope exhibiting higher biogenic silica than the northern transect. Biogenic silica is associated with pore-water enrichment of trace elements such as $\mathrm{Cu}$ and $\mathrm{Ni}$, whereas terrigenous clasts (locations close to the Campbell Slope) and biogenic carbonate (northern transect) are associated with reduced trace elements in pore-waters. 


\section{Chapter 4 Ferromanganese nodules}

\subsection{Introduction}

This chapter first presents an introduction to the geochemistry of deep ocean marine ferromanganese nodules, and then presents and discusses the geochemical data obtained in this study for the ferromanganese nodules collected from the deep ocean around New Zealand.

\subsubsection{Formation conditions}

Ferromanganese nodules form only in specific environments. The settings in which they grow are related to the sedimentary regime of the ocean basin, the regional oceanography (Glasby, 1976), and depth ( ISA, 2010; Hein et al., 2013).

Ferromanganese nodules form by the precipitation of $\mathrm{Fe}$ and $\mathrm{Mn}$ (oxyhydr)oxides onto surfaces that act as nuclei, located on sediments in an oxygen rich environment (Koschinsky and Halbach, 1995). Nodules need to remain in close proximity to the seafloor-ocean interface to continuously grow (Kerr, 1984). As ferromanganese nodules form slowly over millions of years (Manheim, 1986; Puteanus and Halbach, 1988), i.e. 1-5 mm/m.yr. for hydrogenetic precipitation (Koschinsky and Hein, 2003), and $250 \mathrm{~mm} / \mathrm{m}$.yr. for diagenetic precipitation (von Stackelberg, 2000), there must be minimal sediment accumulation so the nodules stay near the seafloor surface and are not buried (Kennett and Watkins, 1975). Thus, ferromanganese nodules form in areas where they are maintained at the sediment surface by fast currents that lead to minimal sediment deposition (Kennett and Watkins, 1975) and/or benthic organisms disturbing the sediment surrounding the nodules (von Stackelberg, 1987).

Ferromanganese nodules require initial nucleation sources for the $\mathrm{Mn}$ oxide and $\mathrm{Fe}$ oxyhydroxide minerals to adsorb to (Koschinsky and Halbach, 1995). Examples of common nucleation sources are; rock fragments, ice-rafted debris, sharks teeth, or fragments of other nodules (Hein et al., 2000). 
The productivity of the overlying waters affects the chemistry of the nodules, and low productivity regions are associated with lower contents of $\mathrm{Ni}$ and $\mathrm{Cu}$ and higher amounts of Fe and Co (Verlaan et al., 2004). Moderately productive regions are associated with greater concentrations of $\mathrm{Mn}, \mathrm{Ni}$ and $\mathrm{Cu}$ (ISA, 2010). In waters with very high productivity levels, there tend to be fewer nodules due to more biogenic sediments deposited and a deeper CCD (Glasby, 1976).

Ferromanganese nodules can exist in both shallow and deep water environments (Calvert and Price, 1977; Hein et al., 2013), however in this study only deep-sea nodules are considered. Deep-sea ferromanganese nodules form at abyssal depths, which typically range from $~ 3500-5500$ mbsl (Hein et al., 2013). At this depth range, the position of the lysocline and CCD can affect the trace metal composition of nodules. This is related to the dissolution of the organic-rich material within the carbonate and the associated trace metals re-entering the water column (Verlaan et al., 2004; Hein and Koschinsky, 2014).

\subsubsection{Genetic types}

Three types of ferromanganese nodules are recognised; hydrogenetic, diagenetic, and hydrothermal (Halbach et al., 1981; Hein et al., 2008) (Figure 4.1). The chemical composition of each type (e.g. $\mathrm{Mn} / \mathrm{Fe})$ is indicative of their formation. Ferromanganese nodules are typically a mixture of these end-member types, however end-members of each nodule type have been reported.

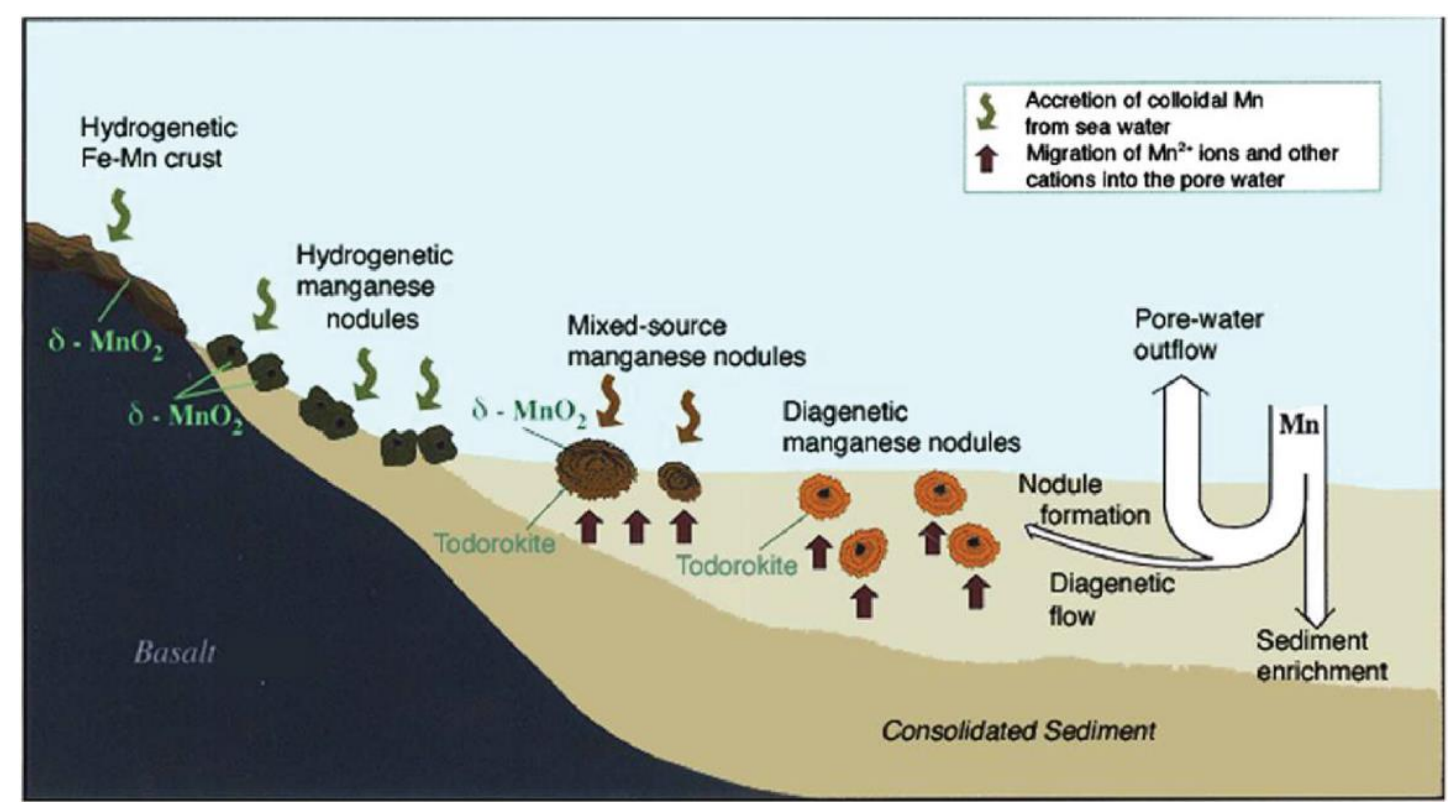

Figure 4.1: Ferromanganese nodule types and the sedimentary environment in which they form. Figure from Hein et al. (2013). 
Hydrogenetic nodules form when Mn oxide and Fe oxyhydroxide colloids in seawater precipitate onto a hard substrate (Burns and Burns, 1975). Trace metal species are adsorbed onto the ferromanganese (oxyhyr)oxide surface directly from seawater. Precipitation of these metal (oxyhydr)oxides is slow (e.g. it would take $\sim 1,000$ years to oxidise $90 \%$ of the $\mathrm{Mn}^{2+}$ ions currently in the ocean (Murray and Brewer, 1977) and is likely catalysed by bacterial activity (Tebo et al., 2004, 2005; Blöthe et al., 2015). Ferromanganese crusts form the hydrogenetic compositional end-member due to the hard substrate on which they form allowing no contribution from diagenetic processes (Hein and Koschinsky, 2014). By contrast, Aplin and Cronan (1985) consider that no ferromanganese nodule can be entirely free of a diagenetic influence. The seafloor substrate that the nodule resides in during growth likely has an influence on the relative role of hydrogenetic versus diagenetic processes. Glasby (2006) suggested that $\mathrm{Mn}^{2+}$ is immobilised in red clays, thus the greater the (red) clay fraction of the substrate, the larger the hydrogenetic component of the nodules. Hydrogenetic nodules typically have $\mathrm{Mn} / \mathrm{Fe}$ ratios of $\sim 1$ (Glasby, 2006).

Diagenetic nodules adsorb trace metals from the pore-water in the underlying sediment (Halbach et al., 1981) and grow faster than hydrogenetic nodules (up to $250 \mathrm{~mm} / \mathrm{Ma}$ ) (von Stackelberg, 2000). The type of diagenesis depends on the oxygen content of the sediment. Oxic diagenesis occurs when biogenic matter is degraded in oxic conditions, leading to enrichment in trace metals in the pore-water (Glasby, 2006), which may then adsorb onto the ferromanganese nodule surface. Oxic diagenesis displays similar elemental enrichment to hydrogenetic nodules as the same trace element adsorption mechanisms occur (Wegorzewski and Kuhn, 2014). Oxic diagenetic nodules have Mn/Fe ratios of $~ 2.5-5$ (Halbach et al., 1981).

Suboxic diagenetic processes occur deeper in the sedimentary column (discussed previously in Chapter 3). Reduced metals in the sediment pore-water migrate by upward diffusion processes and are incorporated onto the iron manganese (oxyhydr)oxide surface (Calvert and Price, 1977). The greater the sediment porosity the more effective the porewater migration process is (Chapter 3). In the anoxic/suboxic environment the iron species preferentially reacts with reduced $\mathrm{H}_{2} \mathrm{~S}$ species to form iron (II) sulphide rather than iron manganese (oxyhydr)oxide. For this reason, suboxic diagenetic ferromanganese nodules have larger $(\geq 5) \mathrm{Mn} / \mathrm{Fe}$ ratios compared to both hydrogenetic and oxic diagenetic nodules (Halbach et al., 1981). 
Hydrothermal nodules form from direct precipitation of trace metal species from hydrothermal fluids mixing with oxic seawater (Hein and Koschinsky, 2014). This process occurs at locations such as mid-ocean ridges, back-arc basins, and hot spot volcanic areas. Hydrothermal nodules are fast growing (> 1,000 mm/Ma) and typically have low concentrations of trace elements (Glasby, 2006). This formation type has not been reported in New Zealand waters. Hydrothermal nodules have variable $\mathrm{Mn} / \mathrm{Fe}$ but are characterised by low metal $(\mathrm{Cu}, \mathrm{Ni}$, and $\mathrm{Co})$ contents.

\subsubsection{Mineralogy}

Three main mineral components have been identified in ferromanganese nodules; authigenic Mn oxides, authigenic Fe oxyhydroxides, and an alumino-silicate component (Margolis and Burns, 1976). In typical seawater conditions (Eh of 0.4-0.5 V, and pH 8), $\mathrm{Mn}^{2+}$ ions oxidise to $\mathrm{Mn}^{4+} \mathrm{O}_{2}$ and $\mathrm{Fe}^{2+}$ ions oxidise to $\mathrm{Fe}^{3+} \mathrm{OOH}$. Both of the resultant species are insoluble colloids (Glasby and Schulz, 1999; Kuhn et al., 2017), that precipitate onto a nucleus to form ferromanganese nodules (Hein et al., 2013) (Figure 4.3). The alumino-silicate component of ferromanganese nodules comprises detrital mineral grains that were incorporated during growth and potentially authigenic minerals such as clays or zeolites (Piper, 1974; Margolis and Burns, 1976).

\subsubsection{Manganese oxide mineralogy}

Precipitation of $\mathrm{Mn}$ is more likely to occur if there is already an existing $\mathrm{Mn}$ oxide (or $\mathrm{Fe}$ oxyhydroxide) surface (Burns and Burns, 1975) (Equation 4.1). Precipitation of Mn is thermodynamically favoured, but kinetically inhibited (Maynard, 2014), meaning that kinetics are the rate controlling step, and that although the reaction can occur spontaneously, oxidation of $\mathrm{Mn}^{2+}$ is slow (Murray and Brewer, 1977). Bacterial mediation is considered to be a catalyst that increases the oxidation rate of $\mathrm{Mn}$ (Blöthe et al., 2015; Tebo et al., 2004, 2005).

$$
\frac{-d\left[\mathrm{Mn}^{2+}\right]}{d t}=k_{0}\left[\mathrm{Mn}^{2+}\right]+k^{\prime}\left[\mathrm{Mn}^{2+}\right]\left[\mathrm{MnO}_{2}\right]
$$

Equation 4.1: Rate law for the oxidation of $\mathrm{Mn}^{2+}$, where $k^{\prime}=\left[\mathrm{P}_{\mathrm{O}_{2}}\right]\left[\mathrm{OH}^{-}\right]^{2}$ (Morgan and Stumm, 1965). This reaction is a second order reaction respective of $\mathrm{OH}^{-}$concentration, and first order respective of the $\mathrm{P}_{02}$ and $\mathrm{Mn}^{2+}$ concentrations (Murray and Brewer, 1977). The oxidation of $\mathrm{Mn}^{2+}$ requires the ion to adsorb to the surface, then an oxidation step (Maynard, 2014). This reaction is autocatalytic, whereby the oxidation of $\mathrm{Mn}^{2+}$ is favoured if there is already a $\mathrm{MnO}_{2}$ surface present. Fe oxides and oxyhydroxides may substitute for the $\mathrm{MnO}_{2}$ surface.

The mineralogy of the Mn oxides is difficult to determine due to poor crystallinity, fine grain size, the tendency for intimate intergrowths with other minerals (e.g. Fe 
oxyhydroxides), and its propensity to irreversibly alter during sample handling (Post, 1999). It has been determined that $\mathrm{Mn}$ oxide minerals consist of $\mathrm{MnO}_{6}{ }^{8-}$ octahedral subunits arranged in layer or tunnel structures (Burns and Burns, 1975), known as phyllomanganates and tectomanganates, respectively (Figure 4.2).

Phyllomanganates are sheet like structures composed of $\mathrm{MnO}_{6}{ }^{8-}$ octahedra that are separated from each other by hydrated cations (Figure 4.2) (Burns and Burns, 1975). Birnessite-buserite is an example of a phyllomanganate with an ordered structure and vernadite is an example of a phyllomanganate with a disordered structure (Manceau et al., 2012).

Birnessite phyllomaganates have a $\sim 7$ distance between the layers, with one water layer plane between these layers (Post, 1999). Buserite phyllomaganates have layers that are separated by a $\sim 10 \AA$ distance with two planes of water (Post, 1999). Vernadite (also known as $\delta-\mathrm{MnO}_{2}$ ) is a disordered phyllomanganate, and also has types with both $\sim 7 \AA$ and $\sim 10 \AA$ distance between the layers. Within the lattice $\mathrm{Mn}^{4+}$ may be substituted by cations such as $\mathrm{Mn}^{3+}, \mathrm{Ni}^{2+}, \mathrm{Cu}^{2+}$, or $\mathrm{Co}^{2+}$, or leave vacancies within the lattice. This causes ion charge deficits which are reduced (stabilised) by incorporating hydrated cations (such as $\left.\mathrm{Na}^{+}, \mathrm{Li}^{+}, \mathrm{Ca}^{2+}\right)$ into the interlayer, and adjacent to vacancies $\left(\mathrm{Mn}^{2+}, \mathrm{Mn}^{3+}, \mathrm{Ni}^{2+}, \mathrm{Cu}^{2+}\right.$, $\mathrm{Zn}^{2+}, \mathrm{Cr}^{2+}$ ) (Manceau et al., 2014; Kuhn et al., 2017).

Vernadite is associated with hydrogenetic nodule accretion, and ordered phyllomanganates (e.g. birnessite and buserite) are associated with diagenetic nodule formation, due to the larger flux of $\mathrm{Mn}^{2+}$ ions in pore-water during diagenetic processes (Wegorzewski et al., 2015).

Tectomanganate minerals such as todorokite have 3D tunnel structures of triple chains of $\mathrm{MnO}_{6}{ }^{8-}$ (Post, 1999) (Figure 4.2). They have a negative charge due to $\mathrm{Mn}^{4+}$ being substituted by ions such as $\mathrm{Mn}^{3+}$ and $\mathrm{Ni}^{2+}$. The mineral structure is stabilised by the incorporation of cations into the tunnel structure.

Todorokite has traditionally been associated with diagenetic nodule formation, but studies link it to hydrothermal nodule formation (Bodeï et al., 2007). It is more crystalline and more stable, and therefore needs more energy and a larger flux of manganese such as from hydrothermal systems. Phyllomanganate minerals high in magnesium (4.1$4.9 \mathrm{wt} \%$ ) may also alter to todokorite (Post \& Bish, 1988; Bodeï et al., 2007) due to hydrated $\mathrm{Mg}^{2+}$ ions having a diameter close to that of the $3 \times 3 \mathrm{MnO}_{6}{ }^{8-}$ tunnel of 
todokorite, thus being a "favourable template ion" (Wegorzewski et al., 2015). The tunnel structure of todokorite reduces its capacity to sorb metals such as $\mathrm{Ni}(\leq 2 \mathrm{wt} \%)$ compared to phyllomanganates (5 wt\%) (Bodeï et al., 2007).

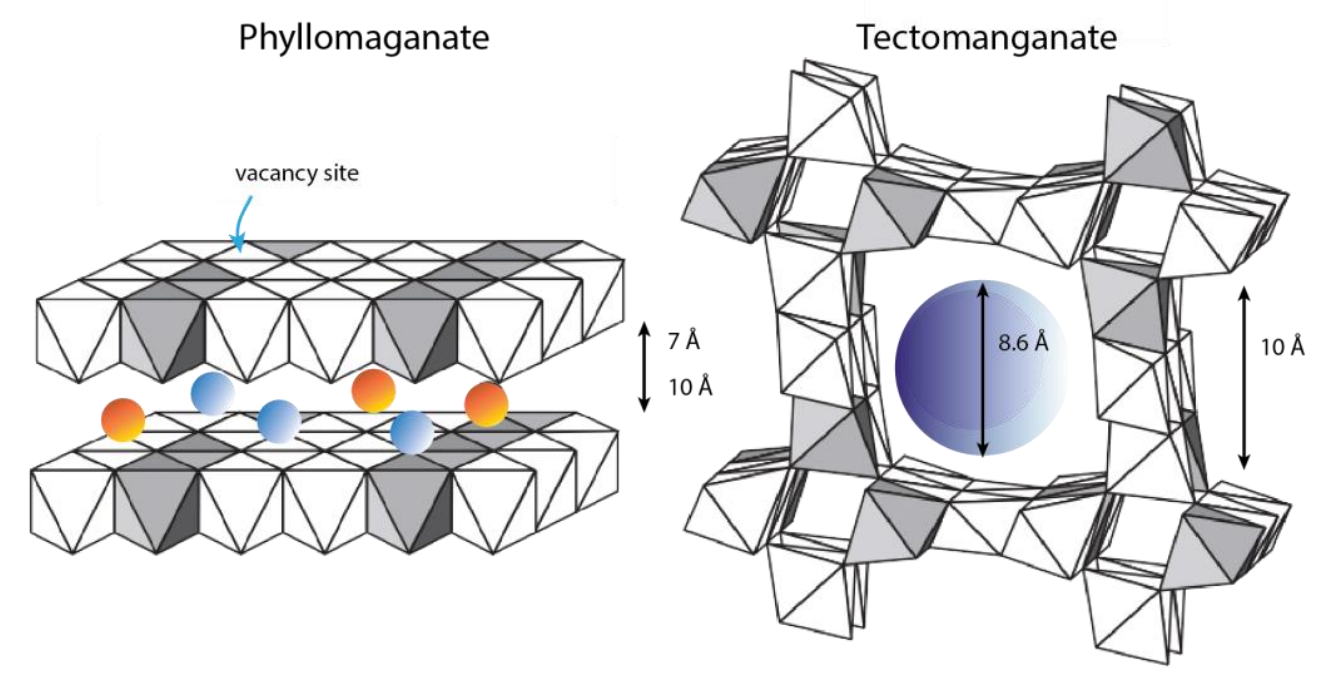

Figure 4.2: Polyhedral representations of phyllomanganate and tectomanganate mineral structures adapted from Manceau et al. (2012). Cations such as $\mathrm{Mn}^{3+}, \mathrm{Ni}^{2+}, \mathrm{Cu}^{2+}$, or $\mathrm{Co}^{2+}$ (indicated by the blue and orange coloured circles) may susbstitute into the crystal lattice of phyllomanganate to stabilise the structure. Hydrated $\mathrm{Mg}^{2+}$ ions may act as a template ion for the tunnel structure in todokorite (Wegorzewski et al., 2015).

\subsubsection{Iron oxyhydroxide mineralogy}

The precipitation of $\mathrm{Fe}$ occurs when the species is oxidised from $\mathrm{Fe}^{2+}$ to $\mathrm{Fe}^{3+}$ in a process shown by Equation 4.2 (below). Fe oxyhydroxides precipitate more readily than to manganese oxide minerals due to the oxidation involving only the solution species, in contrast to $\mathrm{Mn}$ oxide precipitation (Equation 4.1). For this reason $\mathrm{Fe}$ oxyhydroxide minerals are likely to be the initial species to precipitate, with Mn oxide minerals precipitating onto a pre-existing Fe oxyhyrdoxide surface (Burns and Burns, 1975).

$$
\frac{-d\left[\mathrm{Fe}^{2+}\right]}{d t}=k\left[\mathrm{Fe}^{2+}\right]\left[\mathrm{OH}^{-}\right]^{2}
$$

Equation 4.2: Rate law for the oxidation of $\mathrm{Fe}^{2+}$ (Stumm and Lee, 1961). This rate equation is first order with respect to $\mathrm{Fe}^{2+}$ concentration, and second order with respect to $\mathrm{OH}^{-}$ions (Murray and Brewer, 1977).

The Fe species precipitates as an amorphous Fe oxyhydroxide (Hein et al., 2000). Common $\mathrm{Fe}$ oxyhydroxide minerals associated with ferromanganese nodules are feroxyhyte, ferrihydrite, and goethite (Hein and Koschinsky, 2014). These fine grain Fe oxyhydroxides can form intimate intergrowths with Mn minerals such as vernadite (Burns and Burns, 1977; Manceau et al., 2014). 


\subsubsection{Detrital phase}

Fine grained detrital minerals may occur as inclusions within the nodules. These may be detrital minerals such as quartz and alkali feldspar, plagioclase and pyroxene, or authigenic minerals such as phillipsite, a zeolite mineral (Piper, 1974), and CFA. Elements typically associated with the alumino-silicate phases are $\mathrm{Al}, \mathrm{Si}, \mathrm{K}, \mathrm{Ti}, \mathrm{Cr}, \mathrm{Mg}$, Fe, Na, Sc, and Rb (Kuhn et al., 2017).

\subsubsection{Trace metal incorporation}

The trace element composition of ferromanganese nodule deposits is controlled by the ratio of hydrogenetic - oxic diagenetic - suboxic diagenetic incorporation (Dymond et al., 1984). The mineralogy of ferromanganese nodules facilitates their enrichment in trace metals. The adsorbents are dissolved trace elements in seawater or sediment pore-water. Attraction of a species to the ferromanganese nodule surface is correlated by the charge of the ion, its oxidation state, the physical properties of the element, and its concentration in the seawater or pore-water (Koschinsky and Halbach, 1995; Koschinsky and Hein, 2003).

Mn and Fe colloids in seawater are hydrolysed causing surface charges on the oxides (Figure 4.3) (Hein et al., 2013). A negatively charged Mn oxide surface attracts positively charged ions, and the slightly positively charged Fe oxyhydroxide surface attracts neutral and negatively charged ions (Figure 4.3). Both Mn oxide and Fe oxyhydroxide minerals have large surface areas and specific adsorption capacities (Glasby, 2006). The oxidation state of an element can affect the speciation and thus charge of a compound in seawater. Wegorzewski et al. (2015) reported that a higher flux of trace elements (e.g. $\mathrm{Cu}$ ) in seawater or pore-water has a greater effect than mineralogy on enriching ferromanganese nodules in the trace elements. This is exhibited by nodules from the CCZ and Peru basin containing disordered phyllomanganate mineralogy, but varying trace metal concentrations (Wegorzewski et al., 2015)

Nodule growth mechanisms effect trace metal incorporation in the ferromanganese deposits. Hydrogenetic nodules scavenge trace metals from the seawater by surface sorption mechanisms, whereas suboxic-diagenetic nodules structurally incorporate trace elements into the mineralogy (Hein and Koschinsky, 2014). 


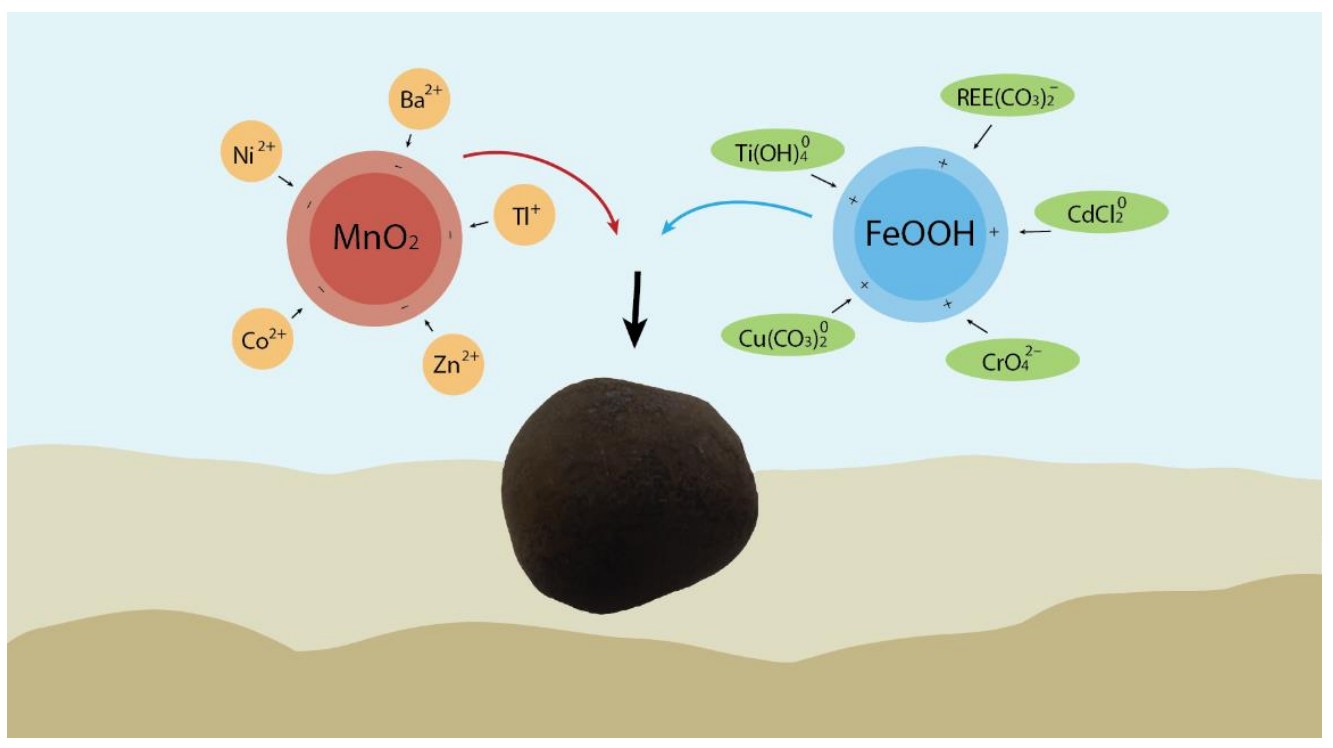

Figure: 4.3: Simplified electrochemical model showing adsorption of dissolved trace metal species onto oppositely charged Fe and Mn oxyhydr(oxide) colloids, and precipitation onto a ferromanganese nodule surface. Adapted from Hein et al. (2013).

The different mechanisms of nodule growth, mineralogy and trace metal incorporation result in distinctive trace metal characteristics that allow discrimination plots to evaluate the relative importance of hydrogenetic versus diagenetic versus hydrothermal growth. $\mathrm{Cu}$ and $\mathrm{Ni}$, which are trace metals of economic interest, are most commonly used together with $\mathrm{Mn} / \mathrm{Fe}$ values (Figure 4.4).

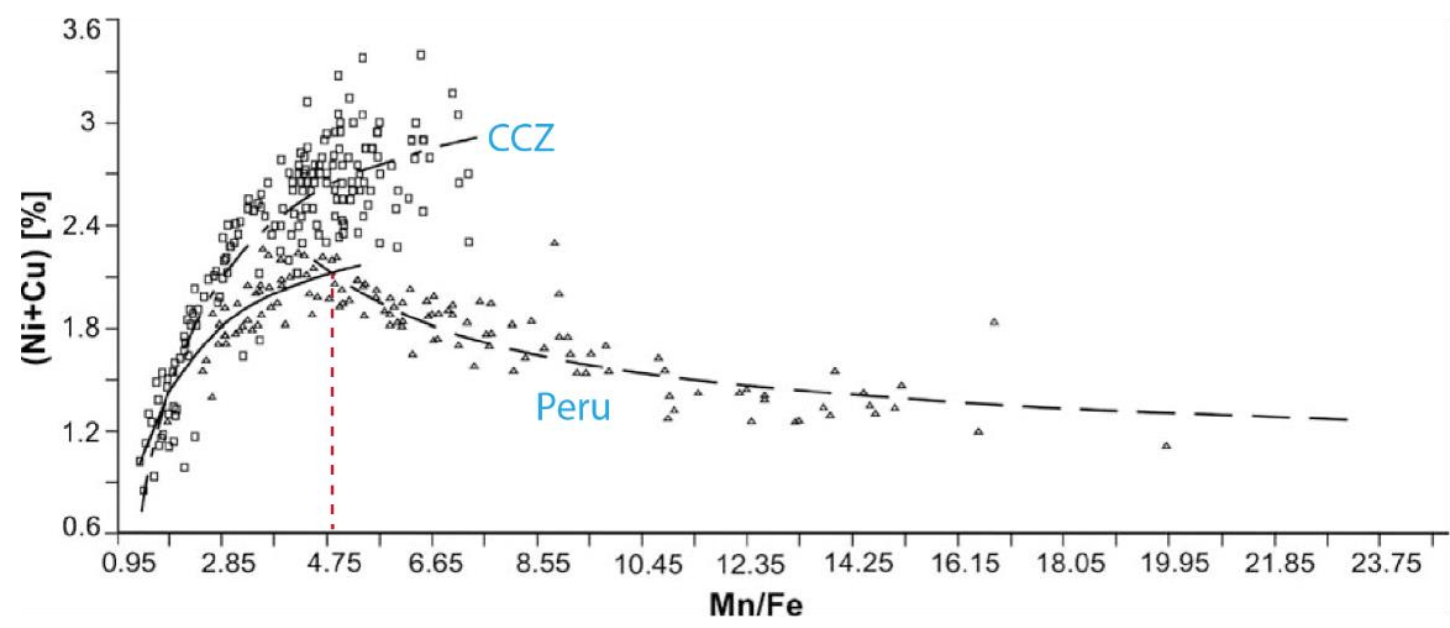

Figure 4.4: Hyperbolic regression curves for $\mathrm{Ni}+\mathrm{Cu}$ vs. $\mathrm{Mn} / \mathrm{Fe}$ for nodule samples from the Clarion Clipperton Zone (CCZ) (upper black dashed line) and Peru Basin (solid black line, and lower black dashed line). The red dashed line indicates the "point of reversal" at $\mathrm{Mn} / \mathrm{Fe} \sim 5$ indicative of suboxic diagenetic growth, and maximum $\mathrm{Cu}+\mathrm{Ni}$ contents. Adapted from Halbach et al. (1981).

\subsubsection{Hydrogenetic trace metal incorporation}

Hydrogenetic trace metal incorporation occurs by processes such as direct adsorption and surface oxidation (Koschinsky and Hein, 2003). Adsorption from seawater occurs by 
coloumbic attraction whereby ions are attracted to a mineral surface of opposing charge. This is a first order process where electrostatic and chemical bonds form (Hein et al., 2013). Surface oxidation is the process where elements with multiple oxidation states in seawater are adsorbed to the ferromanganese surface and oxidised to their insoluble form (Koschinsky and Hein, 2003).

The negative surface charge of manganese oxide attracts elements such as alkali and alkaline earth metals, which tend to be hydrated cations in seawater $\left(\mathrm{Li}^{+}, \mathrm{Na}^{+}, \mathrm{Mg}^{2+}, \mathrm{K}^{+}\right.$, $\left.\mathrm{Ca}^{2+}, \mathrm{Rb}^{+}, \mathrm{Sr}^{2+}, \mathrm{Ba}^{2+}\right)$, heavy metals, for which the major speciation in seawater is a hydrated cation $\left(\mathrm{Mn}^{2+}, \mathrm{Co}^{2+}, \mathrm{Ni}^{2+}, \mathrm{Zn}^{2+}, \mathrm{Tl}(\mathrm{I})\right)$, and the carbonate complex of $\mathrm{Y}$ (Koschinsky and Hein, 2003).

Iron oxyhydroxide minerals attract neutral to negatively charged species and form anionic bonds with slightly positively charged species, carbonate complexes ( $\mathrm{Pb}, \mathrm{Cu}, \mathrm{U}, \mathrm{REE})$, chloro complexes (Cd, Tl), hydroxide complexes (Sc, Ti, Fe, Zr, Hf, Bi, Th, Tl(III)), and oxyanions (V, Cr, As, Mo) (Koschinsky and Halbach, 1995; Koschinsky and Hein, 2003).

Redox sensitive elements may bind to both the manganese and iron phases depending on the oxidation state and the ionic charge of the species (Koschinsky and Hein, 2003). Positively charged cations (e.g. $\mathrm{Co}^{2+}, \mathrm{Ce}^{3+}$, and $\mathrm{Pb}^{2+}$ ) can be oxidised at the $\mathrm{MnO}_{2}$ surface after adsorption, and trace metals such as $\mathrm{V}, \mathrm{Cr}$, As, Mo may be oxidised at the $\mathrm{Fe}$ oxyhydroxide surface (Koschinsky and Hein, 2003). The elements $\mathrm{Cu}$ and $\mathrm{Tl}$ may adsorb to both $\mathrm{Fe}$ and $\mathrm{Mn}$ depending on their oxidation state in seawater. These oxidation processes only occur during hydrogenetic growth due to the oxic conditions required (Glasby, 1973; Glasby et al., 1987).

$\mathrm{REE}^{3+}$ cations tends to exist in seawater as carbonate complexes that are adsorbed and desorbed from ferromanganese surfaces. Cerium has multiple oxidation states in the marine environment, however, and its highest oxidised form is Ce(IV). Dissolved $\mathrm{Ce}^{3+}$ is oxidised to $\mathrm{CeO}_{2}$ on the ferromanganese surface (Elderfield et al., 1988) where it is able to accumulate as it is not desorbed due to the increase in oxidation state. This means that hydrogenetic nodules are enriched in Ce relative to the other REE (Hein and Koschinsky, 2014), whereas diagenetic nodules do not display this trend due to the lack of oxidants in suboxic pore-water. 


\subsubsection{Diagenetic trace metal incorporation}

Suboxic diagenetic ferromanganese mineral surfaces incorporate elements into their mineral structure to balance ion charge deficits (Manceau et al., 2014). These charge deficits may be initiated by incorporation of a $\mathrm{Mn}^{3+}$ ion into the crystal lattice instead of a $\mathrm{Mn}^{4+}$ cation, or by vacancy sites within the lattice. Diagenetic nodules thus tend to absorb elements based on their size and charge, such as $\mathrm{Li}, \mathrm{Ni}, \mathrm{Cu}, \mathrm{Zn}, \mathrm{Mo}$, and $\mathrm{Ga}$ (Kuhn et al., 2017) to stabilise the crystal lattice. Diagenetic nodules with a large suboxic influence (i.e. $\mathrm{Mn} / \mathrm{Fe}$ ratio > 5) have lower concentrations of $\mathrm{Cu}, \mathrm{Ni}, \mathrm{Zn}$ and $\mathrm{Li}$ due to more $\mathrm{Fe}^{2+}$ competing to balance charge deficits (Hein and Koschinsky, 2014). Overall, suboxic diagenetic nodules tend to be lower in trace elements due to their specific sorption processes.

\subsubsection{Hydrothermal trace metal incorporation}

Hydrothermal nodules have low trace element contents due to the rapid precipitation of Mn oxide minerals (> 1,000 mm/Ma), and trace metals associating with other hydrothermal metalliferous deposits such as sulphide deposits (Glasby, 2006). 


\subsection{Methods}

A total of 77 ferromanganese samples were obtained from the NIWA rock store and the outermost rim subsampled and processed to evaluate their geochemical characteristics. Samples were selected from several locations along the Campbell Slope within the DWBC (Chapter 2), form transects approximately perpendicular to the current at differing water depths (Figure 4.5). Samples from the Tasman Sea are located in the same water mass (Figure 2.1) (LCDW - Chapter 2), in a lower energy environment.

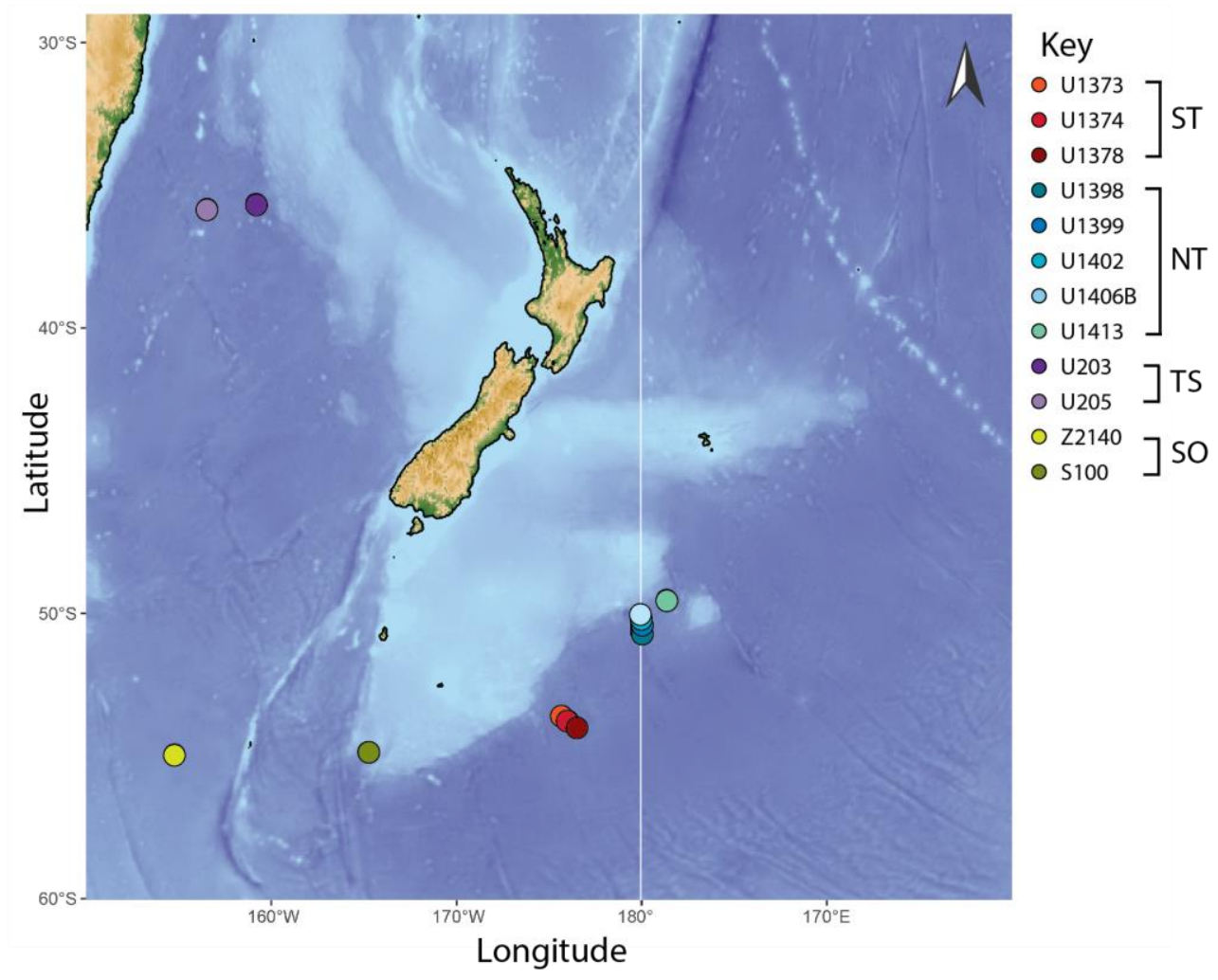

Figure 4.5: Locations where the ferromanganese nodules were sampled. 


\subsubsection{Sampling}

The 77 nodule specimens, (Table 4.1) were chosen based on their location, size, and the completeness of the outer rim.

Table 4.1: Sample counts for each location. Latitude/longitude and depth.

\begin{tabular}{c|c|c|c|c} 
Sample & Latitude & Longitude & Depth & Nodules \\
\hline \hline $\mathbf{U 2 0 3}$ & $35.632^{\circ} \mathrm{S}$ & $159.167^{\circ} \mathrm{E}$ & $4919 \mathrm{~m}$ & 4 \\
\hline $\mathbf{U 2 0 5}$ & $35.810^{\circ} \mathrm{S}$ & $156.530^{\circ} \mathrm{E}$ & $4714 \mathrm{~m}$ & 17 \\
\hline $\mathbf{U 1 4 1 3}$ & $49.519^{\circ} \mathrm{S}$ & $178.654^{\circ} \mathrm{W}$ & $4375 \mathrm{~m}$ & 2 \\
\hline $\mathbf{U 1 4 0 6 B}$ & $49.949^{\circ} \mathrm{S}$ & $179.923^{\circ} \mathrm{E}$ & $4475 \mathrm{~m}$ & 12 \\
\hline $\mathbf{U 1 4 0 2}$ & $50.202^{\circ} \mathrm{S}$ & $179.933^{\circ} \mathrm{E}$ & $4445 \mathrm{~m}$ & 6 \\
\hline $\mathbf{U 1 3 9 9}$ & $50.387^{\circ} \mathrm{S}$ & $179.962^{\circ} \mathrm{E}$ & $4494 \mathrm{~m}$ & 8 \\
\hline $\mathbf{U 1 3 9 8}$ & $50.625^{\circ} \mathrm{S}$ & $179.986^{\circ} \mathrm{E}$ & $4495 \mathrm{~m}$ & 7 \\
\hline $\mathbf{U 1 3 7 3}$ & $53.583^{\circ} \mathrm{S}$ & $175.695^{\circ} \mathrm{E}$ & $4941 \mathrm{~m}$ & 7 \\
\hline $\mathbf{U 1 3 7 4}$ & $53.759^{\circ} \mathrm{S}$ & $176.046^{\circ} \mathrm{E}$ & $4958 \mathrm{~m}$ & 5 \\
\hline $\mathbf{U 1 3 7 8}$ & $53.978^{\circ} \mathrm{S}$ & $176.450^{\circ} \mathrm{E}$ & $4915 \mathrm{~m}$ & 7 \\
\hline $\mathbf{S 1 0 0}$ & $54.857^{\circ} \mathrm{S}$ & $165.225^{\circ} \mathrm{E}$ & $2370 \mathrm{~m}$ & 1 \\
\hline $\mathbf{Z 2 1 4 0}$ & $54.933^{\circ} \mathrm{S}$ & $154.767^{\circ} \mathrm{E}$ & $4058 \mathrm{~m}$ & 1
\end{tabular}

Nodules grow in layers (e.g. Figure 4.6) and are inherently heterogeneous due to the hydrogenetic and diagenetic contributions relating to their growth (Wegorzewski and Kuhn, 2014). In order to relate the mineralogy and chemical composition of the nodule to their modern environment, only the outermost layer (rim) was sampled. A potential sampling heterogeneity stems from both the differing growth rates, depending on growth mechanism, and the slow growth of individual nodules: $\sim 1 \mathrm{~mm}$ of the nodule radius may represent from thousands to a million years of ferromanganese nodule growth (Koschinsky and Hein, 2003). Thus, the outermost $1 \mathrm{~mm}$ of different samples may represent an average of different lengths of time. 


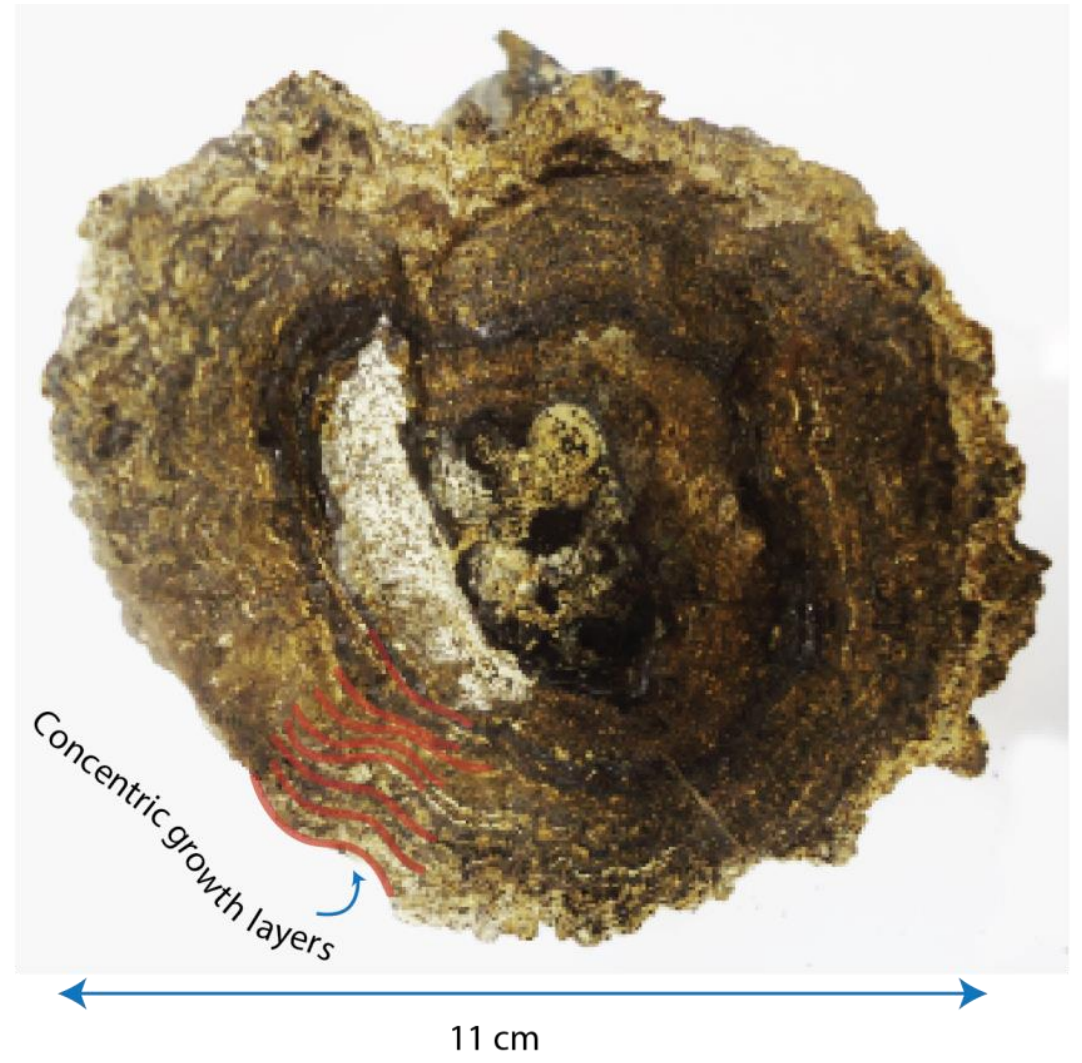

Figure 4.6: Sample U1398-1-D, showing concentric growth layers typical of nodule growth.

Evaluating how representative an analysis may be from a given subsample is crucial in comparing nodule compositions between different spatial settings. Local conditions causing variations in growth rate and style (hydrogenous vs. diagenetic) may impart a variance in the chemistry of the outermost layer of nodules related to the position the nodules were in during their growth (Wegorzewski and Kuhn, 2014) (Figure 4.1): if nodules are relatively fixed in the substrate the lower hemisphere may have a greater diagenetic influence than the upper hemisphere. Round nodules (as opposed to discoidal nodules) are thought to move around, minimising this effect (Glasby, 2006). To minimise the impact of potental sampling heterogeneity, several nodules of varying sizes were sampled from most localities. Furthermore, to evaluate how representative a single analysis is, subsampling of the outermost layer from different sectors of several individual nodules was also conducted.

\subsubsection{Nodule morphology}

Previous studies have found that nodule morphotype (Figure 4.7) is closely linked to the chemical composition of the nodules (Chang et al., 2003a, 2003b; Wright et al., 2005). This is related to the mineralogy of the manganese oxides and iron oxyhydroxides, which in turn reflects the hydrogenetic and diagenetic contributions during growth (Halbach et 
al., 1981). The physical appearance of each nodule was therefore documented. Each nodule was photographed with a ruler for scale (see Appendix C). These photographs were used to determine the length of $\mathrm{x}$ and $\mathrm{y}$ axis of each nodule. The nodules were described following the morphology criteria in Wright et al. (2005) and are summarised in Appendix C, and Figure 4.7.

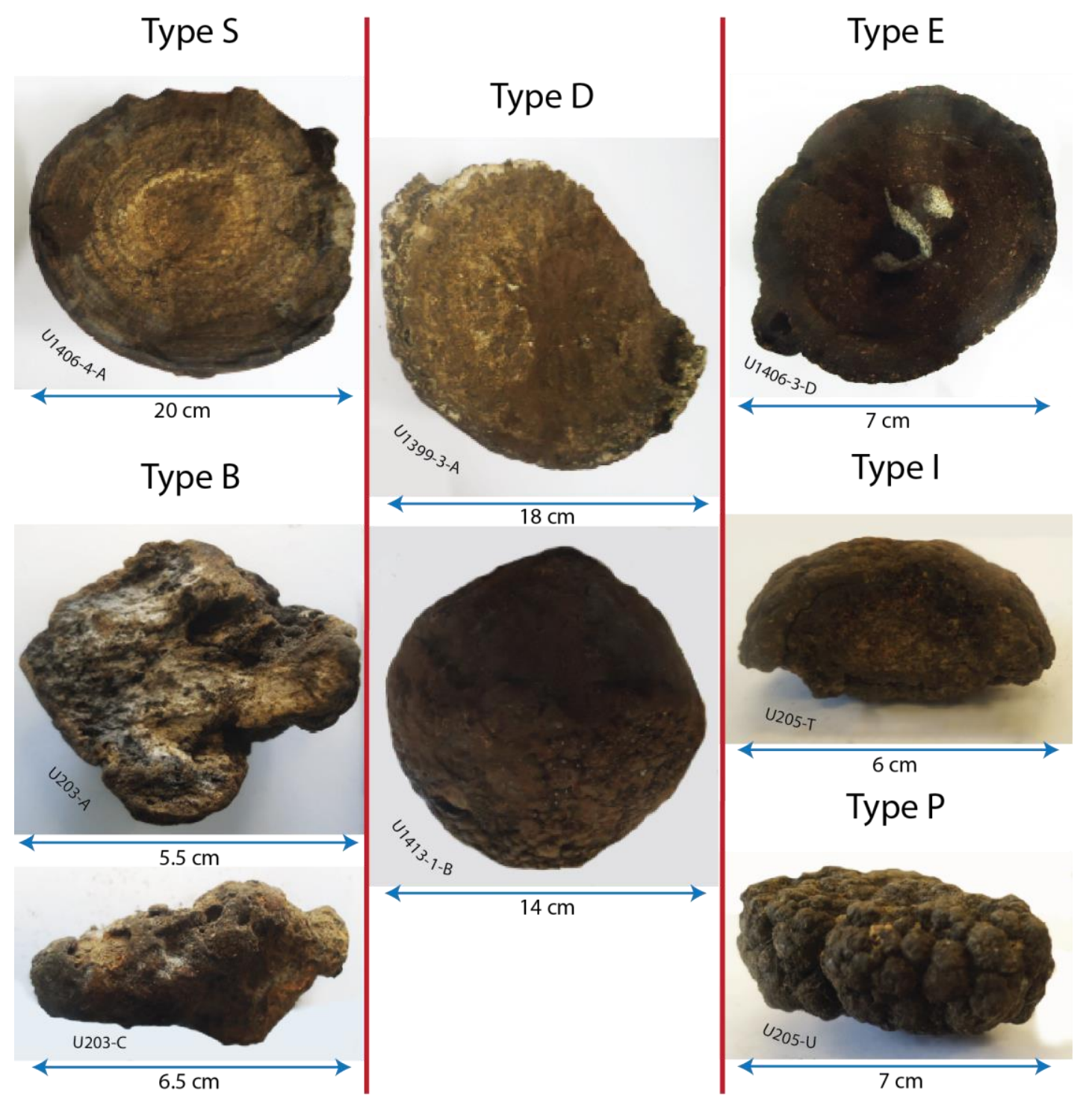

Figure 4.7: Ferromanganese nodule morphotypes. S - spheroidal shaped, D - discoidal, nodules that displayed preferential horizontal growth, E - elongate, nodules that are consistant with vertical growth favoured, B - boulder, thin ferromanganese surface on a rock, $\mathrm{P}$ - polynodular, many small nodules fused to form one sample, I - irregular shaped. Adapted from Wright et al. (2005). Lower case letter are used to denote the surface texture, with superscripts and subscripts indicating differing texture on the top and bottom of nodules respectively. Textures: $\mathrm{s}-\mathrm{smooth}, \mathrm{r}-$ rough, $\mathrm{b}$ - botryoidal. 


\subsubsection{Sample preparation}

Physical sampling of the ferromanganese nodule samples was undertaken in the rock crushing laboratory at Victoria University of Wellington. Care was taken to get a representative sampling of the outermost layer $(1 \mathrm{~mm})$ for geochemical analysis (e.g. Figure 4.8).

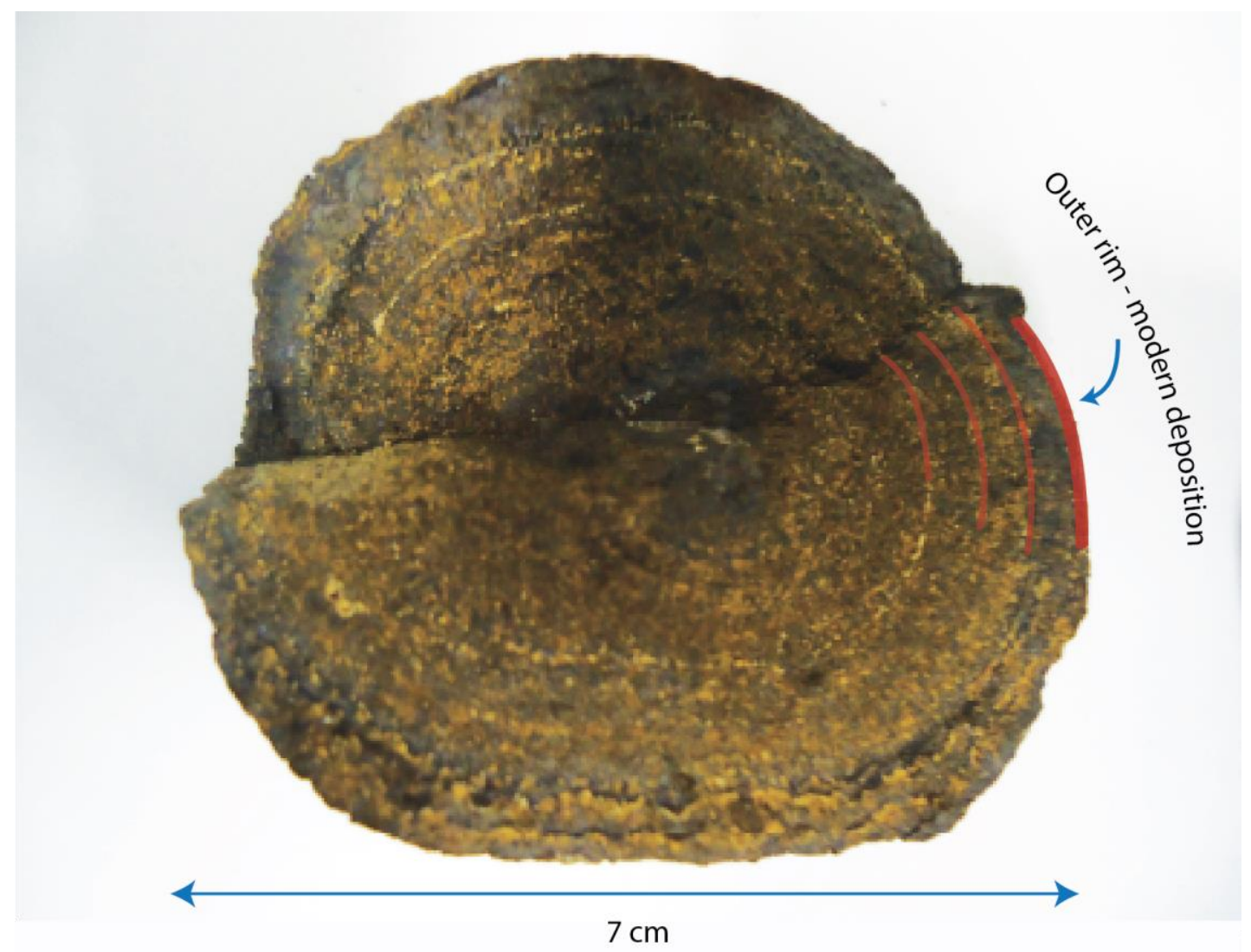

Figure 4.8: The outermost $1 \mathrm{~mm}$ of each nodule was targeted to sample the (near) modern deposition (as indicated on the figure). Nodule U1406-2-A is pictured.

The nodules were first bisected using a cold chisel and rock hammer. Photos were taken of each nodule hemisphere and one half section was archived. A clean ceramic knife was then used to scrape the very outermost layer of the chosen nodule hemisphere. The entire rim of the specimen exterior was scraped to obtain a representative sample of the rim surface. The sample was then ground into a fine powder using a clean ceramic mortar and pestle. Grinding the samples to a powder allows for better homogenisation of the sample and the chemical dissolution procedures are more effective. The resultant powder was stored in a $10 \mathrm{~mL}$ PPE centrifuge-tube for future analysis.

Between sampling each specimen, the ceramic knife was cleaned using ethanol and a Kimwipe. The mortar and pestle was cleaned with ethanol, wiping with a Kimwipe, grinding silica sand in it until no visible nodule residue remained, and then rinsing three 
times with tap water. Both the ceramic knife, and the mortar and pestle were then left to soak overnight in a dilute citric acid solution between each sample. They were then rinsed three times with $18.2 \mathrm{M} \Omega$ ultra-pure water and dried in an oven at $80{ }^{\circ} \mathrm{C}$.

\subsubsection{Inductively coupled plasma mass spectrometry}

Major and trace element compositions were measured using a Thermo Fisher Scientific Element2 sector-field ICP-MS at Victoria University of Wellington. All chemical preparation of the ferromanganese nodule samples for ICP-MS analysis was undertaken in the geochemistry laboratory located at Victoria University of Wellington.

\subsubsection{Reagents and cleaning procedures}

All regents used, unless otherwise stated, were Optima grade. Ultra-pure water of 18.2 M $\Omega$ was used. $22 \mathrm{~mL}$ Savillex Teflon screw-top beakers were cleaned between use with tap water, wiping with a Kimwipe, rinsing them three times with ultra-pure water, submerging them in $50 \%$ concentration Analar $\mathrm{HCl}$ for $>24$ hours at $80{ }^{\circ} \mathrm{C}$ on a hotplate, rinsing three times with ultra-pure water, and sub-boiling in 50\% concentration Analar $\mathrm{HNO}_{3}$ for $>24$ hours on the $80{ }^{\circ} \mathrm{C}$ hotplate. The beakers were then rinsed once with ultrapure water, and then placed in a $2 \mathrm{~L}$ glass beaker, covered with ultra-pure water and placed on a hotplate set at $250{ }^{\circ} \mathrm{C}$ until the water was bubbling vigorously. The glass beaker was then left to cool, the ultra-pure water was replaced and the step was repeated. The beakers were then transferred to the ultra-clean laboratory. Approximately 2-3 mL of $6 \mathrm{M} \mathrm{HNO}_{3}$ was added to each of the Savillex beakers, which were capped and placed on a hotplate set at $120{ }^{\circ} \mathrm{C}$ for a minimum of 24 hours. Each beaker was then rinsed three times with ultra-pure water, and the $6 \mathrm{M} \mathrm{HNO}_{3}$ step repeated. Lastly, the rinsed Savillex beakers were air-dried in a laminar flow hood. $10 \mathrm{~mL}$ PPE centrifuge-tubes were precleaned by adding $\sim 0.5 \mathrm{~mL}$ of $6 \mathrm{M} \mathrm{HNO}_{3}$ and filling with ultra-pure water. The tubes were left to soak for at least one week. The tubes were rinsed three times with ultra-pure water, and air-dried in a laminar flow hood.

\subsubsection{Weighing}

Ferromanganese nodules are hygroscopic (Hein \& Koschinsky, 2014). To obtain an accurate sample weight, it is necessary to remove the absorbed water before weighing. The recommended procedure for weighing such materials is to dry them in an oven at $110^{\circ} \mathrm{C}$ for at least 24 hours (Smith, 1995). However, upon removal from the oven, the powders will immediately begin to reabsorb water from the atmosphere, at a rate affected 
by the humidity of the surrounding environment. Consequently, a series of tests were undertaken to determine a reproducible and reliable way to obtain dry weights for the samples.

Sample powders were weighed at timed intervals immediately following removal from the oven, and then compared to sample powders placed immediately into a desiccator to cool for 30 minutes. The sample powders that were weighed directly out of the oven had initial weights that were unreliable, likely due to convective air currents within the scale (Harris, 2010). The sample powders that cooled in the desiccator first had results that were consistent with a linear moisture gain. Leaving the samples to cool at room temperature would give inaccurate weights as seen in the measurable gain in moisture mass of the other powdered samples. Thus, cooling the samples in a desiccator prior to weighing the samples was determined to be appropriate.

The following method was therefore used for all the sample analyses. Samples were placed in pre-weighed tinfoil boats and transferred to a $110^{\circ} \mathrm{C}$ oven overnight. They were moved directly to a desiccator for a minimum of 30 minutes to cool before being weighed over specific time increments. Timing of the sample powders began once the sample was placed onto the scale, meaning there was a few seconds lag time from the desiccator to the scale. To reduce electrostatic interference the samples were passed through a Mettler Toledo $\mathrm{U}$ ioniser prior to weighing. The weight increase was recorded in 30 second intervals for three minutes and again at the four minute time interval. After four minutes the boat was removed and wax weighing paper was weighed and zeroed. A small subsample (50-100 mg) was weighed onto this wax paper and both the weight and time were recorded. The subsample powder was transferred into a Savillex beaker for chemical processing.

The time series data were then used to back-calculate an initial dry weight for the total sample, and projected forward to estimate the weight the total sample would have been when the subsample was weighed. A ratio of the dry weight to the estimated total weight was calculated. This ratio was multiplied by the sub-sample weight to determine the subsample dry weight (Figure 4.9). It was assumed that because the sample and sub-sample were weighed in succession any changes in humidity would be negligible. The difference in surface area was also assumed to be negligible, as the slope of the increase in weight over time was relatively consistent (in the range of $6.9 \times 10^{6}-2.5 \times 10^{5} \mathrm{~g} / \mathrm{s}$ over the range of sample weights, $\sim 0.1-7.3 \mathrm{~g}$ ). 


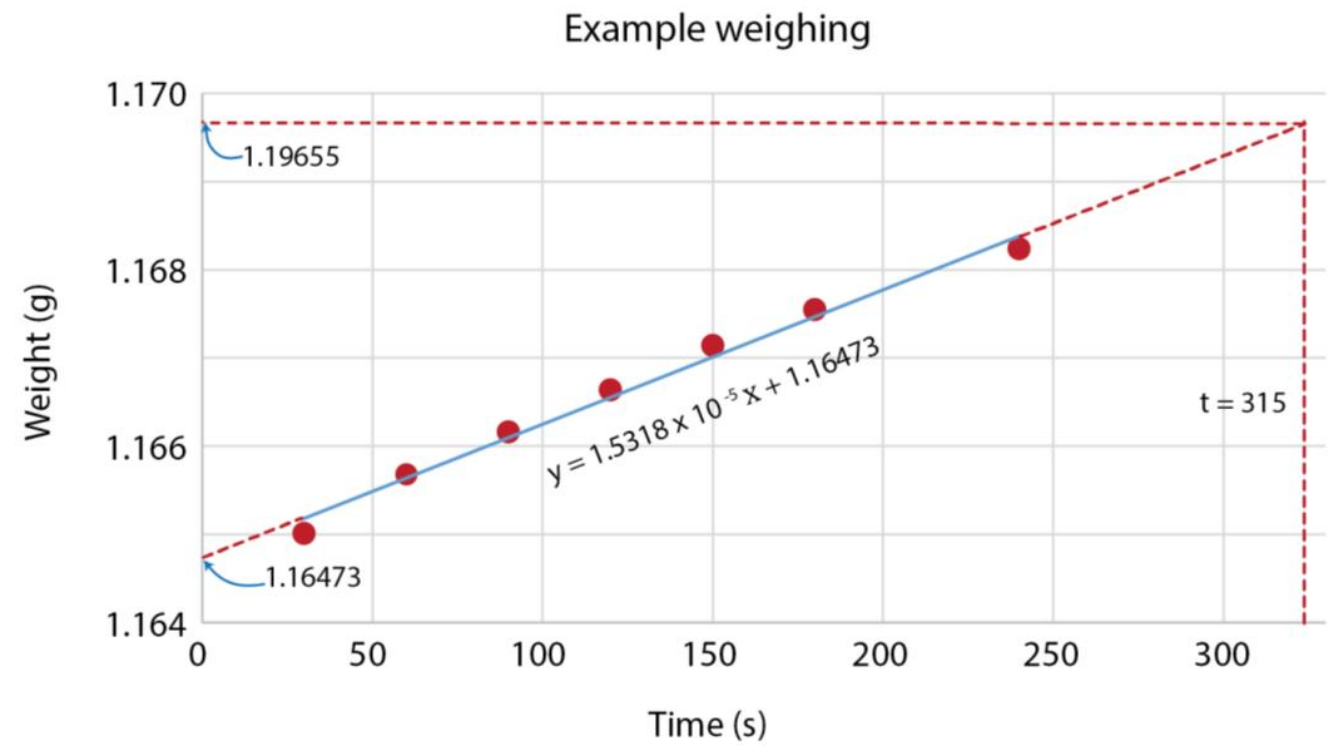

Figure 4.9: The weights measured for sample U1399-1-A-Z are plotted to show the method used to determine dry weights for the sample aliquots. The y-intercept is equal to the dry weight for the powder, an aliquot was then measured at $\mathrm{t}=315 \mathrm{~s}$. The dry aliquot weight could then be calculated using the equation: $\mathrm{W}_{\text {subsample }}\left(\mathrm{t}_{0}\right)=$ ratio of weight gain $x W_{\text {subsample }}$ where the ratio of weight gain $=\frac{W\left(t_{0}\right)}{W\left(t_{\text {subsample }}\right)} \cdot W_{\text {sample }}\left(t_{0}\right)$ is the weight of the sample when time is 0 , this is equivalent to the intercept. $t_{\text {subsample }}$ is the time at which the subsample was weighed, $\mathrm{W}_{\text {sample }}\left(\mathrm{t}_{\text {subsample }}\right)$ is the projected weight of the sample at the time in which the subsample was weighed

\subsubsection{Chemical dissolution}

To investigate the effect of the DWBC on nodule composition the chemical composition of the authigenic component is key. However, all previously reported data, with the exception of Plant (2015), discussed below, from the region studied here and the majority of ferromanganese nodules in the literature, underwent bulk (authigenic plus detrital) dissolution procedures (Chang et al., 2003b). Obtaining a reliably reproducible full dissolution of the authigenic component only, is not a straightforward process. It requires timed leaching, keeping leaches in solution for ICP-MS analysis, and obtaining the true weight of material dissolved (requiring accurate accounts of the tiny amount of detrital material remaining, to calculate the amount of authigenic material dissolved) (Plant, 2015). Although a targeted leaching method may be quicker and less hazardous than a bulk dissolution method, which involves reagents such as hydrofluoric acid (HF), in practise obtaining reliably reproducible results was complex and any data obtained would not be directly comparable to data from the literature, including SRM used to assess data quality. To produce a dataset that is comparable to the literature, bulk samples were dissolved. However, several samples were processed for both bulk, authigenic (leached) and detrital (residual) components to evaluate what elements are significantly impacted by the detrital component. It was hypothesised that the results from both leaching and 
bulk dissolution should be comparable for most trace metals due to the hydrogenous nature of the New Zealand nodule field (Glasby, 2006), and this was tested here by analysis of several samples using both methods.

\subsubsection{Bulk dissolution procedure}

(1) Twelve drops of concentrated $\mathrm{HNO}_{3}$ were added to $22 \mathrm{~mL}$ Savillex Teflon beakers containing the powdered sample. The solution was gently swirled to ensure the sample powder was fully wetted. (2) Fifty drops of concentrated HF were added to the sample. The beakers were recapped and placed on a $120{ }^{\circ} \mathrm{C}$ hotplate to digest for two to three days. (3) After cooling the beakers were uncapped and returned to the hotplate to evaporate to insipient dryness. (4) The residue was covered with concentrated $\mathrm{HNO}_{3}$ and left uncapped to evaporate on the hotplate. This step was repeated, to ensure all traces of HF were driven off. (5) $5 \mathrm{~mL}$ of $6 \mathrm{M} \mathrm{HCl}$ were added to the beakers, which were then recapped and left to reflux on the hotplate overnight. (6) The samples were visually inspected to ensure they were fully in solution and the beakers were then uncapped and placed on the hotplate, where the $\mathrm{HCl}$ was evaporated off. (7) Step 4 was repeated to convert the samples back to nitrate form. (8) $0.5 \mathrm{~mL}$ concentrated $\mathrm{HNO}_{3}$ and $4.5 \mathrm{~mL}$ ultra-pure water were added to the residue. The beakers were then recapped and placed on the hotplate to reflux for several days until the solutions were clear. (9) The solutions were cooled, and transferred to $60 \mathrm{~mL}$ PPE bottles where they were further diluted by adding ultra-pure water until they were in $1 \% \mathrm{HNO}_{3}$ solutions (typically, $35-40 \mathrm{~mL}$ final volume, and an overall dilution factor of 650). (10) Weighed aliquots of these stock solutions were then pipetted into $10 \mathrm{~mL}$ centrifuge tubes. $1 \% \mathrm{HNO} 3$ was then added to get final sample dilution factors of $\sim 55,000$ and $\sim 1,000,000$ for trace element analysis and major element analysis, respectively. A procedural blank was prepared alongside the ferromanganese samples throughout this process for each sample batch.

\subsubsection{Leaching procedure}

The leaching method is based on that developed by Plant (2015). The procedure used in this experiment differed in that $\mathrm{HNO}_{3}$ was used as the carrier fluid for ICP-MS analysis instead of $\mathrm{HCl}$, to reduce potential chloride spectral interferences.

(1) $5 \mathrm{~mL}$ of $6 \mathrm{M} \mathrm{HCl}$ was added to the $22 \mathrm{~mL}$ Savillex Teflon beakers containing the sample powders. (2) The beakers were capped and left to sit at room temperature for 60 minutes, and ultra-sonicated for a further 90 minutes. (3) The sample solutions were quantitatively transferred to acid-washed centrifuge tubes and centrifuged for 10 minutes 
at 3000 rps. (4) During centrifuging the beakers were rinsed three times with ultra-pure water. (5) Detrital-residue was visible at the bottom of the centrifuge tubes. Transfer pipettes were used to transfer only the supernatant to the original beakers, leaving only the detrital-residue in the centrifuge tubes. (6) A small amount of ultra-pure water was added to the centrifuge tubes, which were then shaken and re-centrifuged. (7) Step 5 was repeated as necessary. (8) The beakers were then uncapped and placed on a $120^{\circ} \mathrm{C}$ hotplate to evaporate. (9) The bulk dissolution procedure as detailed above was then conducted on the leachate samples. (10) The detrital residues were transferred from the centrifuge tubes to pre-weighed Savillex beakers by adding ultra-pure water, agitating the centrifuge tubes, and quantitatively transferring the suspended detrital material. This step was repeated as necessary. (11) The Savillex beakers were then uncapped and placed on a $120{ }^{\circ} \mathrm{C}$ hotplate to evaporate until no water remained. (12) The Savillex beakers and detrital residues were weighed. (13) The detrital residue samples were then dissolved using the bulk dissolution procedure.

\subsubsection{Data acquisition and processing}

Samples were analysed twice at two different dilutions (as described above), to determine major element and trace element concentrations (Table 4.2). Samples were introduced to the ICP-MS via a $200 \mu \mathrm{L} / \mathrm{min}$ glass nebuliser and cinnabar spray chamber. Take-up times were typically 45-60 seconds, with washout times of 2 minutes. Instrumental background levels were measured by analysing the $1 \% \mathrm{HNO}_{3}$ solution. These background blank measurements were run every fifth sample and the counts subtracted from the sample data during data processing. Dilutions of USGS SRM NOD-P-1 (Smith, 1995; Axelsson et al., 2002) were used to calibrate the analyses and were run every 8-9 samples throughout the run to account for any instrumental drift. The USGS SRM BHVO-2 (Jochum et al., 2005) was used when analysing the detrital residues. Dilutions of GSJ SRM JMn-1 (Terashima et al., 1995) and USGS SRM NOD-A-1 (Axelsson et al., 2002) were run as secondary standards.

Data was processed by converting the counts per second (CPS) measured on the ICP-MS to ppm for each element in each sample using the dilution factors for each sample (Equation 4.3). 


$$
c_{\text {sample }}=\frac{\frac{C P S_{\text {sample }}}{C F} \times D F_{\text {sample }}}{1000}
$$

Equation 4.3: Processing ICP-MS data. The calibration factors (CF) were calculated by dividing the CPS values of the primary standard by the reference values of Axelsson et al. (2002). DF - dilution factor.

Accuracy was evaluated using the GSJ ferromanganese nodule SRM JMn-1 as a secondary standard. Precision was evaluated using multiple analyses of JMn-1 and duplicates of samples. Full procedural blanks were processed with each sample batch. A sand blank processed through the ceramic mortar and pestle was also run to evaluate any contamination during sample powdering.

Table 4.2: Elements and isotopes measured on the ICP-MS in low, medium, and high resolution for major element $(\sim 1,000,000$ dilution) and trace element ( 50,000 dilution) dilution factors (DF).

\begin{tabular}{|c|c|c|}
\hline Resolution & Major element DF & Trace element DF \\
\hline Low resolution & $\begin{array}{l}{ }^{88} \mathrm{Sr},{ }^{95} \mathrm{Mo},{ }^{137} \mathrm{Ba},{ }^{139} \mathrm{La},{ }^{140} \mathrm{Ce}, \\
{ }^{141} \mathrm{Pr},{ }^{146} \mathrm{Nd},{ }^{208} \mathrm{~Pb},{ }^{209} \mathrm{Bi},{ }^{238} \mathrm{U} .\end{array}$ & $\begin{array}{l}{ }^{7} \mathrm{Li},{ }^{43} \mathrm{Ca},{ }^{85} \mathrm{Rb},{ }^{86} \mathrm{Sr},{ }^{89} \mathrm{Y},{ }^{90} \mathrm{Zr} \text {, } \\
{ }^{95} \mathrm{Mo},{ }^{111} \mathrm{Cd},{ }^{139} \mathrm{La},{ }^{141} \mathrm{Pr},{ }^{146} \mathrm{Nd} \text {, } \\
{ }^{147} \mathrm{Sm},{ }^{151} \mathrm{Eu},{ }^{153} \mathrm{Eu},{ }^{157} \mathrm{Gd},{ }^{159} \mathrm{~Tb}, \\
{ }^{163} \mathrm{Dy},{ }^{165} \mathrm{Ho},{ }^{166} \mathrm{Er},{ }^{169} \mathrm{Tm},{ }^{172} \mathrm{Yb}, \\
{ }^{175} \mathrm{Lu},{ }^{178} \mathrm{Hf},{ }^{205} \mathrm{Tl},{ }^{208} \mathrm{~Pb},{ }^{209} \mathrm{Bi} \text {, } \\
{ }^{232} \mathrm{Th},{ }^{238} \mathrm{U} .\end{array}$ \\
\hline $\begin{array}{l}\text { Medium } \\
\text { resolution }\end{array}$ & $\begin{array}{l}{ }^{24} \mathrm{Mg},{ }^{27} \mathrm{Al},{ }^{47} \mathrm{Ti},{ }^{51} \mathrm{~V},{ }^{55} \mathrm{Mn},{ }^{56} \mathrm{Fe}, \\
{ }^{59} \mathrm{Co},{ }^{60} \mathrm{Ni},{ }^{63} \mathrm{Cu},{ }^{66} \mathrm{Zn} .\end{array}$ & $\begin{array}{l}{ }^{24} \mathrm{Mg},{ }^{27} \mathrm{Al},{ }^{31} \mathrm{P},{ }^{43} \mathrm{Ca},{ }^{45} \mathrm{Sc},{ }^{47} \mathrm{Ti}, \\
{ }^{51} \mathrm{~V},{ }^{52} \mathrm{Cr},{ }^{59} \mathrm{Co},{ }^{60} \mathrm{Ni},{ }^{63} \mathrm{Cu},{ }^{66} \mathrm{Zn} \text {, } \\
{ }^{69} \mathrm{Ga},{ }^{137} \mathrm{Ba},{ }^{140} \mathrm{Ce} .\end{array}$ \\
\hline High resolution & & ${ }^{75}$ As \\
\hline
\end{tabular}




\subsection{Results}

\subsubsection{Accuracy and reproducibility}

Accuracy and experiment reproducibility were evaluated using replicate analyses of the JMn-1 SRM. Table 4.3 reports the element concentrations averaged over 24 analyses for the major element dilutions, and 22 analyses for the trace element dilutions. All elements were within $10 \%$ of the preferred values (Terashima et al., 1995) (Table 4.3), except $\mathrm{Cu}$, $\mathrm{Cr}(\leq 20 \%)$, and $\mathrm{Bi}, \mathrm{Ga}$, and $\mathrm{Zn}(\leq 28 \%)$. The $\mathrm{Cu}$ analysis, however, is within error of a more recently reported $\mathrm{Cu}$ analysis (1.0 ppm, Mohwinkel et al., 2014). Bi was found at very low concentrations in this sample, and is therefore difficult to measure. $\mathrm{Zn}$ can be prone to laboratory contamination. Concentrations for $\mathrm{Tl}$ were not reported for JMn-1 (Terashima et al., 1995).

The SRM NOD-A-1 was also analysed to check the accuracy in one batch, along with JMn-1. Table 4.4 summarises the average major and trace elements for three analyses compared with the reference value of Axelsson et al. (2002). All elements agree within $10 \%$, with the exception of $\mathrm{Sc}(\leq 15 \%) ; \mathrm{P}, \mathrm{Cr}, \mathrm{Ga}$, and $\mathrm{Cd}(\leq 20 \%)$; and $\mathrm{Cu}(\leq 45 \%)$.

Reproducibility was excellent, with most elements better than $\pm 3 \%$ RSD. A more applicable measure of experiment reproducibility for the samples however can be determined from multiple analyses of nodule samples. Table 4.5 summarises the data for sample U1413-1-B, which was fully processed and analysed four times over the course of this project. Reproducibility was comparable to that for JMn-1 with most elements better than 4\% RSD, and many $\leq 2 \%$ RSD (Table 4.5). This suggests the sample powders were well homogenised. 
Table 4.3: Summary of replicate analyses of GSJ SRM JMn-1, $n=24$ for major elements, $\mathrm{n}=22$ for minor elements. Reference values are from Terashima et al. (1995).

\begin{tabular}{|c|c|c|c|c|c|}
\hline Element & $\begin{array}{c}\text { Average } \\
\text { wt } \%\end{array}$ & $\begin{array}{l}\text { STD } \\
\text { wt\% }\end{array}$ & $\underset{\%}{\text { RSD }}$ & $\begin{array}{c}\text { Reference } \\
\text { wt } \%\end{array}$ & $\begin{array}{l}\text { Average/ } \\
\text { Reference }\end{array}$ \\
\hline $\mathrm{Al}_{2} \mathrm{O}_{3}$ & 4.325 & 0.058 & 1.4 & 4.297 & 1.01 \\
\hline MnO & 33.09 & 0.0 & 0.0 & 33.09 & 1.00 \\
\hline MgO & 3.258 & 0.035 & 1.1 & 3.115 & 1.05 \\
\hline $\mathrm{CaO}$ & 3.024 & 0.093 & 3.1 & 2.909 & 1.04 \\
\hline $\mathrm{TiO}_{2}$ & 1.016 & 0.0014 & 1.4 & 1.061 & 0.96 \\
\hline $\mathbf{P}_{2} \mathrm{O}_{5}$ & 0.534 & 0.013 & 2.3 & 0.54 & 0.99 \\
\hline \multirow[t]{2}{*}{$\mathrm{Fe}_{2} \mathrm{O}_{3}$} & 14.587 & 0.382 & 2.6 & 14.4 & 1.01 \\
\hline & ppm & ppm & $\%$ & ppm & \\
\hline $\mathbf{L i}$ & 66.5 & 1.6 & 2.4 & 71.7 & 0.93 \\
\hline Sc & 12.3 & 0.3 & 2.3 & 13 & 0.95 \\
\hline V & 452 & 6.8 & 1.5 & 424 & 1.07 \\
\hline $\mathrm{Cr}$ & 21.8 & 0.8 & 3.7 & 26.6 & 0.82 \\
\hline Co & 1743 & 18.4 & 1.1 & 1732 & 1.01 \\
\hline $\mathbf{N i}$ & 12708 & 161 & 1.3 & 12632 & 1.01 \\
\hline $\mathrm{Cu}$ & 9882 & 146 & 1.5 & 11132 & 0.89 \\
\hline $\mathbf{Z n}$ & 1372 & 25.9 & 1.9 & 1068 & 1.28 \\
\hline $\mathbf{G a}$ & 28.9 & 0.5 & 1.8 & 37.1 & 0.78 \\
\hline As & 82.2 & 3.3 & 4.0 & 75.4 & 1.09 \\
\hline $\mathbf{R b}$ & 10.5 & 0.3 & 2.5 & 10.9 & 0.96 \\
\hline $\mathrm{Sr}$ & 832 & 11.3 & 1.4 & 792 & 1.05 \\
\hline $\mathbf{Y}$ & 111 & 2.9 & 2.6 & 111 & 1.00 \\
\hline $\mathbf{Z r}$ & 357.1 & 8.4 & 2.4 & 344 & 1.04 \\
\hline Mo & 331 & 7.0 & 2.1 & 318 & 1.04 \\
\hline Cd & 14.3 & 0.3 & 2.3 & 15.5 & 0.92 \\
\hline Ba & 1696 & 28.7 & 1.7 & 1714 & 0.99 \\
\hline $\mathbf{L a}$ & 118 & 1.3 & 1.1 & 122 & 0.96 \\
\hline $\mathrm{Ce}$ & 256 & 4.0 & 1.6 & 277 & 0.92 \\
\hline Pr & 30.4 & 0.5 & 1.6 & 31.4 & 0.97 \\
\hline Nd & 126 & 2.3 & 1.8 & 137 & 0.92 \\
\hline $\mathrm{Sm}$ & 28.0 & 0.5 & 1.9 & 30.2 & 0.93 \\
\hline Eu & 6.9 & 0.2 & 2.2 & 7.6 & 0.91 \\
\hline Gd & 29.7 & 0.7 & 2.5 & 29.8 & 1.00 \\
\hline $\mathbf{T b}$ & 4.8 & 0.1 & 2.0 & 4.8 & 1.01 \\
\hline Dy & 28.1 & 0.6 & 2.1 & 28.3 & 0.99 \\
\hline Ho & 5.4 & 0.1 & 2.0 & 5.8 & 0.93 \\
\hline $\mathbf{E r}$ & 14.8 & 0.3 & 2.0 & 14.6 & 1.02 \\
\hline $\mathbf{T m}$ & 2.1 & 0.0 & 1.7 & 2.1 & 0.99 \\
\hline $\mathbf{Y b}$ & 13.8 & 0.3 & 2.0 & 13.8 & 1.00 \\
\hline Lu & 1.9 & 0.0 & 2.0 & 2.1 & 0.92 \\
\hline Hf & 6.2 & 0.1 & 1.7 & 6.2 & 1.00 \\
\hline Tl & 199 & 6.8 & 3.4 & & \\
\hline $\mathbf{P b}$ & 462 & 9.0 & 1.9 & 430 & 1.07 \\
\hline $\mathbf{B i}$ & 5.4 & 0.1 & 1.8 & 4.3 & 1.25 \\
\hline Th & 13.0 & 0.3 & 1.9 & 11.7 & 1.11 \\
\hline $\mathbf{U}$ & 5.0 & 0.1 & 1.7 & 5 & 1.00 \\
\hline
\end{tabular}


Table 4.4: Summary of replicate analyses of USGS SRM NOD-A-1, $\mathrm{n}=3$. Reference values are from Axelsson et al. (2002)

\begin{tabular}{|c|c|c|c|c|c|}
\hline Element & $\begin{array}{c}\text { Average } \\
\text { ppm }\end{array}$ & $\begin{array}{l}\text { STD } \\
\text { ppm }\end{array}$ & $\begin{array}{c}\text { RSD } \\
\%\end{array}$ & $\begin{array}{c}\text { Reference } \\
\text { ppm }\end{array}$ & $\begin{array}{l}\text { Average/ } \\
\text { Reference }\end{array}$ \\
\hline $\mathbf{A l}$ & 19960 & 68.7 & 0.3 & 20800 & 0.96 \\
\hline Mn & 183000 & 0.0 & 0.0 & 183000 & 1.00 \\
\hline Mg & 27845 & 131 & 0.5 & 28300 & 0.98 \\
\hline Ca & 103586 & 424 & 0.4 & 114000 & 0.91 \\
\hline $\mathbf{T i}$ & 2736 & 36.2 & 1.3 & 3030 & 0.90 \\
\hline $\mathbf{P}$ & 4917 & 28.6 & 0.6 & 5920 & 0.83 \\
\hline $\mathbf{F e}$ & 101298 & 330 & 0.3 & 112000 & 0.90 \\
\hline $\mathbf{L i}$ & 77.9 & 0.8 & 1.1 & 76.1 & 1.02 \\
\hline Sc & 11.0 & 0.1 & 0.8 & 12.4 & 0.89 \\
\hline $\mathbf{V}$ & 608 & 7.8 & 1.3 & 660 & 0.92 \\
\hline $\mathrm{Cr}$ & 17.1 & 0.1 & 0.5 & 20.9 & 0.82 \\
\hline Co & 2990 & 1.2 & 0.0 & 3180 & 0.94 \\
\hline $\mathbf{N i}$ & 6533 & 62.0 & 0.9 & 6450 & 1.01 \\
\hline $\mathrm{Cu}$ & 1640 & 3.0 & 0.2 & 1130 & 1.45 \\
\hline $\mathrm{Zn}$ & 784 & 2.9 & 0.4 & 800 & 0.98 \\
\hline Ga & 7.4 & 0.0 & 0.4 & 6.3 & 1.18 \\
\hline As & 284 & 7.4 & 2.6 & 310 & 0.92 \\
\hline $\mathbf{R b}$ & 10.4 & 0.1 & 0.5 & 10.6 & 0.98 \\
\hline $\mathrm{Sr}$ & 1460 & 4.4 & 0.3 & 1630 & 0.90 \\
\hline $\mathbf{Y}$ & 115 & 0.9 & 0.8 & 120 & 0.96 \\
\hline $\mathbf{Z r}$ & 304 & 2.9 & 1.0 & 310 & 0.98 \\
\hline Mo & 407 & 2.7 & 0.7 & 390 & 1.04 \\
\hline Cd & 8.9 & 0.1 & 1.1 & 7.5 & 1.19 \\
\hline Ba & 1588 & 3.9 & 0.2 & 1530 & 1.04 \\
\hline $\mathbf{L a}$ & 107 & 0.3 & 0.2 & 115 & 0.93 \\
\hline $\mathrm{Ce}$ & 678 & 1.2 & 0.2 & 720 & 0.94 \\
\hline Pr & 23.5 & 0.1 & 0.4 & 25 & 0.94 \\
\hline Nd & 97.4 & 0.4 & 0.4 & 98 & 0.99 \\
\hline Sm & 21.5 & 0.1 & 0.7 & 21.9 & 0.98 \\
\hline Eu & 5.2 & 0.0 & 0.3 & 5.2 & 0.99 \\
\hline Gd & 26.2 & 0.1 & 0.5 & 25.4 & 1.03 \\
\hline $\mathbf{T b}$ & 3.9 & 0.0 & 1.2 & 4 & 0.98 \\
\hline Dy & 23.3 & 0.2 & 0.9 & 23.8 & 0.98 \\
\hline Ho & 4.8 & 0.0 & 0.9 & 5 & 0.96 \\
\hline $\mathbf{E r}$ & 13.9 & 0.1 & 0.5 & 14.4 & 0.97 \\
\hline $\mathbf{T m}$ & 2.0 & 0.0 & 0.5 & 2 & 0.98 \\
\hline $\mathbf{Y b}$ & 13.2 & 0.1 & 0.6 & 13.9 & 0.95 \\
\hline Lu & 2.0 & 0.0 & 1.3 & 2.1 & 0.94 \\
\hline Hf & 5.9 & 0.0 & 0.6 & 5.8 & 1.02 \\
\hline Tl & 118 & 0.4 & 0.4 & 120 & 0.98 \\
\hline $\mathbf{P b}$ & 789 & 8.6 & 1.1 & 860 & 0.92 \\
\hline $\mathbf{B i}$ & 10.6 & 0.1 & 1.1 & 10.2 & 1.04 \\
\hline Th & 23.0 & 0.1 & 0.3 & 25.1 & 0.91 \\
\hline $\mathbf{U}$ & 6.3 & 0.0 & 0.4 & 7 & 0.90 \\
\hline
\end{tabular}


Table 4.5: Summary of replicate analyses of sample U1413-1-B, n=4.

\begin{tabular}{c|ccc}
$\mathbf{E l e m e n t}$ & $\begin{array}{c}\text { Average } \\
\text { ppm }\end{array}$ & $\begin{array}{c}\text { STD } \\
\text { ppm }\end{array}$ & $\begin{array}{c}\text { RSD } \\
\text { \% }\end{array}$ \\
\hline \hline $\mathbf{A l}$ & 21804 & 674 & 3.1 \\
$\mathbf{M n}$ & 179027 & 7952 & 4.4 \\
$\mathbf{M g}$ & 13943 & 251 & 1.8 \\
$\mathbf{C a}$ & 22936 & 413 & 1.8 \\
$\mathbf{T i}$ & 10343 & 204 & 2.0 \\
$\mathbf{P}$ & 2953 & 98.3 & 3.3 \\
$\mathbf{F e}$ & 156528 & 4116 & 2.6 \\
& & & \\
$\mathbf{L i}$ & 16.0 & 0.25 & 1.6 \\
$\mathbf{S c}$ & 10.9 & 0.29 & 2.6 \\
$\mathbf{V}$ & 556 & 11.2 & 2.0 \\
$\mathbf{C r}$ & 28.0 & 0.67 & 2.4 \\
$\mathbf{C o}$ & 2458 & 79.5 & 3.2 \\
$\mathbf{N i}$ & 5694 & 144 & 2.5 \\
$\mathbf{C u}$ & 1081 & 43.4 & 4.0 \\
$\mathbf{Z n}$ & 955 & 17.6 & 1.8 \\
$\mathbf{G a}$ & 7.40 & 0.16 & 2.2 \\
$\mathbf{A s}$ & 186 & 4.48 & 2.4 \\
$\mathbf{R b}$ & 14.2 & 0.35 & 2.5 \\
$\mathbf{S r}$ & 1121 & 50.0 & 4.5 \\
$\mathbf{Y}$ & 113 & 2.87 & 2.5 \\
$\mathbf{Z r}$ & 576 & 16.6 & 2.9 \\
$\mathbf{M r}$ & 241 & 3.70 & 1.5 \\
$\mathbf{C d}$ & 6.54 & 0.27 & 4.2 \\
$\mathbf{B a}$ & 1212 & 47.6 & 3.9 \\
$\mathbf{L a}$ & 174 & 7.73 & 4.4 \\
$\mathbf{C e}$ & 884 & 38.2 & 4.3 \\
$\mathbf{P r}$ & 45.0 & 1.92 & 4.3 \\
$\mathbf{N d}$ & 180 & 5.65 & 3.1 \\
$\mathbf{S m}$ & 38.3 & 0.48 & 1.3 \\
$\mathbf{E u}$ & 8.59 & 0.13 & 1.5 \\
$\mathbf{G d}$ & 41.5 & 1.09 & 2.6 \\
$\mathbf{T b}$ & 6.30 & 0.14 & 2.1 \\
$\mathbf{D y}$ & 35.0 & 0.41 & 1.2 \\
$\mathbf{H o}$ & 6.40 & 0.13 & 2.1 \\
$\mathbf{E r}$ & 17.2 & 0.31 & 1.8 \\
$\mathbf{T r}$ & 2.30 & 0.03 & 1.2 \\
$\mathbf{Y b}$ & 15.0 & 0.35 & 2.3 \\
$\mathbf{L u}$ & 2.04 & 0.03 & 1.5 \\
$\mathbf{H f}$ & 12.5 & 0.14 & 1.1 \\
$\mathbf{T l}$ & 111 & 3.96 & 3.6 \\
$\mathbf{P b}$ & 1030 & 31.2 & 3.0 \\
$\mathbf{B i}$ & 8.81 & 0.17 & 1.9 \\
$\mathbf{T h}$ & 71.4 & 0.97 & 1.4 \\
$\mathbf{U}$ & 8.60 & 0.13 & 1.5 \\
& & &
\end{tabular}




\subsubsection{Hemisphere comparison}

Each ferromanganese nodule is inherently heterogeneous due to variable contributions to their growth from diagenetic and hydrogenetic processes. Samples U1399-1-A, U1406B-1-D, U1406B-4-A were sampled from both hemispheres to characterise any bias that might be introduced from sampling only part of the nodule rim. The nodule samples have the morphotypes $E_{r}^{s}, E_{s}$, and $S_{s}$, respectively (Appendix C). Samples chosen for the hemisphere comparison were selected primarily on the basis of size, as the larger nodules have more available sample material. Multiple samples from the nodule Z2140 were also processed and compared. The major and trace element data for the different subsamples for each of the nodules are compared in multi-element diagrams, normalised to Fe content (Figure 4.10), and the data are presented in Appendix D.

Overall, most elements show a good agreement between different samplings of the same nodule. Sample U1406B-1-D in particular, shows excellent agreement for all the elements (Figure 4.10a). Sample U1406B-4-A (Figure 4.10b) is from the same location but is less reproducible than U1406B-1-D, exhibiting moderate disagreement for the elements: Mn, $\mathrm{Al}, \mathrm{Mg}, \mathrm{Ti}, \mathrm{Tl}$, and $\mathrm{Hf}$, and larger variations for the elements: $\mathrm{Ni}, \mathrm{Ba}, \mathrm{Cu}, \mathrm{Zn}, \mathrm{Li}, \mathrm{Rb}, \mathrm{Sc}$, Ga, and Cd. Nodule U1399-1-A (Figure 4.10c) displays some variation for Ca, P, Zr, As, Tl, Cr, and Li. Nodule Z2140 (Figure 4.10d), shows excellent agreement between Z2140$\mathrm{B}$ and Z2140-CEG, and subsample Z2140-ADF exhibiting minor variations in $\mathrm{Al}, \mathrm{Cr}, \mathrm{Li}$, $\mathrm{Rb}$, and $\mathrm{Ga}$. 


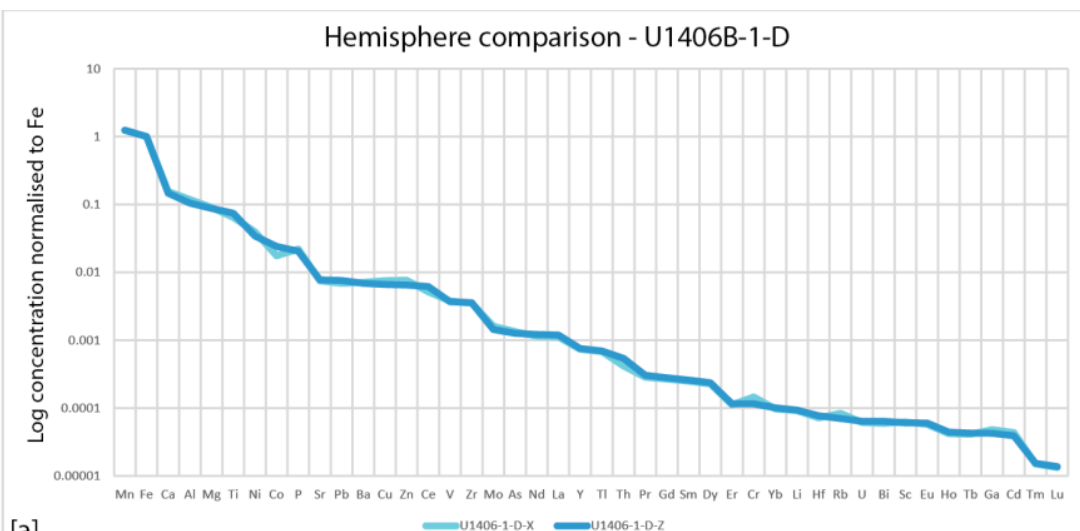

[a] - U1406-1-D-X $U 1406-1-D-2$

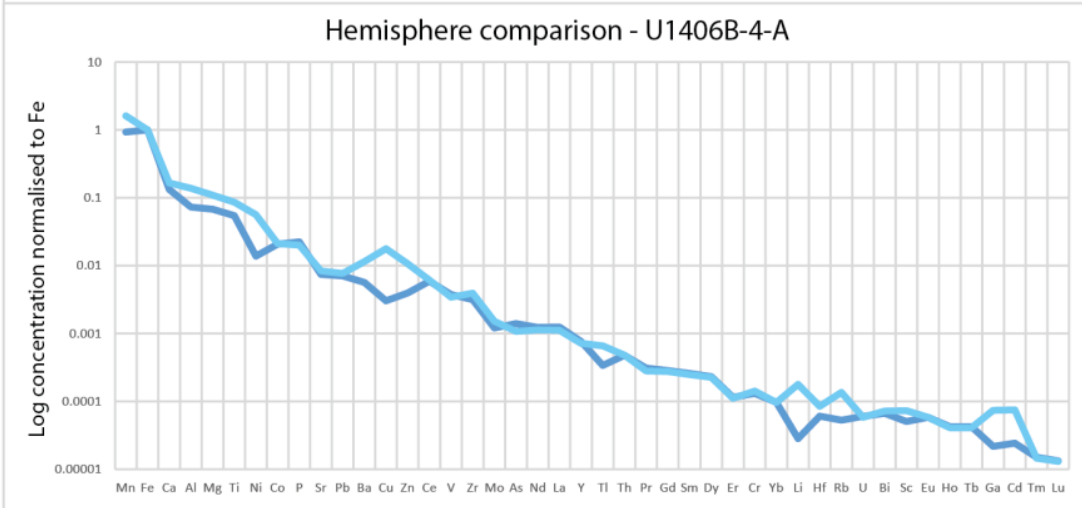

[b]

$\longrightarrow$ U1406-4A-Y $=1406-4-A-Z$

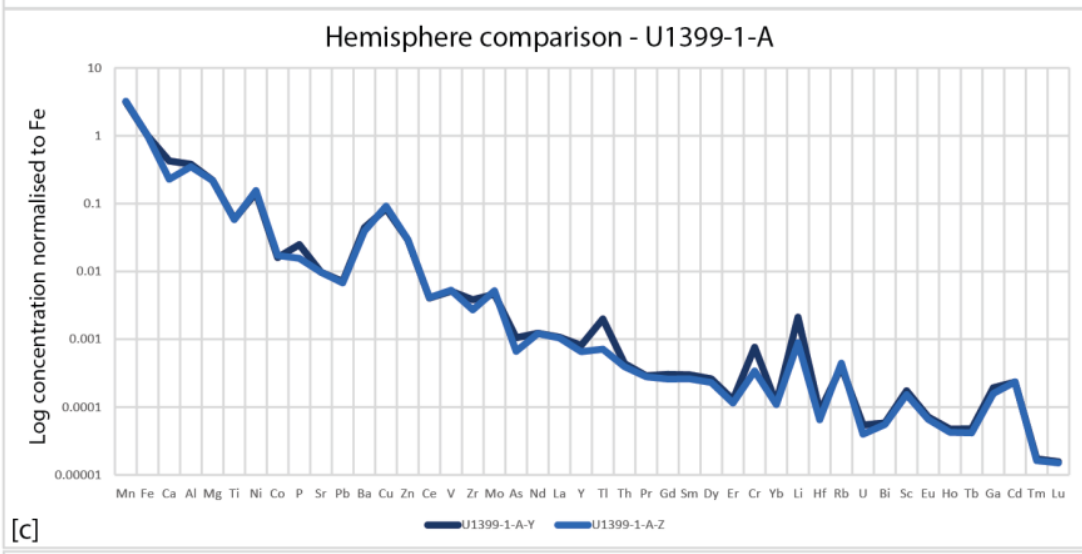

[c]

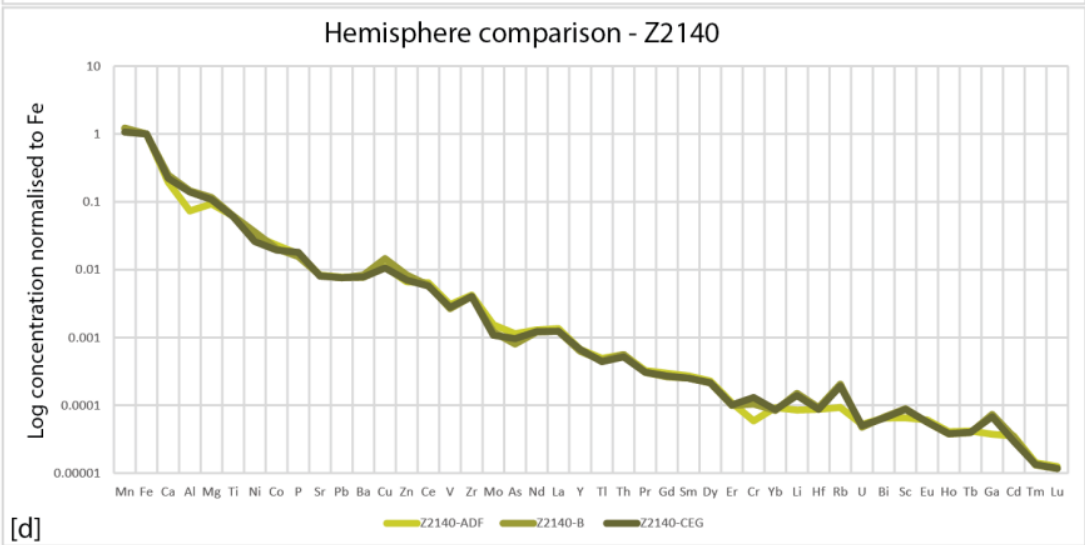

Figure 4.10: Hemisphere comparison for nodules (a) U1406-1-D, (b) U1406-4A, (c) U1399-1-A, and (d) Z2140. The data are normalised to Fe and elements are organised by decreasing elemental concentration of the sample U1406-1-D. 


\subsubsection{Leaching results}

The leaching experiment used a method adapted from Plant (2015) to determine the compositions of alumino-silicate and authigenic ferromanganese components in selected nodules: U1413-1-B from the northern transect, U1374-1-E from the southern transect, U205-DFG from the Tasman Sea, and the USGS SRM NOD-P-1. Figure 4.11 compares the concentrations in the leachate and detrital components for each sample. The full data are presented in Appendix D.

From Figure 4.11 it is apparent that for each sample broadly the same suite of elements ( $\mathrm{Cr}, \mathrm{Rb}, \mathrm{Al}, \mathrm{Zr}, \mathrm{Hf}, \mathrm{Ga}, \mathrm{Sc}, \mathrm{Ca}, \mathrm{Li}, \mathrm{Mg}$, and $\mathrm{Ti}$ ) are associated with the detrital component, with only minor variations between the samples. For most other trace elements, including the REE, $\mathrm{Mn}, \mathrm{Co}, \mathrm{Ni}$, and $\mathrm{Cu}$, the detrital component accounts for less than $5 \%$ of the bulk analysis. U1374-1-E (Figure 4.11b) has less Li, Zr, and Hf in the detrital component; U205-DFG (Figure 4.11c) has higher levels of high field strength elements (Zr, Hf, REE, $\mathrm{Th}$, and $\mathrm{U}$ ), with the detrital component of $\mathrm{Lu}$ accounting for $8.6 \%$ of the bulk composition, compared to $2 \%$ in U1413-1-B (Figure 4.11a). NOD-P-1 detrital component contains higher proportions of $\mathrm{Ti}(23 \%)$ and $\mathrm{U}(7.6 \%)$ than in sample U1413 $(9.0 \%$, and $2 \%)$. 
U1413-1-B

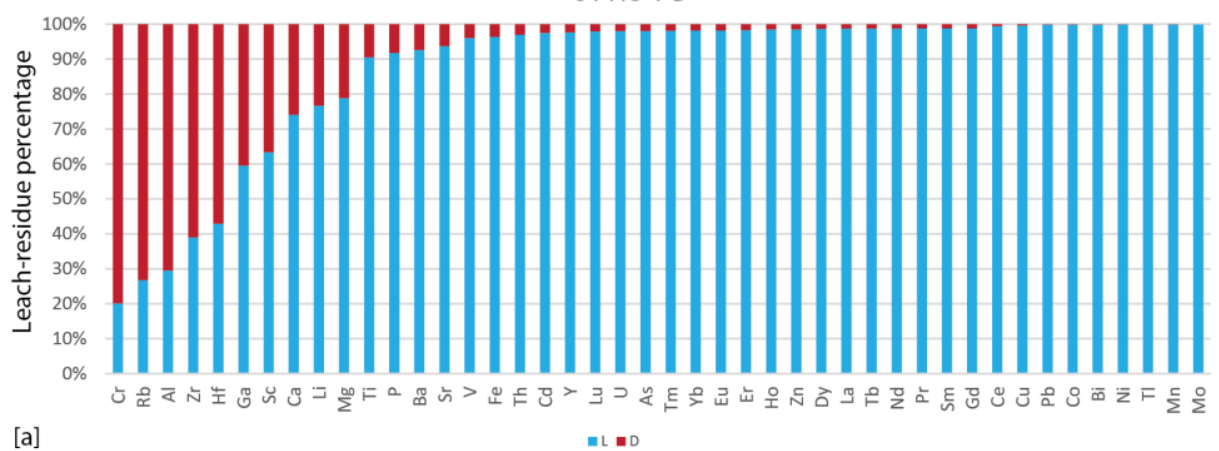

[a]

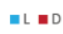

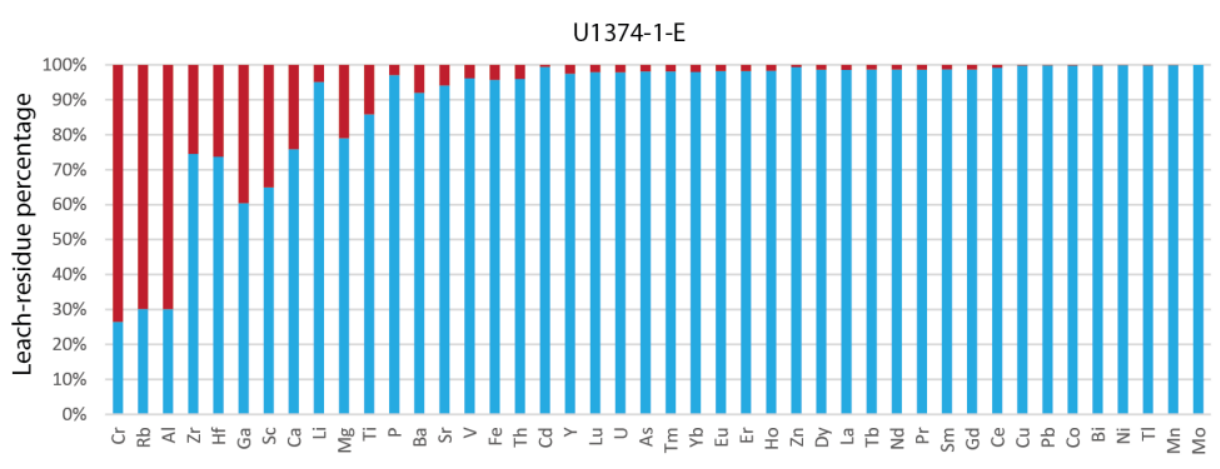

[b]

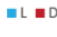

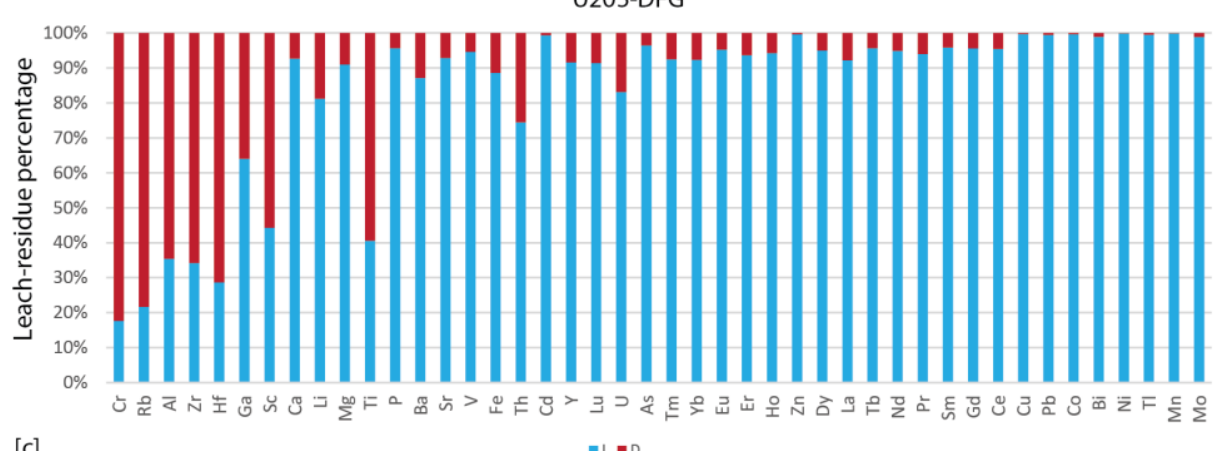

[c]

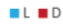

NOD-P-1

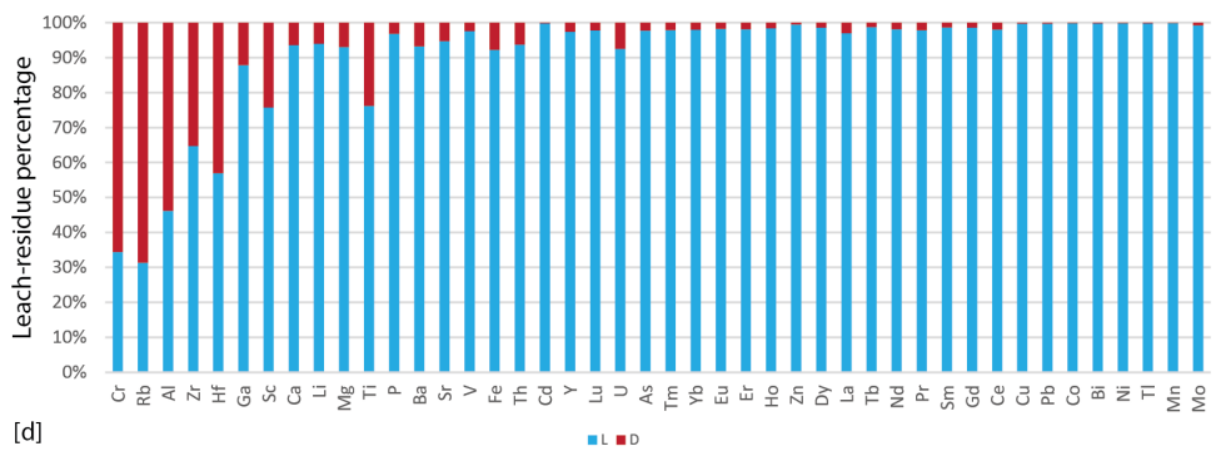

Figure 4.11: Authigenic ( $\mathrm{L}$ - leached) and alumino-silicate ( $\mathrm{D}$ - detrital-residue) phase associations for the samples; (a) U1413-1-B, (b) U1374-1-E, (c) U205-DFG, and (d) the SRM NOD-P-1. Elements are arranged in order of decreasing ratio of the detrital to the leached element concentrations from left to right for the U1413-1-B sample. 


\subsubsection{New Zealand nodule fields}

The major and trace element data for the 77 nodule rims analysed from New Zealand waters are presented in Appendix D and are summarised in Figures 4.12-4.15. The Fe $\mathrm{Cu}+\mathrm{Ni}-\mathrm{Mn}$ ternary diagram (Figure 4.12) and $\mathrm{Cu}+\mathrm{Ni}-\mathrm{Fe} / \mathrm{Mn}$ discrimination diagram (Figure 4.13) are commonly used to identify the contribution of hydrogenetic vs. diagenetic components. Normalised multi-element (Figure 4.14), and REE (Figure 4.15) diagrams are presented to highlight key trends in element distribution among the samples.

The New Zealand nodules plot in a tight trend in the ternary (genetic) discrimination diagram (Figure 4.12) with most samples within the hydrogenetic growth field, but trending towards the diagenetic growth fields. Samples U205 and U1399 fall within Group AB, the mixed hydrogenetic-diagenetic growth field.

$\mathrm{Cu}+\mathrm{Ni}$ vs. Mn/Fe (Figure 4.13) is commonly used to define diagenetic influence (Halbach et al., 1981; Wright et al., 2005). The New Zealand nodules plot on a trend from low $\mathrm{Cu}+\mathrm{Ni}$ and $\mathrm{Mn} / \mathrm{Fe}$ indicative of hydrogenetic growth, extending towards average compositions in the CCZ, Peru, and Indian nodule fields. The New Zealand data can be divided into three groups; low $\mathrm{Cu}+\mathrm{Ni}, \mathrm{Mn} / \mathrm{Fe}$ (area $\mathrm{A}$ ), and two subparallel trends, one with higher $\mathrm{Cu}+\mathrm{Ni}$ (area B) and including average Indian Ocean and $\mathrm{CCZ}$ nodules, and one with lower $\mathrm{Cu}+\mathrm{Ni}($ area $\mathrm{C}$ ) for a given $\mathrm{Mn} / \mathrm{Fe}$, that includes average Peru nodule composition. Overall, most samples with $\mathrm{Mn} / \mathrm{Fe}<5$ reported from the $\mathrm{CCZ}$ fall within area $\mathrm{A}$ and extend to higher $\mathrm{Cu}+\mathrm{Ni}$ for a given $\mathrm{Mn} / \mathrm{Fe}$ than the New Zealand nodules. Nodules with $\mathrm{Mn} / \mathrm{Fe}<5$ from the Peru field also fall largely in area $\mathrm{A}$, but at lower $\mathrm{Cu}+\mathrm{Ni}$ values than the CCZ nodules (Figure 4.12) (Halbach et al., 1981).

Area $\mathrm{C}$ is largely defined by nodules from the Tasman Sea, with one additional sample from the northern Campbell nodule field (from site U1402). Within area C, samples from Tasman Sea U203 display lower Mn/Fe and $\mathrm{Cu}+\mathrm{Ni}$ than samples from U205.

Samples from the southern Campbell nodule field transect plot in both areas A and B. Nodules from site U1373 display the greatest range in composition spanning both areas A and B. Samples from U1374 and U1378 are found only in area B, and samples from $\mathrm{U} 1378$ tend to have higher $\mathrm{Mn} / \mathrm{Fe}$ and $\mathrm{Cu}+\mathrm{Ni}$ than all but one nodule from $\mathrm{U} 1374$.

The northern Campbell nodule field transect displays the most variability, with samples from this transect located in areas A, B, and C. Samples from U1413 plot in the hydrogenetic area A. Samples from U1406B are found in areas A and B, with the majority 
being located in area A. Samples from U1402 tend to be in area B, with one sample in area C. Samples from U1399 are all in area B, except for one sample in area A. Samples from U1398 plot in area B. Samples along this transect do not display an identifiable trend when comparing their location along the transect and their $\mathrm{Mn} / \mathrm{Fe}$ and $\mathrm{Cu}+\mathrm{Ni}$ ratio.

Samples from the Southern Ocean all display hydrogenetic signatures, and plot in area A.

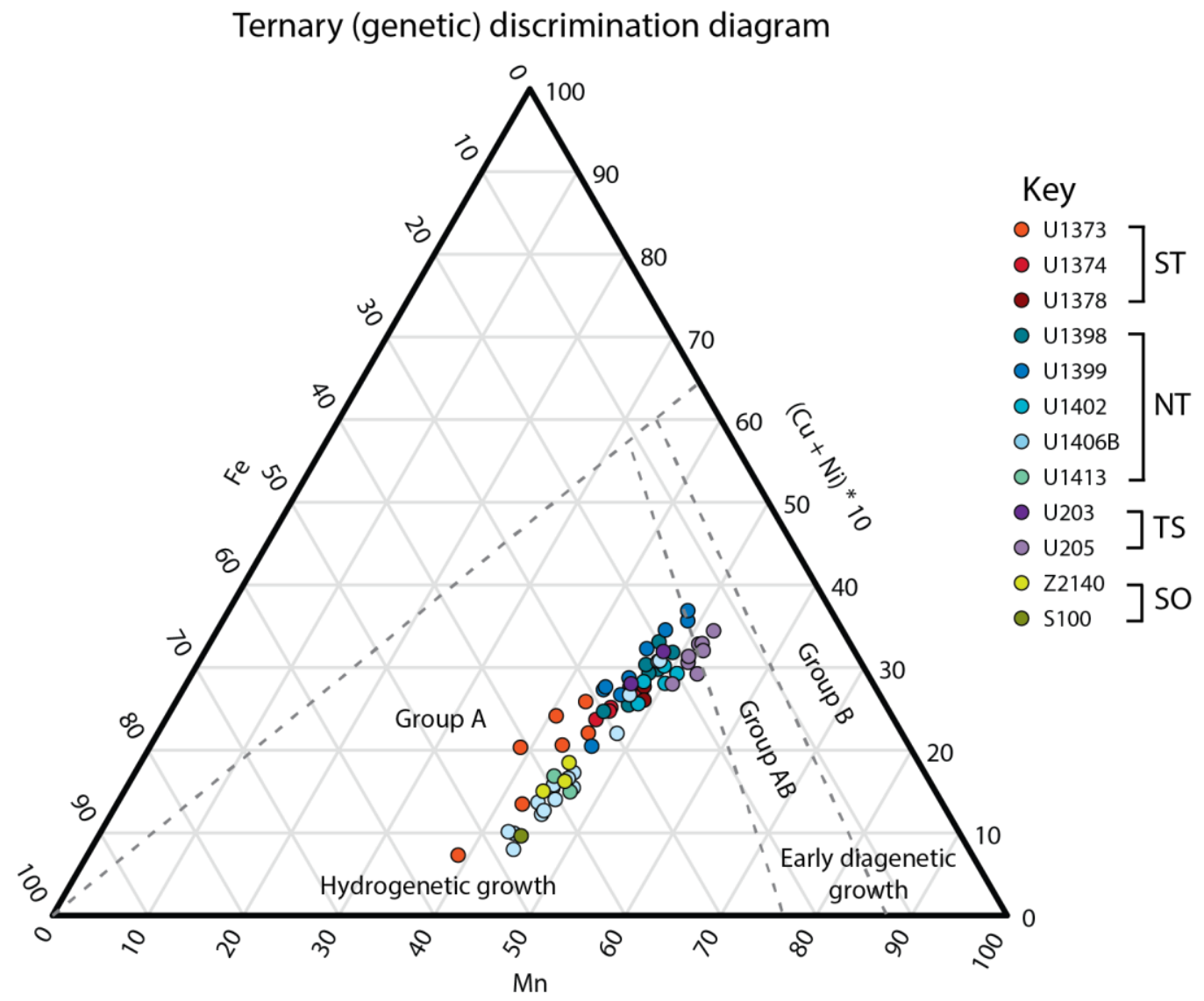

Figure 4.12: Ternary diagram with $\mathrm{Fe}-\mathrm{Mn}-(\mathrm{Ni}+\mathrm{Cu})^{*} 10$ adapted from Bonatti (1972), Halbach et al. (1988), and Wegorzewski and Kuhn (2014) to distinguish the genetic growth types of the ferromanganese nodules. Samples in Group A are consistent with hydrogenetic growth. Group AB represents mixed-type nodules, with compositions consistent with growth from both hydrogenetic and diagenetic processes. Group B is consistent with suboxic diagenetic nodule growth. 


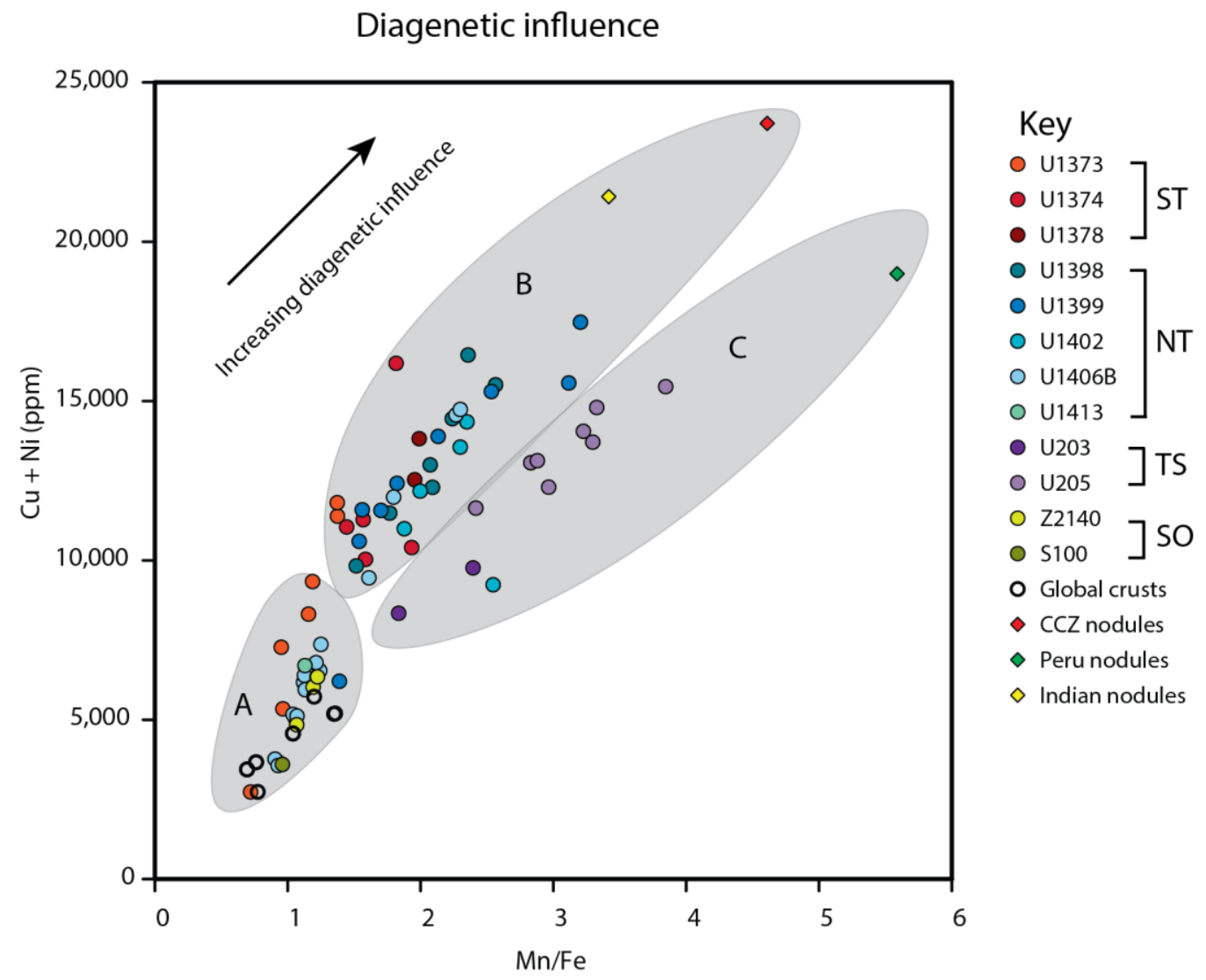

Figure 4.13: $\mathrm{Cu}+\mathrm{Ni}(\mathrm{ppm})$ concentrations vs. $\mathrm{Mn} / \mathrm{Fe}$ for samples analysed in this study. This figure is similar to the hyperbolic regression curves of Halbach et al. (1981), with larger $\mathrm{Mn} / \mathrm{Fe}$ ratios indicating increasing diagenetic influence on growth, but as no nodules have a $\mathrm{Mn} / \mathrm{Fe}$ ratio > 5, no "point of reversal" is observed. A - hydrogenetic growth, B - mixed hydrogenetic-diagenetic growth, with endmembers of compiled bulk CCZ and Indian nodule field data from Hein et al. (2013), C - mixed hydrogenetic-diagenetic growth, with lower $\mathrm{Cu}+\mathrm{Ni}$ and an endmember of compiled bulk Peru Basin nodules from Hein et al. (2013). The endmembers represent bulk analyses; nodules within the field, and individual growth layers, will plot over a range (Figure 4.4) (Wegorzewski and Kuhn, 2014).

The full suite of trace elements for the New Zealand nodules are summarised in multielement plots normalised to Upper Continental Crust (UCC) values (Figure 4.14). The elements are arranged in order of decreasing concentration in the average Southern Ocean samples. These were selected as all samples in this group represent the hydrogenetic endmember for the New Zealand suite. The trace element pattern is the same for all the nodules from the Campbell nodule field that show near pure hydrogenetic formation (e.g. $\mathrm{Mn} / \mathrm{Fe}<1.2$ ). Enrichment of base metals (compared to UCC) range from a factor of 180 250 for $\mathrm{Mn}, 110-252$ for Mo, 75-375 for Co, 40-140 for Ni, and 15-120 for $\mathrm{Cu}$.

Whilst all the nodules follow the same general trend of decreasing concentrations from left to right in Figure 4.14, there are some distinctive spikes to higher or lower concentrations. Samples from the Southern Ocean locations S100 and Z2140 are very similar, except that $\mathrm{S} 100$ has higher concentrations of $\mathrm{Co}, \mathrm{Bi}, \mathrm{Pb}, \mathrm{Cu}$, and $\mathrm{P}_{2} \mathrm{O}_{5}$. 
Samples from the two Tasman Sea nodule locations U203 and U205 display similar patterns to each other, although the U203 samples have higher concentrations of $\mathrm{Al}$ and lower Cr. Overall, nodules from the Tasman Sea locations tend to have lower concentrations of most elements compared with the Southern Ocean samples, particularly the elements $\mathrm{Co}, \mathrm{Bi}, \mathrm{Pb}, \mathrm{Tl}, \mathrm{As}$, and $\mathrm{Ce}$. The exception to this are $\mathrm{Li}, \mathrm{Zn}, \mathrm{Cu}, \mathrm{Cd}, \mathrm{Ni}, \mathrm{Ba}$, $\mathrm{Cr}, \mathrm{Al}$, and $\mathrm{Rb}$ which display enrichments relative to the Southern Ocean samples.

Both southern and northern Campbell nodules display a range of multi-element patterns, with samples from locations U1413 and U1406B having similar patterns to the SO nodules, and samples from locations U1374, U1378, U1398, U1399, and U1402, showing enrichment in $\mathrm{Li}, \mathrm{Zn}, \mathrm{Cu}, \mathrm{Cd}, \mathrm{Ni}$ and $\mathrm{Ba}$, similar to Tasman Sea nodules. Other locations are intermediate between these.

Ferromanganese nodules from the southern Campbell nodule field transect generally display systematic variations depending on where along the transect they lie. Samples from locations U1378 and U1374 show very similar trace element patterns, whereas samples from the U1373 location display the most variation, particularly in the elements $\mathrm{Ni}, \mathrm{Tl}, \mathrm{Cd}, \mathrm{Ba}$, and $\mathrm{Li}$, with overall trace element patterns ranging from being similar to the Southern Ocean samples, to those showing similar enrichment patterns to samples from location U1374 and U1378. Nodules from this transect display slightly lower REE and $\mathrm{Y}$ element concentrations ( $\Sigma \mathrm{REY}, 0.12 \mathrm{wt} \%$, Appendix D) than those found up current at Z2140 in the Southern Ocean ( $\mathrm{REY}, 0.15 \mathrm{wt} \%$ ).

The northern Campbell nodule field transect exhibits by far the largest diversity in element composition. Samples from U1413 display similar trends to the Southern Ocean samples and some nodules from U1373. There is large amount of variation in the U1406B nodules, with samples ranging from trace element patterns similar to U1413 and the Southern Ocean endmembers, to trace element patterns more akin to those of the Tasman Sea nodule field samples. Samples from locations U1402, U1399, and U1398 also exhibit patterns similar to the Tasman Sea nodule field. Averaging the $\Sigma$ REY data from this transect to shows lower $\Sigma$ REY contents $(0.11 \mathrm{wt} \%)$ than those from the Southern Ocean and southern transect, but higher than those from the Tasman Sea ( $\mathrm{REY}, 0.05 \mathrm{wt} \%$ ). However when averaging the samples from locations that exhibited compositions consistent with hydrogenetic growth in this transect (i.e. U1413 and U1406B) the average $\Sigma$ REY is much higher $(0.15 \mathrm{wt} \%)$, comparable to those from the Southern Ocean, with the remaining locations (U1402, U1399, and U1398) having average $\Sigma$ REY of $0.07 \mathrm{wt} \%$. 
This confirms that although samples from the southern transect, and locations U1402, U1399, and U1398 from the northern transect both display patterns consistent with influence from diagenetic growth the southern transect is more enriched in REE and Y. 


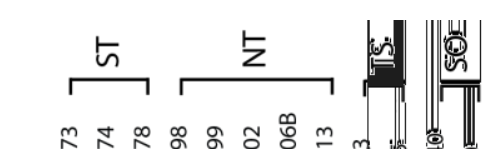

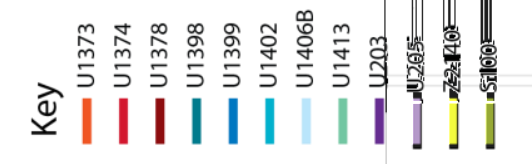
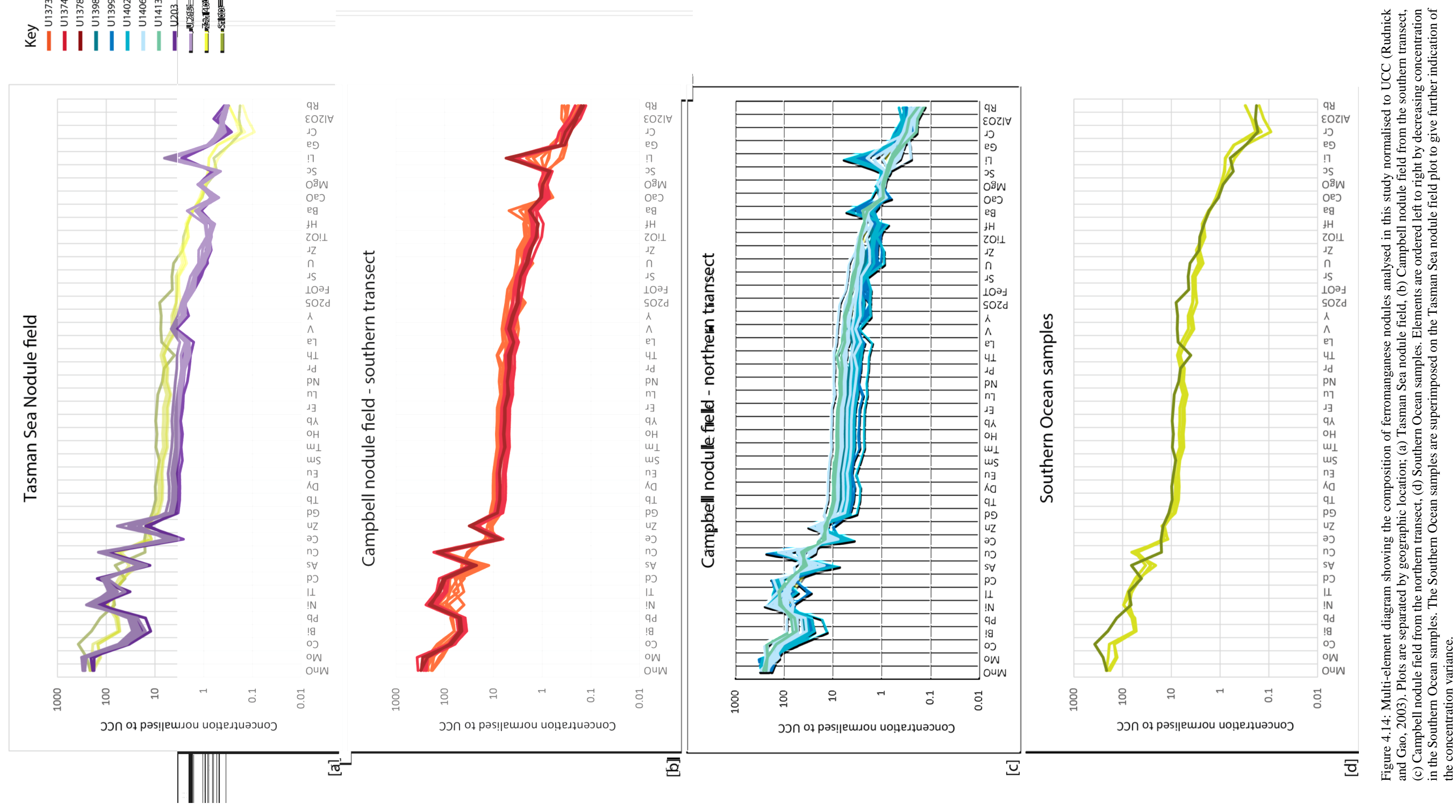
Post-Archaean Average Shale (PAAS) (McLennan, 1989) normalised REE patterns for the nodule suite are presented in Figure 4.15. All samples display similar trends, with a positive Ce anomaly, and higher concentrations of the medium REE. The Ce anomaly ( $\mathrm{Ce}_{\mathrm{SN}} / \mathrm{Ce}_{\mathrm{SN}}$ ) (Bau et al., 2014) has been calculated using Equation 4.4, and values for each nodule are given in Appendix D.

$$
C e_{S N}^{*}=0.5 L a_{S N}+0.5 P r_{S N}
$$

Equation 4.4: Ce anomaly calculation from Bau et al. (2014). SN - shale normalised to PAAS (McLennan, 1989).

Samples from the Tasman nodule field display the lowest overall concentrations of REE, with samples from U203 lower than those from U205. By constrast, the Southern Ocean samples display REE concentrations amongst the highest analysed. The S100 sample has higher concentrations of HREE (Gd, Tb, Dy, Ho, Ir, Tm, Yb and Lu).

For the southern Campbell nodule field transect, samples from U1373 have the largest range in REE concentrations and U1373 include the samples displaying the most enrichment in REE, with concentrations comparable to the Southern Ocean samples. Samples from this transect are generally more enriched in REE than the Tasman Sea nodule field.

The northern Campbell nodule field transect samples have the most overall variability (up to an order of magnitude). Nodules from U1413 and some from U1406B tend to be the most enriched and are comparable to the Southern Ocean samples and most enriched samples from U1373. Nodules from U1402, U1399, and U1398 are less enriched and are comparable to the least enriched sample from U203 in the Tasman nodule field. 

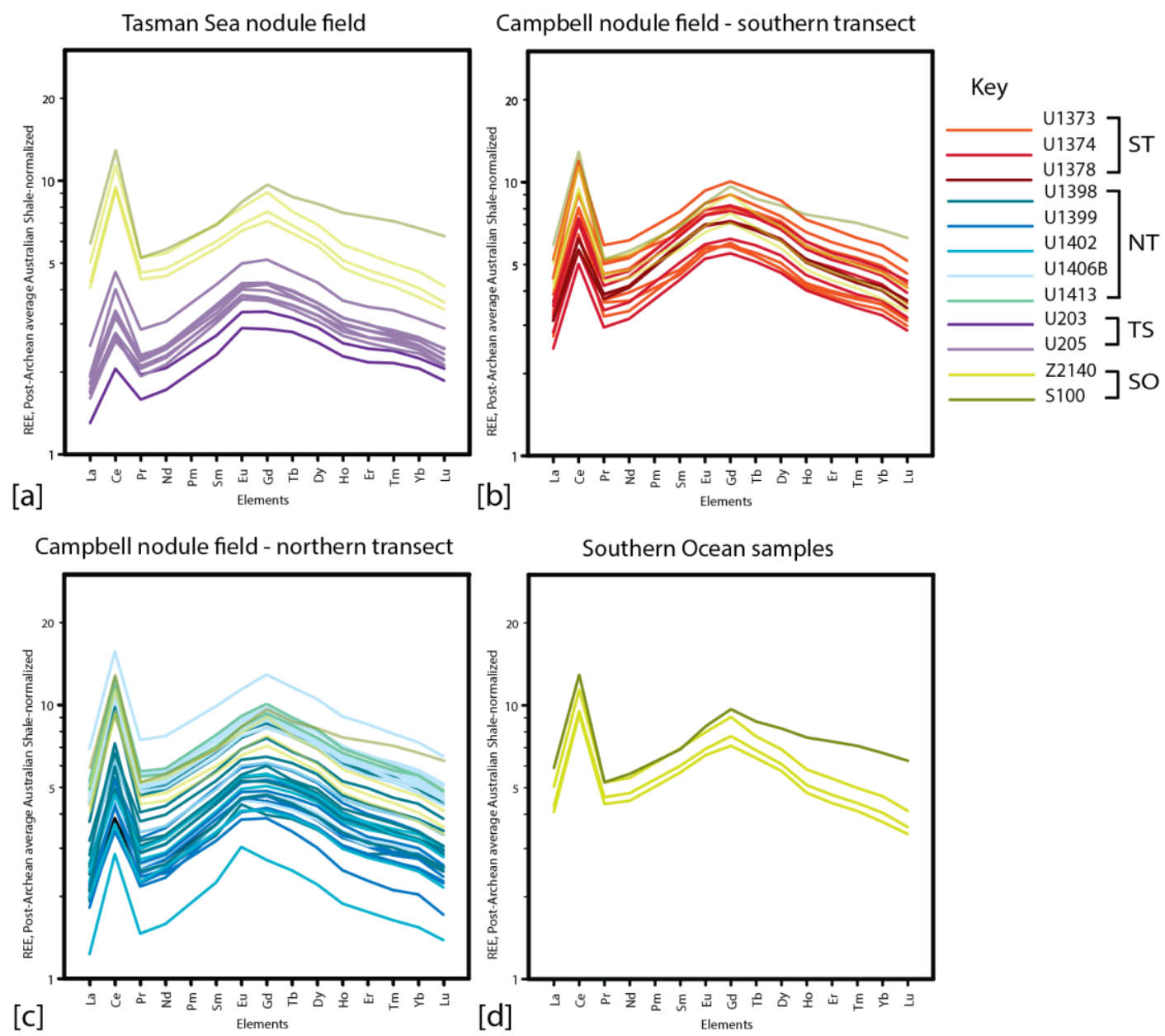

Figure 4.15: Shale (PAAS) normalised REE concentrations of ferromanganese nodules from; (a) Tasman Sea nodule field, (b) southern Campbell nodule field, (c) northern Campbell nodule field, (d) Southern Ocean. The Southern Ocean samples are superimposed onto the REE diagrams from the other locations. The radioactive REE element Pm was not measured on the ICP-MS, and was filled in using Aabel (2014) plotting software.

\subsection{Discussion}

\subsubsection{Influence of the detrital component on bulk compositions.}

The detrital component was isolated to determine the elements associated with this phase and thus determine which elements will be influenced by any detrital material incorporated into the nodules and which are dominated by the authigenic Fe-Mn (oxyhydr)oxide phase. Elements associated with the authigenic Fe-Mn (oxyhydr)oxide phase will provide information on the deep-sea environment and nodule formation. The results of the leaching experiments are shown in Figure 4.11.

The main elements associated with the detrital phase in all locations are $\mathrm{Cr}, \mathrm{Rb}, \mathrm{Al}, \mathrm{Zr}$, Hf, Ga, Sc, Ca, Li, Mg, and Ti (Figure 4.11). The elements Si, K, Al, Ti, Th, Zr, Rb, Fe, and $\mathrm{Mg}$ are expected to be associated with common detrital minerals such as clays, $\mathrm{Fe}-\mathrm{Ti}$ oxides, and zircon (Li \& Schoonmaker, 2003); however, Si and K were not measured on the ICP-MS. The presence of $\mathrm{Ca}$ in the analysed detrital components could indicate a 
carbonate phase and the lack of significant $\mathrm{P}$ incorporated in the detrital component indicates it is not a significant CFA phase. The sediment from U203 in the Tasman Sea has more clay $(7.5 \%)$ and lower amounts of calcium carbonate (3.9\%) (Table 3.2), which may also explain the lower Ca contents in the residue from U205 than those from the Campbell nodule field (Figure 4.11). The presence of other detrital components are compatable with detrital minerals observed in sediments from the nodule locations, including alkali feldspar (e.g. Al, Rb, Li), plagioclase (e.g. Al), olivine (e.g. Mg), pyroxene (e.g. Sc), amphibole (e.g. Ti), mica (e.g. Rb, Ga), clay (many elements), lithic fragments (Table 3.3) and calcium carbonate (e.g. Ca). The presence of $\mathrm{Zr}$ and $\mathrm{Hf}$ in all locations suggests the presence of zircon, and high REE, Th, and $U$ in Tasman samples suggest the presence of other heavy minerals such as monazite, ilmenite, and rutile.

Cr is mainly (70-88\%, residue:bulk ratio) (Figure 4.11, Appendix D) associated with the detrital phase in this leaching experiment. Previous leaching analyses of nodules e.g. Mohwinkel et al. (2014), and statistical testing e.g. Chang et al. (2003b) did not analyse for $\mathrm{Cr}$ in the nodules. Sequential leaching of ferromanganese crusts (Koschinsky and Hein, 2003) indicated $\mathrm{Cr}$ is predominantly associated with the Fe oxyhydroxide phase. In this study, the high proportion of $\mathrm{Cr}$ attributable to the detrital component may reflect the observed occurrence of pyroxene grains in the sediment, which does occur as a phase in associated sediments (see Chapter 3, Table 3.3).

Elements $\mathrm{Mo}, \mathrm{Mn}, \mathrm{Tl}, \mathrm{Ni}, \mathrm{Bi}, \mathrm{Co}, \mathrm{Pb}, \mathrm{Cu}, \mathrm{Cd}, \mathrm{Zn}, \mathrm{As}$, and REE are strongly (> 95\%) attributed to the authigenic component. $\mathrm{Mo}, \mathrm{Mn}, \mathrm{Tl}, \mathrm{Co}, \mathrm{Cu}$, and $\mathrm{Ce}$ are redox sensitive elements (Koschinsky and Hein, 2003), and sorption and surface oxidation to authigenic $\mathrm{Fe}$ and Mn (oxyhydr)oxide surfaces explains their strong enrichment.

\subsubsection{Sample reproducibility}

To be able to use the nodule data to investigate spatial variability in trace element signatures, it is important to evaluate how representative an analysis is for the sample nodule. This was tested in two ways. First; full replicate analyses of a single sample to test powder homogeneity, and second; separate sampling of different hemisphere rims from four individual samples.

The sample powder for U1413-1-B was used as an in-house standard and dissolved and analysed in four separate batches. The relative standard deviation (RSD) was found to be 
$<5 \%$ for all elements (Table 4.5). This is excellent reproducibility, and indicates the sample powder was homogenous, and all detrital components fully dissolved.

The results of the comparisons of rims from different hemispheres of four individual nodules are shown in Figure 4.10. The sub-samples from U1406B-1-D agreed well for all elements. There is some variance shown for some elements between different subsamples of the other three nodules (U1406B-4-A, U1399-1-A and Z2140). The elements $\mathrm{Cr}, \mathrm{Rb}, \mathrm{Al}, \mathrm{Zr}, \mathrm{Hf}, \mathrm{Ga}, \mathrm{Sc}, \mathrm{Ca}, \mathrm{Li}, \mathrm{Mg}$, and $\mathrm{Ti}$ are associated with the detrital phase as discussed above (Figure 4.12). These elements vary between samples for U1406B-4-A, U1399-1-A and Z2140 and can most simply be attributed to variable amounts of detrital material incorporated into the sampled rims. The difference in the concentrations of $\mathrm{P}$ and Ca for U1399-1-A suggest a variably sampled CFA component. The dissimilarity in concentrations of $\mathrm{Mn}, \mathrm{Tl}, \mathrm{Ni}, \mathrm{Ba}, \mathrm{Cu}, \mathrm{Zn}$, and $\mathrm{Cd}$ for U1406-4-A may be attributed to changes in the relative influence of hydrogenetic-diagenetic components, as higher concentrations in these elements are typical of diagnetic growth (Hein \& Koschinsky, 2014).

The results indicate that there may be some variation between hemispheres, and thus a sampling bias may be introduced. The nodules with hemispheres that displayed the greatest and least variation were both sourced from the U1406B location, indicating that the level of homogeneity is not tied to location. U1406B-4-A was the largest nodule analysed (20 x $20 \mathrm{~cm}$, Appendix C), and showed significant differences between the analysed hemispheres. The nodule U1406B-1-D, which reproduced well, was significantly smaller $(12 \times 10 \mathrm{~cm})$, with U1399-1-A intermediate in size $(18 \times 16 \mathrm{~cm})$. Nodule size may be a key factor in the level of variations in hydrogenetic-diagenetic contribution, with larger (spherical) nodules physically rolling less on the seafloor than smaller (spherical) nodules (Glasby, 2006). The majority of nodules sampled were $<16 \mathrm{~cm}$ (Appendix C). If the size factor is correct, this suggests that the other spherical nodules analysed will be representative of the whole nodule as with U1406B-1-D.

These results may also explain the wide variations in the multi-element patterns observed for the nodules from U1406B (and potentially U1373), as seen in Figure 4.15; with potentially variable diagenetic contributions affecting individual nodules that were then variably sampled depending on which hemisphere was selected. This may also be explained by the shape of the nodules. Further hemisphere analyses would be required to test this relationship, particularly with discoidal, elongate and irregular shaped nodules. 
Discoidal or elongate nodules (e.g. U1373-2-B or U1406B-3-D) may, similarly to the larger spherical nodules, vary in their relative diagenetic influence depending on which hemisphere was sampled.

\subsubsection{Geochemistry of the New Zealand nodule fields}

Nodules may be mixtures of growth types. The formation mechanism affects the trace element signature of the ferromanganese nodules. Hydrogenetic nodules typically have $\mathrm{Mn} / \mathrm{Fe}$ ratio of $\sim 1-2.5$, lower $\mathrm{Cu}$ and $\mathrm{Ni}$ contents, and higher REE concentrations than nodules with a diagenetic influence. Hydrogenetic nodules are particularly associated with enrichment in the elements $\mathrm{Co}, \mathrm{Pb}$, and $\mathrm{Ce}$. Diagenetic nodules are associated with enrichment in $\mathrm{Li}, \mathrm{Ni}, \mathrm{Cu}, \mathrm{Zn}, \mathrm{Mo}$, and Ga. As discussed above, the detrital component of the nodules tested from the New Zealand nodule fields is composed of elements such as $\mathrm{Cr}, \mathrm{Rb}, \mathrm{Al}, \mathrm{Zr}, \mathrm{Hf}, \mathrm{Ga}, \mathrm{Sc}, \mathrm{Ca}, \mathrm{Li}, \mathrm{Mg}$, and Ti. Consequently, these elements will be affected by the amount of detrital component, masking the influence of hydrogenetic versus diagenetic factors. Thus, in terms of typical diagnostic trace elements, only Li (diagenetic enrichment) is likely to be affected by variable detrital contributions.

\section{Southern Ocean - hydrogenetic endmembers}

Samples from the Southern Ocean display typical hydrogenetic characteristics. The samples from S100 and Z2140 plot in the hydrogenetic area in Figure 4.12 and the hydrogenetic group A in Figure 4.13. S100 in particular, has almost the lowest $\mathrm{Ni}+\mathrm{Cu}$ and $\mathrm{Mn} / \mathrm{Fe}$, and plots amongst the ferromanganese crust field which represents hydrogenetic formation (Figure 4.13). The multi-element figures were ordered to produce a smooth decreasing pattern for the average Southern Ocean nodules. The variations are thus small, but highlight subtle differences in the trace element signatures of these nodules. S100 samples have higher concentrations than the Z2140 samples for Mo, Co, $\mathrm{Bi}, \mathrm{Pb}, \mathrm{V}$, and $\mathrm{REE}$, and lower $\mathrm{Cu}$ and $\mathrm{Th}$ (Figure 4.14 and Figure 4.15). The lower $\mathrm{Cu}$ coupled with higher $\mathrm{Co}, \mathrm{Pb}, \mathrm{Bi}$, and REE in $\mathrm{S} 100$ samples may indicate a stronger hydrogenetic contribution than found in Z2140. REE profiles for S100 and Z2140 are similar, with the exception of higher REE Gd, Tb, Dy, Ho, Er, Tm, Yb, and Lu in the nodule from S100 (Figure 4.15). This may be caused by alteration of the sample through phosphatisation, which alters REE distribution to become more similar to the pattern seen in seawater whilst maintaining the positive Ce anomaly characteristic of ferromanganese nodules (Koschinsky et al., 1997; Bau et al., 2014). The S100 nodule contains 1.21 wt\% 
$\mathrm{P}_{2} \mathrm{O}_{5}$, the highest of all samples analysed (Appendix C), and phosphate nodules are known from this area (Frontin-Rollet, 2016) indicating changing environmental conditions.

\section{Tasman Sea nodules}

The Tasman Sea nodules (locations U203 and U205) display very different geochemical trends to those found in the Southern Ocean. Based on $\mathrm{Fe}, \mathrm{Mn}, \mathrm{Cu}$ and Ni concentrations (Figure 4.12) the majority of nodules from U205 have a mixed hydrogenetic-early diagenetic type growth, whereas the samples from U203 display predominantly hydrogenetic growth, albeit with a diagenetic contribution. Overall, the nodules from U203 and U205 have similar trace element patterns (Figure 4.14), with the exception of U203 samples having a higher concentration of Al and lower $\mathrm{Cr}$, which likely reflects differing detrital contributions (e.g. more alumino-silicate phases and less (or no) pyroxene). The Tasman nodule field samples are generally less enriched in trace elements than the Southern Ocean samples, with $\mathrm{Co}, \mathrm{Bi}, \mathrm{Pb}, \mathrm{Tl}, \mathrm{As}$, and Ce significantly lower in concentration. The exception to this trend are $\mathrm{Li}, \mathrm{Zn}, \mathrm{Cu}, \mathrm{Cd}, \mathrm{Ni}, \mathrm{Cr}, \mathrm{Al}$, and $\mathrm{Rb}$, which are relatively enriched in the Tasman Sea nodules (Figure 4.15). Li, Cr, Al, and Rb are associated with the detrital phase (Section 4.3.3), suggesting that the Tasman Sea nodules have a higher detrital component than the Southern Ocean nodules. The higher levels of $\mathrm{Zn}, \mathrm{Cu}, \mathrm{Cd}$, and $\mathrm{Ni}$, coupled with lower $\mathrm{Co}, \mathrm{Bi}, \mathrm{Pb}, \mathrm{Tl}$, $\mathrm{As}$, and $\mathrm{Ce}$ are further indications of a higher degree of diagenetic contribution to the Tasman nodules compared to the Southern Ocean samples.

Nodules from both Tasman Sea locations show characteristic ferromanganese (oxyhydr)oxide profiles in the PAAS-normalised REE diagram (Figure 4.15), with a positive $\mathrm{Ce}$ anomaly indicative of seawater origin and the adsorption of $\mathrm{Ce}$ to the $\mathrm{Fe}$ and Mn (oxyhydr)oxide surface (Elderfield et al., 1988). The REE enrichment is higher in the samples from U205, relative to those from U203, however this is not consistent with the consideration that U205 nodules have a greater diagenetic influence than U203 nodules (Figure 4.13). This may be explained by the larger REE component in the detrital phase (i.e. REE-bearing minerals) observed for U205 (Figure 4.13) compared to the other leached samples, however leaching of nodules from U203 would need to be undertaken to identify the composition of the detrital component at this location to be able to evaluate the difference in the REE concentrations with certainty.

In Figure $4.13(\mathrm{Cu}+\mathrm{Ni}$ vs $\mathrm{Mn} / \mathrm{Fe})$ samples from both sites plot in area $\mathrm{C}$ with relatively low $\mathrm{Cu}+\mathrm{Ni}$ for a given $\mathrm{Mn} / \mathrm{Fe}$ compared to the other $\mathrm{NZ}$ nodules. The average 
composition from the Peru nodule field falls at the higher $\mathrm{Mn} / \mathrm{Fe}$ extension of the area $\mathrm{C}$ trend. (Wegorzewski and Kuhn, 2014) interpret lower $\mathrm{Ni}+\mathrm{Cu}$ contents in the Peru nodule field relative to the $\mathrm{CCZ}$ to a higher contribution of suboxic layers relative to hydrogenetic layers, and due to a lower supply of trace elements in the surrounding environment. Nodules from U205 have a Mn/Fe ratio > 2.5 (Appendix D), suggesting it they may also have had a suboxic diagenetic influence.

\section{Campbell nodule field}

Samples from the Campbell nodule field show significantly more chemical variability than either the Southern Ocean or Tasman Sea samples (Figures 4.15, 4.16).

\section{Campbell nodule field - southern transect}

The samples from this transect come from three locations: U1373, U1374, and U1378, listed in order of increasing distance from the Campbell shelf (Figure 4.5)

All samples from this transect fall in the hydrogenetic growth region of Figure 4.12. In $\mathrm{Cu}+\mathrm{Ni}$ versus $\mathrm{Mn} / \mathrm{Fe}$ space (Figure 4.13) nodules from U1373 mainly fall in area A, which is interpreted as hydrogenetic growth. Samples from U1374 and U1378 are all located in area B, which indicates an increasing influence of diagenetic growth. In addition they have positive $\mathrm{Ce}$ anomalies (Figure 4.15), which is also indicative of hydrogenetic growth.

The higher concentrations of $\mathrm{Mo}, \mathrm{Ni}, \mathrm{Cd}, \mathrm{Cu}, \mathrm{Zn}$, and $\mathrm{Li}$, and lower $\mathrm{Co}, \mathrm{Bi}, \mathrm{Pb}, \mathrm{Ce}$ in U1378, U1374 and some samples from U1373, are similar to those seen in the Tasman nodule samples (Figure 4.14), and can be interpreted as reflecting the variable influence of diagenetic processes. However, there are differences from the pattern of enrichments compared to the Tasman Sea nodules, with $\mathrm{Tl}$ higher, and Ba relatively enriched in nodules from U1373. This may be related to the detrital component, with alkali feldspar minerals which are associated with Ba (GERM Partition Coefficient (Kd) Database, 2015), and identified in U1373 (Table 3.3).

Samples from locations along this transect indicate increasing diagenesis with increasing distance from the continental slope (Figure 4.5). However, samples from U1373, the location closest to the slope, display the most compositional variability. This could be caused by current activity, nodule shape and nodule size (Appendix $C$ ). The seven nodules from U1373 include five spherical nodules with diameters ranging from 6 to $16 \mathrm{~cm}$, and 
two elongate nodules $\leq 7 \mathrm{~cm}$ in their longest axis. The highest $\mathrm{Mn} / \mathrm{Fe}$ ratios (1.16 to 1.37), indicative of greater diagenetic influence, are found in the two largest spherical nodules (1-A, 2-A) and the two non-spherical nodules (2-D, 2-E) (Appendix C). The smaller spherical nodules have $\mathrm{Mn} / \mathrm{Fe}<1$. This is consistent with the earlier suggestion that smaller spherical nodules may roll more readily in the currents, reducing the influence of diagenetic processes.

\section{Campbell nodule field - northern transect.}

The northern transect comprises samples from five locations: U1413 (offset from the main transect towards Bollons Seamount), U1406B, U1402, U1399, U1398, listed in order from closest to shelf to furthest away (Figure 4.5).

Two samples from U1399 fall in the mixed hydrogenetic - diagenetic growth field (Figure 4.12), with relatively high $\mathrm{Cu}+\mathrm{Ni}$ and $\mathrm{Mn} / \mathrm{Fe}$, with the remainder ranging across the hydrogenetic field. Samples from the northern transect fall in all three nodule groups based on $\mathrm{Cu}+\mathrm{Ni}$ and $\mathrm{Mn} / \mathrm{Fe}$ (Figure 4.13), although only one sample (from U1402) lies in group C. Sample U1399-2-E plots in hydrogenetic endmember area A, and has a B ${ }_{r}^{s_{r}}$ morphology (Appendix C) where it forms a thin ferromanganese coating on a rock fragment. This can account for the low $\mathrm{Mn} / \mathrm{Fe}$ ratio, as this sample is more crust-like in nature, and hence would be expected to have little if any diagenetic influence.

Nodules from U1413 and some samples from U1406B have similar trace element profiles to the Southern Ocean samples, and tend to be more enriched in $\mathrm{Co}, \mathrm{Bi}, \mathrm{Pb}$, the REE, Th, $\mathrm{V}, \mathrm{Y}, \mathrm{P}, \mathrm{Fe}, \mathrm{Sr}, \mathrm{U}, \mathrm{Zr}$, Ti, and Hf than the Southern Ocean samples. This is a similar trace element pattern to that identified in nodules from U1373 (southern transect). Samples from the locations U1402, U1399, and U1398 display trace element profiles similar to those seen in U1374 and U1378 in the southern transect. Thus, this transect displays similarities with the southern transect, with samples U1402, U1399, and U1398 further from the slope tending to display more diagenetic characteristics than U1406B and U1413 closer to the slope.

\subsection{Conclusions}

Major and trace element chemistry of the outer rims of nodules from locations around New Zealand have been presented. Reproducibility based on replicates of individual powdered samples was excellent, however reproducibility based on sub-sampling different hemispheres was variable, particularly with elements: $\mathrm{Cr}, \mathrm{Rb}, \mathrm{Al}, \mathrm{Zr}, \mathrm{Hf}, \mathrm{Ga}$, 
$\mathrm{Sc}, \mathrm{Ca}, \mathrm{Li}, \mathrm{Mg}$, and Ti, associated with the detrital phase, and elements: Mo, Mn, Tl, Ni, $\mathrm{Bi}, \mathrm{Co}, \mathrm{Pb}, \mathrm{Cu}, \mathrm{Cd}, \mathrm{Zn}, \mathrm{As}$, and REE, associated with the authigenic phase. By examining the chemical composition it is possible to interpret the formation and trace element incorporation of the nodules. The nodules from the Tasman Sea display a greater diagenetic influence, and extend into the mixed hydrogenetic-early diagenetic growth compositional field. It was found that whilst all the samples from the Southern Ocean and Campbell nodule field display dominantly hydrogenetic formation signatures those from the northern and southern Campbell nodule field have a greater compositional range, reflecting variable diagenetic influences and systematic variation with distance from slope, with increased diagenetic influence away from slope. The following chapter will examine the ferromanganese nodule geochemistry in relation to the physical and chemical oceanography and sedimentology discussed in Chapters 2 and 3. 


\section{Chapter 5 Synthesis}

\section{$5.1 \quad$ Introduction}

The outermost rims of ferromanganese nodules from the deep oceans around New Zealand represent material accumulated over approximately 90,000-250,000 years (using a growth rate of $4-11 \mathrm{~mm} / \mathrm{Ma}$ from Graham et al. (2003). This chapter will interpret the authigenic geochemical composition of the analysed nodule rims (Chapter 4) in relation to the oceanography and deep sea sediments discussed in Chapters 2 and 3.

Elements that may be compromised by the detrital component are $\mathrm{Cr}, \mathrm{Rb}, \mathrm{Al}, \mathrm{Zr}, \mathrm{Hf}$, Ga, $\mathrm{Sc}, \mathrm{Ca}, \mathrm{Li}, \mathrm{Mg}$, and $\mathrm{Ti}$, based on leaching experiments on several nodules. $\mathrm{U}$, Th, and the REE may also be associated with detrital components in the Tasman Sea nodules. Key elements (for most samples) that represent the authigenic component are $\mathrm{Mn}, \mathrm{Fe}, \mathrm{Co}, \mathrm{Ni}$, $\mathrm{Cu}, \mathrm{REE}, \mathrm{Zn}, \mathrm{Cd}, \mathrm{Bi}, \mathrm{Tl}, \mathrm{Mo}$, and $\mathrm{Pb}$, and these will therefore reflect formation and enrichment processes.

In the marine environment nutrient-type elements have broadly uniform concentrations throughout the water column and comparable concentrations in different water masses (Chapter 2). By contrast, concentrations of scavenged and hybrid-type elements may vary in the water masses and seawater chemistry may thus influence their uptake into ferromanganese nodules. Elements with scavenged and hybrid-type distribution in the marine environment are $\mathrm{Mn}, \mathrm{Ce}, \mathrm{Pb}, \mathrm{Al}, \mathrm{Fe}, \mathrm{Cu}$ and $\mathrm{Ti}$ (Chapter 2). $\mathrm{Al}$ and $\mathrm{Ti}$ have been identified to signify the detrital phase in manganese nodules, thus will not display information on seawater concentrations. Likewise, the concentrations of $\mathrm{Mn}, \mathrm{Cu}$ and $\mathrm{Fe}$ may not be useful due to the differing partitioning of the elements between authigenic hydrogenetic and diagenetic growth mechanisms. Ce is characteristic of the hydrogenetic influence on nodules, but the distribution of Ce could not be well characterised for the LCDW (Chapter 2), as only one transect displaying Ce concentrations was available. This leaves $\mathrm{Pb}$, which may be expected to be lower in nodules near the nepheloid layer due to particle scavenging, however there is no clear relationship between $\mathrm{Pb}$ content in the nodules and the observed distribution of the nepheloid layer. Instead, Pb concentrations 
broadly decrease with increasing $\mathrm{Mn} / \mathrm{Fe}$, and are uniformly lowest in the Tasman Sea nodules that are characterised by high $\mathrm{Mn} / \mathrm{Fe}$ and larger diagenetic input (Appendix $\mathrm{D}$ ), and where no nepheloid layer has been reported. The Tasman Sea sediments are relatively rich in clays, consistent with their lower energy environment, and $\mathrm{Pb}$ may be scavenged into the clay particles reducing availability for the nodules. Alternatively, the relationship of decreasing $\mathrm{Pb}$ content with $\mathrm{Mn} / \mathrm{Fe}$ may simply reflect interplay of hydrogenetic and diagenetic formation mechanisms, with $\mathrm{Pb}$ uptake enriched in hydrogenetic (lower $\mathrm{Mn} / \mathrm{Fe})$ processes.

\subsection{Southern Ocean nodule field}

There were two nodules from the Southern Ocean; Z2140 is located west of Macquarie Island at 4,058 m depth, and site S100 east of Macquarie Ridge at the base of Campbell Plateau at 2,370 $\mathrm{m}$ depth. At both these locations the nodules have compositions consistent with hydrogenetic growth.

Both samples are located in the LCDW, with the modelled velocity of Carter and Wilkin (1999) (Figure 5.1) suggesting that site S100 is located in low velocity currents, whereas Z2140 is likely located in a high energy environment. The substrates to these localities were not analysed in this study, however the hemisphere comparison on the sample from Z2140 (Figure 4.10) suggests it had incorporated a detrital component. Both samples are above the CCD, which is located at $\sim 4,600 \mathrm{~m}$ in this region (Bostock et al., 2011). The nodule rims are enriched in elements typically associated with hydrogenetic formation (e.g. $\mathrm{Co}, \mathrm{Ce}$, and $\mathrm{Pb}$ ). Fast currents and a mud substrate would readily account for a chemical composition consistent with a low diagenetic contribution and lower concentrations of trace elements such as $\mathrm{Cu}$ and $\mathrm{Ni}$ in samples from Z2140. Evidence for a hydrothermal input (e.g. high Mn, low trace element concentrations) is absent for these nodules. In particular, the high Co content in the S100 rim (0.65 wt\%) suggests no hydrothermal activity in the area, as Co is anti-correlated with hydrothermal activity (Manheim and Lane-Bostwick, 1988). The REE pattern for the nodule from S100 may indicate secondary phosphatisation, due to the higher HREE (Bau et al., 2014). This would be consistent with the observation of phosphate nodules in the area (Frontin-Rollet, 2016).

The overall composition of S100 and Z2140 appears to be most similar to those found in the Cook Islands (Hein et al., 2015), which also display Mn/Fe ratios of around unity and high concentrations of $\Sigma$ REY $(0.17 \mathrm{wt} \%$, samples from Southern Ocean are 0.13- 
$0.18 \mathrm{wt} \%$ ) compared with the CCZ ( $\mathrm{REY}$ of $0.08 \mathrm{wt} \%$ ) and Peru ( $\Sigma \mathrm{REY}$ of $0.04 \mathrm{wt} \%$ ) nodule fields (Hein and Koschinsky, 2014). The Cook Island Nodule Field also is also characterised by strong oxic bottom currents, but is at $>4700 \mathrm{~m}$ depth, deeper than $\mathrm{S} 100$ and Z2140. The sediment type in the Cook Islands is a zeolite-rich brown clay (Hein et al., 2015). Both regions thus have a fine-grained substrate, suggesting the current regime and nodule formation mechanisms may be similar.

\subsection{Campbell nodule field}

Nodules from the Campbell nodule Field fall along two transects roughly perpendicular to the Campbell Slope (Figure 5.1). The southern transect comprises three localities with nodule and sediment samples, and two additional sediment localities. The northern transect has four nodule sample localities on the main transect, and a fifth offset toward Bollons Gap (Figure 5.1). Sediments were also analysed from two additional localities along this transect.

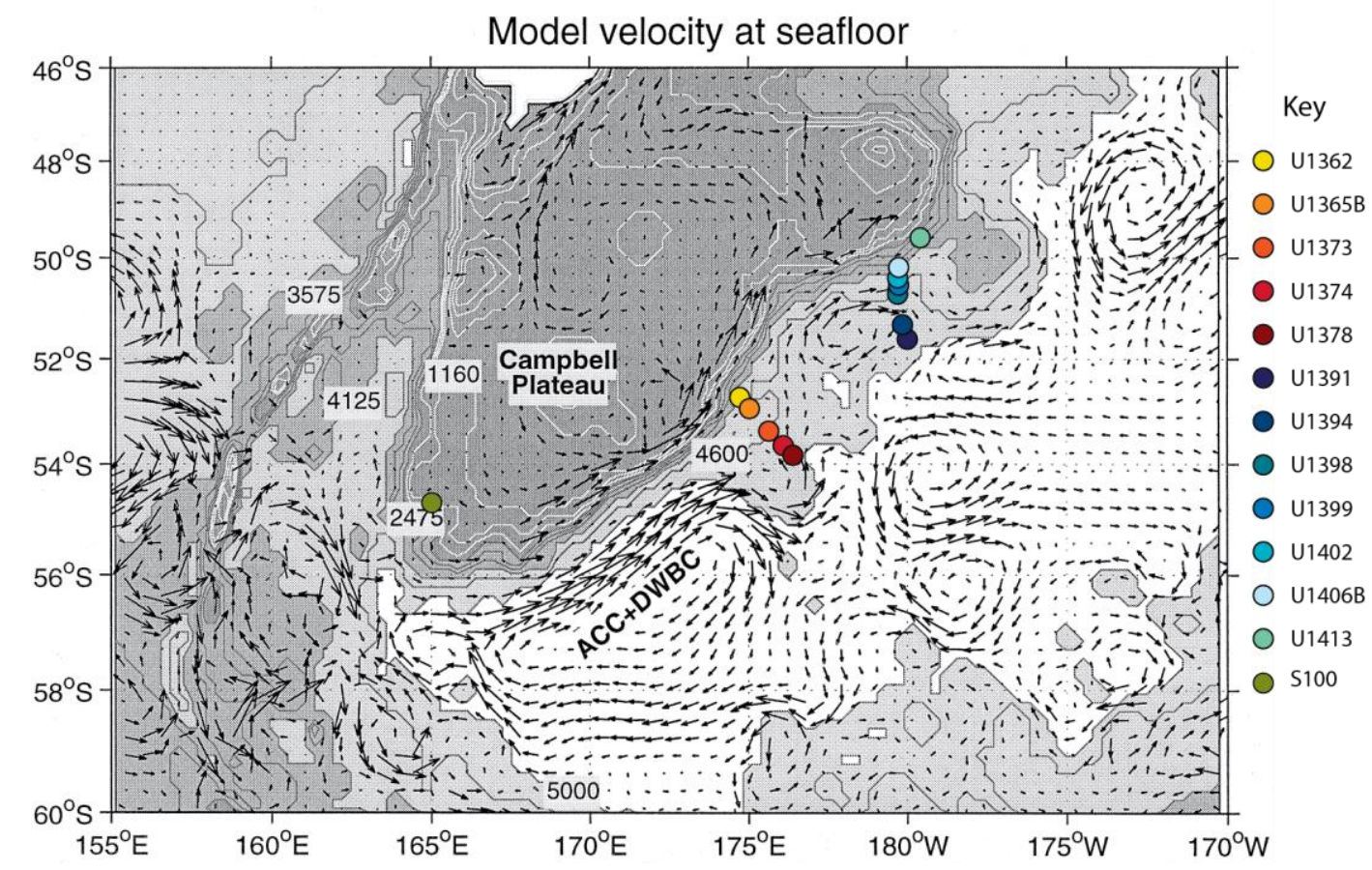

Figure 5.1: Model seafloor current velocity around the Campbell Nodule Field (adapted from Carter and Wilkin, 1999). Arrows are proportional to flow velocity.

All nodules analysed from the Campbell nodule field display positive Ce anomalies, moderately low $\mathrm{Cu}$ and $\mathrm{Ni}$ contents $(0.06-0.64,0.2-1.2 \mathrm{wt} \%)$, and $\mathrm{Mn} / \mathrm{Fe}(0.7-3.2)$, indicating no hydrothermal influence and predominantly hydrogenetic type growth. However, they show systematic variations in their trace element chemistry interpreted as reflecting an increasing diagenetic influence with increasing distance from the Campbell Slope. The Campbell nodule field is characterised by fast currents where the DWBC 
impinges along the Campbell Slope, and eddies occurring approximately nine times a year (Stanton and Morris, 2004).

Nodule samples from U1373 in the southern transect, display compositions indicative of a varied hydrogenetic-diagenetic contribution ranging from similar to the Southern Ocean nodules (hydrogenetic) through to increasing oxic diagenetic character. In contrast, all nodules from U1374 and U1378 further away from the slope exhibit more diagenetic characteristics relative to the samples from the Southern Ocean.

The sediments from the three nodule sites have comparable grainsize distributions, although the sand size component decreases with distance from the slope (20\%, $11 \%$ and $5 \%$, respectively). Only site U1378 has calcium carbonate content $>20 \%$, consistent with it being above the CCD, despite being located at 4,915 m depth, and the CCD thought to be at $\sim$ 4,600 mbsl (Bostock et al., 2011). The three sediments are dominantly silt grainsize, and U1373 and U1374 sediments contained slightly more biogenic silica than site U1378. The terrigenous component of the sediment indicates a largely oceanic crust source (Figure 3.8), with minerals such as quartz, alkali feldspar, amphibole, plagioclase and garnet found in the sand fraction (Table 3.3). The presence of micronodules (Table 3.2) in sediments from this region may indicate a moderately shallow oxic-suboxic boundary, as micronodules precipitate in oxic sediments, and a deep oxic zone (e.g. 1$2 \mathrm{~m}$ ) would not be sampled by dredging. A moderately shallow oxic-suboxic boundary would explain the chemical composition indicating a diagenetic influence in these nodules as this would supply a larger flux of $\mathrm{Mn}^{2+}$ ions to the ferromanganese (oxyhydr)oxide surface, thus leading to a higher $\mathrm{Mn} / \mathrm{Fe}$ ratio.

The two sediment samples from closer to the slope (U1362 and U1365B) were much coarser grained, and reflect a more continental source, with $\mathrm{U} 1362$ above the CCD, and $\mathrm{U} 1365 \mathrm{~B}$ just below based on $\mathrm{CaCO}_{3}$ content (Table 3.1). These samples displayed erosion patterns (Figure 3.7), and previous analyses of a nodule from U1365B (Plant, 2015) indicates a composition typical of hydrogenetic growth.

Nodules from U1413 in the northern transect near Bollons Seamount display compositions consistent with dominantly hydrogenetic growth, with $\mathrm{Mn} / \mathrm{Fe}$ of $\sim 1.2$, and higher contents of REE compared to other nodules on this transect. This location is the shallowest and is characterised by sediment with the highest calcium carbonate content (Figure 3.4). Neither the modelled current velocity at the seafloor (Figure 5.1) nor the particle distribution indicate the presence of erosive currents. (Carter and McCave, 1997) 
state that nodules from this area were coated in a muddy sediment layer that is likely periodically eroded to keep the nodules at the surface. The absence of constant erosive currents suggests that this location would be more prone to diagenetic influences, with accumulation of sediment and relatively limited nodule rolling. However, the lack of apparent diagenetic influence in nodules from this location may be due to the high biogenic carbonate content in the sediment diluting trace elements in the pore-water (ISA, 2010). Further, over the period of ferromanganese rim accumulation, the periodic erosion required to keep the nodules at the surface, likely associated with the intermittent eddies, may be sufficient to reduce diagenetic processes. The nodules from this site are also quite spherical and smooth (Appendix D), suggesting mobility within the currents during growth.

Nodules from U1406B on the northern transect have major and minor element compositions consistent with both hydrogenetic growth and nodules interpreted to have a larger diagenetic influence (Figure 4.13). The trace element and REE profiles also display this range of patterns (Figure 4.14). Analysis of the sediments from this transect (Figure 3.7) indicates site U1406B undergoes erosion and displays similarities to U1365B in the southern transect with a particle distribution consistent with an erosive environment and a large terrigenous component identified in the sand fraction (Table 3.3). This appears higher than the modelled seafloor velocity of (Carter and Wilkin, 1999) and may be explained by the model using a grid that was too coarse. The greater sand fraction in this sediment may indicate a larger porosity and thus permeability, which in turn would result in a deep oxic layer and potentially increased oxic diagenetic influence, which may be indicated by the higher $\mathrm{Mn} / \mathrm{Fe}$ ratios of several samples from this location (Figure 3.10), however the majority display $\mathrm{Mn} / \mathrm{Fe}$ ratios around unity.

The lack of diagenetic influence in a subset of the nodules from this location may be due to dilution of the trace elements in the pore-water due to the high component of nonreactive terrigenous material and the trace element poor biogenic carbonate in the sediment. Another possible explanation is erosion of the sediments due to the ACC and DWBC and intermittent eddies. Such currents and eddies could disturb the redox profile in the sedimentary column, inputting oxic waters into the sediment. This would have the effect of releasing $\mathrm{Mn}^{2+}$ ions into the overlying seawater where they may oxidise onto a ferromanganese nodule. The larger nodules and underlying (compacted) sediments would likely undergo less movement during eddy activity, which could explain the influence of diagenetic growth on some of the larger nodules. 
Ferromanganese nodules from locations U1402, U1399 and U1398 (Figure 5.1) display compositions consistent with a variable influence from diagenetic growth, and exhibit trace element and REE profiles similar to the nodules from the outer southern transect (U1374 and U1378). Two sub-samples from a U1399 nodule have a Mn/Fe ratio > 3, and a second nodule has a $\mathrm{Mn} / \mathrm{Fe}>2.5$, indicating a composition consistent with significant influence of oxic diagenetic growth. These were from two large nodules $(17 \mathrm{~cm}$ and $18 \mathrm{~cm}$ in diameter), whereas the remaining nodules are all $<10 \mathrm{~cm}$ in diameter, with $\mathrm{Mn} / \mathrm{Fe}$ $\leq 2.1$, so the mechanism hypothesised for the large nodules from the southern transect localities may also be relevant to location U1399.

Sediments from locations U1402, U1399 and U1398 are calcareous silts and all locations are above the CCD. These sediments display particle distributions similar to the nodule locations from the southern transect and do not exhibit the same level of erosion interpreted for the sediment from U1406B. This may explain the higher interpreted diagenetic-growth contribution compared to that seen in the U1406B nodules.

The overall pattern of increasing diagenetic influence in the nodules further from the Campbell Plateau slope at both transects is broadly consistent with the trend in nodule facies proposed by Chang et al. (2003a), based on nodule morphology and seafloor substrate (Chapter 1). However, in detail there are differences; most notably, site U1413, was mapped as a diagenetic facies whereas the chemistry of the samples analysed here are consistent with a hydrogenetic origin and minimal diagenetic influence. On the main transects, the boundary between significant diagenetic influence and a more strongly hydrogenetic origin is closer to the slope on the basis of the nodule rim chemistry, than in the proposed nodule facies. In the southern transect, sites U1373 and U1374 were classed as within an abyssal hydrogenetic facies, and only location U1378 in the abyssal diagenetic facies (Chang et al., 2003a), whereas the nodule outer-rim chemistry indicates a similar diagenetic influence for both U1378 and U1374 nodules, and variable hydrogenetic-diagenetic influence at location U1373. In the northern transect, sites U1402 and U1399 were considered to have a lesser diagenetic influence than site U1398, which is also inconsistent with the chemistry.

Chang et al. (2003a) hydrogenetic interpretation was based on dominantly spherical smooth nodule morphologies, whereas the diagenetic nodules were inferred to be characterised by non-spherical, botyroidal nodules, or fused/multi-nucleated nodules. Whilst analyses of the latter morphologies do seem to show diagenetic chemical 
signatures, several of the larger spherical nodules in particular also showed diagenetic chemical characteristics, suggesting morphology alone may underestimate diagenetic influences. Additionally, the chemistry measured here represents only the outermost rim of the nodules whereas nodule morphology will reflect the cumulative, longer history of the nodule growth and it may be that facies boundaries have shifted over the millions of years that the nodule field has grown.

It has previously been suggested that nodules that form below the CCD on a siliceous substrate are higher in trace elements than nodules that form on terrigenous or biogenic calcium carbonate substrate (Wegorzewski and Kuhn, 2014). Ferromanganese nodules from the Campbell nodule field lie on the same trend as those from the CCZ and the central Indian Ocean basin, but display a generally more hydrogenetic character (Figure 4.13). However, overall the $\mathrm{CCZ}$ nodules typically have higher $\mathrm{Ni}+\mathrm{Cu}$ concentrations for a given $\mathrm{Mn} / \mathrm{Fe}$, than both the central Indian Ocean nodules and the Campbell nodules (Halbach et al., 1981; Hein and Koschinsky, 2014).

Nodules from the $\mathrm{CCZ}$ are enriched in trace elements such as $\mathrm{Cu}$ and $\mathrm{Ni}$ interpreted as a consequence of their formation in siliceous ooze below the CCD (Verlaan et al., 2004). The siliceous ooze is permeable and supplies trace metals by oxic diagenetic processes. The CCZ has a deep oxic-suboxic boundary of 2-3 m under present conditions, but it may have been shallower in the past (Wegorzewski et al., 2015).

The composition of the central Indian Ocean basin nodules varies geographically, but is generally consistent with growth from hydrogenetic and oxic-diagenetic mechanisms $(\mathrm{Mn} / \mathrm{Fe}$ ratio of 1.8-4.8) and lower trace elements than the CCZ (Hein and Koschinsky, 2014). Nodules from this location sit in substrates with a range of siliceous ooze, terrigenous matter, and pelagic clays (Mukhopadhyay et al., 2008).The lower trace metal concentrations in central Indian Ocean nodules compared to $\mathrm{CCZ}$ nodules is considered to be due to the higher terrigenous content leading to a reduced amount of trace elements available to be mobilised during early diagenesis (Mukhopadhyay and Ghosh, 2010). $\mathrm{Cu}+\mathrm{Ni}+\mathrm{Co}$ contents in central Indian Ocean nodules range from $2.48-2.53 \mathrm{wt} \%$ (Hein and Koschinsky, 2014), this is much higher than that found in the Campbell nodule field (0.49-1.87 wt\%) (Appendix D). 


\subsection{Tasman Sea nodule field}

The two Tasman Sea nodule sites, U203 and U205, are located on the northern extension of the slow Tasman deep water boundary current. These samples display the characteristic hydrogenetic positive Ce anomaly, however some samples from U205 have a greater influence from diagenetic processes than observed for most of the other NZ nodules. Nodules from U205 are generally more enriched in all elements (e.g. $\mathrm{Ni}, \mathrm{Cu}, \mathrm{Ce}$, and REE) than the U203 nodules. However, compared to the more southern NZ nodule fields, they have lower concentrations of $\mathrm{Co}, \mathrm{Bi}, \mathrm{Pb}, \mathrm{Tl}$, and $\Sigma \mathrm{REY}$. In particular, nodule samples from both Tasman Sea locations exhibit lower $\mathrm{Cu}+\mathrm{Ni}$ for a given $\mathrm{Mn} / \mathrm{Fe}$, producing a trend on the $\mathrm{Cu}+\mathrm{Ni}$ versus $\mathrm{Mn} / \mathrm{Fe}$ plot that extends towards average Peru Basin nodules (Figure 4.13). Despite this, they do appear in a similar space in the $\mathrm{Cu}+\mathrm{Ni} v \mathrm{vs} . \mathrm{Mn} / \mathrm{Fe}$ discrimination plot (Figure 4.13), they do not appear to form in similar environments. The lower $\mathrm{Cu}$ and $\mathrm{Ni}$ contents in the Peru Basin nodules compared to the $\mathrm{CCZ}$ has been interpreted to be the result of "a higher contribution of suboxic-diagenetic layers and a distinctly lower percentage of hydrogenetic layers in nodules from the Peru Basin" (Kuhn et al., 2017). This would not appear to be the case for the Tasman Sea nodules as no samples from this region have a $\mathrm{Mn} / \mathrm{Fe}$ ratio > 5, indicative of suboxic diagenetic growth, and all samples display a positive Ce anomaly, absent in suboxic diagenetic growth. The nodules from U203 have similar $\Sigma$ REY contents to the Peru nodules $(0.04-0.05 \mathrm{wt} \%$ and $\sim 0.04 \mathrm{wt} \%$, respectively) (Hein and Koschinsky, 2014), and the nodules from U205 have slightly higher $\Sigma$ REY $(0.05-0.08 \mathrm{wt} \%)$. The Peru Basin is also characterised by nodules forming at or above the CCD at 4,250 m depth, and a shallow suboxic zone located $10 \mathrm{~cm}$ below the surface (Koschinsky et al., 2001). By contrast, the Tasman Sea nodules are located below the CCD (Bostock et al., 2011), with U203 and U205 located at 4,919 m and 4,714 m, respectively. The lower $\mathrm{Ni}, \mathrm{Cu}$ and other trace element contents in the Tasman Sea nodules are unlikely to originate from the same processes as in the Peru Basin. Instead, this character may be due to a larger terrigenous component in the sediments resulting in less pore-water enrichment of trace metals, rather than suboxic diagenetic processes.

Both a sediment sample from U203 and the detrital component of a ferromanganese nodule from U205 were analysed. Sediments from U203 are in the mud-sized faction, with negligible biogenic carbonate and little biogenic silica, suggesting a higher terrigenous component than found in the Campbell nodule field. The sediment from the Tasman Sea was interpreted to have reduced permeability due to the higher clay 
component (Table 3.1), which in turn suggests that nodules from this area would have a relatively small contribution from diagenetic processes, due to reduced upward diffusion of $\mathrm{Mn}^{2+}$. Nonetheless, nodules from U203 have Mn/Fe ratios of 1.8-2.4, higher than that expected of pure hydrogenetic samples. Sediment samples were not available from U205, but the leaching experiment indicated that the detrital component included in a nodule rim from site U205 contains significant levels of high field strength elements, actinides, and REE (Figure 4.11), which are commonly associated with heavy minerals such as monazite, ilmenite, and rutile. Samples from U203 may also have similarly high REE contents in the detrital phase. If they do not, it would explain why nodules from U205 display compositions consistent with a higher diagenetic contribution; if they do, it would mean that the measured REE in the U203 nodules overestimates the true concentrations present in the authigenic Fe-Mn (oxyhydr)oxides, in which concentrations are already significantly lower than those seen in nodules from the Campbell nodule field. 


\section{Chapter 6 Conclusions and future work}

\subsection{Conclusions}

This study aimed to characterise the geochemistry of ferromanganese nodules rims from the deep waters around New Zealand, and interpret the formation conditions relative to the regional sedimentology and oceanography.

The samples analysed are from locations several thousand kilometres apart in essentially the same water mass, but with different environmental characteristics (e.g. depth, CCD, sediment source). This is a unique sample set world-wide, as it spans a large spatial range, and has co-existing sediment samples, that allows nodule formation processes to be evaluated from one water mass and in highly varying local conditions. The samples are from the main nodule collection from New Zealand waters, collected from multiple research voyages. They include samples from: northern and southern transects of the Campbell nodule field; samples in the Southern Ocean, to the east and west of Macquarie Ridge; and nodules from the Tasman Sea. The two Southern Ocean locations represent the southwestern-most sampling beneath the LCDW, with the Tasman Sea locations lying along a weaker current transporting the LCDW into the Tasman basin, and the Campbell nodule field locations sampling the LCDW in the main DWBC flow in to the South Pacific Basin. Samples from the Campbell nodule field form two transects approximately perpendicular to the main current and the Campbell Plateau Subantarctic Slope.

Overall, the nodules have compositions dominated by hydrogenetic processes, with lesser, variable oxic-diagenetic influences. Location influences the formation mechanism and composition of the nodules, with an interplay amongst the interrelated current velocity, water depth, and sediment type being key factors. Of these, the main influence on the composition of the Campbell nodule field appears to be the strength of the currents. The most erosive environments, U1406B from the northern Campbell nodule field transect, closest to the slope, and Z2140 to the west of Macquarie Ridge, display the most hydrogenetic composition. Nodules in a less energetic environment (as interpreted on the 
basis of the sediment particle distribution) display a greater influence from diagenetic processes.

By contrast, seawater chemistry appears to play a less critical role, however this could not be fully evaluated for scavenged-type or hybrid-type elements (e.g. $\mathrm{Mn}, \mathrm{Ce}, \mathrm{Pb}, \mathrm{Al}$, $\mathrm{Fe}, \mathrm{Cu}$ and $\mathrm{Ti}$ ) given the sparsity of water chemistry data from the overlying waters.

This study identified endmember compositions for the New Zealand nodule fields, where Southern Ocean and Tasman Sea localities include nodules with hydrogenetic, and mixed hydrogenetic - diagenetic endmember trace element composition profiles, respectively. The Campbell nodule field samples span these two extremes, with some subtle differences apparent when compared to the Tasman Sea diagenetic compositions. There was no indication of hydrothermal influence in any nodules sampled.

Leaching experiments identified the following elements as being significantly (87-10\% of the total element in the bulk rock) influenced by detrital material that may be incorporated into the nodules: $\mathrm{Cr}, \mathrm{Rb}, \mathrm{Al}, \mathrm{Zr}, \mathrm{Hf}, \mathrm{Ga}, \mathrm{Sc}, \mathrm{Ca}, \mathrm{Li}, \mathrm{Mg}$, and $\mathrm{Ti}$ in a general order of decreasing detrital influence. Hence, interpreting variations in these elements with respect to hydrological processes is difficult based on bulk analyses only. For the Tasman Sea samples, a wider range of elements were compromised by the detrital component, including U, Th, and the REE (comprising 4.5-25\% of the total detrital analysis), which most likely reflects greater proportions of heavy minerals in the sediments present at these locations, based on an interpretation of a greater terrigenous, less biogenic sediment composition, and the association of these elements with minerals such as zircon, monazite, ilmenite, and rutile.

The hydrogenetic endmember samples from the Southern Ocean, which showed no evidence for any diagenetic influence, have $\mathrm{Mn} / \mathrm{Fe}$ of $1.0-1.2$, and minor and trace elements incorporated in the following order from generally greater to lesser concentrations normalised to UCC: Mo, Co, Bi, Pb, Ni, Tl, Cd, As, Cu, Ce, Zn, Gd, REE (excluding Ce), Th, V, Y, P, Fe, Sr, U, Zr, Ti, Hf, Ba, Ca, Mg, Sc, Li, Ga, Cr, Al, Rb. This pattern is the same for all the nodules from the Campbell nodule field that show near pure hydrogenetic formation (e.g. $\mathrm{Mn} / \mathrm{Fe}<1.2$ ). Enrichment of base metals (compared to UCC) range from a factor of 180-250 for Mn, 110-252 for Mo, 75-375 for Co, 40-140 for $\mathrm{Ni}$, and $15-120$ for $\mathrm{Cu}$. 
The diagenetic influenced samples, exemplified by the Tasman Sea samples, but also including samples from the Campbell nodule field transects (particularly locations further from the slope), are notably enriched in $\mathrm{Ni}, \mathrm{Cd}, \mathrm{Cu}, \mathrm{Zn}$, and $\mathrm{Li}$ above the hydrogenetic baseline, and to a lesser extent $\mathrm{Co}, \mathrm{Bi}, \mathrm{Pb}, \mathrm{As}$, and $\mathrm{Ce}$. This trend is consistent regardless of location, and supports the assertion that seawater is less influential than sedimentary pore-water.

The composition of sediments from the nodule locations was also documented and evaluated as potential detrital components in nodules from those locations and as factors contributing to potential pore-water chemistry. Sediments from the Campbell nodule field are variable, with some being below the CCD and displaying a mixed biogenic silicaterrigenous composition. The terrigenous component of these sediments is consistent with an oceanic crustal source.

In general, it was found that:

- Sediments located closer to the Campbell Slope have a larger terrigenous component, which is consistent with a continental crustal source, and a grainsize profile indicative of erosive current flow.

- Sediments with larger clasts have a larger diagenetic contribution due to the greater amount of diffusion of $\mathrm{Mn}^{2+}$ ions. This however is not observed in one sample location (U1406B) that exhibits mainly hydrogenetic growth. This may be due to pore-water dilution due to detrital clast non-reactive behaviour during early diagenesis, or due to erosion of the surficial sediments disrupting the diagenetic processes in the sedimentary column by oxidising the $\mathrm{Mn}^{2+}$ ions and promoting authigenic nodule formation.

- A prominent nepheloid layer is also present along the Subantarctic Slope, and eddies that occur approximately nine times a year along the Subantarctic Slope effect the deep-sea sediments, seawater chemistry, and thus the ferromanganese nodule composition. This may explain the hydrogenetic composition of nodules closer to the slope.

Nodules from the Tasman Sea were identified to have lower $\mathrm{Cu}+\mathrm{Ni}$ for given $\mathrm{Mn} / \mathrm{Fe}$ than those found in the Campbell nodule field. Lower trace elements in the Tasman Sea are interpreted to be linked with a higher terrigenous component substrate relative to the 
Campbell nodule field. This suggests that the main control on ferromanganese nodule composition in the Tasman Sea is its sedimentary environment.

\subsection{Future work}

This study answered questions about the composition of, and trace metal incorporation in, ferromanganese nodules from New Zealand nodule fields particularly in relation to the oceanography and sedimentology. However, as with all studies, it raises more questions and some areas that would benefit from further work are indicated in the following.

\subsubsection{Ferromanganese nodules}

The effect of mineralogy on the trace element incorporation and profiles among the nodules could not be investigated in this study. Whilst, previous studies have reported Xray diffraction analyses and mineralogy of nodules from the Campbell nodule field (Chang et al., 2003b) the validity of these analyses is questionable due to the propensity of manganese oxide minerals to alter once out of their natural environment. Thus future work involving immediate XRD analysis of freshly collected nodules from the Campbell nodule field and Tasman nodule field would be key to determine the mineral phases present in the nodules. This information would be vital to fully interpret compositional differences between the Tasman nodule field and the Campbell nodule field identified in this study.

\subsubsection{Sedimentology}

A limitation of this study was the lack of information regarding the exact porosity, permeability and redox condition of the sediments. Attempts were made to mitigate this by interpreting elemental proxies relating to the bulk sediments; however, ideally the porosity and permeability of the sediments would be quantified, and pore-water measurements conducted to identify the redox zones and trace element enrichments/depletions. Pore-water analyses have mainly been concentrated on elements of economic interest such as $\mathrm{Ni}$ and $\mathrm{Cu}$, with less focus on other trace metals. With higher resolution instrumentation it should be possible to analyse a larger range of elements.

The typical HF bulk dissolution does not fully dissolve refractory minerals associated with marine sediments (e.g. zircons). Attempts were made during this study to adapt a method to dissolve the marine sediments for trace metals analysis. The ammonium fluoride method is a fairly new methodology that has typically been used for igneous 
rocks (Hu et al., 2013). Adapting this technique to sediments with a calcium carbonate component proved complex and there was insufficient time to develop and test this fully. Once fully developed and tested, such a method would provide further an increased understanding of the chemistry of the marine sediments.

Micronodules in the sedimentary column are considered to be important sources of $\mathrm{Mn}$ oxide minerals that are recycled during suboxic-diagenesis. Non-steady state diagenesis, as interpreted to occur along the Campbell Slope due to the high energy environment may influence micronodule formation and composition. Further work could be undertaken to fully characterise micronodules, and their relationship between the oxic-suboxic boundaries in erosional environments.

Suspended particles in the nepheloid layer may scavenge elements such as $\mathrm{Mn}$ and $\mathrm{Pb}$ from the water column. Suspended matter in the Campbell nepheloid layer is transported by the fast flowing ACC and DWBC. The ACC bifurcates from the DWBC at $49^{\circ} \mathrm{S}$, causing the DWBC to slow down, leading to a lower energy environment. This may initiate deposition of particles suspended in the nepheloid layer, producing a sediment enriched in these scavenged metals. This could cause a unique environment with an abundance of manganese oxide minerals, which may have consequences for the diagenetic conditions of the sediments. It is likely that due to a high sediment accumulation rate no ferromanganese nodules would form, but analyses of ferromanganese (oxyhydr)oxide coating on foraminifera in the sediment could provide insights into the sedimentary environment.

\subsubsection{Oceanography}

Identifying the full extent of the New Zealand nodule field using bathymetric imaging is a long range, but important objective. The rough sea conditions typical of the Southern Ocean - Southwest Pacific Ocean overlying the nodule field may cause difficulties with conventional ship-based imaging. This could be resolved by using equipment such as a remotely operated submersibles. The specific properties of trace elements in seawater leads to scavenged elements displaying variable concentrations in deep waters. To fully understand the chemical oceanography of the region it is necessary to conduct a GEOTRACES style research voyage in the area to identify the concentration profiles of trace elements in the regions where the nodules are forming. 
The presence of a permanent nepheloid layer along the Subantarctic Slope of the Campbell Plateau will influence the seawater chemistry and sedimentology, and in turn the ferromanganese nodule chemistry. To understand this dynamic environment further work is required such as: identifying the extent of the nepheloid layer, its change over time, examining the chemistry of the suspended particles, and analysing the chemical composition trace metals mobilised and adsorbed in the nepheloid layer. 


\section{Appendix A Oceanography figures}
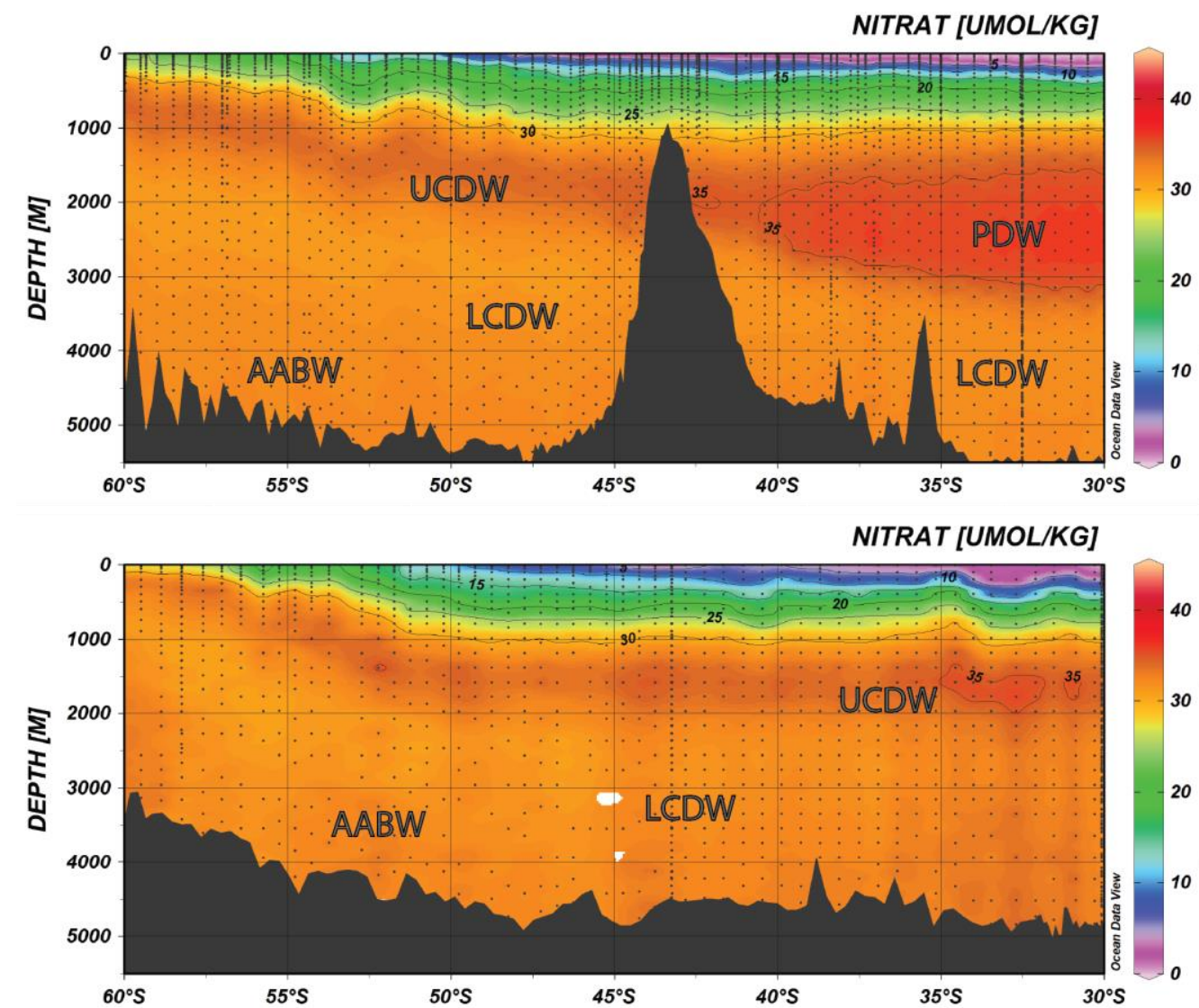

Figure A.1: Nitrate profiles along the P15 and P11 GLODAP transects. The deep water masses: AABW, LCDW, UCDW, and PDW have been identified and labelled. 

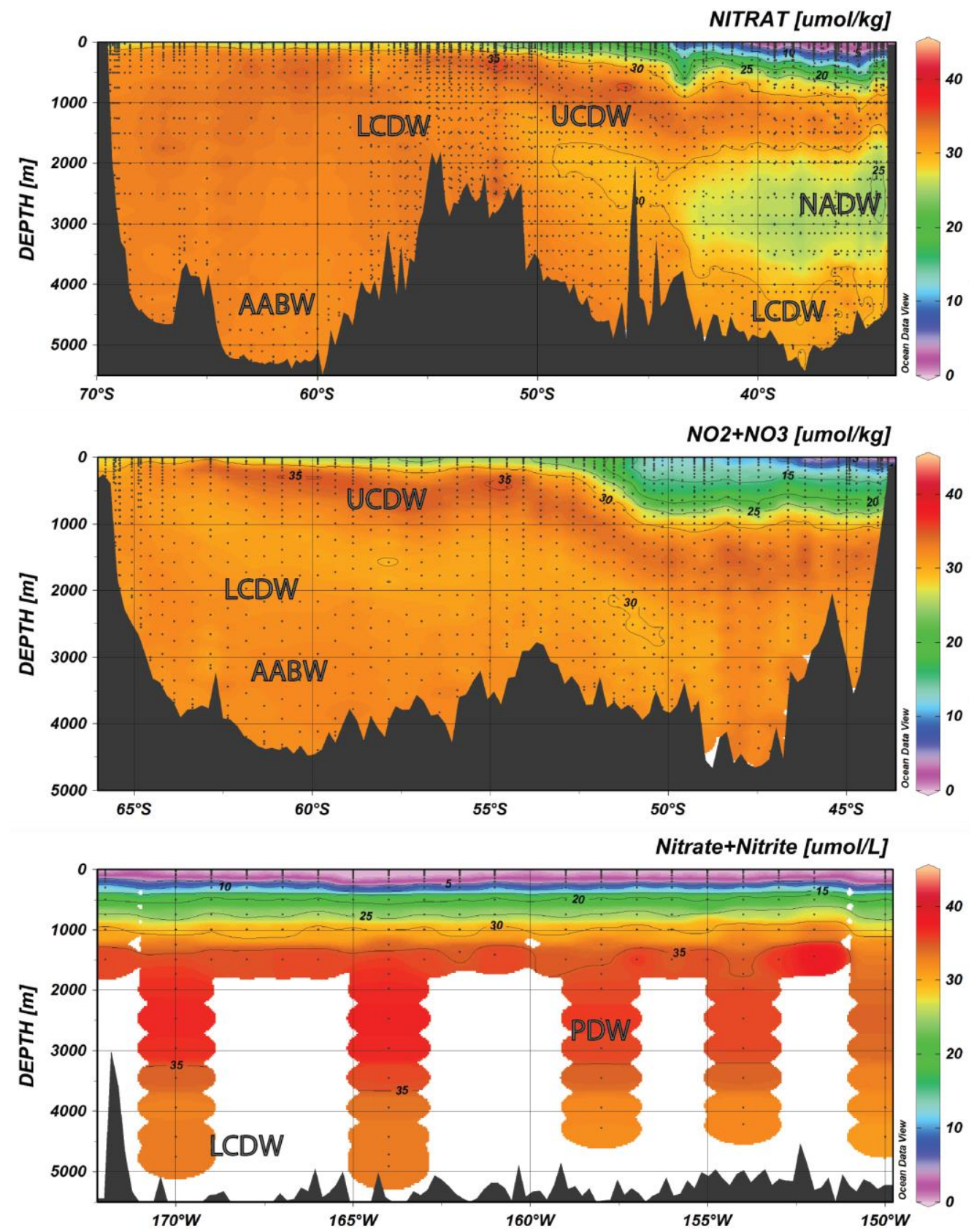

Figure A.2: Nitrate profiles along the GIPY4, SR3, and GP13 GEOTRACES transects. The deep water masses: AABW, LCDW, UCDW, NADW and PDW have been identified and labelled. 

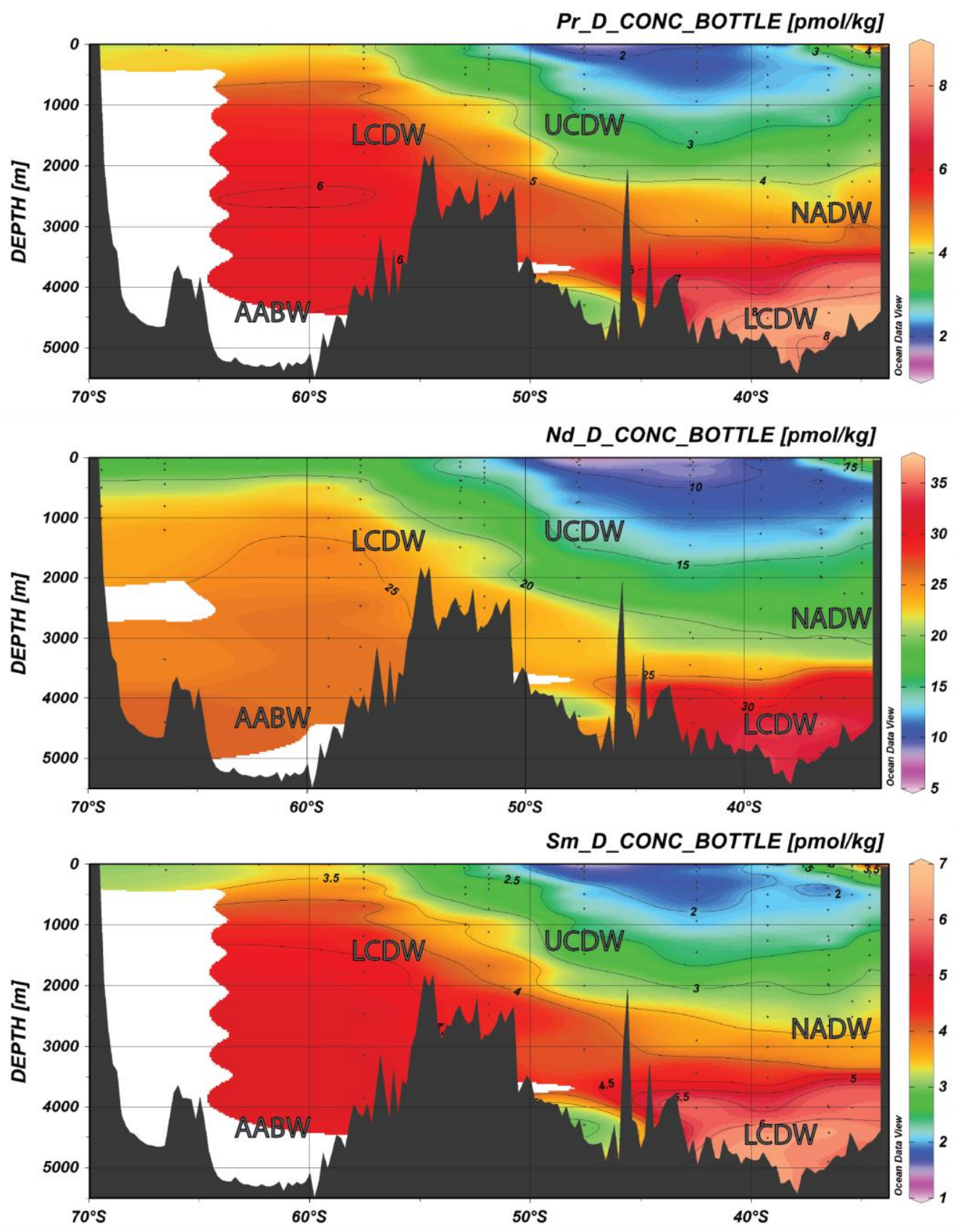

Figure A.3: Dissolved Praseodymium, Neodymium and Samarium profiles for the GIPY4 GEOTRACES transect in the South Atlantic Ocean. The deep water masses: AABW, LCDW, UCDW, and NADW identified in the hydrographic data are labelled. 

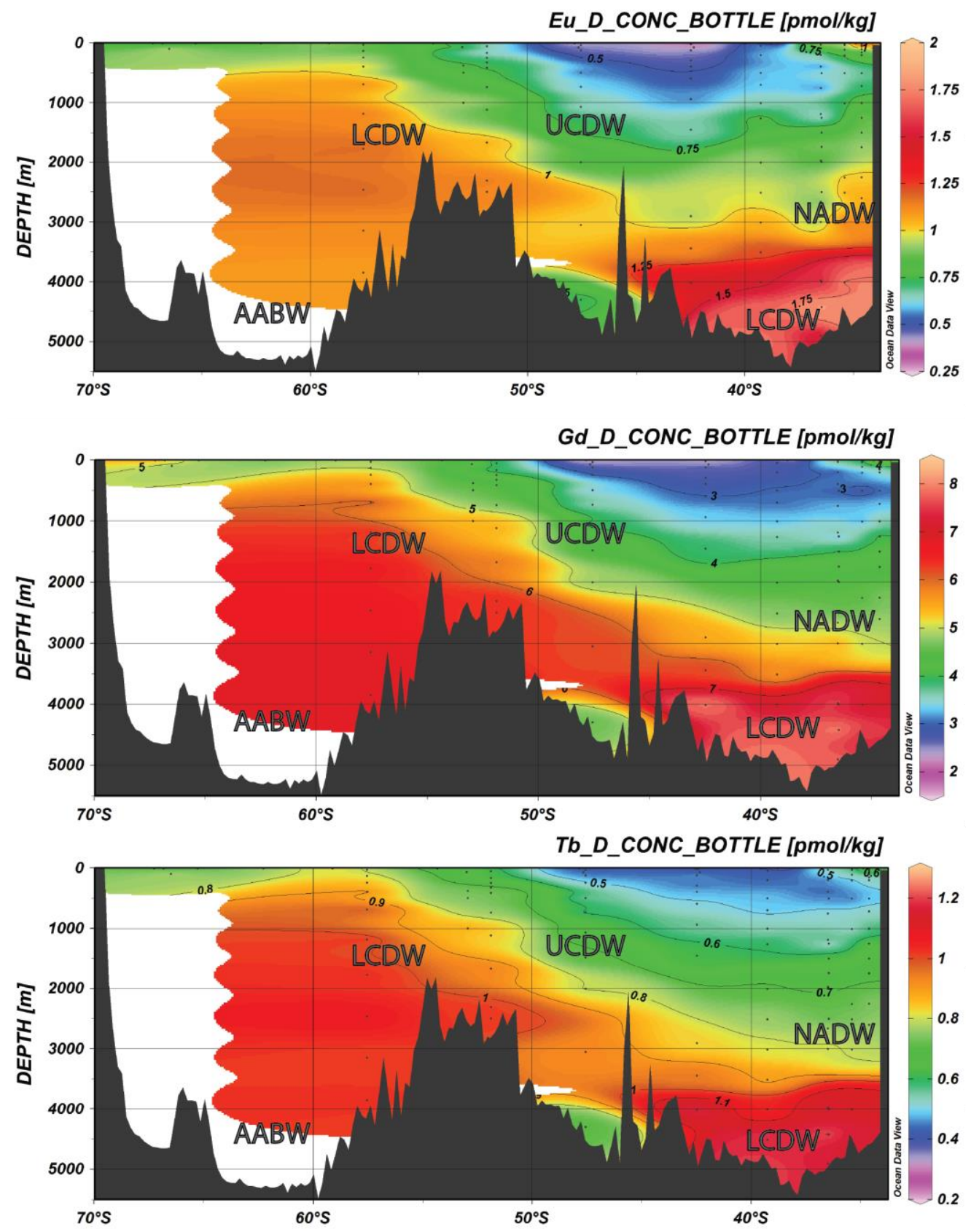

Figure A.4: Dissolved Europium, Gadolinium and Terbium profiles for the GIPY4 GEOTRACES transect in the South Atlantic Ocean. The deep water masses: AABW, LCDW, UCDW, and NADW identified in the hydrographic data are labelled. 

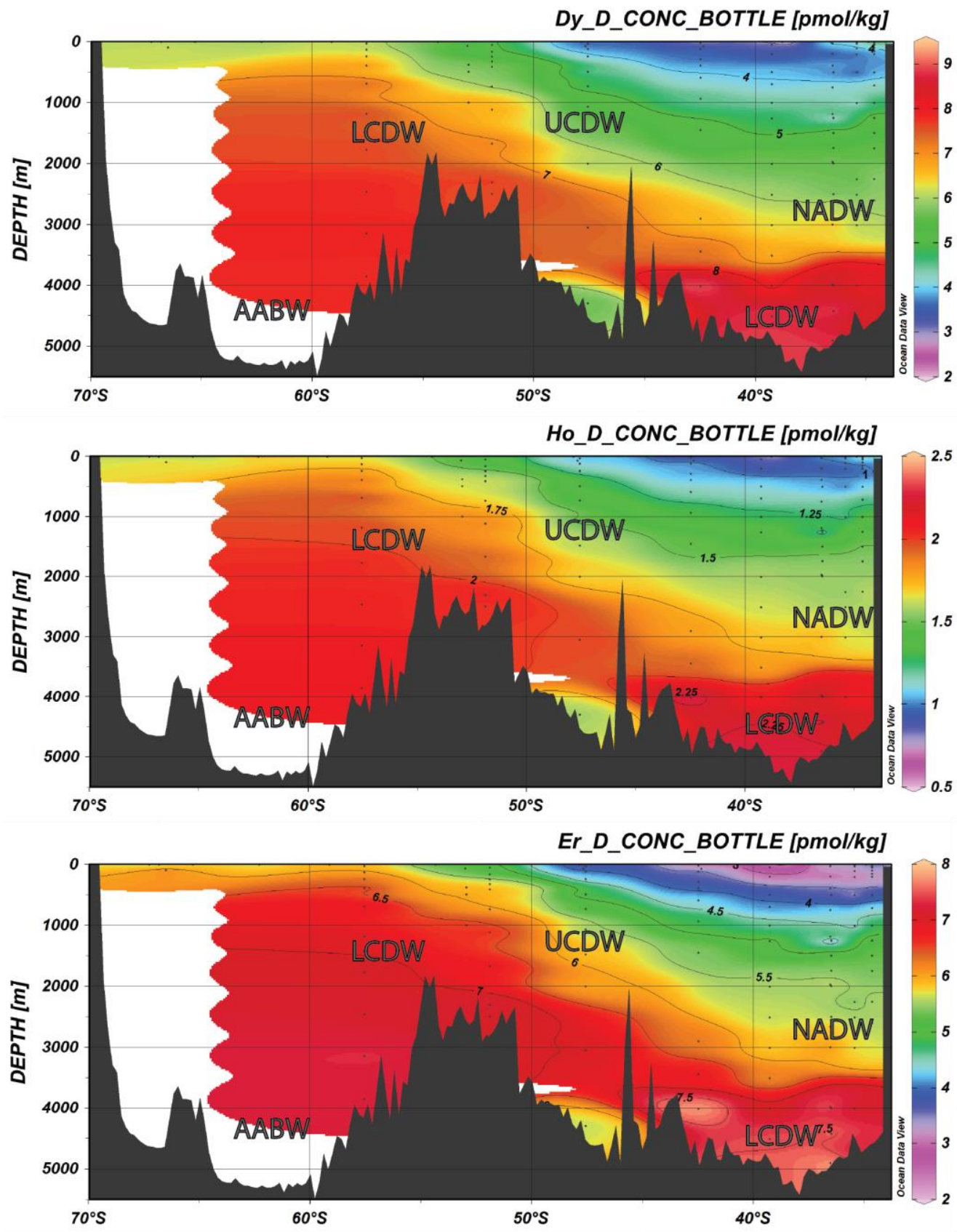

Figure A.5: Dissolved Dysprosium, Holmium and Erbium profiles for the GIPY4 GEOTRACES transect in the South Atlantic Ocean. The deep water masses: AABW, LCDW, UCDW, and NADW identified in the hydrographic data are labelled. 

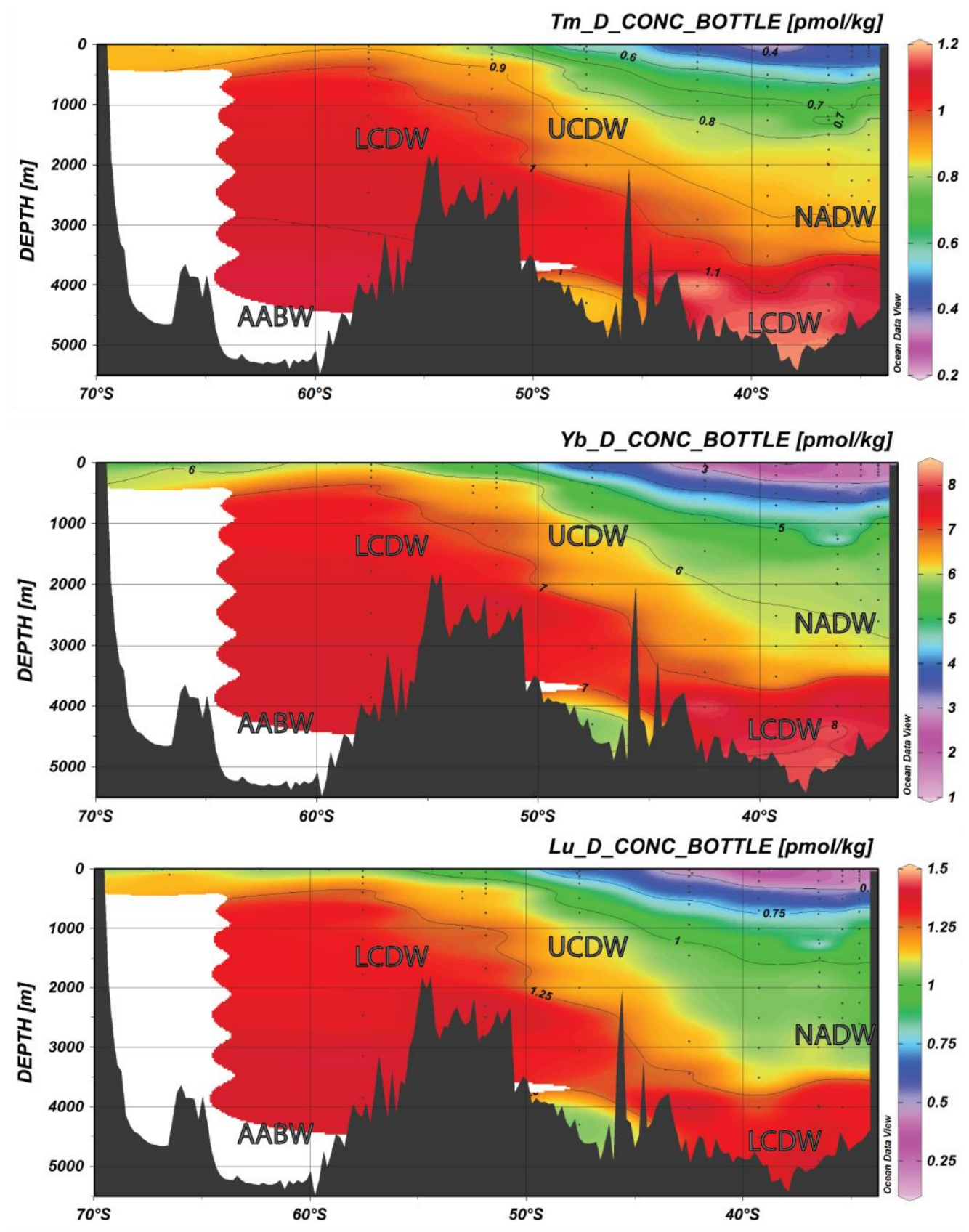

Figure A.6: Dissolved Thulium, Ytterbium and Lutetium profiles for the GIPY4 GEOTRACES transect in the South Atlantic Ocean. The deep water masses: AABW, LCDW, UCDW, and NADW identified in the hydrographic data are labelled. 


\section{Appendix B Sedimentary data}

All supplementary information listed below can be found on the digital appendices CD located at the back of this thesis.

\section{B.1 Grainsize data}

B.2 GRADISTAT data

B.3 Calcium carbonate data

\section{B.4 XRF data}


Appendix C Ferromanganese nodule characteristics

\section{Distribution}

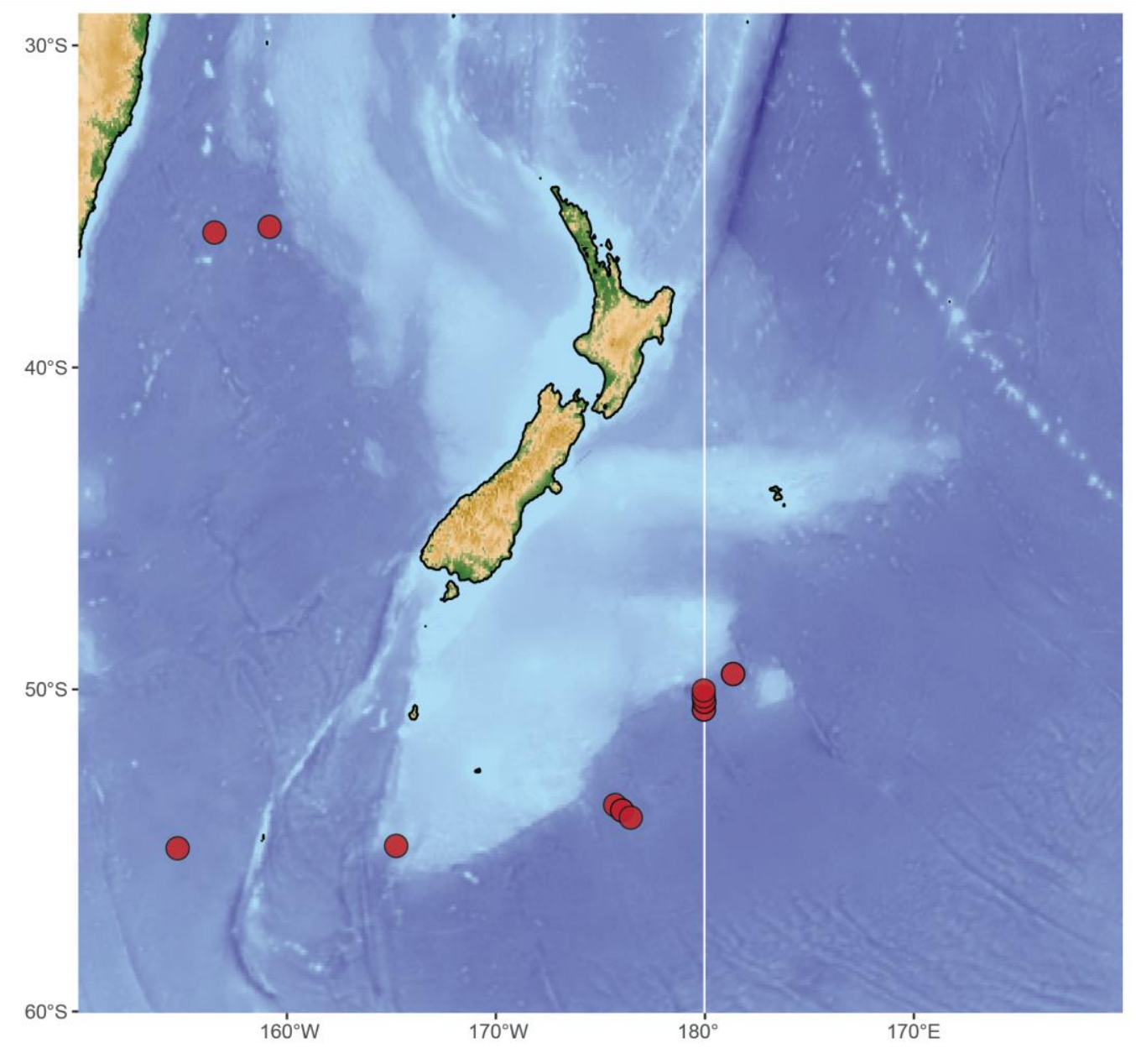




\section{Nodules}

S100

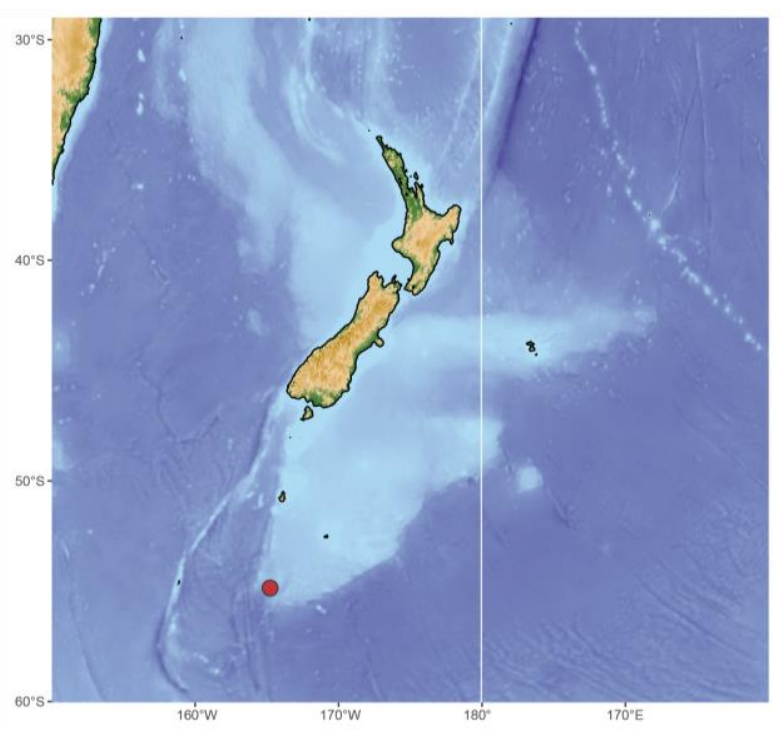

Location: Southwest Campbell

Plateau

Latitude: $54.9^{\circ} \mathrm{S}$

Longitude: $165.2^{\circ} \mathrm{W}$

Depth: 2370 m

Number of nodules: 1

Notes: One sample analysed.

Sample name: $\mathbf{S 1 0 0}$

Size: $8 \times 4.5 \mathrm{~cm}$

Morphotype: $\mathrm{P}_{\mathrm{s}}$

Comments: Fused nodules with a smooth surface texture. The photo

is of the nodule halved. 

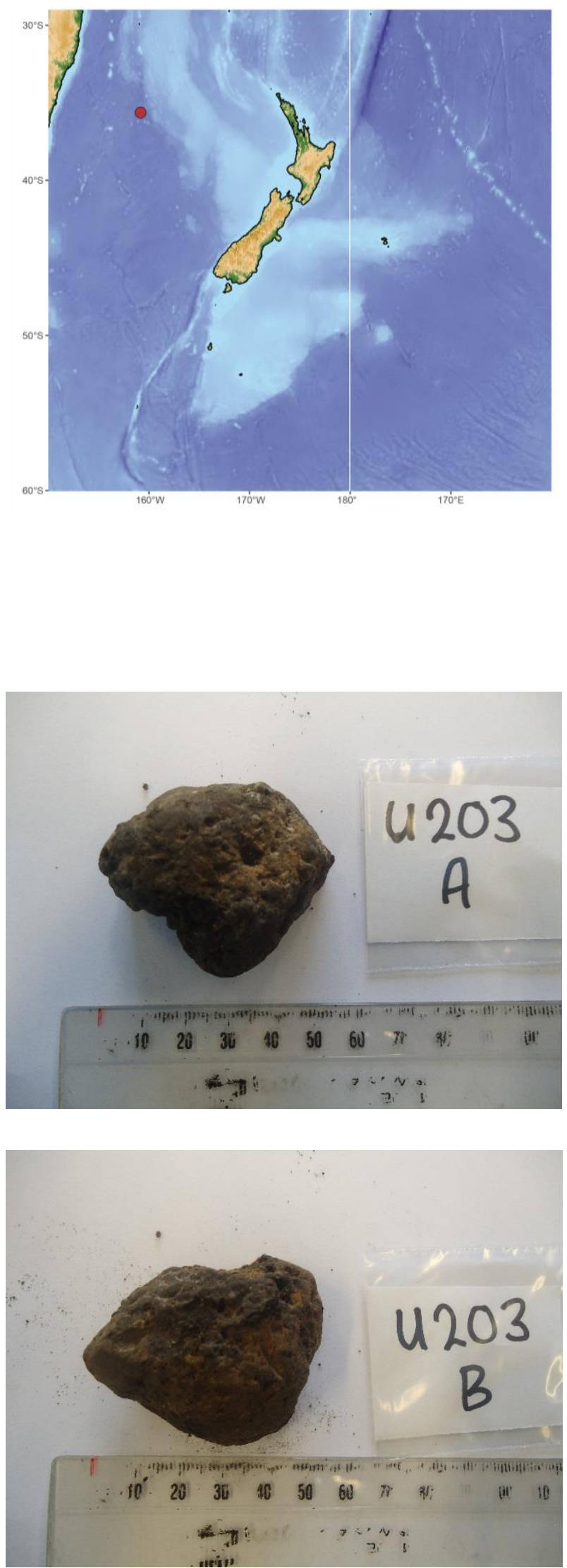

Location: Tasman Basin

Latitude: $35.6^{\circ} \mathrm{S}$

Longitude: $159.2^{\circ} \mathrm{W}$

Depth: 4919 m

Number of nodules: 4

Notes: Samples U203-A and U203-

D, and U203-B and U203-C were combined to obtain enough material for analysis.

Sample name: U203-A

Size: 5.5 x $5 \mathrm{~cm}$

Morphotype: $\mathrm{B}_{\mathrm{s}}$

Descriptions: Ferromanganese

coating on pumaceous core.

Sample name: U203-B

Size: 5.5 x $5 \mathrm{~cm}$

Morphotype: $\mathrm{B}_{\mathrm{s}}$

Descriptions: Ferromanganese coating on pumaceous core. 


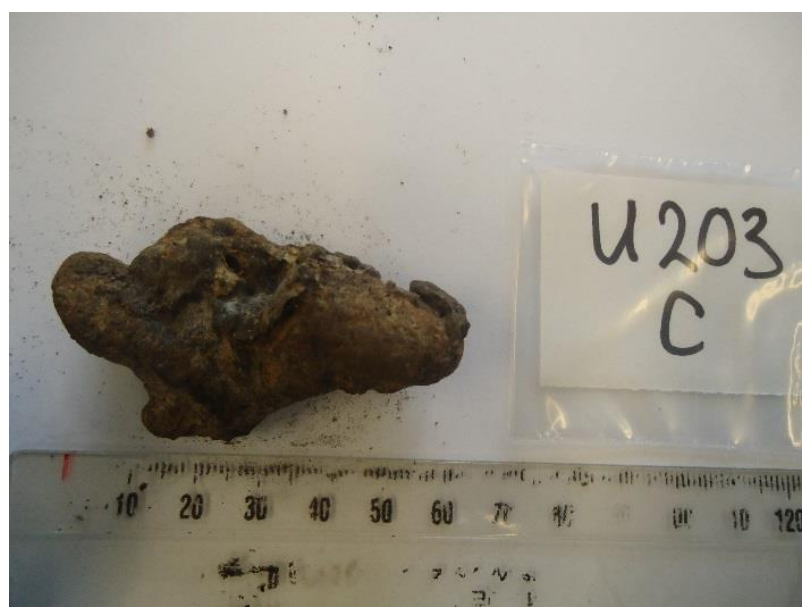

Sample name: U203-C

Size: $6.5 \times 3.5 \mathrm{~cm}$

Morphotype: $\mathrm{B}_{\mathrm{s}}$

Descriptions: Ferromanganese

coating on pumaceous core.

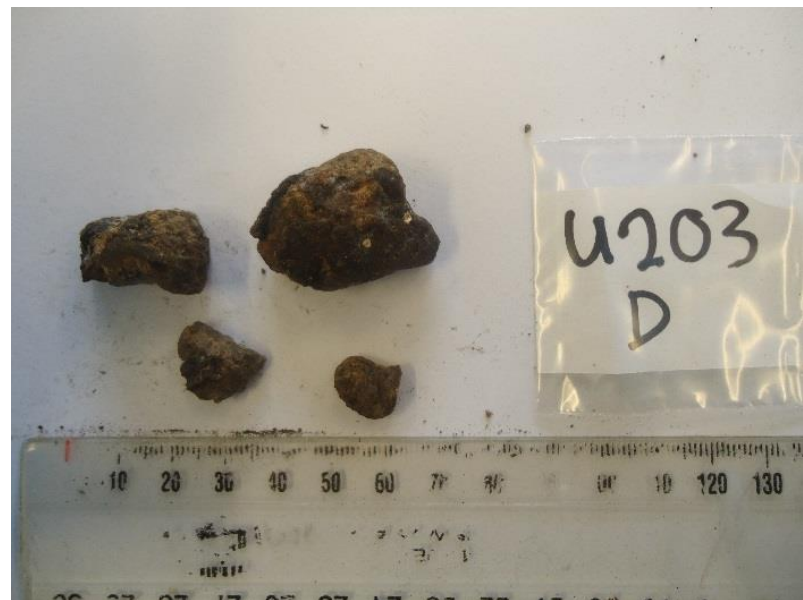

Sample name: U203-D

Size: 3 x $4 \mathrm{~cm}, 2.5 \times 2 \mathrm{~cm}, 1.5 \times$

$1 \mathrm{~cm}, 1 \times 1 \mathrm{~cm}$.

Morphotype: $\mathrm{B}_{\mathrm{s}}$

Descriptions: Ferromanganese coating on pumaceous core.

Combination of four smaller samples. 

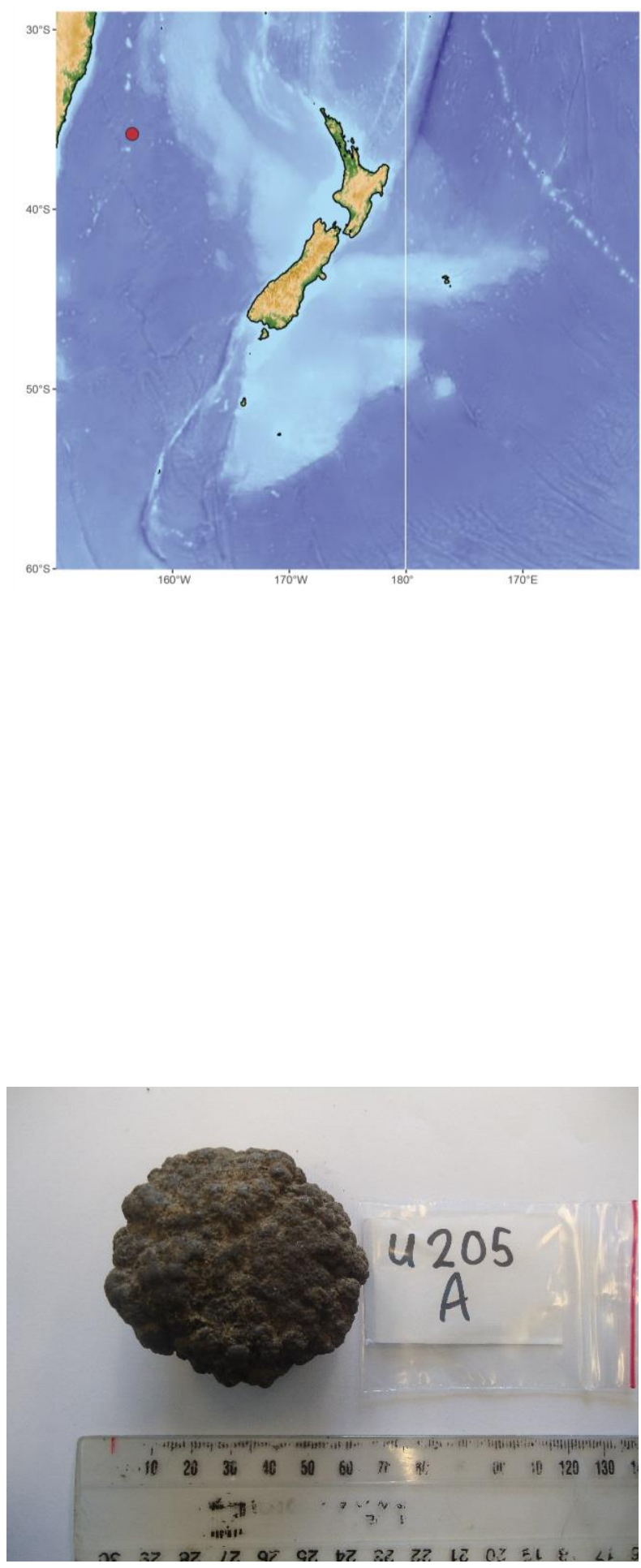

\section{Location: Tasman Basin}

Latitude: $35.8^{\circ} \mathrm{S}$

Longitude: $156.5^{\circ} \mathrm{W}$

Depth: 4714 m

Number of nodules: 17

Notes: Samples U205-A, U205-B, U205-E, and U205-H; U205-C and U205-J; U205-D, U205-F, and U205-G; U205-S and U205-U; U205-T, U205-V, and U205-W were combined to obtain enough material for analysis. U205-DFG was also analysed after the leaching procedure was done.

\section{Sample name: U205-A}

Size: $6.5 \times 6 \mathrm{~cm}$

Morphotype: $\mathrm{D}_{\mathrm{r}}$

Descriptions: Showing preferred growth along the equatorial plane. Rough texture. 


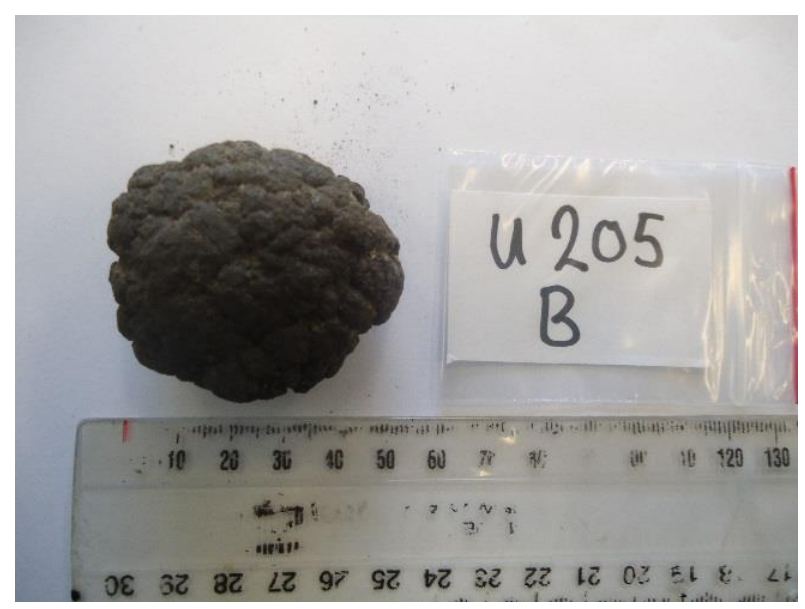

Sample name: U205-B

Size: 5.5 x $5 \mathrm{~cm}$

Morphotype: $\mathrm{D}_{\mathrm{r}}$

Descriptions: Showing preferred

growth along the equatorial plane.

Rough texture.

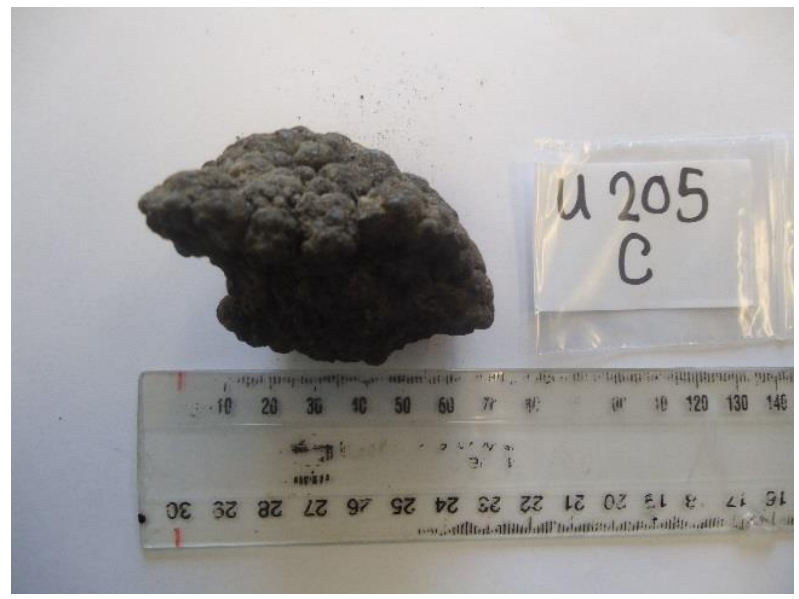

Sample name: U205-C

Size: $8 \times 5.5 \mathrm{~cm}$

Morphotype: $\mathrm{I}_{\mathrm{r}}$

Descriptions: Irregular shape, may have been broken. Rough texture.

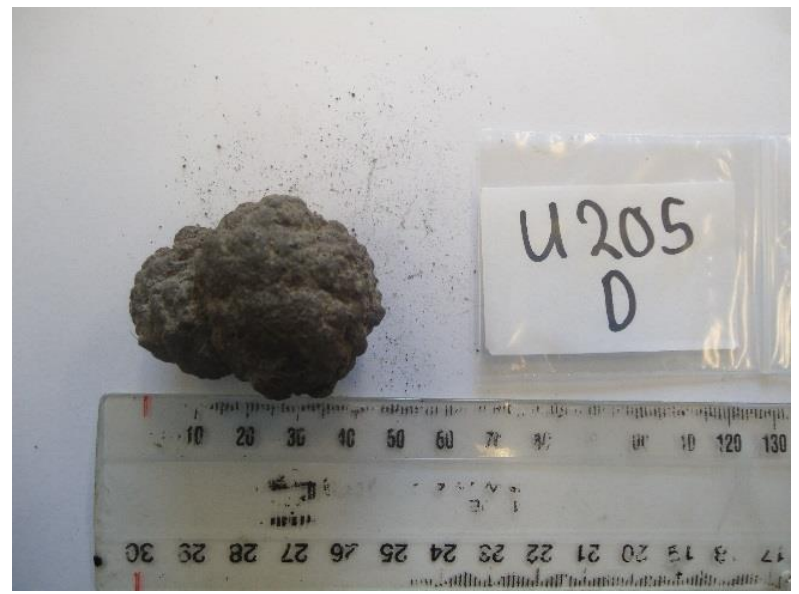

Sample name: U205-D

Size: $5 \times 4 \mathrm{~cm}$

Morphotype: $\mathrm{P}_{\mathrm{r}}$

Descriptions: Multiple small nodules fused together. Rough texture. 

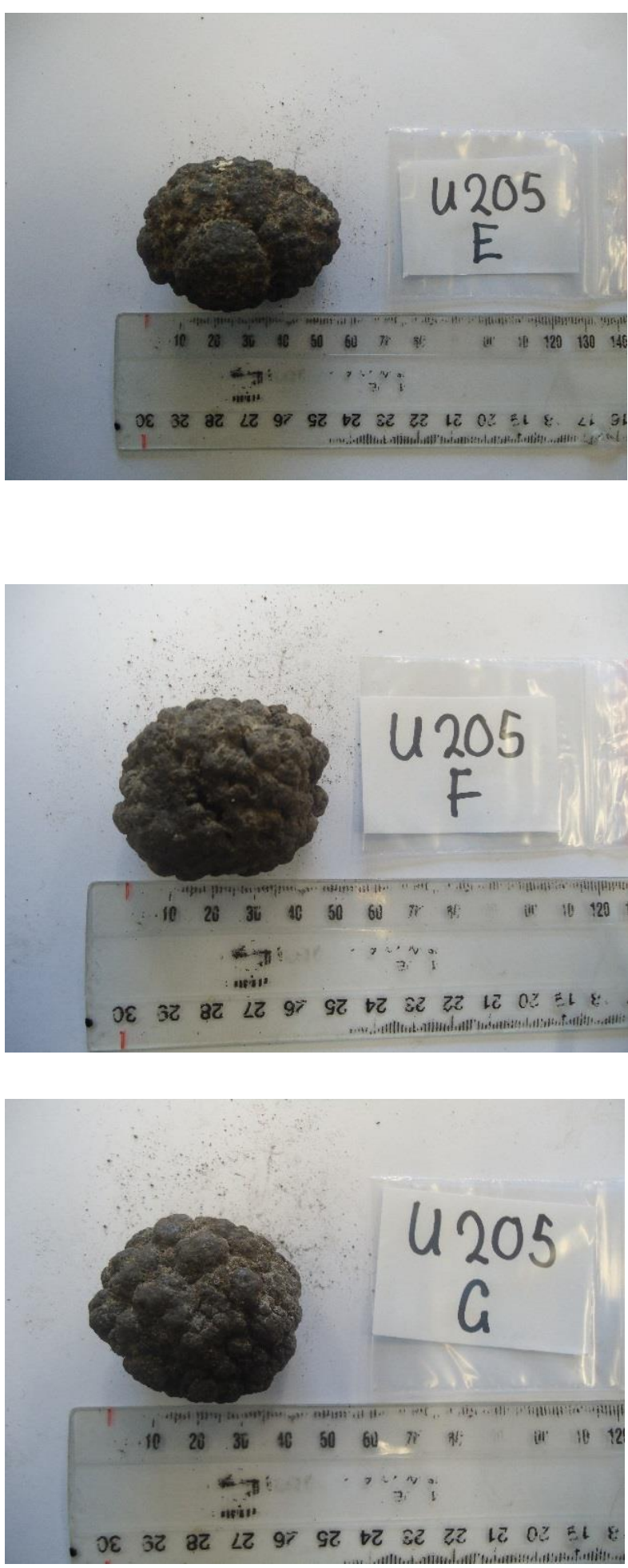

Sample name: U205-E

Size: $6 \times 4.5 \mathrm{~cm}$

Morphotype: $\mathrm{D}_{\mathrm{r}}$

Descriptions: Showing preferred growth along the equatorial plane. Rough texture. Almost polynodular, as there is one nodule fused to the main nodule.

Sample name: U205-F

Size: 5.5 x $5 \mathrm{~cm}$

Morphotype: $\mathrm{D}_{\mathrm{r}}$

Descriptions: Showing preferred growth along the equatorial plane.

Rough texture.

Sample name: U205-G

Size: 4.5 x $4.5 \mathrm{~cm}$

Morphotype: $\mathrm{D}_{\mathrm{b}}$

Descriptions: Showing preferred growth along the equatorial plane. Botryoidal texture. 


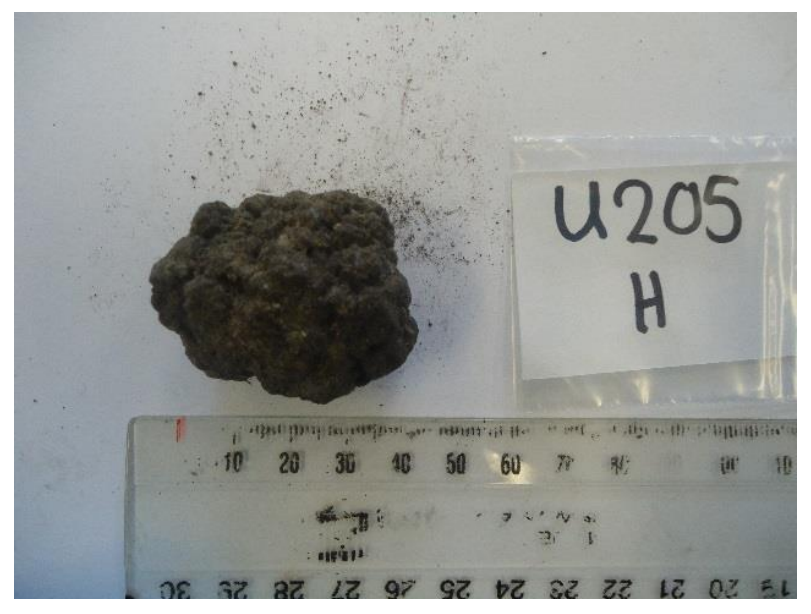

Sample name: U205-H

Size: 5 x $4.5 \mathrm{~cm}$

Morphotype: $\mathrm{D}_{\mathrm{r}}$

Descriptions: Showing preferred

growth along the equatorial plane.

Rough texture.

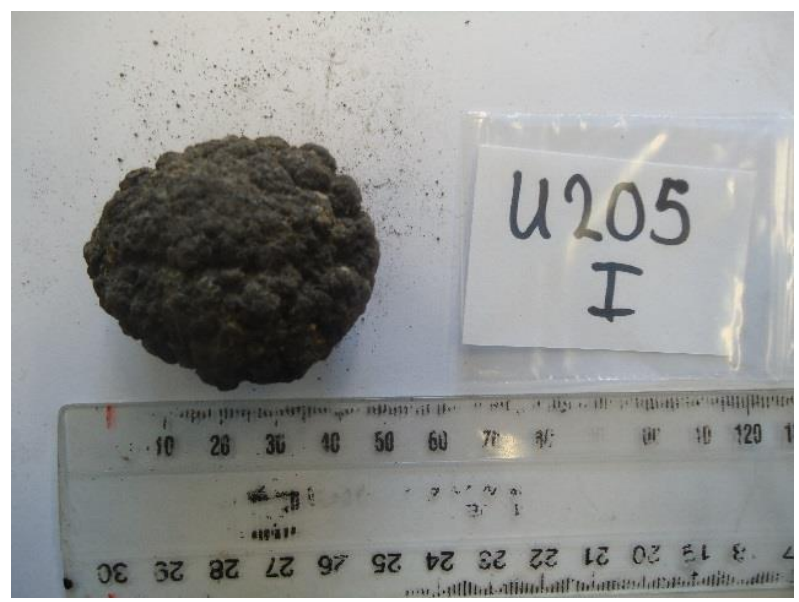

Sample name: U205-I

Size: 5 x $4.5 \mathrm{~cm}$

Morphotype: $\mathrm{D}_{\mathrm{r}}$

Descriptions: Showing preferred growth along the equatorial plane.

Rough texture.

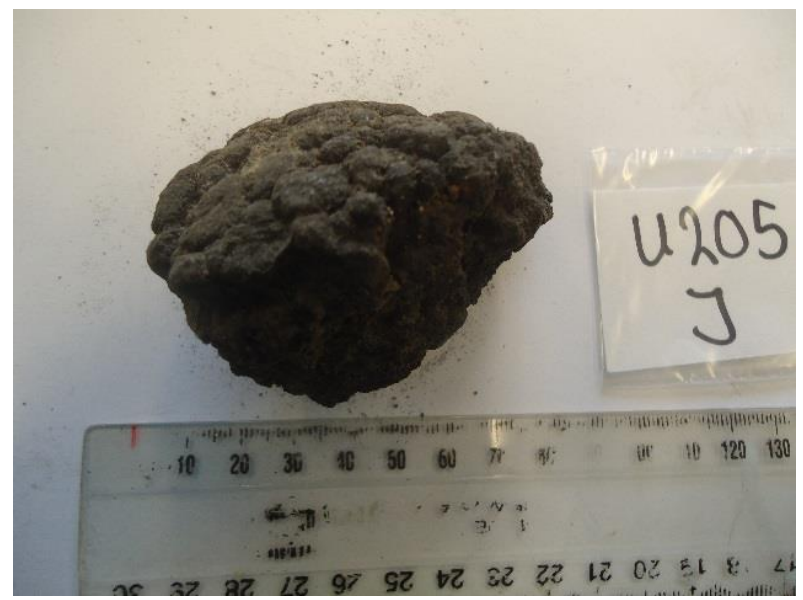

Sample name: U205-J

Size: 8.5 x $5.5 \mathrm{~cm}$

Morphotype: $\mathrm{D}_{\mathrm{b}}$

Descriptions: Showing preferred growth along the equatorial plane. Botryoidal texture. 

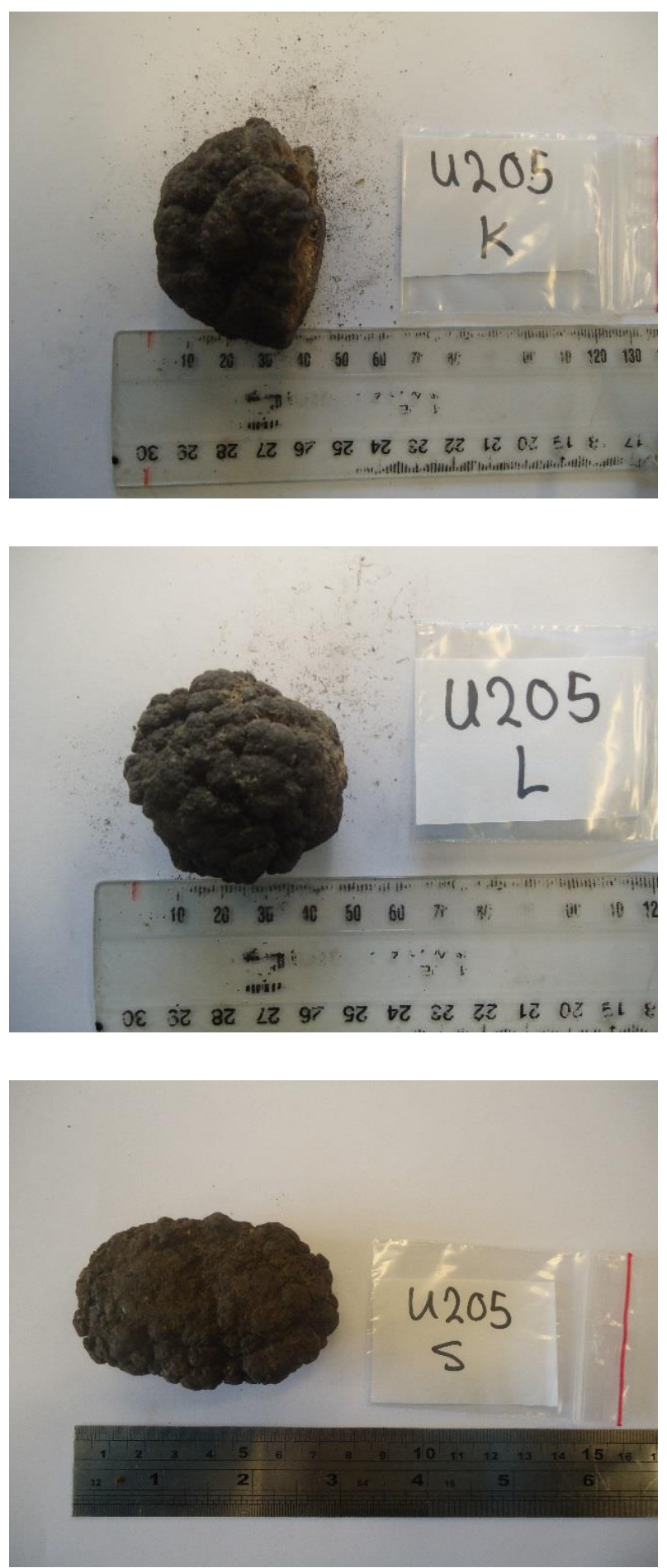

Sample name: U205-S

Size: 7.5 x $5.5 \mathrm{~cm}$

Morphotype: $\mathrm{D}_{\mathrm{r}}^{\mathrm{s}}$

Descriptions: Showing preferred growth along the equatorial plane. Smooth texture on top, rough on the bottom. The top may have been eroded. 

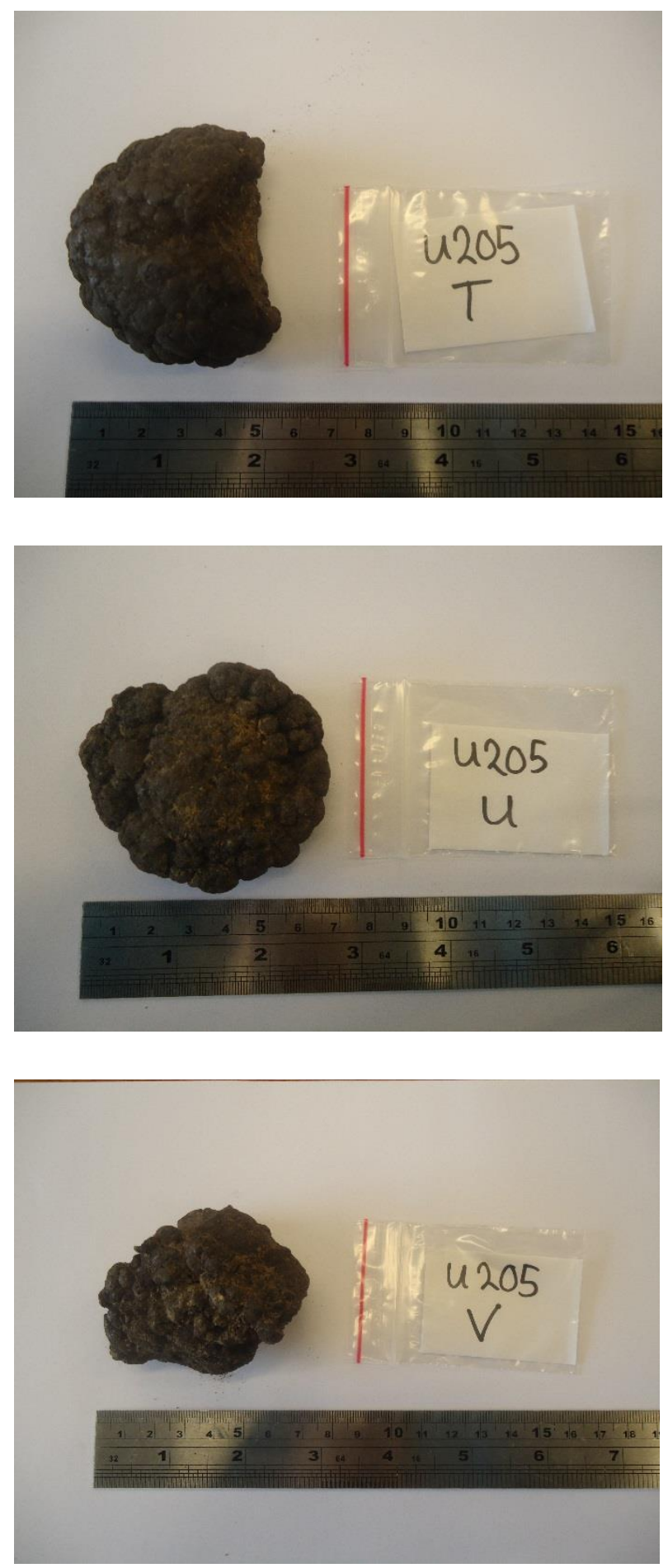

Sample name: U205-T

Size: $5.5 \times 5.5 \mathrm{~cm}$

Morphotype: $\mathrm{D}^{\mathrm{r}} \mathrm{b}$

Descriptions: Showing preferred growth along the equatorial plane.

Rough texture on top, botryoidal on the bottom.

Sample name: U205-U

Size: 7 x $5.5 \mathrm{~cm}$

Morphotype: $\mathrm{D}^{\mathrm{r}} \mathrm{b}$

Descriptions: Showing preferred growth along the equatorial plane. Rough texture on top, botryoidal on the bottom.

Sample name: $\mathbf{U 2 0 5}-\mathbf{V}$

Size: $8 \times 6 \mathrm{~cm}$

Morphotype: $\mathrm{I}_{\mathrm{b}}$

Descriptions: Irregular shape with botryoidal texture. This nodule was already halved/broken. 


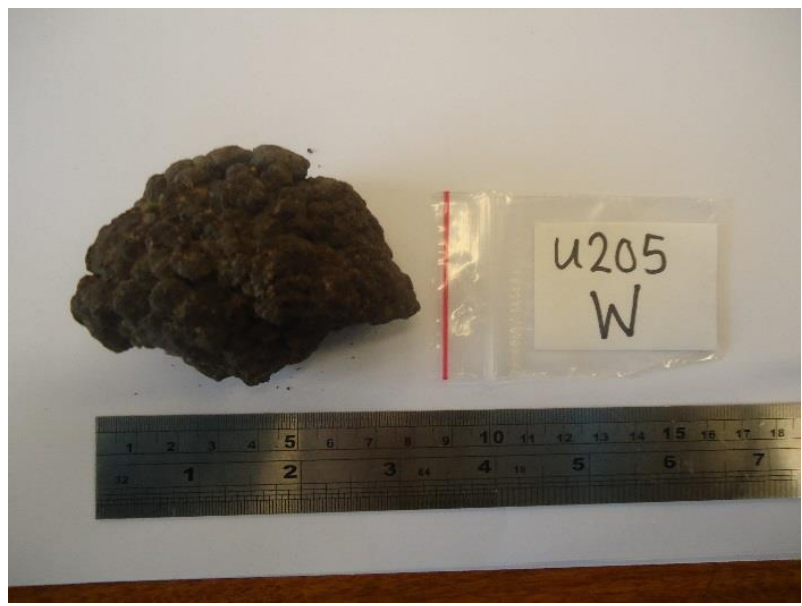

Sample name: U205-W

Size: 9 × $6 \mathrm{~cm}$

Morphotype: $\mathrm{I}_{\mathrm{b}}$

Descriptions: Irregular shape with botryoidal and rough texture. This nodule was already halved/broken. 


\section{U1373}

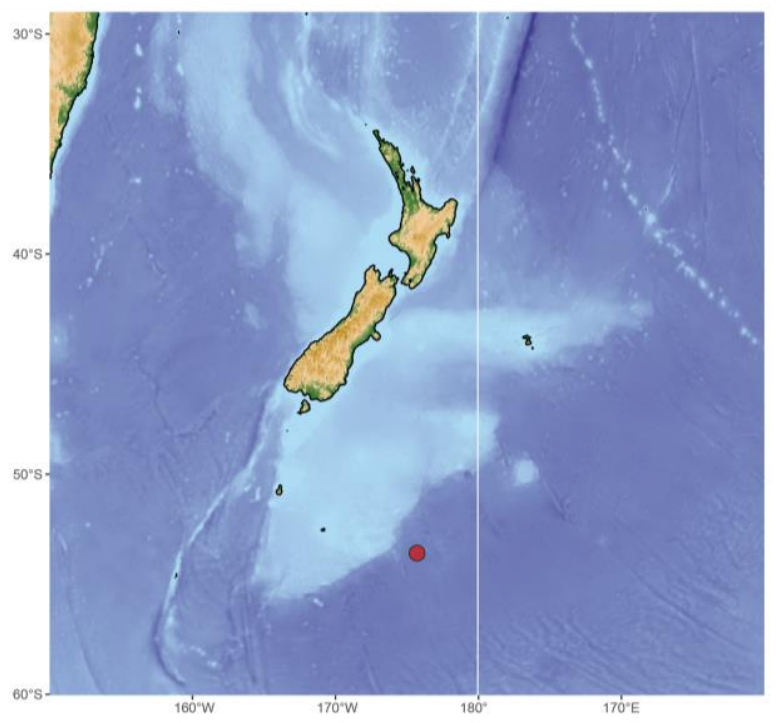

Location: Endeavour Banks

Latitude: $53.6^{\circ} \mathrm{S}$

Longitude: $175.7^{\circ} \mathrm{W}$

Depth: $4941 \mathrm{~m}$

Number of nodules: 7

Notes: Sample U1373-1-A, and

U1373-2-A was analysed twice.

Sample name: U1373-1-A

Size: 15 x $15 \mathrm{~cm}$

Morphotype: $\mathrm{D}_{\mathrm{b}}^{\mathrm{r}}$

Descriptions: Large nodule.

Showing preferred growth along the equatorial plane. Rough texture on top, botryoidal on the bottom.

Sample name: U1373-1-B

Size: 15 x $15 \mathrm{~cm}$

Morphotype: $\mathrm{E}_{\mathrm{r}}^{\mathrm{s}}$

Descriptions: Large nodule.

Showing preferred growth along the one plane. Smooth texture on top, botryoidal on the bottom. There is white material on the nodule. May have been eroded. 


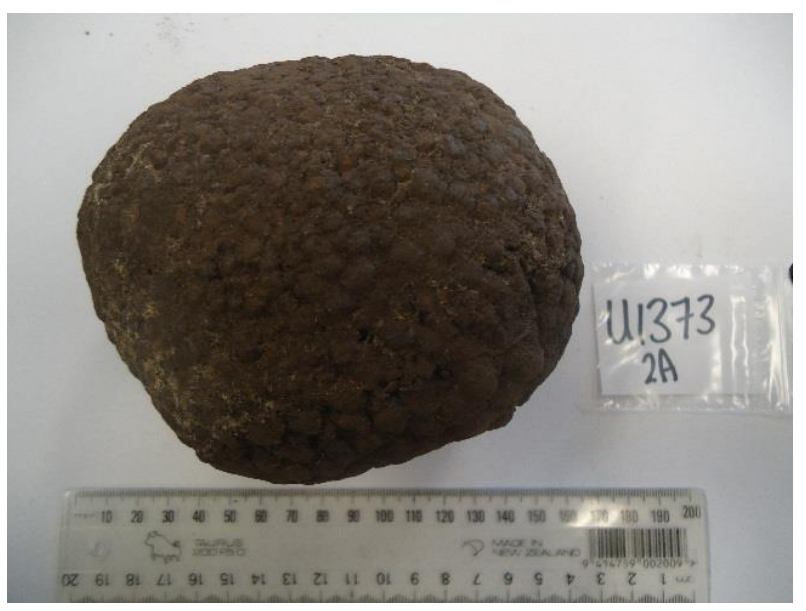

Sample name: U1373-2-A

Size: 16 x $16 \mathrm{~cm}$

Morphotype: $\mathrm{D}_{\mathrm{r}}$

Descriptions: Large nodule.

Showing preferred growth along the equatorial plane. Rough texture.

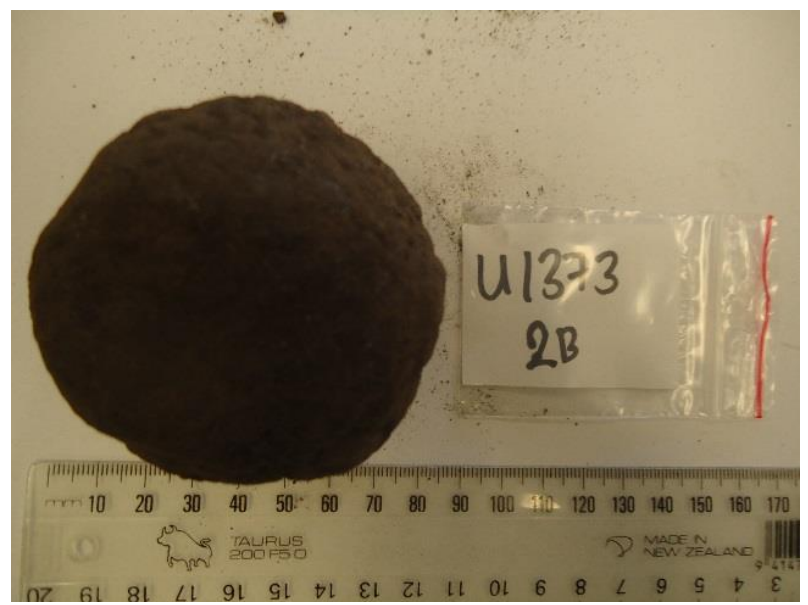

Sample name: U1373-2-B

Size: 9 × $9 \mathrm{~cm}$

Morphotype: $\mathrm{D}^{\mathrm{s}}{ }_{\mathrm{b}}$

Descriptions: Showing preferred growth along the equatorial plane. Smooth texture on top, botryoidal on the bottom. May have been eroded.

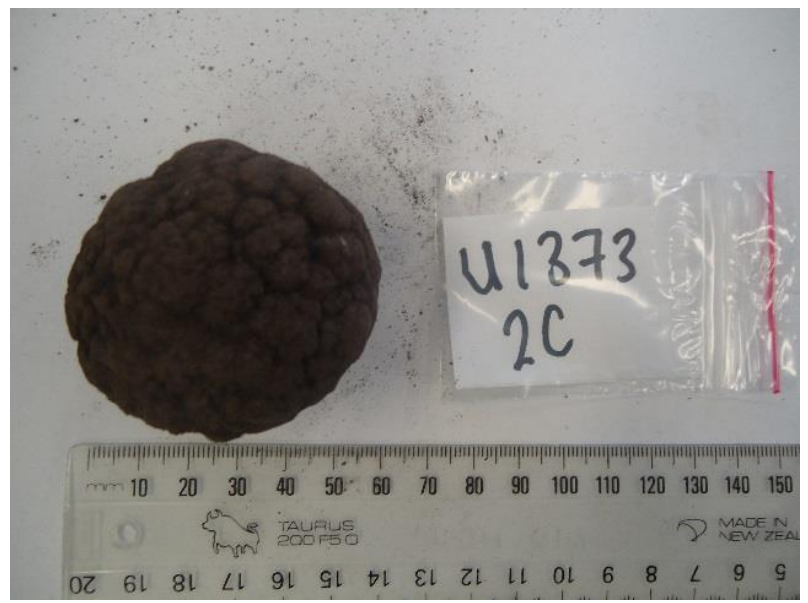

Sample name: U1373-2-C

Size: $7 \times 6 \mathrm{~cm}$

Morphotype: $\mathrm{S}_{\mathrm{b}}$

Descriptions: Spherical, botryoidal nodule. 

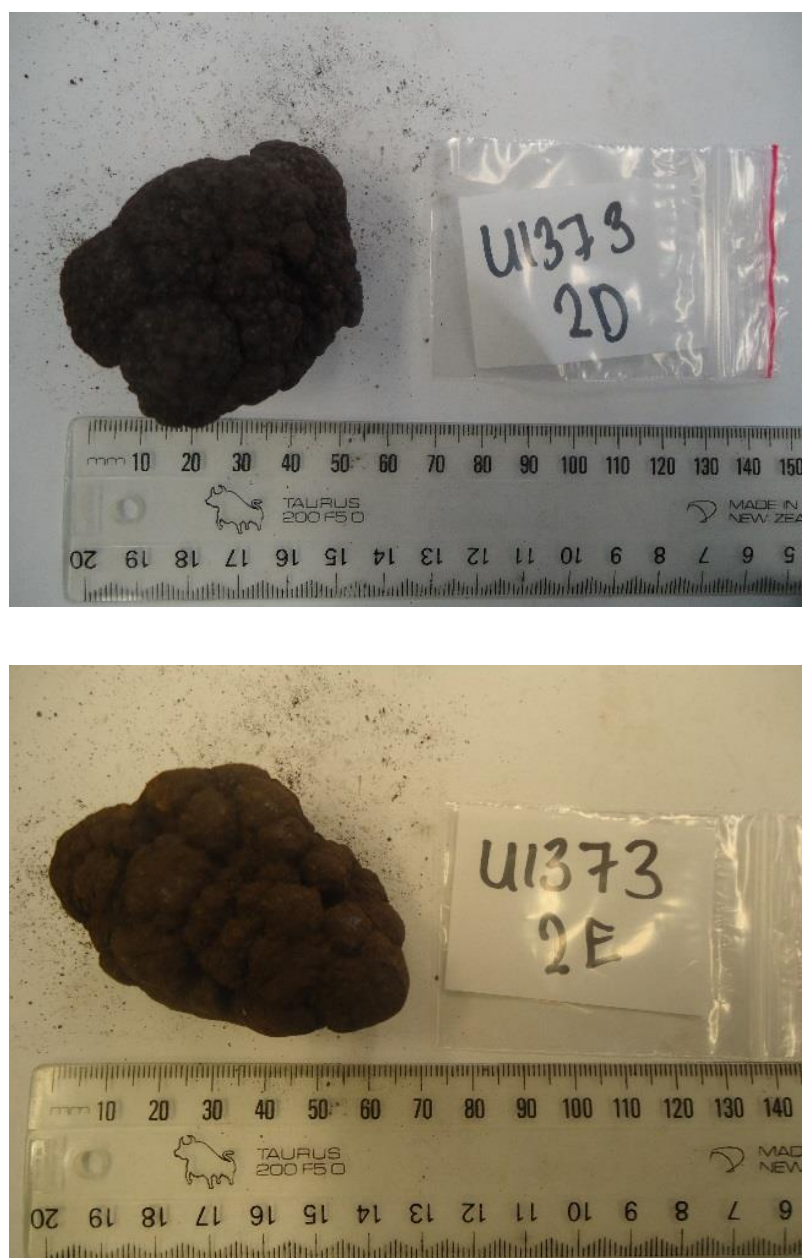

Sample name: U1373-2-D

Size: $6 \times 4 \mathrm{~cm}$

Morphotype: $\mathrm{P}_{\mathrm{b}}$

Descriptions: Fused nodules, with botryoidal texture.

Sample name: U1373-2-E

Size: 7 x $5 \mathrm{~cm}$

Morphotype: $\mathrm{P}_{\mathrm{b}}^{\mathrm{s}}$

Descriptions: Fused nodules, with smooth texture on the top, and botryoidal texture on the bottom. 


\section{U1374}
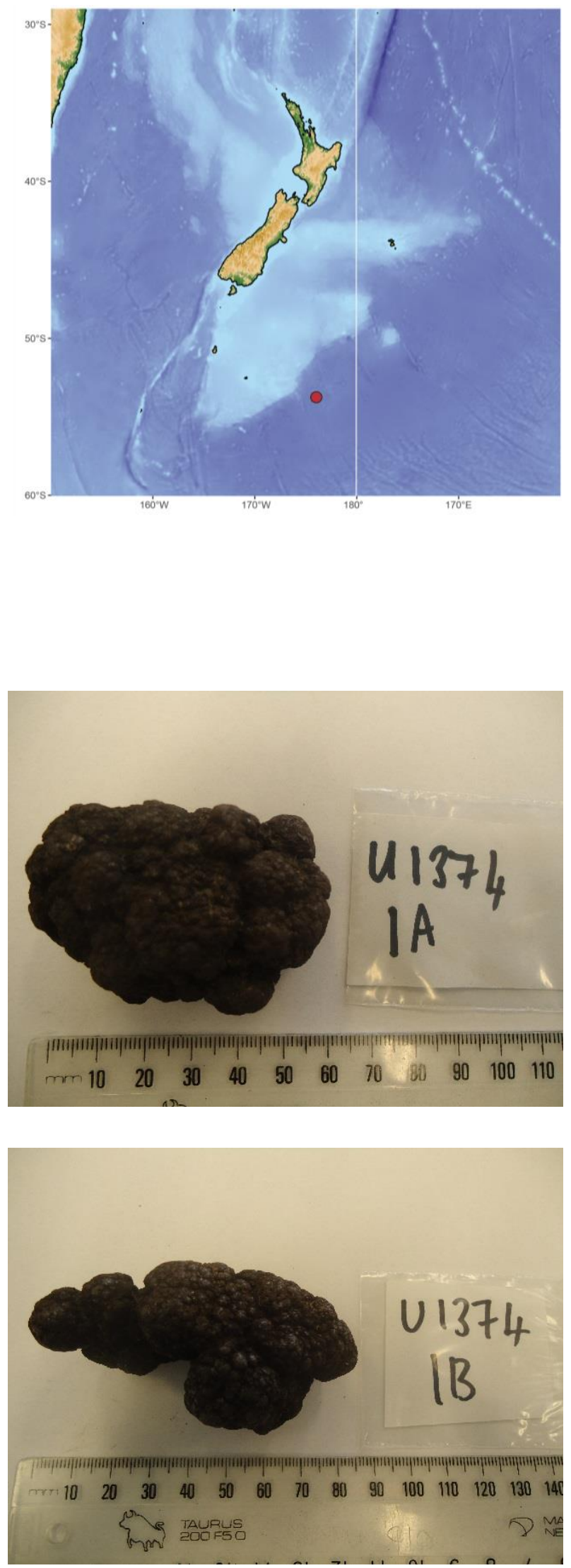

Location: Endeavour Banks

Latitude: $53.8^{\circ} \mathrm{S}$

Longitude: $176.0^{\circ} \mathrm{W}$

Depth: 4958 m

Number of nodules: 5

Notes: U1374-1-A, U1374-1-B, and U1374-1-C were analysed twice.

U1374-1-E was also analysed after the leaching procedure was done.

Sample name: U1374-1-A

Size: 7 x $5 \mathrm{~cm}$

Morphotype: $\mathrm{P}^{\mathrm{r}}{ }_{\mathrm{b}}$

Descriptions: Fused nodules.

Rough texture on top, botryoidal on the bottom.

Sample name: U1374-1-B

Size: 9 × $3 \mathrm{~cm}$

Morphotype: $\mathrm{P}^{\mathrm{r}} \mathrm{b}$

Descriptions: Fused nodules.

Rough texture on top, botryoidal on the bottom. 

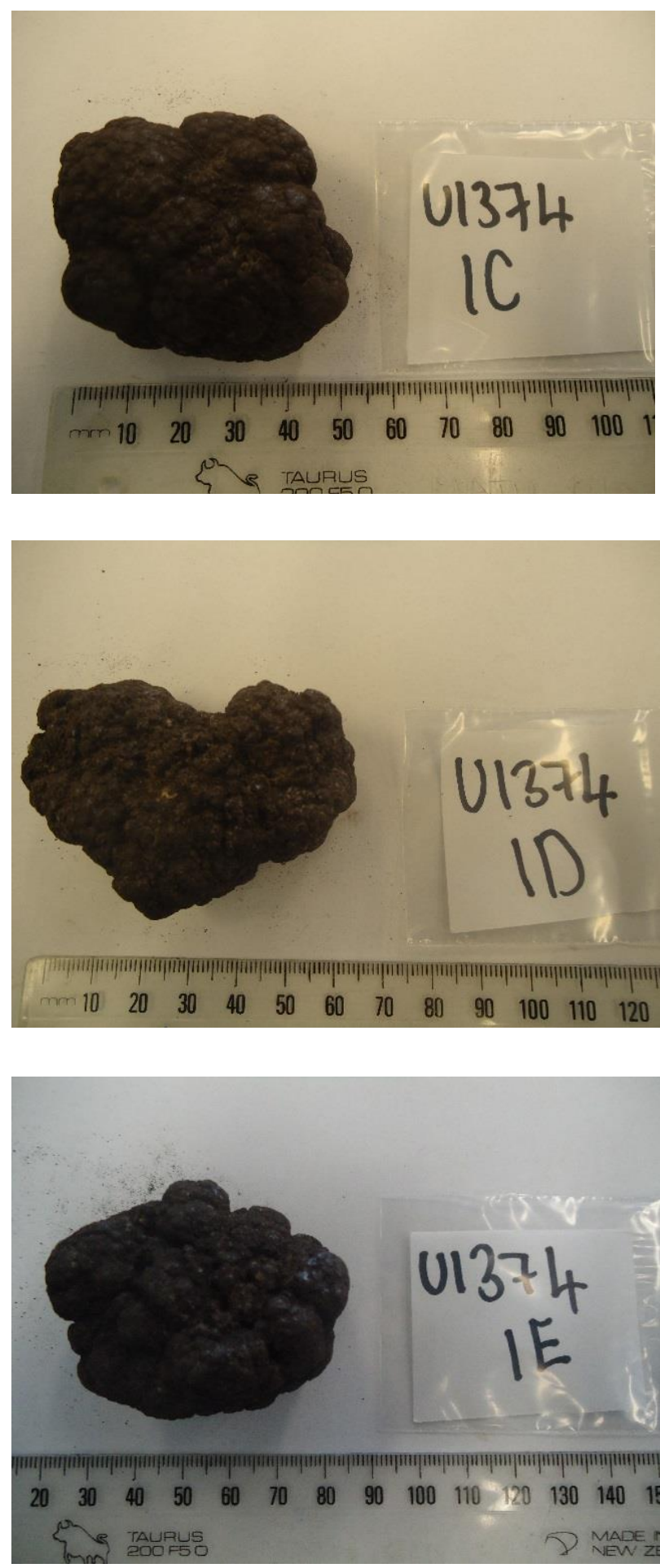

Sample name: U1374-1-C

Size: $6 \times 5 \mathrm{~cm}$

Morphotype: $\mathrm{P}^{\mathrm{r}}$

Descriptions: Fused nodules.

Rough texture on top, botryoidal on the bottom.

\section{Sample name: U1374-1-D}

Size: 7 x $5 \mathrm{~cm}$

Morphotype: $\mathrm{I}_{\mathrm{b}}$

Descriptions: Irregular, heart shaped nodule. Rough texture on top, botryoidal on the bottom.

\section{Sample name: U1374-1-E}

Size: 7 x $5 \mathrm{~cm}$

Morphotype: $\mathrm{E}_{\mathrm{b}}^{\mathrm{r}}$

Descriptions: Elongate shape.

Rough texture on top, botryoidal on the bottom. 


\section{U1378}
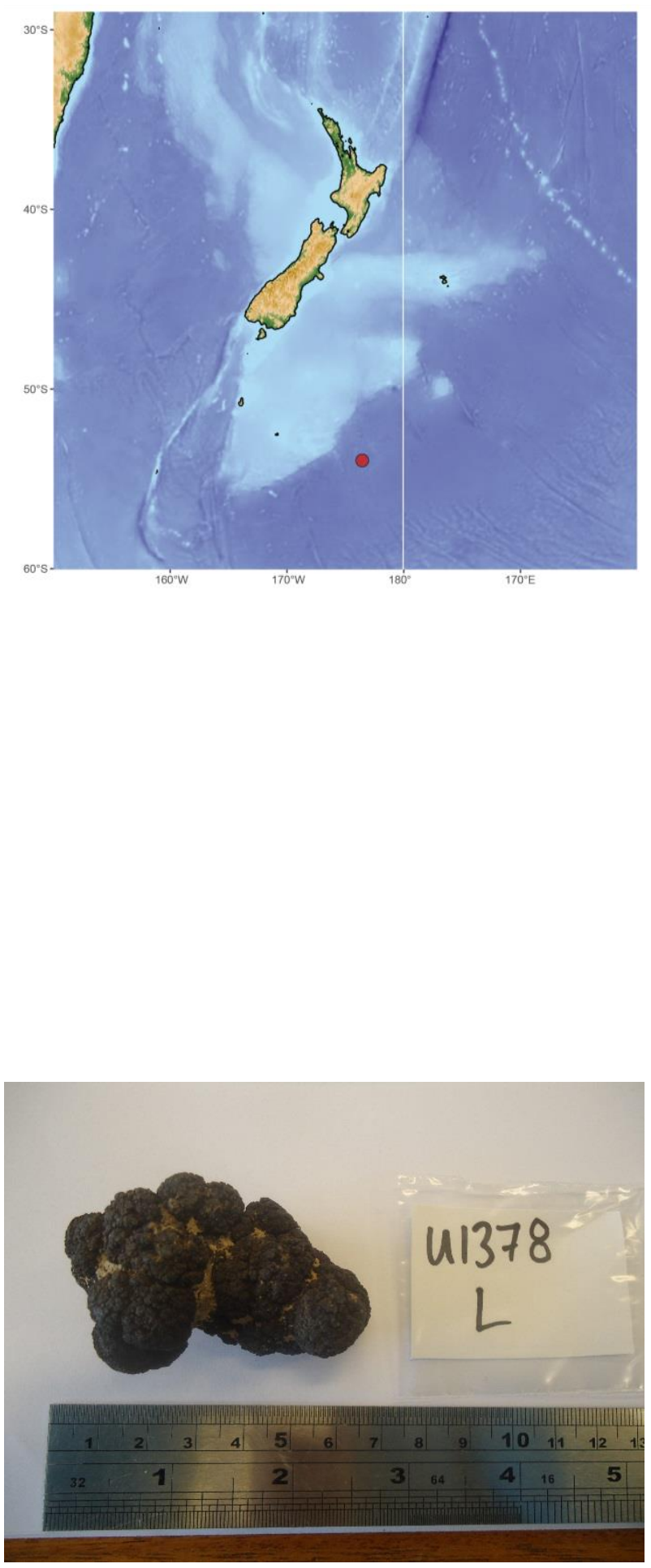

\section{Location: Endeavour Banks}

Latitude: $50.6^{\circ} \mathrm{S}$

Longitude: $180.0^{\circ} \mathrm{W}$

Depth: 4915 m

Number of nodules: 7

Notes: Samples were rinsed repeatedly with ultra-pure water to remove sediment. During sampling care was taken to avoid getting debris in the sample. Samples U1378-M, U1378-O, and U1378-P; and U1378-L, U1378-R, U1378-Q, and U1378-U were combined to obtain enough material for analysis.

Sample name: U1378-L

Size: 7 x $5 \mathrm{~cm}$

Morphotype: $\mathrm{Pr}_{\mathrm{r}}$

Descriptions: Fused nodules with a rough texture. Some sediment remained in the crevices. 


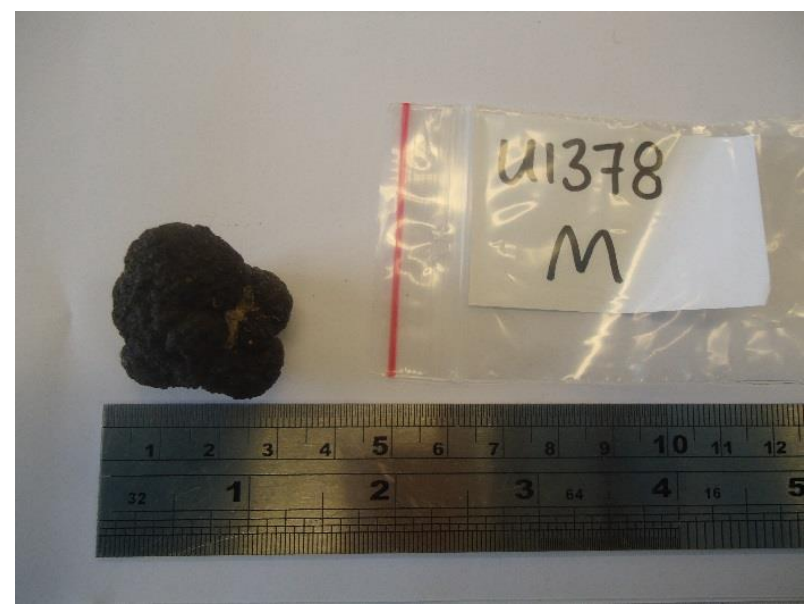

Sample name: U1378-M

Size: 3 x $3 \mathrm{~cm}$

Morphotype: $\mathrm{P}_{\mathrm{r}}$

Descriptions: Fused nodules with a rough texture. Some sediment remained in the crevices.

Sample name: U1378-N

Size: 5 x $4.5 \mathrm{~cm}$

Morphotype: $\mathrm{P}_{\mathrm{r}}$

Descriptions: Fused nodules with a rough texture. Some sediment remained in the crevices.

Sample name: U1378-O

Size: $6 \times 5 \mathrm{~cm}$

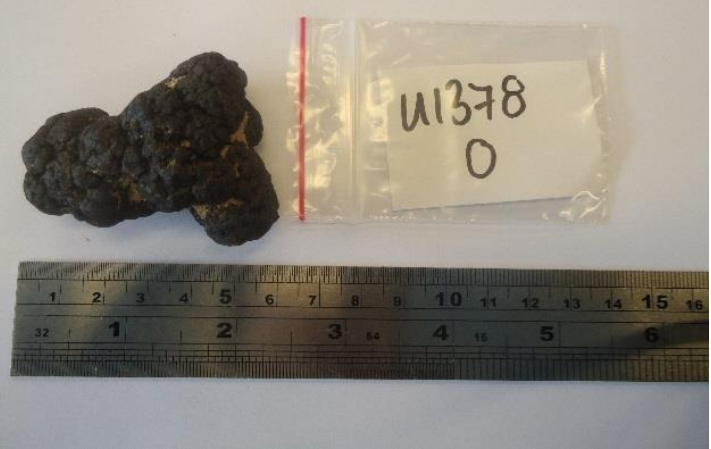

Morphotype: $\mathrm{P}_{\mathrm{r}}$

Descriptions: Fused nodules with a rough texture. Some sediment remained in the crevices. 


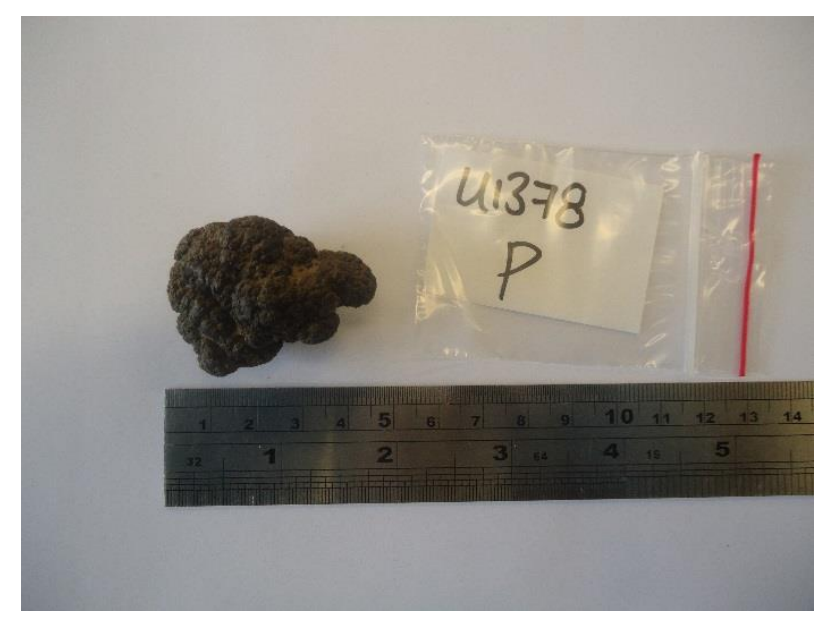

Sample name: U1378-P

Size: 4.5 x $3.5 \mathrm{~cm}$

Morphotype: $\mathrm{Pr}_{\mathrm{r}}$

Descriptions: Fused nodules with a rough texture. Some sediment remained in the crevices.

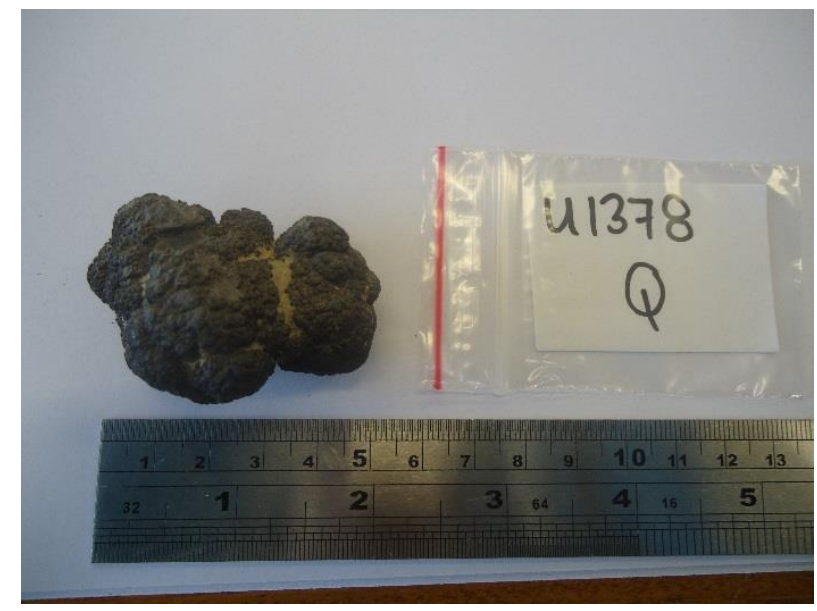

\section{Sample name: U1378-Q}

Size: $5.5 \times 4 \mathrm{~cm}$

Morphotype: $\mathrm{Pr}_{\mathrm{r}}$

Descriptions: Fused nodules with a rough texture. Some sediment remained in the crevices.

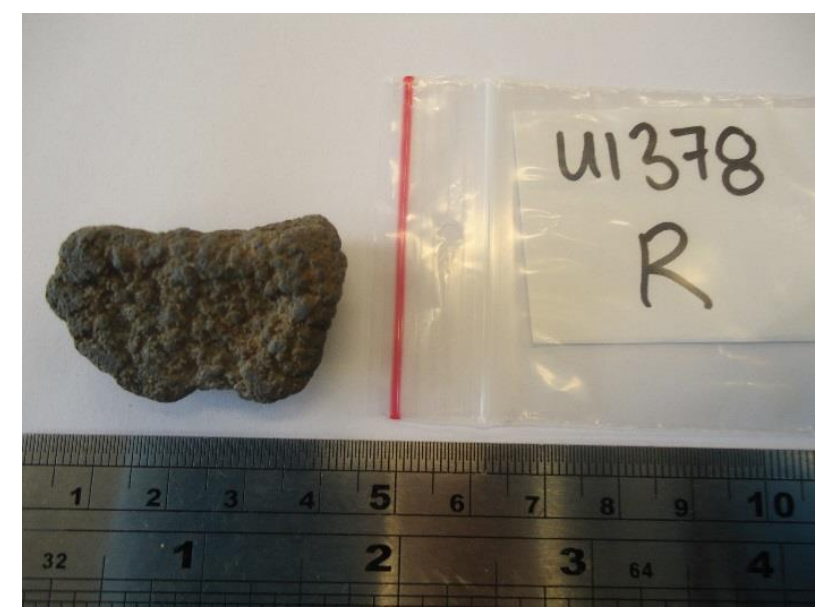

\section{Sample name: U1378-R}

Size: 4 x $3 \mathrm{~cm}$

Morphotype: $\mathrm{I}_{\mathrm{r}}$

Descriptions: Irregular flat shape with a rough texture. 


\section{U1398}

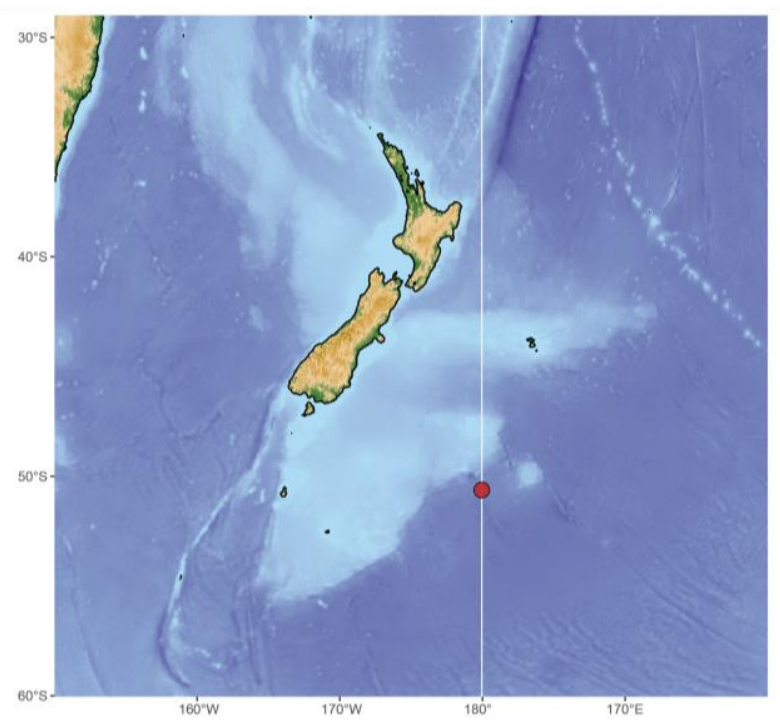

\section{Location: Bollons Gap}

Latitude: $50.6^{\circ} \mathrm{S}$

Longitude: $180.0^{\circ} \mathrm{W}$

Depth: 4495 m

Number of nodules: 7

Notes: Seven samples were analysed.

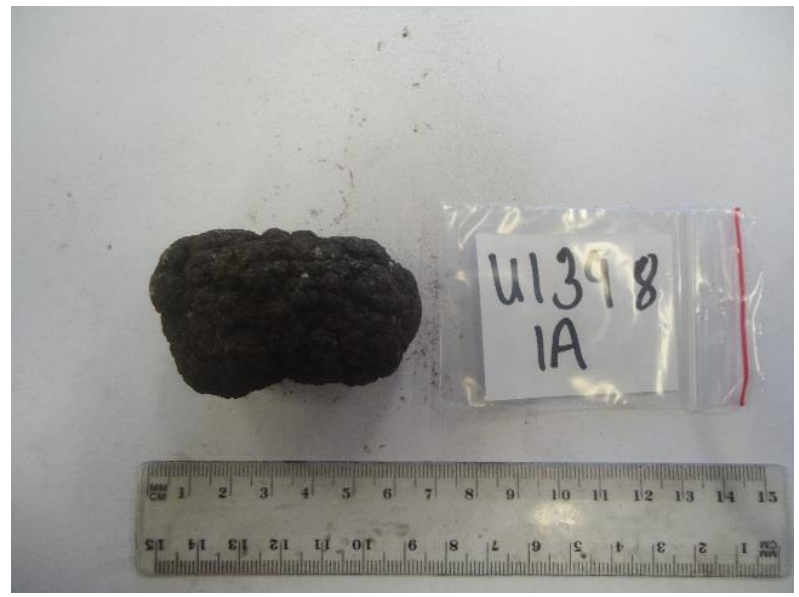

Sample name: U1398-1-A

Size: 7 x $4 \mathrm{~cm}$

Morphotype: $\mathrm{E}_{\mathrm{b}}^{\mathrm{r}}$

Descriptions: Elongate, spherical in shape. Rough texture on top, botryoidal on the bottom.

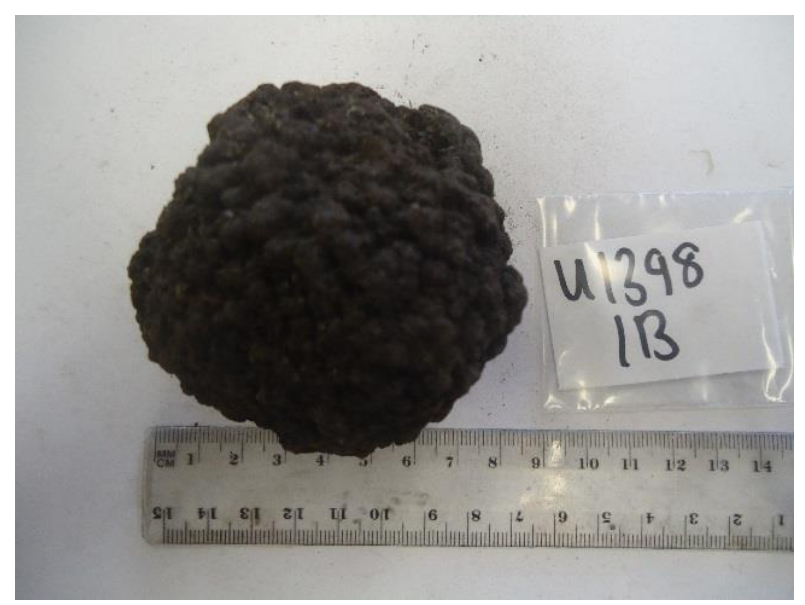

Sample name: U1398-1-B

Size: $10 \times 9 \mathrm{~cm}$

Morphotype: $\mathrm{E}_{\mathrm{b}}$

Descriptions: Elongate, spherical in shape. Botryoidal texture. Inner core may have a phosphate nodule component. 


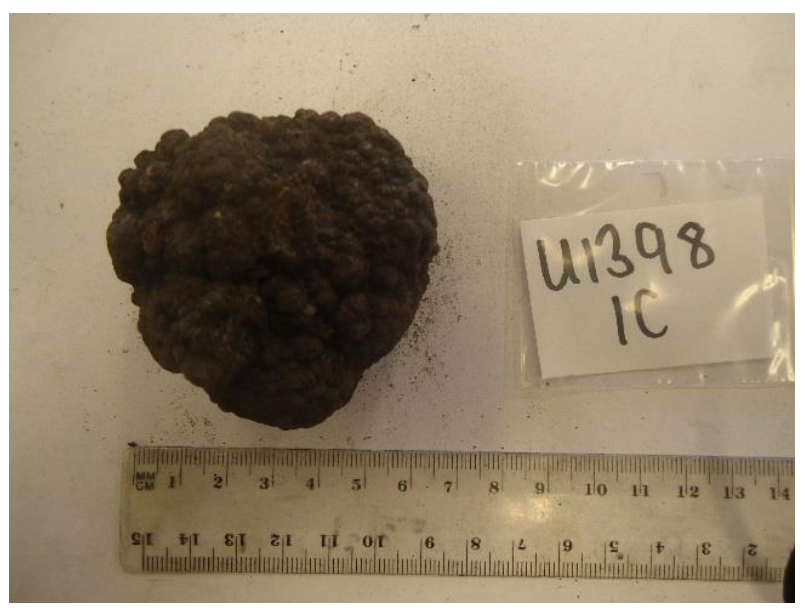

Sample name: U1398-1-C

Size: $7 \times 7 \mathrm{~cm}$

Morphotype: $\mathrm{P}_{\mathrm{b}}$

Descriptions: Fused nodules, with botryoidal texture.

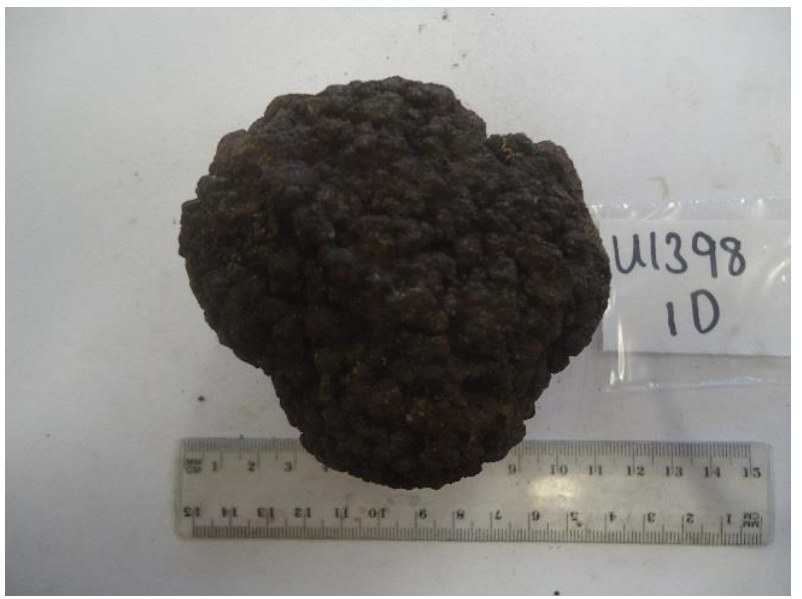

Sample name: U1398-1-D

Size: 11 x $10 \mathrm{~cm}$

Morphotype: $\mathrm{E}^{\mathrm{r}} \mathrm{b}$

Descriptions: Elongate, spherical in shape. Rough texture on top, botryoidal on the bottom.

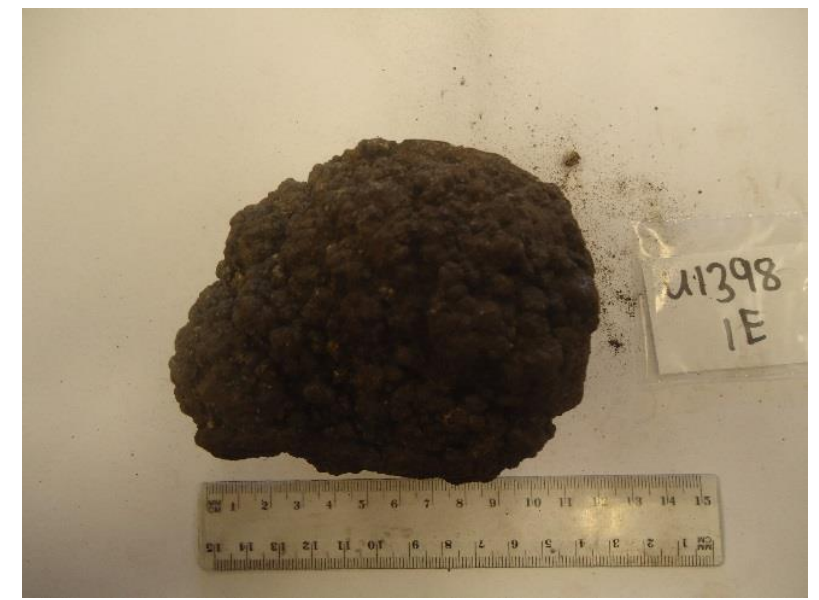

Sample name: U1398-1-E

Size: 13 x $12 \mathrm{~cm}$

Morphotype: $\mathrm{E}_{\mathrm{b}}^{\mathrm{r}}$

Descriptions: Elongate nodule with one large protrusion. Rough texture on top, botryoidal on the bottom. Inner core may have a phosphate nodule component. 


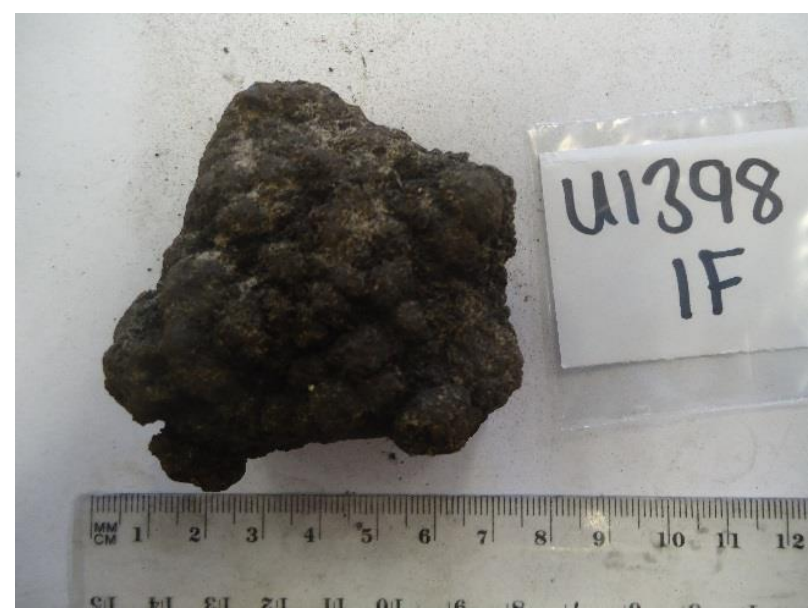

Sample name: U1398-1-F

Size: 7 x $7 \mathrm{~cm}$

Morphotype: $\mathrm{I}_{\mathrm{b}}$

Descriptions: Descriptions: There is concentric growth preferentially on the top and bottom. The initial nucleus is flat. Rough texture on top, botryoidal on the bottom.

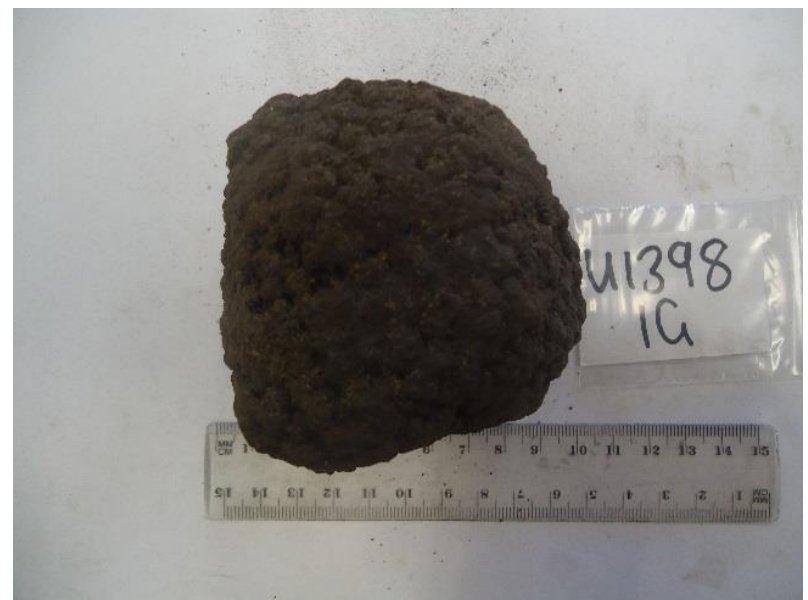

Sample name: U1398-1-G

Size: 11 x $10 \mathrm{~cm}$

Morphotype: $\mathrm{D}^{\mathrm{r}}{ }_{\mathrm{b}}$

Descriptions: Discoidal, almost spherical. It show a preferred growth direction. Rough texture on top, botryoidal on the bottom. 


\section{U1399}

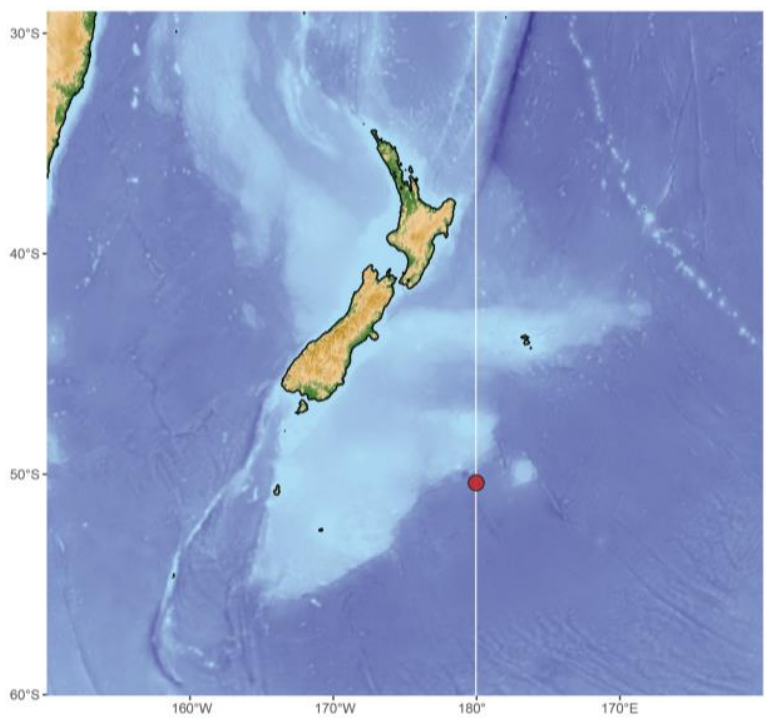

\section{Location: Bollons Gap}

Latitude: $50.4^{\circ} \mathrm{S}$

Longitude: $180.0^{\circ} \mathrm{W}$

Depth: 4494 m

Number of nodules: 8

Notes: Samples U1399-2-A,

U1399-2-B, U1399-2-C, U1399-2-

D, U1399-2-E, and U1399-2-F

were analysed twice.

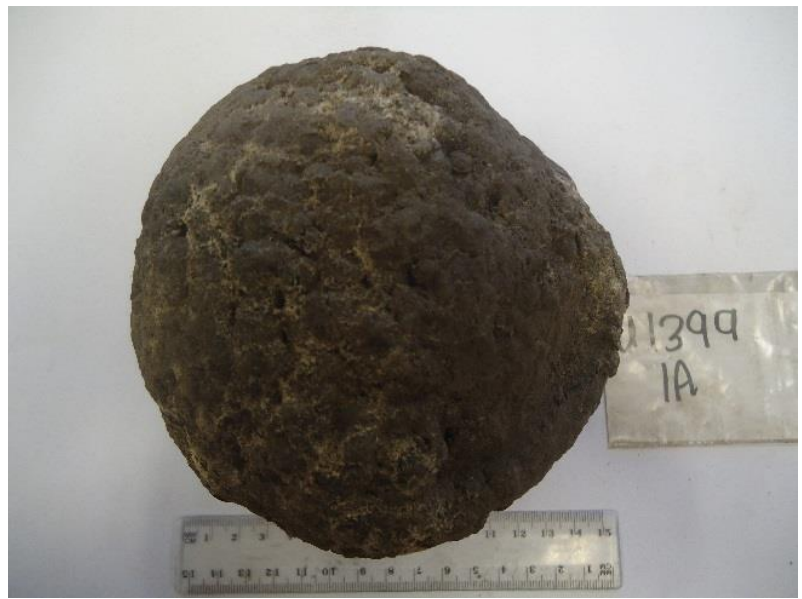

Sample name: U1399-1-A

Size: 18 x $16 \mathrm{~cm}$

Morphotype: $\mathrm{E}_{\mathrm{r}}^{\mathrm{s}}$

Descriptions: Elongate, spherical in shape. Large nodule with some of the outer rim potentially missing. Some fused-looking micro-nodules on surface, possibly eroded. There is a light coloured substance coating the outside. 

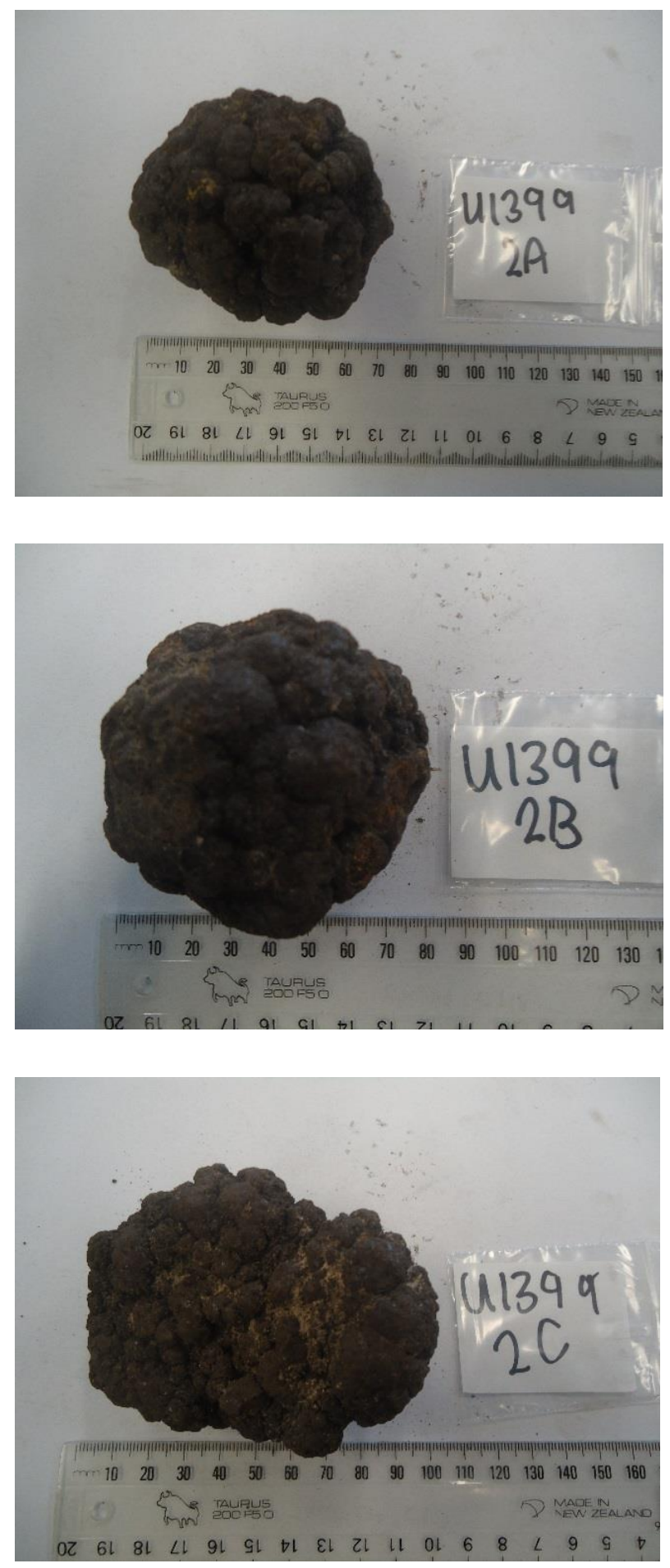

Sample name: U1399-2-A

Size: $9 \times 8 \mathrm{~cm}$

Morphotype: $\mathrm{D}_{\mathrm{b}}^{\mathrm{r}}$

Descriptions: Discoidal/ elongate shape. Rough texture on top, botryoidal on the bottom.

Sample name: U1399-2-B

Size: $8.5 \times 8 \mathrm{~cm}$

Morphotype: $\mathrm{D}_{\mathrm{b}}^{\mathrm{s}}$

Descriptions: Discoidal, almost spherical shape. Botryoidal and smooth texture displayed.

Sample name: U1399-2-C

Size: $10 \times 8 \mathrm{~cm}$

Morphotype: $\mathrm{E}^{\mathrm{r}} \mathrm{b}$

Descriptions: There is concentric growth preferentially on the top and bottom. The initial nucleus is flat. Rough texture on top, botryoidal on the bottom. 

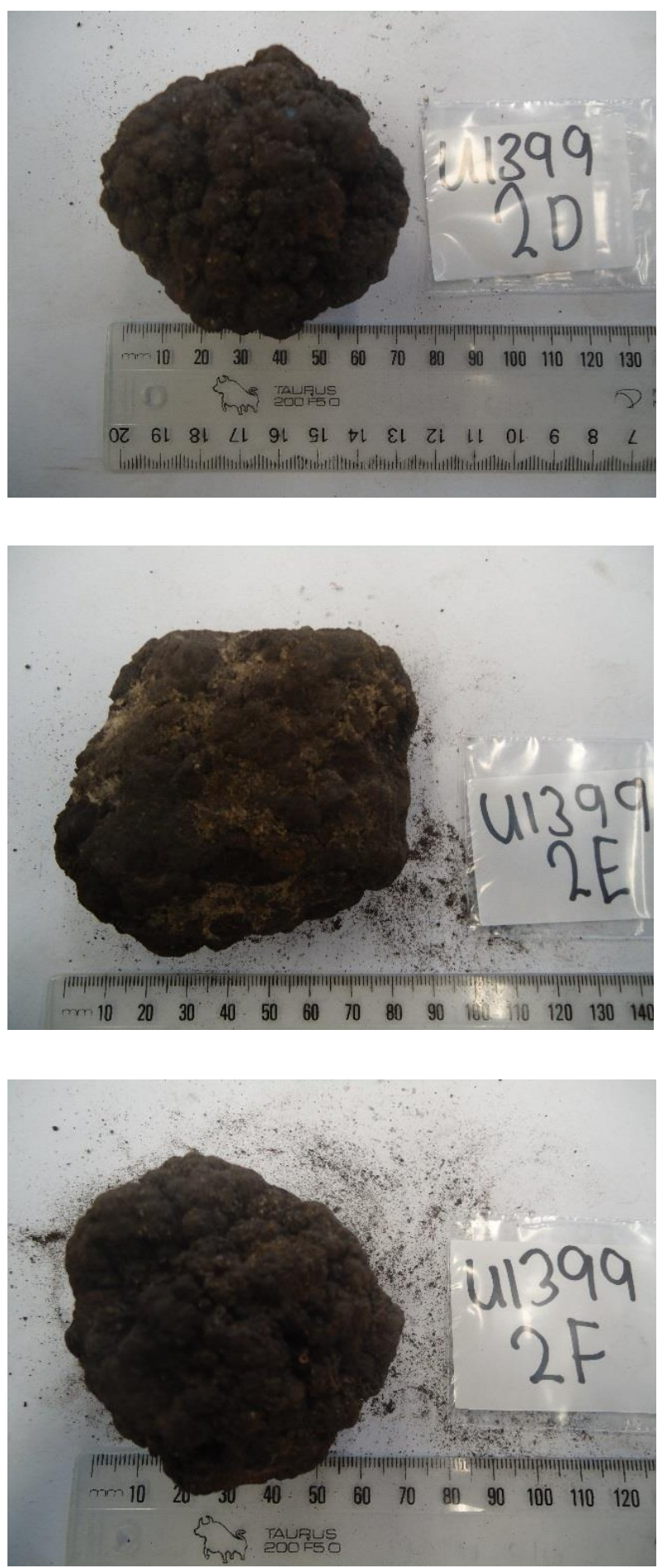

Sample name: U1399-2-D

Size: $8 \times 7.5 \mathrm{~cm}$

Morphotype: $\mathrm{D}^{\mathrm{r}} \mathrm{b}$

Descriptions: Discoidal, almost speherical shape. Rough texture on top, botryoidal on the bottom.

Sample name: U1399-2-E

Size: 9 x $8.5 \mathrm{~cm}$

Morphotype: $\mathrm{B}^{\mathrm{s}}{ }_{\mathrm{r}}$

Descriptions: A ferromanganese encrusted onto a rock.

Sample name: U1399-2-F

Size: $8 \times 7.5 \mathrm{~cm}$

Morphotype: $\mathrm{D}^{\mathrm{r}} \mathrm{b}$

Descriptions: Bulbous and rough texture on outside. 


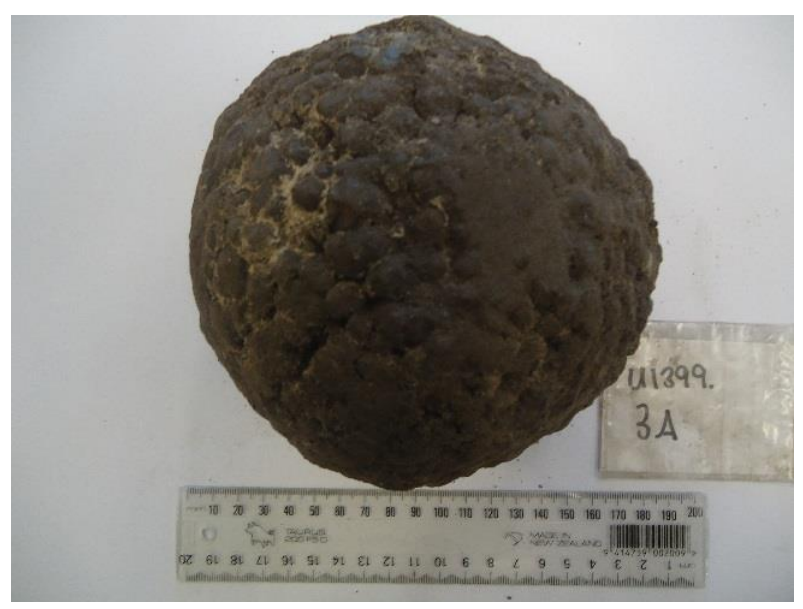

Sample name: U1399-3-A

Size: 18 x $17 \mathrm{~cm}$

Morphotype: $\mathrm{D}^{\mathrm{r}} \mathrm{b}$

Descriptions: Unclear if some outer rim is missing, discoidal growth, or eroded. Some fused micro-nodules seem eroded. There is a light coloured substance coating the outside. Only the obvious rim was sampled.

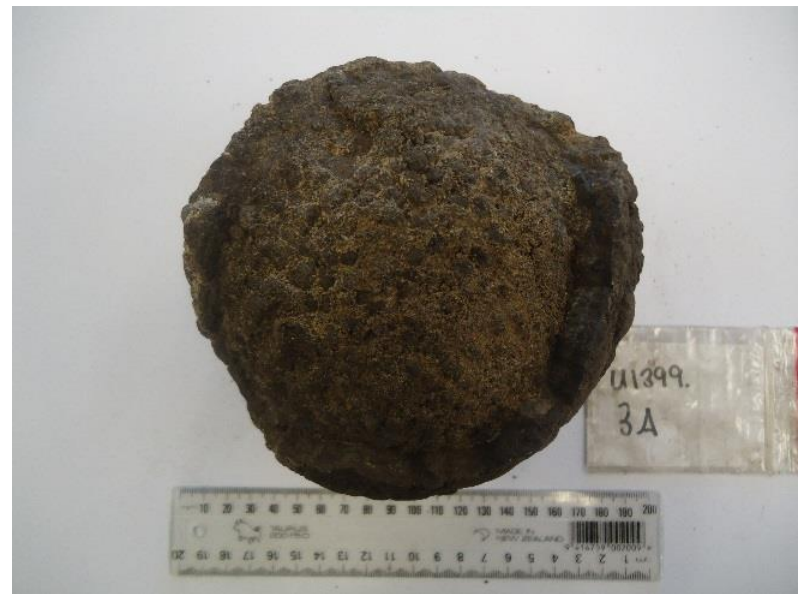




\section{U1402}

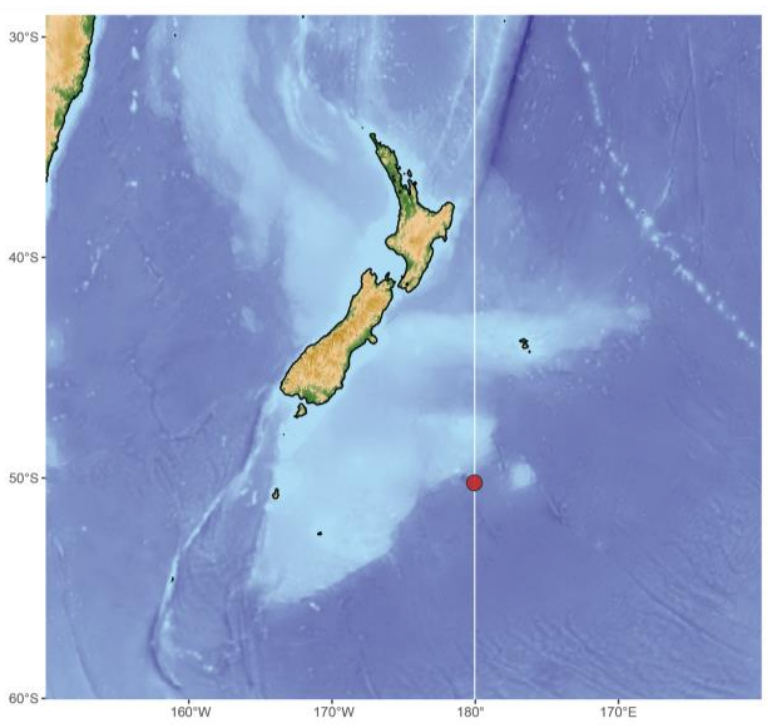

\section{Location: Bollons Gap}

Latitude: $50.2^{\circ} \mathrm{S}$

Longitude: $179.9^{\circ} \mathrm{W}$

Depth: 4445 m

Number of nodules: 6

Notes: Five nodules rims, and one bulk nodule were analysed.

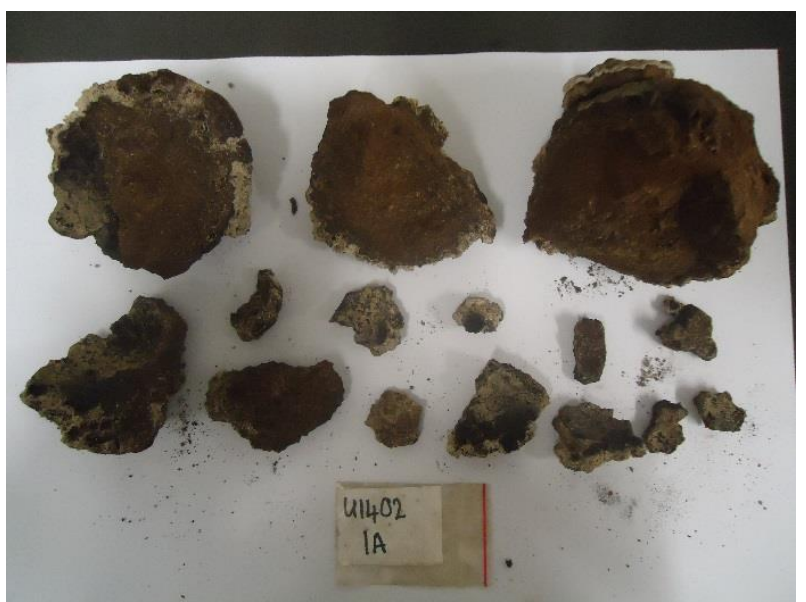

Sample name: U1402-1-A

Size: 13.5 x $12 \mathrm{~cm}$

Morphotype: $\mathrm{D}_{\mathrm{b}}$

Descriptions: Discoidal shape with botryoidal texture. There is some white matter on the nodule. This is a photo of the nodule halved. 

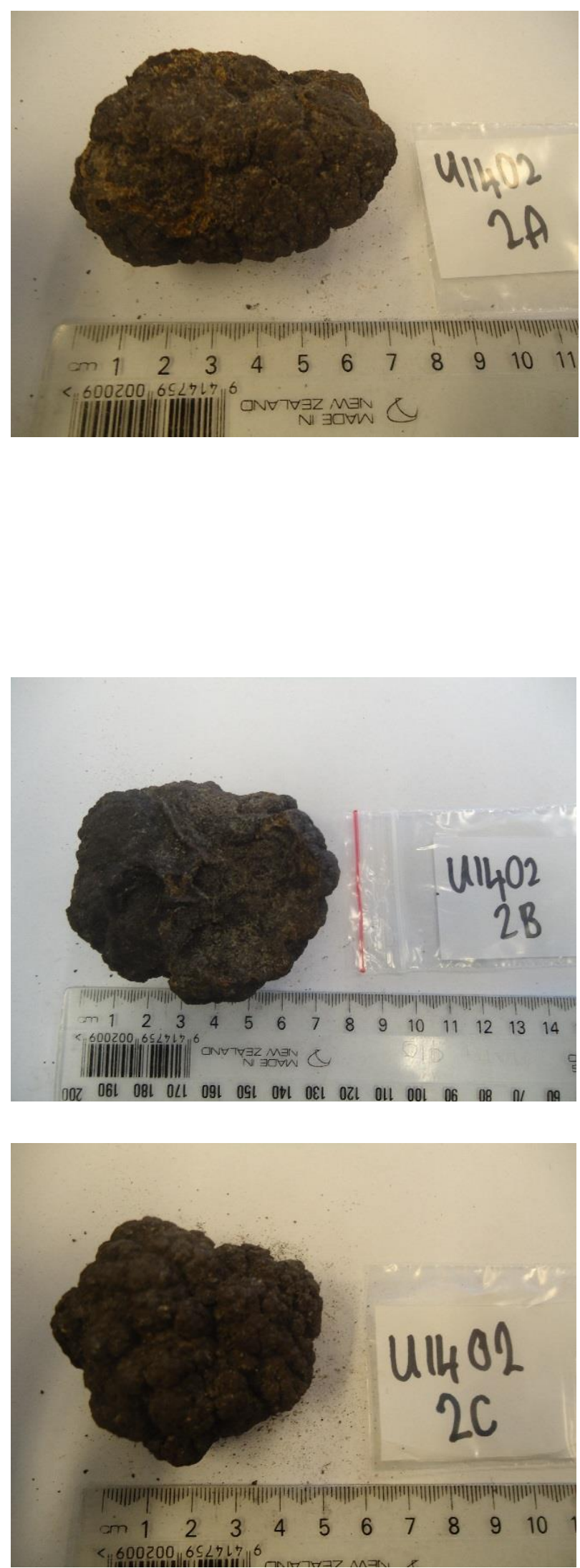

Sample name: U1402-2-A

Size: 7 x $5 \mathrm{~cm}$

Morphotype: $\mathrm{P}_{\mathrm{b}}^{\mathrm{r}}$

Descriptions: Fused nodules. Rough texture on top, bulbous on bottom. This nodule disintegrated upon attempted sampling of the outer rim. Material from this nodule was ground and analysed, thus can be considered a bulk nodule composition.

Sample name: U1402-2-B

Size: $8 \times 6 \mathrm{~cm}$

Morphotype: $\mathrm{I}^{\mathrm{s}} \mathrm{b}$

Descriptions: This nodule may be broken, only the material that appear to be outer rim was sampled.

Sample name: U1402-2-C

Size: 5 x $5 \mathrm{~cm}$

Morphotype: $\mathrm{E}_{\mathrm{b}}$

Descriptions: Elongate shape with boytroidal texture. There is some white matter on the nodule. 


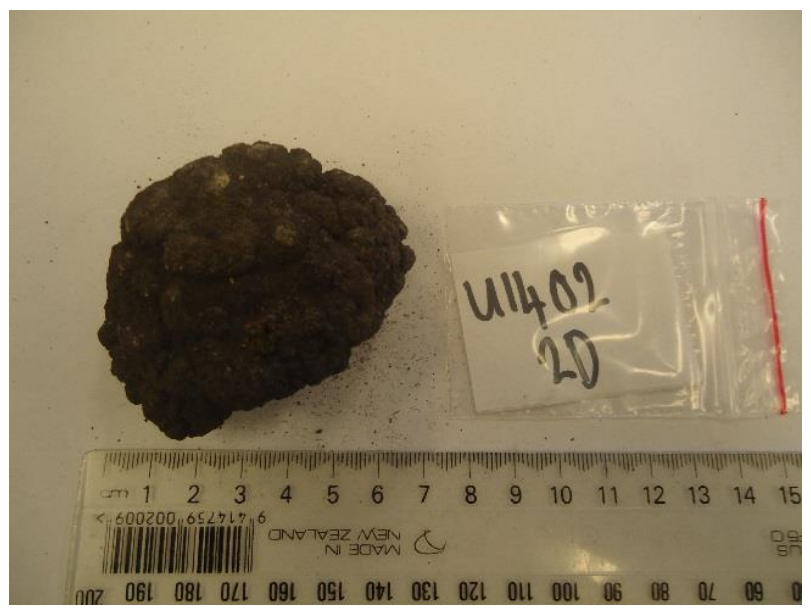

Sample name: U1402-2-D

Size: 7 × $6 \mathrm{~cm}$

Morphotype: $\mathrm{E}_{\mathrm{b}}^{\mathrm{s}}$

Descriptions: Top has smooth

texture, the bottom has botryoidal texture.

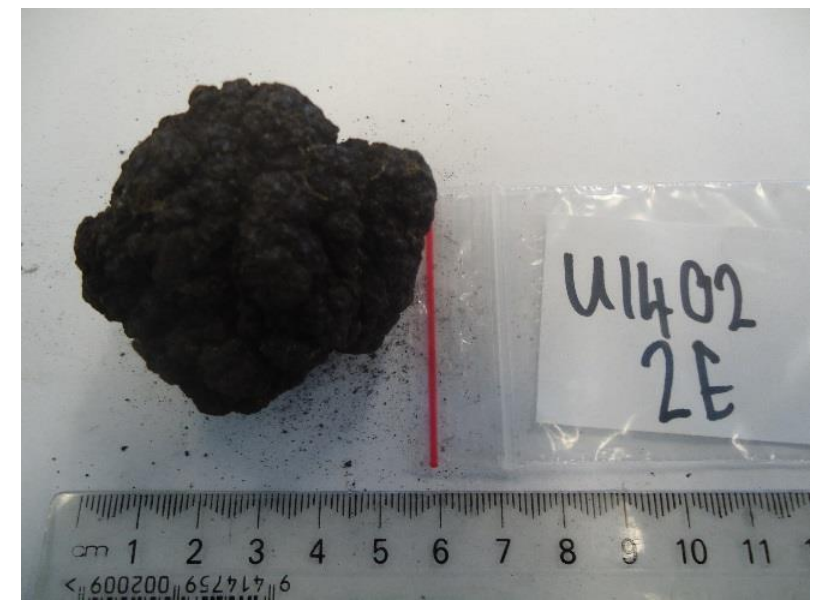

Sample name: U1402-2-E

Size: $6 \times 6 \mathrm{~cm}$

Morphotype: $\mathrm{P}^{\mathrm{r}}$

Descriptions: Fused nodules, the top has a rough texture, the bottom has a botryoidal texture. 


\section{U1406B}

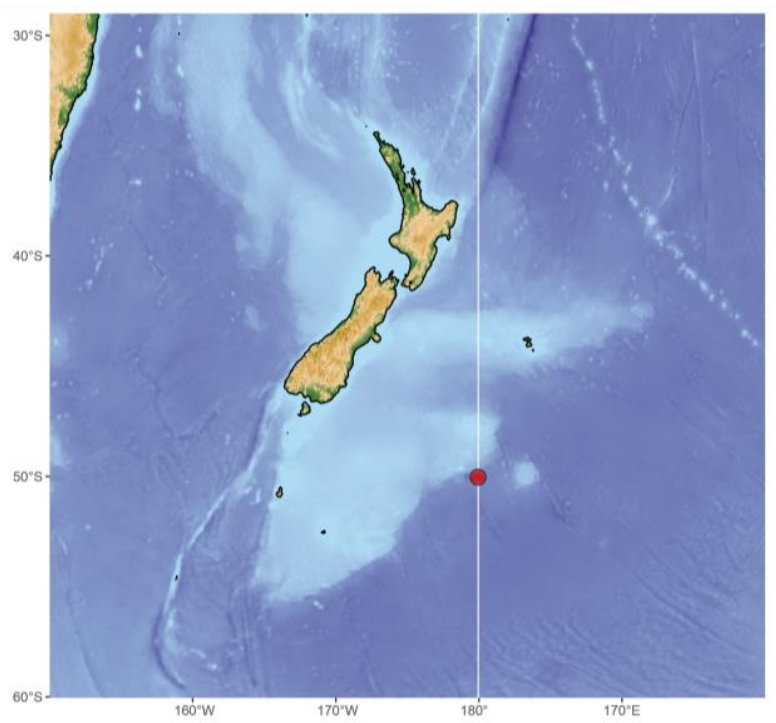

Location: Bollons Gap

Latitude: $49.9^{\circ} \mathrm{S}$

Longitude: $179.9^{\circ} \mathrm{W}$

Depth: 4475 m

Number of nodules: 12

Notes: U1406B-1-D and U1406B-4

had both hemispheres sampled.

U1406B-1-B and U1406B-2-B

were analysed twice.

Sample name: U1406B-1-A

Size: $10 \times 9 \mathrm{~cm}$

Morphotype: $\mathrm{S}_{\mathrm{r}}^{\mathrm{s}}$

Descriptions: Spherical in shape.

One large protrusion on the outer rim

\section{Sample name: U1406B-1-B}

Size: 11 x $10 \mathrm{~cm}$

Morphotype: $\mathrm{I}_{\mathrm{r}}^{\mathrm{s}}$

Descriptions: Irregular shape. Some protrusions on the outer rim. 

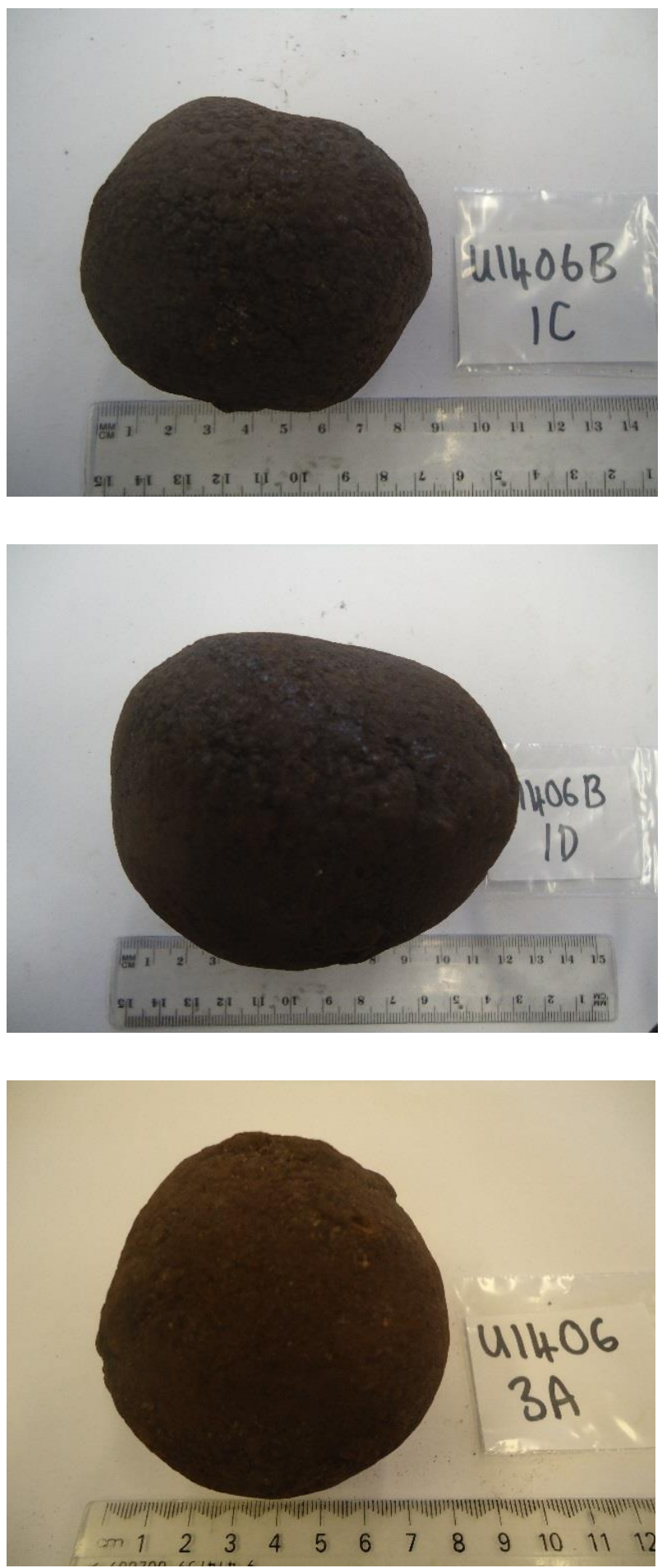

Sample name: U1406B-1-C

Size: $10 \times 9 \mathrm{~cm}$

Morphotype: $\mathrm{E}_{\mathrm{s}}$

Descriptions: Elongate, spherical in shape. Some protrusions on the outer rim. Some of the outer rim is missing.

\section{Sample name: U1406B-1-D}

Size: 12 x $10 \mathrm{~cm}$

Morphotype: $\mathrm{E}_{\mathrm{s}}$

Descriptions: Elongate, spherical in shape.

Sample name: U1406B-2-A

Size: 7 × $6 \mathrm{~cm}$

Morphotype: $\mathrm{E}_{\mathrm{r}}^{\mathrm{s}}$

Descriptions: Elongate, spherical in shape. One large protrusion on the outer rim 

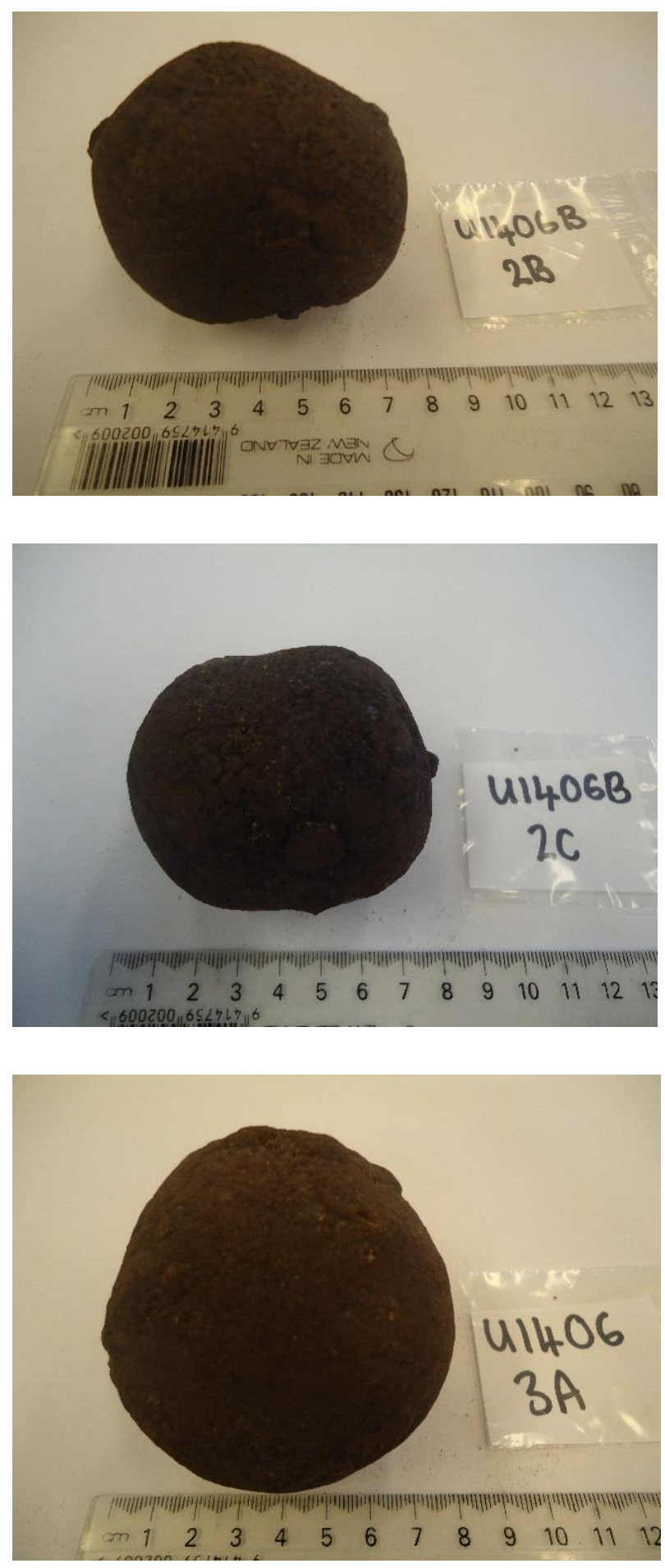

Sample name: U1406B-2-B

Size: $7 \times 6 \mathrm{~cm}$

Morphotype: $\mathrm{E}_{\mathrm{r}}^{\mathrm{s}}$

Descriptions: Elongate, spherical in shape. One large protrusion on the outer rim

Sample name: U1406B-2-C

Size: 7 × $6 \mathrm{~cm}$

Morphotype: $\mathrm{E}_{\mathrm{s}}$

Descriptions: Elongate, spherical in shape. Some protrusions on the outer rim.

Sample name: U1406B-3-A

Size: $9 \times 9 \mathrm{~cm}$

Morphotype: $\mathrm{S}_{\mathrm{r}}$

Descriptions: Elongate, spherical in shape. One large protrusion on the outer rim. 


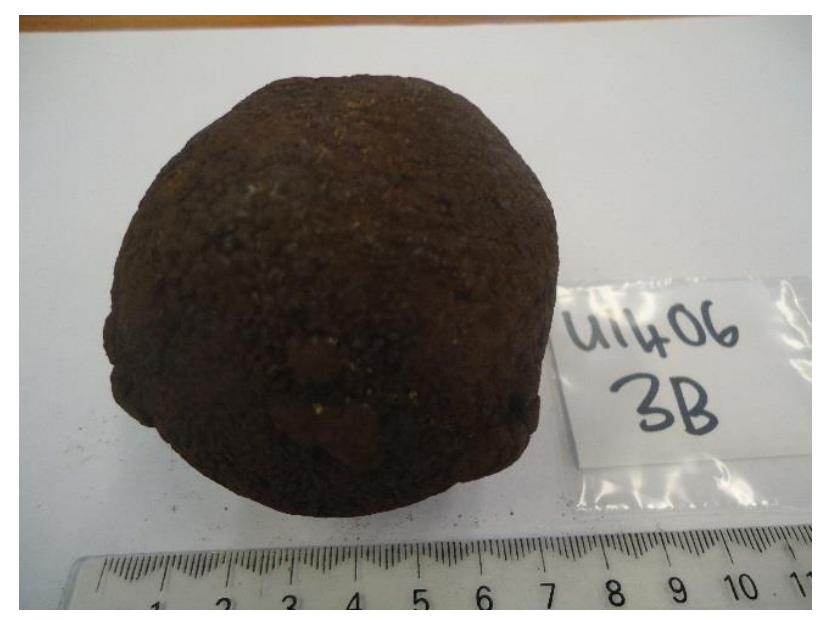

Sample name: U1406B-3-B

Size: $8 \times 7 \mathrm{~cm}$

Morphotype: $\mathrm{E}_{\mathrm{s}}$

Descriptions: Elongate, spherical in shape. Some protrusions on the outer rim.

\section{Sample name: U1406B-3-C}

Size: $8 \times 8 \mathrm{~cm}$

Morphotype: $\mathrm{S}_{\mathrm{r}}^{\mathrm{s}}$

Descriptions: Elongate, spherical in shape. Some protrusions on the outer rim.
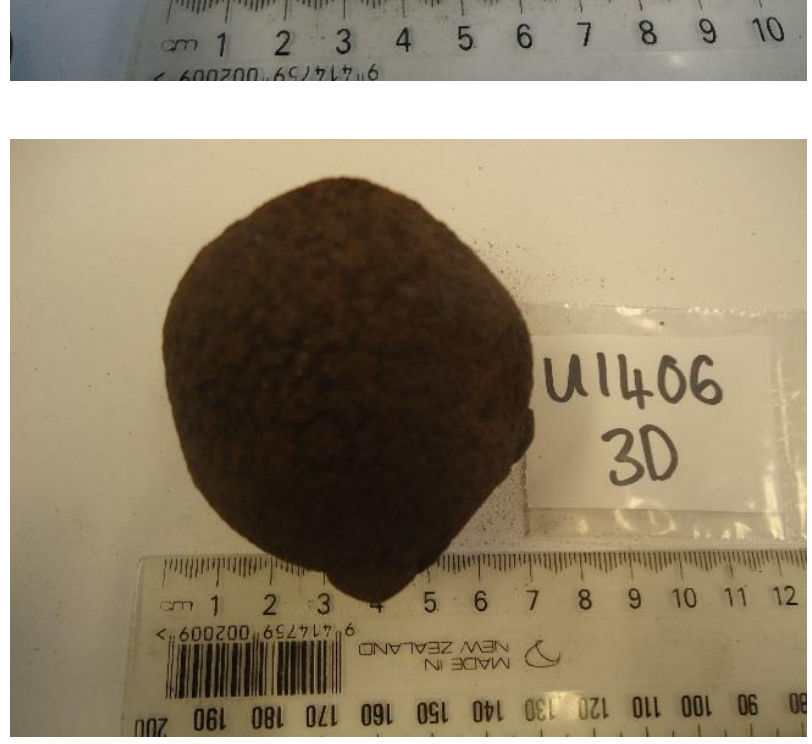

Sample name: U1406B-3-D

Size: $7 \times 7 \mathrm{~cm}$

Morphotype: $\mathrm{E}_{\mathrm{r}}^{\mathrm{s}}$

Descriptions: Elongate, spherical in shape. Some protrusions on the outer rim. 


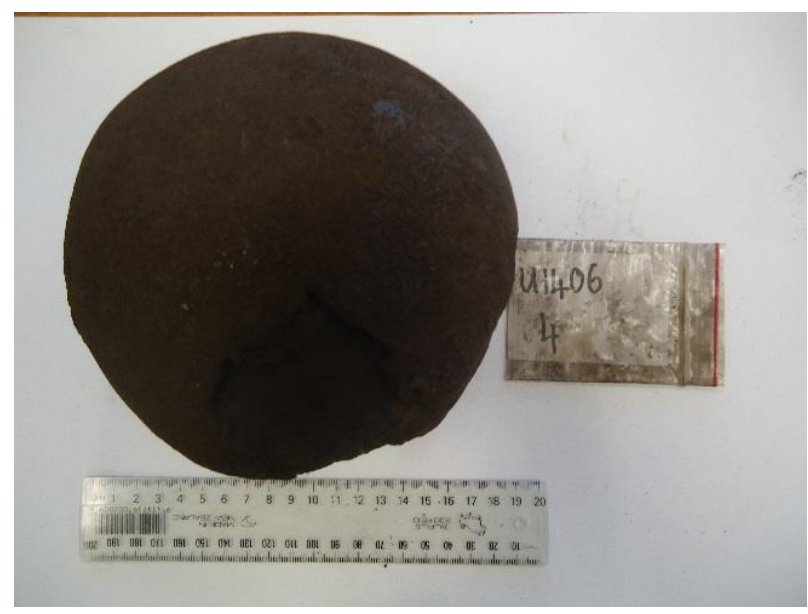

Sample name: U1406B-4-A

Size: 20 × $20 \mathrm{~cm}$

Morphotype: $\mathrm{S}_{\mathrm{s}}$

Descriptions: Large, smooth

nodule. Some of the outer rim is

missing. 


\section{U1413}

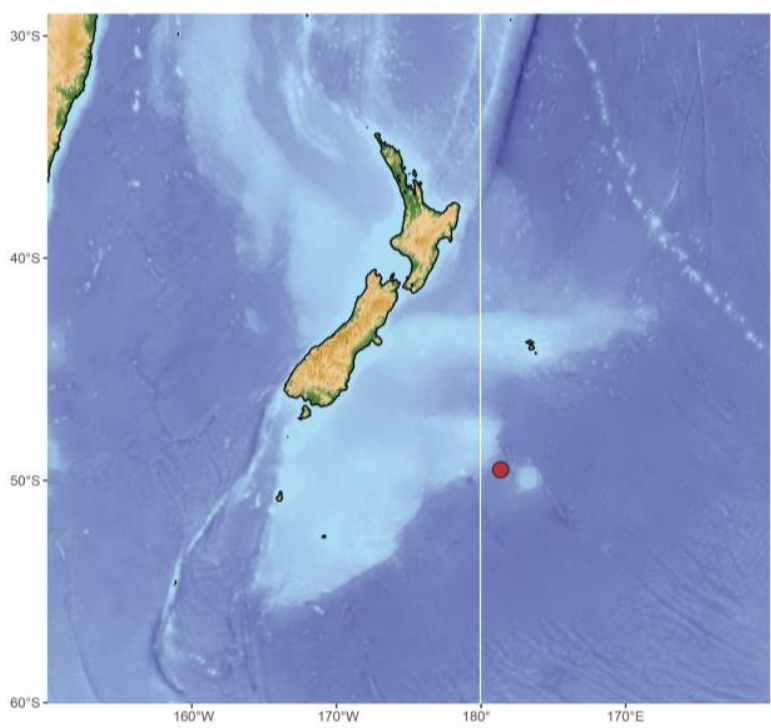

\section{Location: Bollons Gap}

Latitude: $49.5^{\circ} \mathrm{S}$

Longitude: $178.7^{\circ} \mathrm{W}$

Depth: 4375 m

Number of nodules: 2

Notes: U1413-1-A was analysed twice. U1413-1-B was analysed five times, and was run with each batch. U1413-1-B was also analysed using the leaching procedure.

Sample name: U1413-1-A

Size: 12 x $12 \mathrm{~cm}$

Morphotype: $\mathrm{E}_{\mathrm{r}}^{\mathrm{s}}$

Descriptions: Rough texture. Some of the outer rim is missing. Overall shape is elongate spherical. 


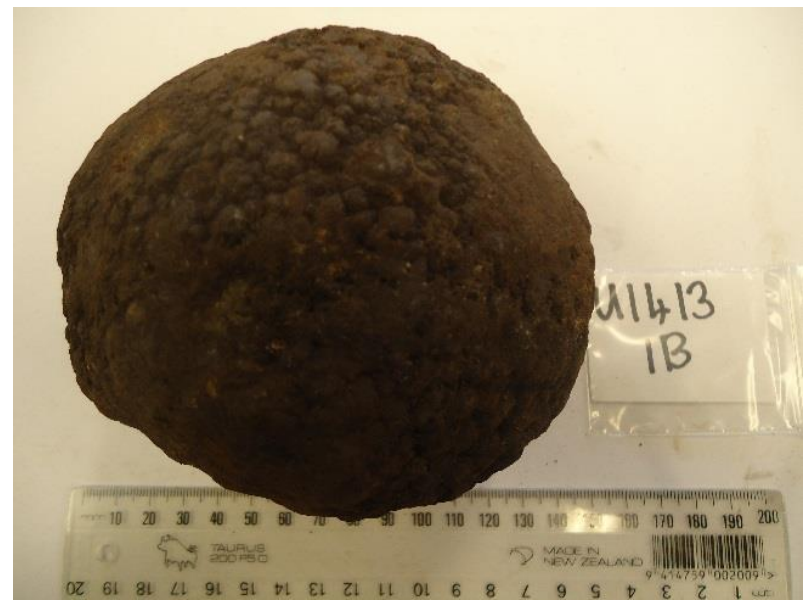

Sample name: U1413-1-B

Size: 14 x $14 \mathrm{~cm}$

Morphotype: $\mathrm{D}_{\mathrm{r}}^{\mathrm{s}}$

Description: Some sections have bulbous bits as rough, others are smooth. Overall shape is elongate spherical. This sample may have been eroded. 

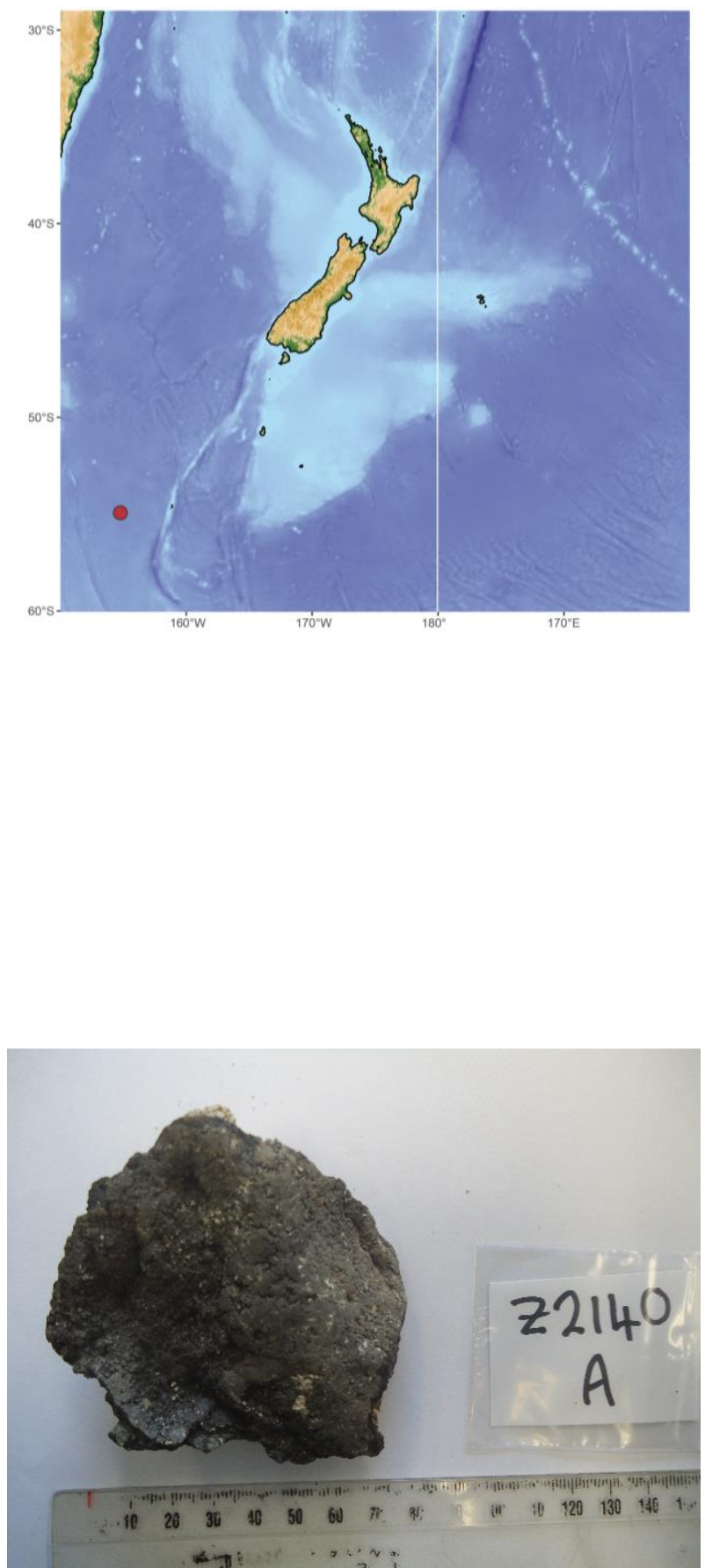

Location: West of Macquarie

\section{Island}

Latitude: $54.9^{\circ} \mathrm{S}$

Longitude: $180.0^{\circ} \mathrm{W}$

Depth: 4058 m

Number of nodules: 7 crust

fragments

Notes: These samples are crusts.

Samples Z2140-A, Z2140-D, and Z2140-F; and Z2140-C, Z2140-E, and $\mathrm{Z} 2140-\mathrm{G}$ were combined to obtain enough material for analysis.

Sample name: Z2140-A

Size: 8.5 x $8.5 \mathrm{~cm}$

Morphotype: $\mathrm{B}_{\mathrm{s}}$

Description: Ferromanganese coating on a friable substrate. There is darker tube-like structures within the substrate. 

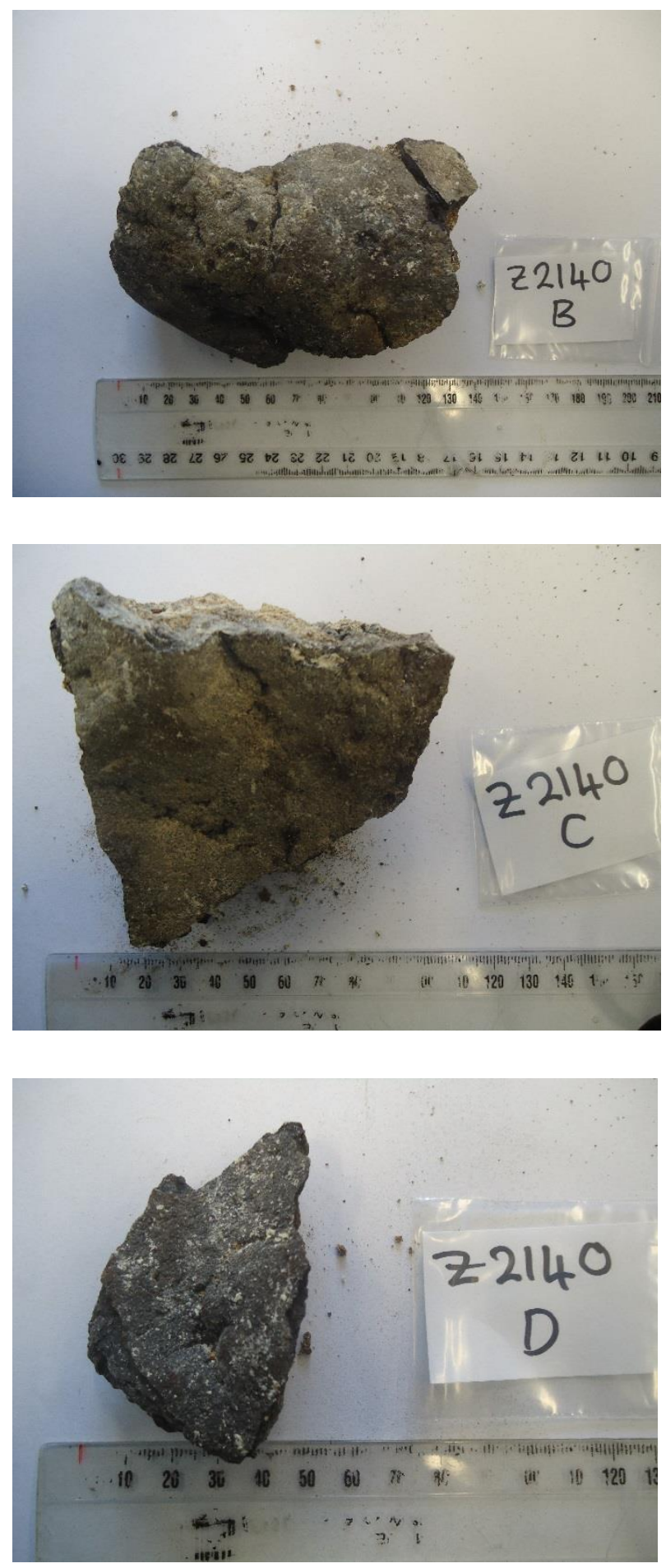

Sample name: Z2140-B

Size: 15 x $10 \mathrm{~cm}$

Morphotype: $\mathrm{B}_{\mathrm{s}}$

Descriptions: Ferromanganese

coating on a friable substrate. There

is darker tube-like structures within the substrate.

Sample name: Z2140-C

Size: 10.5 x $10 \mathrm{~cm}$

Morphotype: $\mathrm{B}_{\mathrm{s}}$

Descriptions: Ferromanganese

coating on a friable substrate. There is darker tube-like structures within the substrate.

Sample name: Z2140-D

Size: 7.5 x $5 \mathrm{~cm}$

Morphotype: $\mathrm{B}_{\mathrm{s}}$

Descriptions: Ferromanganese

coating on a friable substrate. There is darker tube-like structures within the substrate. 

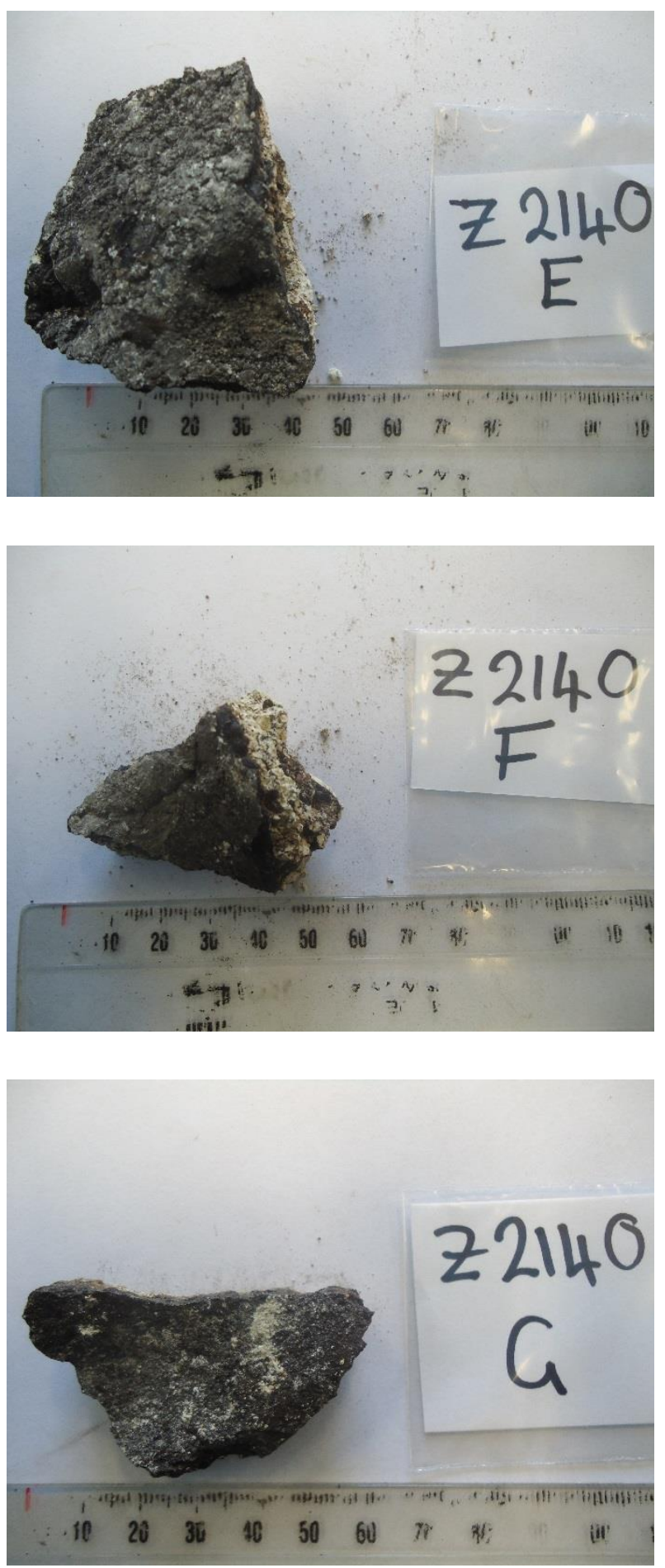

Sample name: Z2140-E

Size: $6 \times 5 \mathrm{~cm}$

Morphotype: $\mathrm{B}_{\mathrm{s}}$

Descriptions: Ferromanganese coating on a friable substrate. There is darker tube-like structures within the substrate.

Sample name: Z2140-F

Size: 5.5 x $4.5 \mathrm{~cm}$

Morphotype: $\mathrm{B}_{\mathrm{s}}$

Descriptions: Ferromanganese coating on a friable substrate. There is darker tube-like structures within the substrate.

Sample name: Z2140-G

Size: $6 \times 3.5 \mathrm{~cm}$

Morphotype: $\mathrm{B}_{\mathrm{s}}$

Descriptions: Ferromanganese coating on a friable substrate. There is darker tube-like structures within the substrate. 
Appendix D Major, minor and trace elements - ICP-MS 


\begin{tabular}{|c|c|c|c|c|c|c|c|c|c|c|}
\hline & $\begin{array}{l}\text { Tasman Se } \\
\text { U203 }\end{array}$ & U203 & U205 & $\mathrm{U} 205$ & U205 & U205 & U205 & U205 & U205 & U205 \\
\hline Sample & AD & BC & ABEH & CJ & DFG & I & $\mathbf{K}$ & $\mathbf{L}$ & SU & TVW \\
\hline Mn (wt\%) & 13.85 & 14.68 & 21.86 & 22.26 & 21.93 & 21.34 & 23.33 & 23.20 & 22.30 & 21.15 \\
\hline $\mathbf{F e}$ & 7.55 & 6.13 & 7.72 & 7.51 & 6.80 & 7.41 & 6.07 & 6.97 & 6.76 & 8.75 \\
\hline Co & 0.09 & 0.06 & 0.08 & 0.09 & 0.07 & 0.08 & 0.07 & 0.07 & 0.07 & 0.10 \\
\hline $\mathbf{N i}$ & 0.57 & 0.71 & 0.95 & 0.90 & 1.05 & 0.99 & 1.20 & 1.07 & 1.03 & 0.83 \\
\hline $\mathbf{C u}$ & 0.26 & 0.27 & 0.36 & 0.33 & 0.36 & 0.33 & 0.35 & 0.41 & 0.34 & 0.34 \\
\hline $\mathrm{Mn} / \mathrm{Fe}$ & 1.84 & 2.40 & 2.83 & 2.97 & 3.23 & 2.88 & 3.85 & 3.33 & 3.30 & 2.42 \\
\hline $\mathrm{Ni}+\mathrm{Cu}$ & 0.83 & 0.98 & 1.31 & 1.23 & 1.41 & 1.31 & 1.55 & 1.48 & 1.37 & 1.16 \\
\hline $\mathrm{Co}+\mathrm{Ni}+\mathrm{Cu}$ & 0.92 & 1.04 & 1.38 & 1.32 & 1.47 & 1.39 & 1.62 & 1.55 & 1.45 & 1.26 \\
\hline $\mathbf{L i}(\mathbf{p p m})$ & 63.5 & 68.1 & 118.7 & 116.9 & 136.5 & 153.5 & 135.2 & 104.4 & 131.7 & 132.5 \\
\hline Mg & 18749 & 19204 & 16780 & 17169 & 17684 & 17366 & 18461 & 18449 & 17737 & 19992 \\
\hline Al & 42352 & 50867 & 33444 & 32202 & 34007 & 34499 & 33980 & 37274 & 30074 & 31906 \\
\hline $\mathbf{P}$ & 1625 & 1616 & 1878 & 1834 & 1748 & 1838 & 1520 & 1706 & 1737 & 1883 \\
\hline $\mathbf{C a}$ & 13637 & 15717 & 14899 & 13282 & 18421 & 16040 & 14533 & 12489 & 15884 & 15749 \\
\hline $\mathbf{T i}$ & 2887 & 2936 & 3008 & 3346 & 2755 & 3283 & 2649 & 2819 & 2832 & 3373 \\
\hline Sc & 9.0 & 9.4 & 6.6 & 6.8 & 6.5 & 6.6 & 7.0 & 6.3 & 6.3 & 7.4 \\
\hline $\mathbf{V}$ & 352 & 350 & 448 & 407 & 407 & 407 & 398 & 431 & 407 & 448 \\
\hline $\mathrm{Cr}$ & 24.6 & 27.6 & 48.3 & 34.7 & 35.5 & 33.0 & 34.3 & 39.2 & 46.2 & 41.9 \\
\hline $\mathbf{Z n}$ & 903 & 1041 & 2062 & 2001 & 2240 & 2029 & 2322 & 3957 & 2214 & 1441 \\
\hline $\mathbf{G a}$ & 12.5 & 14.1 & 12.8 & 13.9 & 13.9 & 12.5 & 14.0 & 14.1 & 13.6 & 14.9 \\
\hline As & 70 & 61 & 82 & 94 & 79 & 80 & 71 & 74 & 85 & 107 \\
\hline $\mathbf{R b}$ & 26.2 & 31.8 & 29.8 & 29.7 & 29.6 & 29.3 & 29.2 & 29.5 & 26.6 & 27.2 \\
\hline $\mathrm{Sr}$ & 400 & 360 & 507 & 481 & 476 & 511 & 462 & 498 & 492 & 603 \\
\hline $\mathbf{Y}$ & 50 & 43 & 60 & 57 & 54 & 59 & 50 & 52 & 59 & 71 \\
\hline $\mathbf{Z r}$ & 175 & 135 & 167 & 206 & 155 & 170 & 160 & 143 & 161 & 245 \\
\hline
\end{tabular}




\begin{tabular}{|c|c|c|c|c|c|c|c|c|c|c|}
\hline Mo & 195 & 227 & 304 & 324 & 325 & 285 & 350 & 323 & 354 & 352 \\
\hline Cd & 12.1 & 13.8 & 10.5 & 8.6 & 10.5 & 10.7 & 11.3 & 9.9 & 9.4 & 9.7 \\
\hline $\mathbf{B a}$ & 929 & 713 & 938 & 922 & 815 & 837 & 867 & 905 & 807 & 1379 \\
\hline La & 65 & 50 & 73 & 75 & 64 & 69 & 61 & 66 & 70 & 95 \\
\hline $\mathrm{Ce}$ & 214 & 164 & 267 & 320 & 207 & 253 & 213 & 221 & 261 & 370 \\
\hline $\operatorname{Pr}$ & 17.3 & 14.0 & 19.9 & 20.4 & 18.2 & 19.3 & 17.0 & 18.6 & 19.6 & 25.3 \\
\hline Nd & 70 & 58 & 85 & 84 & 76 & 82 & 72 & 78 & 84 & 104 \\
\hline Sm & 15.1 & 12.9 & 19.3 & 19.0 & 17.6 & 18.3 & 16.8 & 17.4 & 19.6 & 23.2 \\
\hline $\mathbf{E u}$ & 3.6 & 3.1 & 4.5 & 4.4 & 4.1 & 4.3 & 4.0 & 4.1 & 4.6 & 5.4 \\
\hline Gd & 15.5 & 13.4 & 19.7 & 19.5 & 17.4 & 18.5 & 17.0 & 17.3 & 19.8 & 24.0 \\
\hline $\mathbf{T b}$ & 2.4 & 2.2 & 3.0 & 2.9 & 2.7 & 2.9 & 2.6 & 2.7 & 3.1 & 3.6 \\
\hline Dy & 13.6 & 12.0 & 16.7 & 15.9 & 15.1 & 16.1 & 14.4 & 15.0 & 16.8 & 19.9 \\
\hline Но & 2.5 & 2.3 & 3.1 & 2.9 & 2.9 & 3.0 & 2.7 & 2.8 & 3.1 & 3.6 \\
\hline Er & 6.9 & 6.2 & 8.5 & 8.1 & 7.6 & 8.1 & 7.3 & 7.6 & 8.5 & 9.9 \\
\hline Tm & 1.0 & 0.9 & 1.2 & 1.1 & 1.1 & 1.1 & 1.0 & 1.0 & 1.1 & 1.4 \\
\hline $\mathbf{Y b}$ & 6.3 & 5.8 & 7.6 & 7.1 & 7.0 & 7.3 & 6.6 & 6.8 & 7.5 & 8.8 \\
\hline $\mathbf{L u}$ & 0.9 & 0.8 & 1.1 & 1.0 & 1.0 & 1.0 & 0.9 & 0.9 & 1.1 & 1.3 \\
\hline Hf & 3.9 & 3.4 & 3.6 & 4.6 & 3.3 & 3.7 & 3.8 & 3.1 & 3.4 & 5.0 \\
\hline Tl & 36.4 & 29.3 & 64.6 & 36.9 & 64.0 & 79.9 & 69.4 & 53.1 & 64.8 & 60.7 \\
\hline $\mathbf{P b}$ & 432 & 266 & 533 & 511 & 438 & 525 & 387 & 454 & 504 & 598 \\
\hline $\mathbf{B i}$ & 3.0 & 2.0 & 4.2 & 3.7 & 3.4 & 3.9 & 2.5 & 3.2 & 4.2 & 4.6 \\
\hline Th & 28.0 & 19.6 & 25.4 & 30.8 & 21.8 & 24.9 & 20.0 & 22.8 & 25.6 & 36.6 \\
\hline $\mathbf{U}$ & 2.3 & 2.5 & 3.0 & 3.1 & 2.9 & 3.1 & 2.6 & 2.7 & 3.1 & 3.5 \\
\hline ¿REY (wt\%) & 0.05 & 0.04 & 0.06 & 0.06 & 0.05 & 0.06 & 0.05 & 0.05 & 0.06 & 0.08 \\
\hline$\left(\mathrm{Ce} / \mathrm{Ce}^{*}\right)_{\mathrm{SN}(\mathrm{PAAS})}$ & 1.47 & 1.42 & 1.60 & 1.88 & 1.39 & 1.58 & 1.51 & 1.44 & 1.61 & 1.73 \\
\hline
\end{tabular}




\begin{tabular}{|c|c|c|c|c|c|c|c|c|c|c|}
\hline & \multicolumn{10}{|c|}{ Campbell Nodule Field - northern transect } \\
\hline & $\mathrm{U} 1413$ & U1413 & U1413 & $\mathrm{U} 1413$ & $\mathrm{U} 1413$ & $\mathrm{U} 1406 \mathrm{~B}$ & $\mathrm{U} 1406 \mathrm{~B}$ & $\mathrm{U} 1406 \mathrm{~B}$ & $\mathrm{U} 1406 \mathrm{~B}$ & U1406B \\
\hline Sample & 1-A & 1-B (1) & 1-B (2) & 1-B (3) & 1-B (4) & 1-A & 1-B & 1-C & 1-D-X & 1-D-Z \\
\hline $\operatorname{Mn}(w t \%)$ & 19.79 & 17.51 & 17.71 & 17.16 & 19.24 & 17.92 & 22.75 & 18.55 & 19.58 & 19.80 \\
\hline $\mathbf{F e}$ & 16.22 & 15.50 & 15.32 & 15.44 & 16.36 & 16.01 & 10.03 & 17.54 & 15.67 & 15.95 \\
\hline Co & 0.38 & 0.24 & 0.24 & 0.24 & 0.26 & 0.21 & 0.17 & 0.27 & 0.27 & 0.38 \\
\hline $\mathbf{N i}$ & 0.51 & 0.56 & 0.56 & 0.56 & 0.59 & 0.48 & 1.10 & 0.40 & 0.62 & 0.55 \\
\hline $\mathbf{C u}$ & 0.12 & 0.11 & 0.11 & 0.11 & 0.12 & 0.14 & 0.35 & 0.10 & 0.12 & 0.11 \\
\hline $\mathbf{M n} / \mathbf{F e}$ & 1.22 & 1.13 & 1.16 & 1.11 & 1.18 & 1.12 & 2.27 & 1.06 & 1.25 & 1.24 \\
\hline $\mathrm{Ni}+\mathrm{Cu}$ & 0.63 & 0.67 & 0.67 & 0.66 & 0.71 & 0.62 & 1.46 & 0.50 & 0.74 & 0.65 \\
\hline $\mathrm{Co}+\mathrm{Ni}+\mathrm{Cu}$ & 1.01 & 0.91 & 0.91 & 0.90 & 0.97 & 0.83 & 1.63 & 0.77 & 1.01 & 1.04 \\
\hline Li (ppm) & 13.5 & 15.7 & 15.8 & 16.0 & 16.3 & 16.0 & 45.2 & 11.9 & 14.3 & 14.8 \\
\hline Mg & 12851 & 13899 & 13854 & 13669 & 14352 & 13666 & 17597 & 13583 & 14141 & 13957 \\
\hline Al & 14360 & 21303 & 21811 & 21201 & 22900 & 23474 & 21411 & 21320 & 18534 & 16662 \\
\hline $\mathbf{P}$ & 2983 & 2819 & 2995 & 2914 & 3085 & 3162 & 1631 & 3751 & 3434 & 3264 \\
\hline $\mathbf{C a}$ & 23219 & 22776 & 23322 & 23314 & 22331 & 23682 & 19021 & 23658 & 24282 & 23422 \\
\hline $\mathbf{T i}$ & 10145 & 10205 & 10248 & 10224 & 10695 & 10314 & 7810 & 10178 & 10134 & 11879 \\
\hline Sc & 9.8 & 10.7 & 10.7 & 10.9 & 11.4 & 11.8 & 10.9 & 11.1 & 9.8 & 9.6 \\
\hline $\mathbf{V}$ & 513 & 549 & 553 & 546 & 575 & 518 & 320 & 622 & 592 & 585 \\
\hline $\mathrm{Cr}$ & 17.0 & 27.3 & 28.3 & 27.4 & 29.0 & 32.5 & 21.5 & 29.7 & 22.7 & 18.3 \\
\hline $\mathbf{Z n}$ & 857 & 945 & 941 & 947 & 985 & 874 & 1968 & 1265 & 1197 & 1036 \\
\hline Ga & 6.0 & 7.2 & 7.5 & 7.3 & 7.6 & 8.8 & 15.3 & 7.0 & 7.5 & 6.7 \\
\hline As & 161 & 187 & 179 & 189 & 189 & 176 & 69 & 202 & 210 & 201 \\
\hline $\mathbf{R b}$ & 10.6 & 13.9 & 14.2 & 14.0 & 14.8 & 17.9 & 20.9 & 14.6 & 13.0 & 11.2 \\
\hline $\mathrm{Sr}$ & 1238 & 1097 & 1097 & 1082 & 1207 & 1141 & 795 & 1297 & 1173 & 1232 \\
\hline $\mathbf{Y}$ & 119 & 111 & 111 & 111 & 118 & 107 & 56 & 125 & 115 & 120 \\
\hline $\mathbf{Z r}$ & 577 & 558 & 576 & 569 & 603 & 588 & 327 & 609 & 551 & 570 \\
\hline
\end{tabular}




\begin{tabular}{|c|c|c|c|c|c|c|c|c|c|c|}
\hline Mo & 233 & 236 & 241 & 239 & 246 & 167 & 166 & 200 & 251 & 228 \\
\hline $\mathbf{C d}$ & 7.0 & 6.4 & 6.5 & 6.3 & 7.0 & 6.7 & 14.2 & 5.6 & 6.8 & 6.2 \\
\hline $\mathbf{B a}$ & 1464 & 1186 & 1181 & 1188 & 1295 & 1340 & 1465 & 1390 & 1114 & 1094 \\
\hline La & 201 & 170 & 170 & 170 & 188 & 166 & 81 & 199 & 175 & 190 \\
\hline $\mathrm{Ce}$ & 1005 & 871 & 862 & 854 & 949 & 744 & 473 & 888 & 808 & 982 \\
\hline $\operatorname{Pr}$ & 50.5 & 43.8 & 44.0 & 43.8 & 48.3 & 41.2 & 21.4 & 49.3 & 44.4 & 48.3 \\
\hline Nd & 198 & 176 & 177 & 176 & 189 & 167 & 89 & 194 & 179 & 193 \\
\hline $\mathrm{Sm}$ & 43.0 & 37.8 & 38.1 & 38.2 & 39.1 & 35.6 & 20.3 & 40.7 & 38.9 & 41.1 \\
\hline $\mathbf{E u}$ & 9.8 & 8.6 & 8.8 & 8.8 & 9.0 & 8.2 & 4.9 & 9.3 & 9.0 & 9.6 \\
\hline Gd & 47.0 & 40.9 & 41.0 & 40.7 & 43.3 & 38.4 & 21.7 & 44.9 & 41.7 & 44.5 \\
\hline $\mathbf{T b}$ & 7.0 & 6.2 & 6.3 & 6.3 & 6.5 & 5.9 & 3.3 & 6.7 & 6.4 & 6.8 \\
\hline Dy & 38.1 & 34.7 & 35.3 & 34.5 & 35.5 & 32.6 & 18.3 & 37.0 & 35.6 & 37.7 \\
\hline Ho & 6.9 & 6.3 & 6.4 & 6.3 & 6.6 & 6.0 & 3.3 & 6.8 & 6.5 & 7.0 \\
\hline $\mathbf{E r}$ & 18.3 & 16.9 & 17.2 & 16.9 & 17.7 & 16.0 & 9.0 & 18.3 & 17.4 & 18.4 \\
\hline $\mathbf{T m}$ & 2.4 & 2.3 & 2.3 & 2.3 & 2.3 & 2.2 & 1.2 & 2.4 & 2.4 & 2.4 \\
\hline $\mathbf{Y b}$ & 15.6 & 14.8 & 14.7 & 15.0 & 15.6 & 13.9 & 8.0 & 15.9 & 15.1 & 16.0 \\
\hline $\mathbf{L u}$ & 2.1 & 2.0 & 2.0 & 2.0 & 2.1 & 1.9 & 1.1 & 2.2 & 2.1 & 2.2 \\
\hline Hf & 11.5 & 12.3 & 12.6 & 12.4 & 12.6 & 11.3 & 7.5 & 11.5 & 11.2 & 12.3 \\
\hline Tl & 112.1 & 107.4 & 110.8 & 117.8 & 108.9 & 74.6 & 115.2 & 78.4 & 106.6 & 110.1 \\
\hline $\mathbf{P b}$ & 1192 & 1006 & 1065 & 1056 & 992 & 899 & 591 & 1057 & 1078 & 1207 \\
\hline $\mathbf{B i}$ & 10.5 & 8.6 & 9.0 & 8.7 & 9.0 & 8.4 & 5.3 & 9.8 & 9.3 & 10.1 \\
\hline Th & 86.0 & 69.9 & 72.1 & 71.3 & 72.5 & 54.3 & 36.5 & 66.6 & 64.9 & 86.1 \\
\hline $\mathbf{U}$ & 8.0 & 8.4 & 8.7 & 8.5 & 8.7 & 8.4 & 4.4 & 9.8 & 9.6 & 10.2 \\
\hline$\Sigma \operatorname{REY}(\mathbf{w t} \%)$ & 0.18 & 0.15 & 0.15 & 0.15 & 0.17 & 0.14 & 0.08 & 0.16 & 0.15 & 0.17 \\
\hline$\left(\mathrm{Ce} / \mathrm{Ce}^{*}\right)_{\mathrm{SN}(\mathrm{PAAS})}$ & 2.29 & 2.32 & 2.29 & 2.27 & 2.29 & 2.07 & 2.60 & 2.06 & 2.11 & 2.35 \\
\hline
\end{tabular}




\begin{tabular}{|c|c|c|c|c|c|c|c|c|c|c|}
\hline & $\begin{array}{l}\text { Campbel } \\
\text { U1406B }\end{array}$ & $\begin{array}{c}\text { Nodule Fi } \\
\text { U1406B }\end{array}$ & $\begin{array}{l}\text { ld - north } \\
\text { U1406B }\end{array}$ & $\begin{array}{l}\text { ern transe } \\
\text { U1406B }\end{array}$ & U1406B & U1406B & U1406B & U1406B & $\mathrm{U} 1406 \mathrm{~B}$ & U1402 \\
\hline Sample & 2-A & 2-B & $2-\mathrm{C}$ & 3-A & 3-B & 3-C & 3-D & 4-A-Y & 4-A-Z & 1-A \\
\hline Mn (wt\%) & 18.02 & 15.99 & 16.61 & 19.31 & 21.14 & 18.73 & 18.18 & 19.72 & 20.64 & 16.02 \\
\hline $\mathbf{F e}$ & 16.01 & 17.22 & 15.97 & 17.05 & 11.76 & 15.43 & 16.99 & 21.24 & 12.80 & 6.29 \\
\hline Co & 0.26 & 0.25 & 0.23 & 0.27 & 0.17 & 0.27 & 0.26 & 0.44 & 0.27 & 0.10 \\
\hline $\mathbf{N i}$ & 0.50 & 0.29 & 0.40 & 0.47 & 0.89 & 0.53 & 0.39 & 0.29 & 0.72 & 0.53 \\
\hline $\mathbf{C u}$ & 0.14 & 0.08 & 0.12 & 0.12 & 0.31 & 0.15 & 0.12 & 0.06 & 0.23 & 0.39 \\
\hline $\mathbf{M n} / \mathbf{F e}$ & 1.13 & 0.93 & 1.04 & 1.13 & 1.80 & 1.21 & 1.07 & 0.93 & 1.61 & 2.55 \\
\hline $\mathrm{Ni}+\mathrm{Cu}$ & 0.64 & 0.37 & 0.52 & 0.59 & 1.20 & 0.68 & 0.51 & 0.36 & 0.95 & 0.92 \\
\hline $\mathrm{Co}+\mathrm{Ni}+\mathrm{Cu}$ & 0.90 & 0.62 & 0.75 & 0.87 & 1.37 & 0.95 & 0.77 & 0.80 & 1.22 & 1.02 \\
\hline $\mathbf{L i}(\mathbf{p p m})$ & 13.0 & 9.8 & 15.8 & 11.9 & 34.7 & 14.9 & 12.4 & 6.0 & 22.7 & 95.1 \\
\hline Mg & 12882 & 12573 & 13205 & 13466 & 14644 & 13606 & 13140 & 14407 & 13955 & 17278 \\
\hline Al & 19435 & 19655 & 20246 & 19631 & 18800 & 18547 & 20739 & 15439 & 17638 & 30775 \\
\hline $\mathbf{P}$ & 3435 & 3585 & 3286 & 3263 & 2178 & 3223 & 3530 & 4757 & 2566 & 1100 \\
\hline $\mathrm{Ca}$ & 23737 & 24948 & 24257 & 22409 & 22097 & 23928 & 26682 & 28101 & 21143 & 40934 \\
\hline $\mathbf{T i}$ & 9990 & 9555 & 10129 & 11045 & 10398 & 10911 & 9839 & 11570 & 11030 & 4689 \\
\hline Sc & 10.3 & 11.2 & 11.1 & 11.2 & 10.4 & 10.5 & 11.6 & 10.7 & 9.3 & 14.1 \\
\hline $\mathbf{V}$ & 549 & 597 & 527 & 575 & 382 & 515 & 527 & 795 & 439 & 268 \\
\hline $\mathrm{Cr}$ & 23.9 & 32.7 & 29.6 & 24.9 & 27.8 & 24.0 & 31.8 & 27.7 & 18.2 & 51.2 \\
\hline $\mathbf{Z n}$ & 1133 & 856 & 1003 & 977 & 1774 & 1115 & 998 & 836 & 1367 & 1250 \\
\hline Ga & 7.3 & 6.0 & 6.9 & 6.6 & 9.1 & 7.4 & 6.9 & 4.6 & 9.4 & 12.4 \\
\hline As & 186 & 221 & 176 & 187 & 104 & 163 & 176 & 297 & 137 & 35 \\
\hline $\mathbf{R b}$ & 14.9 & 13.9 & 13.8 & 12.1 & 16.2 & 13.2 & 13.3 & 11.2 & 17.3 & 36.6 \\
\hline $\mathbf{S r}$ & 1197 & 1214 & 1155 & 1308 & 943 & 1189 & 1257 & 1581 & 1068 & 611 \\
\hline $\mathbf{Y}$ & 112 & 125 & 106 & 110 & 73 & 103 & 108 & 162 & 92 & 34 \\
\hline $\mathbf{Z r}$ & 563 & 605 & 574 & 616 & 434 & 568 & 614 & 671 & 502 & 167 \\
\hline
\end{tabular}




\begin{tabular}{|c|c|c|c|c|c|c|c|c|c|c|}
\hline Mo & 204 & 199 & 156 & 180 & 178 & 175 & 138 & 256 & 193 & 197 \\
\hline Cd & 6.7 & 4.8 & 5.9 & 6.2 & 10.4 & 6.9 & 6.2 & 5.1 & 9.5 & 10.1 \\
\hline $\mathbf{B a}$ & 1224 & 1142 & 1179 & 1340 & 1178 & 1263 & 1294 & 1199 & 1466 & 3221 \\
\hline La & 177 & 191 & 169 & 188 & 108 & 166 & 184 & 264 & 143 & 47 \\
\hline $\mathrm{Ce}$ & 827 & 844 & 784 & 879 & 576 & 827 & 859 & 1250 & 781 & 227 \\
\hline $\operatorname{Pr}$ & 44.3 & 48.1 & 43.3 & 45.9 & 28.1 & 42.7 & 45.6 & 65.7 & 35.8 & 12.9 \\
\hline Nd & 178 & 192 & 173 & 186 & 113 & 169 & 182 & 261 & 145 & 54 \\
\hline $\mathrm{Sm}$ & 38.5 & 41.6 & 37.4 & 37.9 & 25.7 & 35.8 & 38.3 & 54.9 & 31.8 & 12.4 \\
\hline $\mathbf{E u}$ & 8.8 & 9.6 & 8.6 & 8.6 & 6.0 & 8.3 & 8.7 & 12.3 & 7.4 & 3.3 \\
\hline Gd & 41.6 & 45.5 & 39.9 & 41.3 & 27.9 & 38.4 & 42.5 & 60.1 & 35.2 & 12.6 \\
\hline $\mathbf{T b}$ & 6.3 & 6.7 & 6.1 & 6.1 & 4.1 & 5.9 & 6.2 & 9.0 & 5.2 & 1.9 \\
\hline Dy & 34.4 & 37.9 & 33.6 & 33.9 & 23.1 & 32.8 & 33.4 & 49.1 & 28.8 & 10.3 \\
\hline Ho & 6.3 & 7.0 & 6.1 & 6.2 & 4.1 & 5.9 & 6.2 & 9.0 & 5.2 & 1.9 \\
\hline $\mathbf{E r}$ & 16.6 & 18.7 & 16.4 & 16.7 & 11.2 & 15.7 & 16.6 & 24.2 & 14.2 & 5.0 \\
\hline $\mathbf{T m}$ & 2.3 & 2.4 & 2.2 & 2.2 & 1.5 & 2.1 & 2.1 & 3.2 & 1.9 & 0.7 \\
\hline $\mathbf{Y b}$ & 14.9 & 15.9 & 14.0 & 14.5 & 9.7 & 13.4 & 14.1 & 20.6 & 12.3 & 4.3 \\
\hline Lu & 2.0 & 2.2 & 1.9 & 1.9 & 1.3 & 1.9 & 1.9 & 2.8 & 1.7 & 0.6 \\
\hline Hf & 11.1 & 11.6 & 11.6 & 11.6 & 8.9 & 11.6 & 11.5 & 12.9 & 10.8 & 3.8 \\
\hline Tl & 76.3 & 69.1 & 76.2 & 66.0 & 83.2 & 78.8 & 73.3 & 71.9 & 84.2 & 45.3 \\
\hline $\mathbf{P b}$ & 1114 & 1107 & 1049 & 1037 & 740 & 1098 & 1077 & 1498 & 980 & 277 \\
\hline $\mathbf{B i}$ & 10.1 & 9.7 & 9.1 & 9.7 & 6.5 & 9.4 & 10.0 & 14.1 & 9.2 & 2.1 \\
\hline Th & 64.5 & 64.5 & 60.0 & 61.6 & 42.8 & 66.3 & 66.5 & 100.7 & 61.4 & 18.6 \\
\hline $\mathbf{U}$ & 9.1 & 9.6 & 8.8 & 8.6 & 6.5 & 8.7 & 8.7 & 12.7 & 7.4 & 2.3 \\
\hline$\Sigma \operatorname{REY}(\mathbf{w t} \%)$ & 0.15 & 0.16 & 0.14 & 0.16 & 0.10 & 0.15 & 0.15 & 0.22 & 0.13 & 0.04 \\
\hline$\left(\mathrm{Ce} / \mathrm{Ce}^{*}\right)_{\mathrm{SN}(\mathrm{PAAS})}$ & 2.15 & 2.02 & 2.11 & 2.18 & 2.40 & 2.26 & 2.16 & 2.18 & 2.51 & 2.12 \\
\hline
\end{tabular}




\begin{tabular}{|c|c|c|c|c|c|c|c|c|c|c|}
\hline & \multicolumn{10}{|c|}{ Campbell Nodule Field - northern transect } \\
\hline & $\mathrm{U} 1402$ & $\mathrm{U} 1402$ & U1402 & U1402 & U1399 & U1399 & U1399 & U1399 & U1399 & U1399 \\
\hline Sample & $2-B$ & $2-C$ & 2-D & $2-E$ & 1-A-Y & $1-A-Z$ & 2-A & 2-B & 2-C & 2-D \\
\hline Mn (wt\%) & 20.83 & 24.19 & 20.56 & 23.27 & 21.26 & 22.79 & 19.87 & 17.08 & 20.00 & 18.47 \\
\hline Fe & 11.09 & 10.52 & 10.29 & 9.91 & 6.82 & 7.11 & 10.90 & 11.10 & 11.75 & 11.83 \\
\hline Co & 0.11 & 0.13 & 0.12 & 0.13 & 0.11 & 0.12 & 0.13 & 0.11 & 0.14 & 0.10 \\
\hline $\mathbf{N i}$ & 0.71 & 0.96 & 0.85 & 1.03 & 0.98 & 1.10 & 0.90 & 0.74 & 0.78 & 0.78 \\
\hline $\mathbf{C u}$ & 0.39 & 0.39 & 0.36 & 0.41 & 0.57 & 0.65 & 0.34 & 0.32 & 0.38 & 0.38 \\
\hline $\mathrm{Mn} / \mathrm{Fe}$ & 1.88 & 2.30 & 2.00 & 2.35 & 3.12 & 3.20 & 1.82 & 1.54 & 1.70 & 1.56 \\
\hline $\mathrm{Ni}+\mathrm{Cu}$ & 1.10 & 1.36 & 1.22 & 1.43 & 1.56 & 1.75 & 1.24 & 1.06 & 1.16 & 1.16 \\
\hline $\mathrm{Co}+\mathrm{Ni}+\mathrm{Cu}$ & 1.21 & 1.49 & 1.34 & 1.56 & 1.67 & 1.87 & 1.37 & 1.17 & 1.29 & 1.26 \\
\hline $\mathbf{L i}(\mathbf{p p m})$ & 134.9 & 117.6 & 100.8 & 97.6 & 143.3 & 63.2 & 90.0 & 72.9 & 61.2 & 98.6 \\
\hline Mg & 19318 & 16206 & 17572 & 15688 & 14948 & 15430 & 15939 & 16162 & 15536 & 17970 \\
\hline Al & 27274 & 22145 & 23816 & 20583 & 25905 & 24834 & 24337 & 22991 & 18491 & 26286 \\
\hline $\mathbf{P}$ & 1458 & 2145 & 1786 & 1976 & 1690 & 1105 & 1993 & 1574 & 1885 & 1629 \\
\hline $\mathbf{C a}$ & 19246 & 24076 & 22747 & 22530 & 28805 & 16246 & 23829 & 20693 & 20908 & 21044 \\
\hline $\mathbf{T i}$ & 5054 & 5458 & 5523 & 5714 & 4018 & 4113 & 5272 & 5221 & 5158 & 5050 \\
\hline Sc & 12.6 & 10.1 & 11.2 & 9.6 & 11.8 & 10.9 & 10.5 & 11.1 & 10.8 & 12.1 \\
\hline $\mathbf{V}$ & 350 & 451 & 399 & 440 & 347 & 374 & 414 & 356 & 417 & 375 \\
\hline $\mathrm{Cr}$ & 40.6 & 34.9 & 40.8 & 38.8 & 52.0 & 24.2 & 36.1 & 37.1 & 33.5 & 45.8 \\
\hline Zn & 1684 & 2290 & 1738 & 2072 & 1995 & 2089 & 1657 & 1320 & 1430 & 1458 \\
\hline Ga & 13.8 & 9.2 & 11.0 & 8.4 & 13.1 & 11.3 & 10.4 & 12.8 & 11.4 & 15.4 \\
\hline As & 73 & 113 & 93 & 104 & 71 & 47 & 106 & 85 & 109 & 91 \\
\hline $\mathbf{R b}$ & 29.0 & 18.4 & 21.5 & 16.6 & 26.7 & 31.3 & 19.6 & 21.8 & 17.5 & 25.9 \\
\hline $\mathrm{Sr}$ & 647 & 826 & 716 & 803 & 663 & 689 & 772 & 668 & 802 & 654 \\
\hline $\mathbf{Y}$ & 50 & 66 & 62 & 65 & 55 & 47 & 65 & 56 & 68 & 50 \\
\hline $\mathbf{Z r}$ & 276 & 297 & 288 & 297 & 260 & 193 & 321 & 330 & 365 & 309 \\
\hline
\end{tabular}




\begin{tabular}{|c|c|c|c|c|c|c|c|c|c|c|}
\hline Mo & 233 & 289 & 248 & 291 & 314 & 368 & 283 & 237 & 303 & 269 \\
\hline Cd & 13.9 & 12.0 & 11.5 & 11.1 & 15.9 & 16.7 & 10.5 & 9.7 & 11.2 & 10.0 \\
\hline Ba & 1096 & 1009 & 932 & 941 & 3000 & 2786 & 956 & 938 & 1259 & 937 \\
\hline La & 76 & 98 & 84 & 94 & 73 & 74 & 92 & 81 & 100 & 76 \\
\hline $\mathrm{Ce}$ & 291 & 381 & 336 & 375 & 275 & 292 & 393 & 358 & 416 & 341 \\
\hline Pr & 19.9 & 27.0 & 23.3 & 26.2 & 19.7 & 19.9 & 25.5 & 22.0 & 27.0 & 20.7 \\
\hline Nd & 87 & 111 & 96 & 110 & 83 & 86 & 105 & 92 & 111 & 85 \\
\hline Sm & 19.0 & 24.9 & 22.1 & 25.2 & 20.3 & 18.5 & 24.1 & 21.2 & 25.2 & 19.0 \\
\hline $\mathbf{E u}$ & 4.4 & 5.9 & 5.2 & 5.9 & 4.9 & 4.7 & 5.7 & 4.9 & 5.9 & 4.4 \\
\hline Gd & 19.2 & 25.7 & 22.6 & 25.9 & 20.7 & 18.4 & 24.4 & 21.7 & 26.1 & 19.6 \\
\hline $\mathbf{T b}$ & 3.0 & 4.1 & 3.6 & 4.0 & 3.3 & 3.0 & 3.8 & 3.4 & 4.0 & 3.1 \\
\hline Dy & 16.5 & 22.3 & 20.0 & 21.8 & 17.7 & 16.4 & 21.1 & 18.2 & 22.1 & 16.5 \\
\hline Ho & 3.0 & 4.0 & 3.6 & 4.0 & 3.2 & 3.0 & 3.8 & 3.3 & 3.9 & 3.0 \\
\hline Er & 7.9 & 10.6 & 9.4 & 10.6 & 8.7 & 8.1 & 10.2 & 8.6 & 10.6 & 7.9 \\
\hline Tm & 1.1 & 1.4 & 1.3 & 1.4 & 1.2 & 1.2 & 1.4 & 1.1 & 1.4 & 1.1 \\
\hline $\mathbf{Y b}$ & 7.0 & 9.1 & 8.4 & 9.0 & 7.8 & 7.7 & 8.9 & 7.7 & 9.5 & 7.2 \\
\hline $\mathbf{L u}$ & 0.9 & 1.3 & 1.1 & 1.2 & 1.1 & 1.1 & 1.2 & 1.0 & 1.3 & 1.0 \\
\hline Hf & 5.4 & 5.8 & 5.7 & 6.0 & 5.9 & 4.6 & 6.8 & 7.1 & 6.4 & 6.7 \\
\hline Tl & 116.2 & 111.3 & 150.0 & 103.7 & 135.4 & 50.8 & 112.7 & 86.9 & 93.8 & 82.0 \\
\hline $\mathbf{P b}$ & 450 & 672 & 576 & 631 & 483 & 480 & 606 & 561 & 631 & 470 \\
\hline $\mathbf{B i}$ & 3.7 & 5.5 & 4.9 & 5.3 & 4.0 & 3.9 & 5.0 & 4.5 & 5.2 & 4.2 \\
\hline Th & 26.1 & 34.1 & 31.2 & 34.3 & 29.8 & 28.1 & 36.7 & 33.9 & 34.6 & 31.2 \\
\hline $\mathbf{U}$ & 3.7 & 5.0 & 4.7 & 5.0 & 3.7 & 2.8 & 4.8 & 4.0 & 5.0 & 4.0 \\
\hline IREY (wt\%) & 0.06 & 0.08 & 0.07 & 0.08 & 0.06 & 0.06 & 0.08 & 0.07 & 0.08 & 0.07 \\
\hline$\left(\mathrm{Ce} / \mathrm{Ce}^{*}\right)_{\mathrm{SN}(\mathrm{PAAS})}$ & 1.72 & 1.70 & 1.74 & 1.73 & 1.66 & 1.74 & 1.86 & 1.94 & 1.83 & 1.97 \\
\hline
\end{tabular}




\begin{tabular}{|c|c|c|c|c|c|c|c|c|c|c|}
\hline & $\begin{array}{c}\text { Campbell } \\
\text { U1399 }\end{array}$ & $\begin{array}{l}\text { Nodule Fi } \\
\text { U1399 }\end{array}$ & $\begin{array}{c}\text { d - north } \\
\text { U1399 }\end{array}$ & $\begin{array}{l}\text { rn transect } \\
\text { U1398 }\end{array}$ & U1398 & U1398 & U1398 & U1398 & U1398 & U1398 \\
\hline Sample & $2-\mathrm{E}$ & $2-\mathrm{F}$ & 3-A & 1-A & 1-B & 1-C & 1-D & 1-E & $1-F$ & 1-G \\
\hline Mn (wt\%) & 14.01 & 19.83 & 20.78 & 23.54 & 21.46 & 20.03 & 18.06 & 20.11 & 23.89 & 23.33 \\
\hline Fe & 10.08 & 9.30 & 8.20 & 10.51 & 12.14 & 9.58 & 11.91 & 9.70 & 9.31 & 9.89 \\
\hline Co & 0.14 & 0.10 & 0.12 & 0.15 & 0.15 & 0.12 & 0.13 & 0.11 & 0.11 & 0.10 \\
\hline $\mathbf{N i}$ & 0.34 & 0.96 & 0.92 & 1.06 & 0.78 & 0.88 & 0.69 & 0.92 & 1.02 & 1.17 \\
\hline $\mathbf{C u}$ & 0.29 & 0.43 & 0.61 & 0.38 & 0.36 & 0.35 & 0.29 & 0.38 & 0.53 & 0.47 \\
\hline $\mathrm{Mn} / \mathrm{Fe}$ & 1.39 & 2.13 & 2.53 & 2.24 & 1.77 & 2.09 & 1.52 & 2.07 & 2.57 & 2.36 \\
\hline $\mathrm{Ni}+\mathrm{Cu}$ & 0.62 & 1.39 & 1.53 & 1.44 & 1.15 & 1.23 & 0.98 & 1.30 & 1.55 & 1.64 \\
\hline $\mathrm{Co}+\mathrm{Ni}+\mathrm{Cu}$ & 0.76 & 1.49 & 1.65 & 1.59 & 1.30 & 1.35 & 1.11 & 1.41 & 1.66 & 1.75 \\
\hline Li (ppm) & 34.5 & 111.5 & 53.0 & 85.0 & 86.6 & 108.4 & 78.0 & 74.3 & 143.3 & 100.2 \\
\hline Mg & 15209 & 17243 & 14747 & 15245 & 13523 & 13781 & 14276 & 14181 & 18363 & 16039 \\
\hline Al & 30822 & 25630 & 22405 & 18958 & 20484 & 21428 & 26449 & 26780 & 32478 & 28800 \\
\hline $\mathbf{P}$ & 1142 & 1482 & 1164 & 2230 & 2241 & 1907 & 2102 & 1766 & 1690 & 1931 \\
\hline $\mathbf{C a}$ & 17781 & 22499 & 17859 & 24099 & 21410 & 21452 & 24506 & 19551 & 28805 & 23071 \\
\hline $\mathbf{T i}$ & 4760 & 4721 & 4491 & 5401 & 6216 & 5057 & 6187 & 5264 & 4858 & 5466 \\
\hline Sc & 12.1 & 10.7 & 10.6 & 9.3 & 10.0 & 9.4 & 11.0 & 10.0 & 11.8 & 10.5 \\
\hline $\mathbf{V}$ & 281 & 348 & 342 & 463 & 460 & 384 & 400 & 356 & 403 & 412 \\
\hline $\mathrm{Cr}$ & 33.1 & 44.4 & 20.1 & 31.1 & 28.4 & 30.6 & 35.8 & 33.0 & 52.0 & 37.3 \\
\hline $\mathbf{Z n}$ & 671 & 1713 & 1902 & 2130 & 1880 & 2002 & 1316 & 1355 & 2107 & 1685 \\
\hline Ga & 12.4 & 12.6 & 10.9 & 8.3 & 8.0 & 9.1 & 9.8 & 11.1 & 13.1 & 12.6 \\
\hline As & 52 & 76 & 51 & 116 & 126 & 103 & 106 & 87 & 71 & 101 \\
\hline $\mathbf{R b}$ & 28.1 & 22.2 & 28.7 & 14.4 & 14.1 & 17.2 & 20.0 & 21.4 & 26.7 & 22.9 \\
\hline $\mathbf{S r}$ & 702 & 640 & 711 & 870 & 890 & 759 & 865 & 706 & 766 & 778 \\
\hline $\mathbf{Y}$ & 41 & 51 & 52 & 71 & 76 & 65 & 76 & 58 & 55 & 61 \\
\hline $\mathbf{Z r}$ & 357 & 260 & 237 & 326 & 390 & 323 & 404 & 294 & 260 & 321 \\
\hline
\end{tabular}




\begin{tabular}{|c|c|c|c|c|c|c|c|c|c|c|}
\hline Mo & 155 & 290 & 304 & 304 & 266 & 280 & 207 & 254 & 314 & 355 \\
\hline Cd & 5.8 & 11.1 & 15.0 & 10.7 & 9.5 & 9.8 & 9.9 & 10.5 & 15.9 & 11.7 \\
\hline $\mathbf{B a}$ & 1744 & 902 & 1982 & 924 & 959 & 878 & 1201 & 1026 & 1350 & 1030 \\
\hline La & 79 & 69 & 84 & 101 & 122 & 93 & 113 & 87 & 76 & 86 \\
\hline $\mathrm{Ce}$ & 431 & 294 & 368 & 427 & 530 & 386 & 494 & 388 & 307 & 427 \\
\hline Pr & 20.9 & 19.2 & 21.9 & 28.8 & 33.1 & 25.4 & 30.2 & 22.9 & 21.5 & 24.0 \\
\hline Nd & 82 & 79 & 90 & 120 & 134 & 105 & 122 & 94 & 91 & 98 \\
\hline Sm & 17.7 & 19.0 & 20.0 & 27.7 & 29.3 & 24.1 & 27.2 & 21.3 & 20.3 & 22.6 \\
\hline $\mathbf{E u}$ & 4.1 & 4.4 & 4.8 & 6.4 & 6.8 & 5.6 & 6.5 & 4.9 & 4.9 & 5.3 \\
\hline Gd & 17.9 & 19.2 & 20.3 & 28.5 & 30.1 & 24.8 & 28.6 & 21.8 & 20.7 & 23.5 \\
\hline $\mathbf{T b}$ & 2.7 & 3.0 & 3.2 & 4.4 & 4.7 & 3.9 & 4.5 & 3.4 & 3.3 & 3.7 \\
\hline Dy & 14.1 & 16.7 & 17.8 & 24.3 & 26.1 & 21.2 & 24.6 & 18.9 & 17.7 & 20.7 \\
\hline Но & 2.5 & 3.0 & 3.3 & 4.3 & 4.6 & 3.9 & 4.5 & 3.4 & 3.2 & 3.7 \\
\hline Er & 6.5 & 8.1 & 8.7 & 11.4 & 12.3 & 10.3 & 11.9 & 9.2 & 8.7 & 10.0 \\
\hline Tm & 0.9 & 1.1 & 1.2 & 1.5 & 1.7 & 1.4 & 1.6 & 1.2 & 1.2 & 1.4 \\
\hline $\mathbf{Y b}$ & 5.7 & 7.1 & 8.4 & 9.7 & 10.8 & 9.0 & 10.6 & 8.1 & 7.8 & 9.0 \\
\hline $\mathbf{L u}$ & 0.7 & 1.0 & 1.1 & 1.3 & 1.5 & 1.2 & 1.4 & 1.1 & 1.1 & 1.2 \\
\hline Hf & 7.6 & 5.8 & 4.9 & 7.1 & 8.7 & 6.9 & 9.1 & 7.1 & 5.9 & 7.7 \\
\hline Tl & 25.3 & 100.2 & 68.6 & 94.8 & 97.2 & 113.5 & 99.5 & 92.9 & 135.4 & 111.9 \\
\hline $\mathbf{P b}$ & 550 & 463 & 633 & 732 & 757 & 618 & 687 & 517 & 483 & 564 \\
\hline $\mathbf{B i}$ & 4.7 & 3.9 & 4.8 & 6.2 & 6.1 & 5.3 & 5.9 & 4.5 & 4.0 & 5.1 \\
\hline Th & 33.9 & 27.7 & 32.4 & 41.1 & 45.4 & 35.5 & 45.8 & 36.1 & 29.8 & 38.8 \\
\hline $\mathbf{U}$ & 2.8 & 3.8 & 3.3 & 5.1 & 5.8 & 4.8 & 5.2 & 4.1 & 3.7 & 4.6 \\
\hline IREY (wt\%) & 0.07 & 0.06 & 0.07 & 0.09 & 0.10 & 0.08 & 0.10 & 0.07 & 0.06 & 0.08 \\
\hline$\left(\mathrm{Ce} / \mathrm{Ce}^{*}\right)_{\mathrm{SN}(\mathrm{PAAS})}$ & 2.43 & 1.84 & 1.97 & 1.81 & 1.91 & 1.82 & 1.94 & 2.00 & 1.74 & 2.15 \\
\hline
\end{tabular}




\begin{tabular}{|c|c|c|c|c|c|c|c|c|c|c|}
\hline & $\begin{array}{c}\text { Campbell } \\
\text { U1373 }\end{array}$ & $\begin{array}{l}\text { Nodule Fi } \\
\text { U1373 }\end{array}$ & $\begin{array}{l}\text { d - south } \\
\text { U1373 }\end{array}$ & $\begin{array}{l}\text { rn transect } \\
\text { U1373 }\end{array}$ & U1373 & U1373 & U1373 & U1374 & U1374 & U1374 \\
\hline Sample & $1-A$ & $1-B$ & $2-\mathrm{A}$ & $2-B$ & $2-\mathrm{C}$ & 2-D & $2-\mathrm{E}$ & $1-\mathrm{A}$ & $1-B$ & $1-\mathrm{C}$ \\
\hline Mn (wt\%) & 18.88 & 13.89 & 14.00 & 16.81 & 14.53 & 24.11 & 19.50 & 18.30 & 18.89 & 27.28 \\
\hline Fe & 13.73 & 14.59 & 12.10 & 17.44 & 20.15 & 17.56 & 16.42 & 11.54 & 9.77 & 15.02 \\
\hline Co & 0.15 & 0.13 & 0.13 & 0.25 & 0.22 & 0.18 & 0.13 & 0.11 & 0.11 & 0.15 \\
\hline $\mathbf{N i}$ & 0.77 & 0.39 & 0.55 & 0.44 & 0.19 & 0.83 & 0.66 & 0.69 & 0.74 & 1.15 \\
\hline $\mathrm{Cu}$ & 0.37 & 0.34 & 0.28 & 0.10 & 0.08 & 0.35 & 0.28 & 0.31 & 0.30 & 0.47 \\
\hline $\mathrm{Mn} / \mathrm{Fe}$ & 1.37 & 0.95 & 1.16 & 0.96 & 0.72 & 1.37 & 1.19 & 1.59 & 1.93 & 1.82 \\
\hline $\mathrm{Ni}+\mathrm{Cu}$ & 1.14 & 0.73 & 0.83 & 0.53 & 0.27 & 1.18 & 0.93 & 1.00 & 1.04 & 1.62 \\
\hline $\mathrm{Co}+\mathrm{Ni}+\mathrm{Cu}$ & 1.29 & 0.86 & 0.96 & 0.78 & 0.49 & 1.36 & 1.07 & 1.11 & 1.15 & 1.76 \\
\hline $\mathbf{L i}(\mathbf{p p m})$ & 25.0 & 18.3 & 17.4 & 10.6 & 9.0 & 50.5 & 36.7 & 82.9 & 98.5 & 118.7 \\
\hline Mg & 16796 & 12939 & 13868 & 13091 & 12392 & 16553 & 14615 & 11658 & 11744 & 17251 \\
\hline Al & 27960 & 32932 & 25508 & 19840 & 19871 & 22902 & 25966 & 15940 & 13450 & 23113 \\
\hline $\mathbf{P}$ & 1961 & 1449 & 1591 & 3269 & 3631 & 2725 & 2685 & 2053 & 1851 & 2585 \\
\hline $\mathbf{C a}$ & 20627 & 15436 & 18990 & 21674 & 23174 & 22053 & 23902 & 19526 & 18113 & 26927 \\
\hline $\mathbf{T i}$ & 6599 & 6528 & 5991 & 8033 & 8771 & 7227 & 6819 & 4655 & 3932 & 6235 \\
\hline Sc & 12.8 & 12.9 & 13.8 & 10.7 & 12.0 & 12.2 & 13.0 & 9.5 & 8.7 & 12.8 \\
\hline $\mathbf{V}$ & 405 & 341 & 296 & 590 & 652 & 604 & 502 & 407 & 384 & 543 \\
\hline $\mathrm{Cr}$ & 31.0 & 24.7 & 32.2 & 27.9 & 29.4 & 33.7 & 35.0 & 29.1 & 24.9 & 41.1 \\
\hline $\mathbf{Z n}$ & 1371 & 707 & 838 & 900 & 711 & 1477 & 1309 & 1407 & 1462 & 2062 \\
\hline $\mathbf{G a}$ & 10.1 & 11.0 & 11.7 & 6.1 & 5.5 & 7.6 & 9.8 & 6.1 & 5.8 & 9.4 \\
\hline As & 94 & 60 & 72 & 210 & 218 & 162 & 136 & 117 & 110 & 145 \\
\hline $\mathbf{R b}$ & 25.7 & 33.1 & 29.6 & 15.0 & 11.7 & 15.7 & 24.1 & 11.8 & 10.7 & 17.7 \\
\hline $\mathbf{S r}$ & 904 & 803 & 798 & 1120 & 1206 & 1161 & 1048 & 794 & 712 & 1079 \\
\hline $\mathbf{Y}$ & 71 & 69 & 70 & 113 & 129 & 99 & 102 & 77 & 68 & 101 \\
\hline $\mathbf{Z r}$ & 399 & 464 & 450 & 567 & 622 & 476 & 548 & 340 & 261 & 437 \\
\hline
\end{tabular}




\begin{tabular}{|c|c|c|c|c|c|c|c|c|c|c|}
\hline Mo & 197 & 123 & 143 & 253 & 183 & 270 & 225 & 246 & 277 & 406 \\
\hline Cd & 7.3 & 4.4 & 5.5 & 4.9 & 3.6 & 7.7 & 7.0 & 7.6 & 9.1 & 11.7 \\
\hline $\mathbf{B a}$ & 1824 & 1827 & 3028 & 1090 & 1148 & 1227 & 1373 & 834 & 806 & 1160 \\
\hline La & 121 & 128 & 104 & 171 & 199 & 170 & 148 & 108 & 94 & 139 \\
\hline $\mathrm{Ce}$ & 581 & 639 & 513 & 929 & 952 & 718 & 641 & 447 & 399 & 586 \\
\hline $\operatorname{Pr}$ & 32.7 & 32.0 & 28.5 & 44.2 & 51.9 & 45.4 & 40.7 & 30.0 & 26.0 & 39.2 \\
\hline Nd & 134 & 125 & 114 & 179 & 207 & 182 & 163 & 123 & 107 & 160 \\
\hline Sm & 26.5 & 25.4 & 25.9 & 38.9 & 43.2 & 35.9 & 36.6 & 28.2 & 24.4 & 37.0 \\
\hline $\mathbf{E u}$ & 6.1 & 5.9 & 6.3 & 9.0 & 10.0 & 8.2 & 8.5 & 6.4 & 5.7 & 8.5 \\
\hline Gd & 27.3 & 27.9 & 27.0 & 41.9 & 46.8 & 37.6 & 38.2 & 28.9 & 25.6 & 38.2 \\
\hline $\mathbf{T b}$ & 4.3 & 4.1 & 4.1 & 6.4 & 7.2 & 5.9 & 6.0 & 4.5 & 4.0 & 5.9 \\
\hline Dy & 23.7 & 22.6 & 22.5 & 35.1 & 40.0 & 31.9 & 33.6 & 25.2 & 21.8 & 32.9 \\
\hline Ho & 4.2 & 4.1 & 4.0 & 6.5 & 7.2 & 5.8 & 6.0 & 4.5 & 4.0 & 6.0 \\
\hline $\mathbf{E r}$ & 11.4 & 11.2 & 10.9 & 17.2 & 19.3 & 15.2 & 15.9 & 12.0 & 10.6 & 15.7 \\
\hline Tm & 1.5 & 1.5 & 1.4 & 2.3 & 2.5 & 2.0 & 2.1 & 1.6 & 1.4 & 2.1 \\
\hline $\mathbf{Y b}$ & 10.0 & 10.1 & 9.6 & 14.9 & 16.6 & 13.3 & 13.9 & 10.4 & 9.2 & 13.6 \\
\hline Lu & 1.3 & 1.4 & 1.3 & 2.0 & 2.2 & 1.8 & 1.8 & 1.4 & 1.2 & 1.9 \\
\hline Hf & 8.9 & 9.4 & 9.5 & 12.1 & 12.8 & 9.2 & 11.4 & 6.8 & 5.0 & 8.7 \\
\hline Tl & 68.9 & 36.4 & 46.7 & 70.9 & 59.5 & 90.0 & 73.2 & 81.3 & 90.5 & 132.5 \\
\hline $\mathbf{P b}$ & 763 & 802 & 760 & 1170 & 1301 & 872 & 979 & 714 & 645 & 968 \\
\hline $\mathbf{B i}$ & 6.8 & 6.9 & 7.4 & 10.0 & 10.2 & 8.0 & 8.3 & 6.2 & 5.6 & 8.5 \\
\hline Th & 53.8 & 52.2 & 52.4 & 85.7 & 89.3 & 60.4 & 62.5 & 44.6 & 38.6 & 60.0 \\
\hline $\mathbf{U}$ & 4.8 & 4.2 & 4.3 & 8.7 & 9.2 & 7.0 & 6.7 & 5.1 & 4.7 & 6.8 \\
\hline IREY (wt\%) & 0.11 & 0.11 & 0.09 & 0.16 & 0.17 & 0.14 & 0.13 & 0.09 & 0.08 & 0.12 \\
\hline$\left.(\mathrm{Ce} / \mathrm{Ce})^{*}\right)_{\mathrm{SN}(\mathrm{PAAS})}$ & 2.12 & 2.30 & 2.16 & 2.45 & 2.15 & 1.87 & 1.89 & 1.80 & 1.85 & 1.81 \\
\hline
\end{tabular}




\begin{tabular}{|c|c|c|c|c|c|c|c|c|}
\hline & \multicolumn{4}{|c|}{ Campbell Nodule Field - southern } & \multicolumn{3}{|c|}{ Southern Ocean } & \multirow[b]{2}{*}{ Z2140 } \\
\hline & U1374 & U1374 & U1378 & U1378 & S100 & Z2140 & Z2140 & \\
\hline Sample & 1-D & 1-E & LRQU & MOP & & ADF & B & CEG \\
\hline Mn (wt\%) & 20.95 & 21.00 & 24.00 & 23.52 & 24.11 & 16.90 & 15.39 & 14.12 \\
\hline Fe & 13.36 & 14.54 & 12.06 & 12.02 & 17.56 & 14.18 & 12.57 & 13.22 \\
\hline Co & 0.11 & 0.13 & 0.14 & 0.13 & 0.18 & 0.33 & 0.26 & 0.26 \\
\hline $\mathbf{N i}$ & 0.80 & 0.79 & 0.98 & 0.89 & 0.83 & 0.45 & 0.45 & 0.34 \\
\hline $\mathbf{C u}$ & 0.33 & 0.31 & 0.40 & 0.37 & 0.35 & 0.16 & 0.18 & 0.14 \\
\hline $\mathbf{M n} / \mathbf{F e}$ & 1.57 & 1.44 & 1.99 & 1.96 & 1.37 & 1.19 & 1.22 & 1.07 \\
\hline $\mathrm{Ni}+\mathrm{Cu}$ & 1.13 & 1.11 & 1.38 & 1.25 & 1.18 & 0.60 & 0.63 & 0.48 \\
\hline $\mathrm{Co}+\mathrm{Ni}+\mathrm{Cu}$ & 1.24 & 1.24 & 1.52 & 1.38 & 1.36 & 0.93 & 0.89 & 0.74 \\
\hline $\mathbf{L i}(\mathbf{p p m})$ & 103.6 & 87.2 & 118.3 & 132.9 & 50.5 & 12.1 & 18.9 & 18.5 \\
\hline Mg & 13929 & 13915 & 14523 & 14777 & 16553 & 13216 & 14612 & 14299 \\
\hline $\mathbf{A l}$ & 18714 & 18322 & 15913 & 17378 & 22902 & 10449 & 18355 & 18531 \\
\hline $\mathbf{P}$ & 2213 & 2655 & 2010 & 2122 & 2725 & 2419 & 1959 & 2383 \\
\hline $\mathbf{C a}$ & 21230 & 23353 & 26222 & 27807 & 22053 & 27774 & 31295 & 29445 \\
\hline $\mathbf{T i}$ & 5280 & 5752 & 5180 & 5072 & 7227 & 8769 & 7834 & 8009 \\
\hline Sc & 10.7 & 11.1 & 9.5 & 10.0 & 12.2 & 9.3 & 11.2 & 11.5 \\
\hline $\mathbf{V}$ & 452 & 511 & 444 & 473 & 604 & 434 & 336 & 369 \\
\hline $\mathbf{C r}$ & 35.3 & 28.6 & 23.7 & 30.8 & 33.7 & 8.4 & 13.1 & 17.2 \\
\hline $\mathbf{Z n}$ & 1679 & 1538 & 2124 & 1942 & 1477 & 941 & 1054 & 929 \\
\hline $\mathbf{G a}$ & 7.3 & 7.2 & 6.1 & 7.3 & 7.6 & 5.3 & 9.2 & 9.0 \\
\hline As & 119 & 152 & 106 & 130 & 162 & 162 & 101 & 128 \\
\hline $\mathbf{R b}$ & 13.7 & 13.7 & 11.8 & 13.2 & 15.7 & 13.3 & 25.7 & 25.4 \\
\hline $\mathbf{S r}$ & 889 & 957 & 891 & 890 & 1161 & 1178 & 1035 & 1065 \\
\hline $\mathbf{Y}$ & 88 & 96 & 82 & 88 & 99 & 95 & 79 & 88 \\
\hline $\mathbf{Z r}$ & 395 & 424 & 325 & 347 & 476 & 597 & 508 & 532 \\
\hline
\end{tabular}




\begin{tabular}{|c|c|c|c|c|c|c|c|c|}
\hline Mo & 289 & 303 & 250 & 313 & 270 & 218 & 152 & 143 \\
\hline Cd & 8.9 & 8.3 & 8.7 & 9.7 & 7.7 & 5.0 & 4.3 & 3.9 \\
\hline $\mathbf{B a}$ & 975 & 964 & 1165 & 1127 & 1227 & 1095 & 1043 & 1027 \\
\hline La & 124 & 135 & 119 & 119 & 170 & 193 & 156 & 164 \\
\hline $\mathrm{Ce}$ & 499 & 563 & 493 & 451 & 718 & 908 & 740 & 759 \\
\hline $\operatorname{Pr}$ & 34.1 & 36.9 & 34.4 & 33.0 & 45.4 & 46.2 & 38.5 & 40.7 \\
\hline Nd & 141 & 152 & 141 & 139 & 182 & 184 & 152 & 162 \\
\hline Sm & 32.9 & 35.2 & 33.1 & 32.4 & 35.9 & 38.7 & 31.6 & 33.4 \\
\hline $\mathbf{E u}$ & 7.4 & 8.1 & 7.6 & 7.5 & 8.2 & 8.6 & 7.1 & 7.5 \\
\hline Gd & 33.6 & 36.5 & 33.3 & 33.2 & 37.6 & 42.3 & 33.2 & 36.0 \\
\hline $\mathbf{T b}$ & 5.2 & 5.7 & 5.2 & 5.1 & 5.9 & 6.0 & 5.0 & 5.3 \\
\hline Dy & 29.0 & 31.4 & 28.7 & 28.6 & 31.9 & 32.3 & 26.9 & 28.5 \\
\hline Ho & 5.2 & 5.6 & 5.0 & 5.2 & 5.8 & 5.8 & 4.8 & 5.1 \\
\hline $\mathbf{E r}$ & 13.9 & 14.8 & 13.2 & 13.7 & 15.2 & 15.4 & 12.5 & 13.4 \\
\hline Tm & 1.8 & 2.0 & 1.7 & 1.8 & 2.0 & 2.0 & 1.7 & 1.8 \\
\hline $\mathbf{Y b}$ & 11.9 & 12.8 & 11.3 & 11.7 & 13.3 & 13.1 & 10.6 & 11.4 \\
\hline Lu & 1.6 & 1.7 & 1.5 & 1.6 & 1.8 & 1.8 & 1.5 & 1.6 \\
\hline Hf & 7.8 & 8.6 & 6.4 & 6.6 & 9.2 & 12.4 & 11.7 & 11.6 \\
\hline Tl & 92.2 & 113.9 & 111.1 & 123.2 & 90.0 & 70.0 & 57.5 & 58.5 \\
\hline $\mathbf{P b}$ & 797 & 963 & 873 & 809 & 872 & 1101 & 953 & 1011 \\
\hline $\mathbf{B i}$ & 6.8 & 7.9 & 7.9 & 7.1 & 8.0 & 9.2 & 8.4 & 8.5 \\
\hline Th & 49.0 & 57.1 & 52.3 & 46.9 & 60.4 & 79.6 & 70.7 & 68.7 \\
\hline $\mathbf{U}$ & 5.7 & 6.7 & 5.3 & 5.8 & 7.0 & 7.5 & 6.0 & 6.6 \\
\hline IREY (wt\%) & 0.10 & 0.11 & 0.10 & 0.10 & 0.14 & 0.16 & 0.13 & 0.14 \\
\hline$\left.(\mathrm{Ce} / \mathrm{Ce})^{*}\right)_{\mathrm{SN}(\mathrm{PAAS})}$ & 1.76 & 1.83 & 1.76 & 1.65 & 1.87 & 2.21 & 2.19 & 2.14 \\
\hline
\end{tabular}




\begin{tabular}{|c|c|c|c|c|c|c|c|c|}
\hline & \multicolumn{4}{|c|}{ Authigenic component } & \multicolumn{4}{|c|}{ Residual-detrital component } \\
\hline & U1413 & U1374 & U205 & NOD-P-1 & U1413 & U1374 & U205 & NOD-P-1 \\
\hline Sample & 1-B & $1-E$ & DFG & & $1-B$ & $1-\mathrm{E}$ & DFG & \\
\hline Mn (wt\%) & 23.93 & 27.09 & 31.66 & 36.38 & 0.05 & 0.08 & 0.06 & 0.18 \\
\hline Fe & 20.04 & 17.57 & 8.35 & 6.67 & 2.09 & 2.63 & 2.30 & 2.32 \\
\hline Co & 0.33 & 0.18 & 0.09 & 0.29 & 0.00 & 0.00 & 0.00 & 0.00 \\
\hline $\mathbf{N i}$ & 0.81 & 1.07 & 1.58 & 1.65 & 0.00 & 0.00 & 0.00 & 0.01 \\
\hline $\mathrm{Cu}$ & 0.15 & 0.44 & 0.56 & 1.41 & 0.00 & 0.00 & 0.00 & 0.02 \\
\hline Li (ppm) & 17.7 & 105 & 164 & 166 & 14.8 & 18.1 & 81.0 & 43.5 \\
\hline Mg & 14844 & 14374 & 23120 & 23517 & 10915 & 12833 & 4883 & 7200 \\
\hline Al & 8557 & 6986 & 16601 & 14291 & 55907 & 54444 & 64815 & 68180 \\
\hline $\mathbf{P}$ & 3745 & 3371 & 2434 & 2564 & 923 & 341 & 236 & 341 \\
\hline $\mathbf{C a}$ & 23791 & 22249 & 20516 & 26630 & 22859 & 23708 & 3452 & 7525 \\
\hline $\mathbf{T i}$ & 12622 & 6277 & 1569 & 2541 & 3623 & 3467 & 4905 & 3257 \\
\hline Sc & 9.5 & 9.1 & 4.1 & 9.1 & 15.0 & 16.5 & 10.9 & 12.0 \\
\hline $\mathbf{V}$ & 712 & 632 & 551 & 627 & 80.4 & 84.5 & 67.6 & 63.9 \\
\hline $\mathrm{Cr}$ & 7.9 & 10.4 & 9.8 & 6.1 & 86.1 & 97.0 & 98.1 & 47.5 \\
\hline $\mathbf{Z n}$ & 1287 & 2022 & 3231 & 2528 & 53.4 & 45.0 & 30.7 & 57.0 \\
\hline Ga & 5.8 & 5.3 & 12.7 & 30.9 & 10.9 & 11.7 & 15.2 & 17.4 \\
\hline As & 248 & 186 & 105 & 107 & 13.4 & 12.0 & 8.2 & 10.3 \\
\hline $\mathbf{R b}$ & 5.5 & 5.4 & 9.7 & 9.5 & 41.3 & 42.1 & 75.1 & 85.5 \\
\hline $\mathrm{Sr}$ & 1372 & 1161 & 620 & 800 & 253 & 243 & 102 & 182 \\
\hline $\mathbf{Y}$ & 150 & 121 & 73 & 110 & 10.2 & 10.4 & 14.2 & 11.9 \\
\hline $\mathbf{Z r}$ & 300 & 393 & 70 & 224 & 1288 & 452 & 290 & 500 \\
\hline Mo & 330 & 390 & 452 & 846 & 0.0 & 0.0 & 11.1 & 26.8 \\
\hline Cd & 8.5 & 10.5 & 15.2 & 28.0 & 0.6 & 0.2 & 0.2 & 0.3 \\
\hline $\mathbf{B a}$ & 1458 & 1143 & 1000 & 3136 & 320 & 336 & 315 & 933 \\
\hline
\end{tabular}




\begin{tabular}{|c|c|c|c|c|c|c|c|c|}
\hline La & 228 & 174 & 82 & 127 & 7.9 & 8.8 & 14.9 & 16.2 \\
\hline $\mathrm{Ce}$ & 1185 & 736 & 285 & 374 & 18.0 & 20.2 & 28.9 & 31.2 \\
\hline Pr & 58.9 & 47.9 & 23.9 & 37.9 & 2.0 & 2.3 & 3.3 & 3.4 \\
\hline Nd & 236 & 196 & 105 & 159 & 8.1 & 9.0 & 12.1 & 12.3 \\
\hline Sm & 52.0 & 44.8 & 24.2 & 38.3 & 1.8 & 2.0 & 2.3 & 2.2 \\
\hline Eu & 12.1 & 10.3 & 5.7 & 9.2 & 0.6 & 0.6 & 0.6 & 0.7 \\
\hline Gd & 55.7 & 46.2 & 24.1 & 37.7 & 1.9 & 2.1 & 2.4 & 2.2 \\
\hline Tb & 8.5 & 7.1 & 3.8 & 6.0 & 0.3 & 0.3 & 0.4 & 0.3 \\
\hline Dy & 46.3 & 40.0 & 21.0 & 33.6 & 1.8 & 1.9 & 2.4 & 2.0 \\
\hline Ho & 8.6 & 7.0 & 3.9 & 6.2 & 0.4 & 0.4 & 0.5 & 0.4 \\
\hline Er & 23.0 & 18.6 & 10.5 & 16.8 & 1.1 & 1.1 & 1.5 & 1.3 \\
\hline Tm & 3.1 & 2.5 & 1.4 & 2.3 & 0.2 & 0.2 & 0.2 & 0.2 \\
\hline Yb & 20.0 & 16.0 & 9.3 & 16.1 & 1.0 & 1.1 & 1.7 & 1.4 \\
\hline Lu & 2.7 & 2.2 & 1.3 & 2.2 & 0.2 & 0.2 & 0.3 & 0.2 \\
\hline Hf & 7.5 & 8.0 & 1.3 & 3.0 & 27.2 & 9.6 & 6.7 & 9.4 \\
\hline Tl & 150 & 131 & 90 & 248 & 0.4 & 0.6 & 0.9 & 2.1 \\
\hline $\mathbf{P b}$ & 1417 & 1225 & 623 & 583 & 5.5 & 6.8 & 7.5 & 7.0 \\
\hline $\mathbf{B i}$ & 11.8 & 9.8 & 4.7 & 7.1 & 0.0 & 0.0 & 0.1 & 0.1 \\
\hline Th & 94.8 & 70.2 & 23.3 & 19.3 & 8.0 & 9.9 & 17.1 & 5.3 \\
\hline $\mathbf{U}$ & 11.6 & 8.4 & 3.4 & 4.7 & 0.6 & 0.6 & 1.5 & 1.5 \\
\hline
\end{tabular}


$\stackrel{N}{\infty}$ 


\section{Appendix E JMn-1 (GSJ SRM) data from ICP-MS runs}

All supplementary information listed below can be found on the digital appendices CD located at the back of this thesis.

\section{E.1 Major elements}

E.2 Trace elements 


\section{References}

Aabel, 2014. . Gigawiz Ltd. Co., OK.

Aller, R.C., 1990. Bioturbation and Manganese Cycling in Hemipelagic Sediments. Philos. Trans. R. Soc. Lond. Ser. Math. Phys. Sci. 331, 51-68. doi:10.2307/53653

Amante, C., Eakins, B.W., 2009. noaa. Technical Memorandum. NESDIS.

Anderson, R.F., 2014. Chemical Tracers of Particle Transport, in: Treatise on Geochemistry. Elsevier, pp. 259-280.

Aplin, A.C., Cronan, D.S., 1985. Ferromanganese oxide deposits from the Central Pacific Ocean, II. Nodules and associated sediments. Geochim. Cosmochim. Acta 49, 437-451. doi:10.1016/0016-7037(85)90035-3

Axelsson, M.D., Rodushkin, I., Ingri, J., Öhlander, B., 2002. Multielemental analysis of Mn-Fe nodules by ICP-MS: optimisation of analytical method. The Analyst 127, 76-82. doi:10.1039/b105706p

Baker, E.T., Feely, R.A., 1978. Chemistry of Oceanic Particulate Matter and Sediments: Implications for Bottom Sediment Resuspension. Science 200, 533-535.

Bau, M., Schmidt, K., Koschinsky, A., Hein, J., Kuhn, T., Usui, A., 2014. Discriminating between different genetic types of marine ferro-manganese crusts and nodules based on rare earth elements and yttrium. Chem. Geol. 381, 1-9. doi:10.1016/j.chemgeo.2014.05.004

Beggs, J.M., Challis, G.A., Cook, R.A., 1990. Basement geology of the Campbell Plateau: Implications for correlation of the Campbell Magnetic Anomaly System. N. Z. J. Geol. Geophys. 33, 401-404. doi:10.1080/00288306.1990.10425696

Bender, M.L., Heggie, D.T., 1984. Fate of organic carbon reaching the deep sea floor: a status report. Geochim. Cosmochim. Acta 48, 977-986. doi:10.1016/00167037(84)90189-3

Bennett, R.H., O'Brien, N.R., Hulbert, M.H., 1991. Determinants of Clay and Shale Microfabric Signatures: Processes and Mechanisms, in: Bennett, R.H., Bryant, W.R., Hulbert, M.H., Chiou, W.A., Faas, R.W., Kasprowicz, J., Li, H., Lomenick, T., O’Brien, N. R., Pamukcu, S., Smart, P., Weaver, C.E., Yamamoto, T. (Eds.), Microstructure of Fine-Grained Sediments: From Mud to Shale. Springer New York, New York, NY, pp. 5-32. doi:10.1007/978-1-4612-4428-8_2

Berner, R.A., 1980. Early diagenesis: a theoretical approach. Princeton University Press.

Bhatia, M.R., 1983. Plate Tectonics and Geochemical Composition of Sandstones. J. Geol. 91, 611-627. doi:10.2307/30064711

Blöthe, M., Wegorzewski, A., Müller, C., Simon, F., Kuhn, T., Schippers, A., 2015. Manganese-Cycling Microbial Communities Inside Deep-Sea Manganese Nodules. Environ. Sci. Technol. 49, 7692-7700. doi:10.1021/es504930v

Blott, S.J., 2010. GradiStat Version 8.0: a grain size distribution and statistics package for the analysis of unconsolidated sediments by sieving or laser granulometer. Kenneth Pye \& Associates Ltd., Crowthorne, UK.

Blott, S.J., Pye, K., 2001. GRADISTAT: a grain size distribution and statistics package for the analysis of unconsolidated sediments. Earth Surf. Process. Landf. 26, 1237-1248. doi:10.1002/esp.261 
Bodeï, S., Manceau, A., Geoffroy, N., Baronnet, A., Buatier, M., 2007. Formation of todorokite from vernadite in Ni-rich hemipelagic sediments. Phys. Chem. Soils Aquifers Spec. Issue Honor Garrison Sposito 71, 5698-5716. doi:10.1016/j.gca.2007.07.020

Bonatti, E., 1972. Classification and genesis of submarine iron-manganese deposits. Ferromanganese Depos. Ocean Floor 149-166.

Bostock, H.C., Barrows, T.T., Carter, L., Chase, Z., Cortese, G., Dunbar, G.B., Ellwood, M., Hayward, B., Howard, W., Neil, H.L., Noble, T.L., Mackintosh, A., Moss, P.T., Moy, A.D., White, D., Williams, M.J.M., Armand, L.K., 2013. A review of the Australian-New Zealand sector of the Southern Ocean over the last $30 \mathrm{ka}$ (Aus-INTIMATE project). Quat. Sci. Rev. 74, 35-57.

Bostock, H.C., Hayward, B.W., Neil, H.L., Currie, K.I., Dunbar, G.B., 2011. Deep-water carbonate concentrations in the southwest Pacific. Deep Sea Res. Part Oceanogr. Res. Pap. 58, 72-85. doi:10.1016/j.dsr.2010.11.010

Boudreau, B., 2013. Diagenetic models and their implementation: modelling transport and reactions in aquatic sediments. Springer Berlin Heidelberg, 1-414.

Boudreau, B.P., Scott, M.R., 1978. A model for the diffusion-controlled growth of deepsea manganese nodules. Am J Sci 278, 903-929.

Boyd, P.W., Ellwood, M.J., 2010. The biogeochemical cycle of iron in the ocean. Nat. Geosci. 3, 675-682. doi:10.1038/ngeo964

Breitzke, M., 2006. Physical Properties of Marine Sediments, in: Schulz, H.D., Zabel, M. (Eds.), Marine Geochemistry. Springer Berlin Heidelberg, Berlin, Heidelberg, pp. 27-71. doi:10.1007/3-540-32144-6_2

Broecker, W.S., Peng, T.-H., 1982. Tracers in the Sea. Lamont-Doherty Geological Observatory, Columbia University, 125-159.

Bruland, K.W., 1980. Oceanographic distributions of cadmium, zinc, nickel, and copper in the North Pacific. Earth Planet. Sci. Lett. 47, 176-198.

Bruland, K.W., Middag, R., Lohan, M.C., 2014. Controls of Trace Metals in Seawater, in: Treatise on Geochemistry. Elsevier, pp. 19-51.

Bruland, K.W., Orians, K.J., Cowen, J.P., 1994. Reactive trace metals in the stratified central North Pacific. Geochim. Cosmochim. Acta 58, 3171-3182.

Buat-Menard, P., Chesselet, R., 1979. Variable influence of the atmospheric flux on the trace metal chemistry of oceanic suspended matter. Earth Planet. Sci. Lett. 42, 399-411.

Burdige, D.J., 2006. Geochemistry of Marine Sediments. Princeton University Press, Princeton, New Jersey. doi:10.1086/533614

Burdige, D.J., 1993. The biogeochemistry of manganese and iron reduction in marine sediments. Earth-Sci. Rev. 35, 249-284.

Burns, R.G., Burns, V.M., 1977. Mineralogy, in: G.P. Glasby (Ed.), Elsevier Oceanography Series. Elsevier, pp. 185-248. doi:10.1016/S04229894(08)71021-3

Burns, R.G., Burns, V.M., 1975. Mechanism for nucleation and growth of manganese nodules. Nature 255, 130-131.

Callender, E., Bowser, C.J., 1980. Manganese and copper geochemistry of interstitial fluids from manganese nodule-rich pelagic sediments of the northeastern equatorial Pacific Ocean. Am. J. Sci. 280, 1063-1096.

Calvert, S.E., Pedersen, T.F., 1993. Geochemistry of recent oxic and anoxic marine sediments: implications for the geological record. Mar. Geol. 113, 67-88.

Calvert, S.E., Price, N.B., 1977. Chapter 3 Shallow Water, Continental Margin and Lacustrine Nodules: Distribution and Geochemistry, in: G.P. Glasby (Ed.), Elsevier Oceanography Series. Elsevier, pp. 45-86. doi:10.1016/S04229894(08)71017-1 
Calvert, S. E., Price, N.B., 1977. Geochemical variation in ferromanganese nodules and associated sediments from the Pacific Ocean. Mar. Chem. 5, 43-74.

Carter, L., McCave, I.N., 1997. The sedimentary regime beneath the deep western boundary current inflow to the southwest Pacific Ocean. J. Sediment. Res. 67 (6): 1005-1017.

Carter, L., Neil, H.L., McCave, I.N., 2000. Glacial to interglacial changes in noncarbonate and carbonate accumulation in the SW Pacific Ocean, New Zealand. Palaeogeogr. Palaeoclimatol. Palaeoecol. 162, 333-356.

Carter, L., Wilkin, J., 1999. Abyssal circulation around New Zealand - A comparison between observations and a global circulation model. Mar. Geol. 159, 221-239.

Chang, S.., Choi, H., Lee, S.R., Graham, I.J., Wright, I., 2003a. Ferromanganese nodules in the vicinity of Bollons Seamount SE of the Campbell Plateau, SW Pacific Ocean. Part 1, Distribution and external morphology. Institute of Geological \& Nuclear Sciences, Lower Hutt, New Zealand. Institute of Geological \& Nuclear Sciences science report 2003/13 41p.

Chang, S.., Choi, H., Lee, S.R., Graham, I.J., Wright, I., 2003b. Ferromanganese nodules in the vicinity of Bollons Seamount SE of the Campbell Plateau, SW Pacific Ocean. Part 2, Petrography and chemistry Distribution and external morphology. Institute of Geological \& Nuclear Sciences, Lower Hutt, New Zealand. Institute of Geological \& Nuclear Sciences science report 2003/14 70p.

Chester, R., 1990. Sediment interstitial waters and diagenesis, in: Chester, R. (Ed.), Marine Geochemistry. Springer Netherlands, Dordrecht, pp. 468-528. doi:10.1007/978-94-010-9488-7_14

Chiswell, S.M., Bostock, H.C., Sutton, P.J., Williams, M.J., 2015. Physical oceanography of the deep seas around New Zealand: a review. N. Z. J. Mar. Freshw. Res. 49, $286-317$.

Conway, C.E., Bostock, H.C., Baker, J.A., Wysoczanski, R.J., Verdier, A.-L., 2012. Evolution of Macquarie Ridge Complex seamounts: Implications for volcanic and tectonic processes at the Australia-Pacific plate boundary south of New Zealand. Mar. Geol. 295-298, 34-50. doi:10.1016/j.margeo.2011.11.009

Craig, H., Turekian, K.K., 1976. The GEOSECS program: 1973-1976. Earth Planet. Sci. Lett. 32, 217-219.

Cronan, D.S., 1975. Manganese nodules and other ferromanganese oxide deposits from the Atlantic Ocean. J. Geophys. Res. 80, 3831-3837. doi:10.1029/JC080i027p03831

Cronan, D.S., Hodkinson, R.A., 1994. Element supply to surface manganese nodules along the Aitutaki-Jarvis Transect, South Pacific. J. Geol. Soc. 151, 391-401.

de Baar, H.J.W., 2005. Synthesis of iron fertilization experiments: From the Iron Age in the Age of Enlightenment. J. Geophys. Res. 110. doi:10.1029/2004JC002601

Duce, R.A., Liss, P.S., Merrill, J.T., Atlas, E.L., Buat-Menard, P., Hicks, B.B., Miller, J.M., Prospero, J.M., Arimoto, R., Church, T.M., Ellis, W., Galloway, J.N., Hansen, L., Jickells, T.D., Knap, A.H., Reinhardt, K.H., Schneider, B., Soudine, A., Tokos, J.J., Tsunogai, S., Wollast, R., Zhou, M., 1991. The atmospheric input of trace species to the world ocean. Glob. Biogeochem. Cycles 5, 193-259.

Dunn, D.A., 1980. Revised techniques for quantative calcium carbonate analysis using the "Karbonat-Bombe", and comparisons to other methods. J. Sediment. Res. 50, 631-637.

Dymond, J., Lyle, M., Finney, B., Piper, D.Z., Murphy, K., Conard, R., Pisias, N., 1984. Ferromanganese nodules from MANOP Sites $\mathrm{H}, \mathrm{S}$, and $\mathrm{R}-$ Control of mineralogical and chemical composition by multiple accretionary processes. Geochim. Cosmochim. Acta 48, 931-949. 
Elderfield, H., 1976. Manganese fluxes to the oceans. Mar. Chem. 4, 103-132. doi:10.1016/0304-4203(76)90001-3

Elderfield, H., Schultz, and A., 1996. Mid-Ocean Ridge Hydrothermal Fluxes and the Chemical Composition of the Ocean. Annu. Rev. Earth Planet. Sci. 24, $191-224$.

Elderfield, H., Whitfield, M., Burton, J.D., Bacon, M.P., Liss, P.S., 1988. The Oceanic Chemistry of the Rare-Earth Elements [and Discussion]. Philos. Trans. R. Soc. Lond. Ser. Math. Phys. Sci. 325, 105-126. doi:10.2307/38104

Emerson, S.R., Huested, S.S., 1991. Ocean anoxia and the concentrations of molybdenum and vanadium in seawater. Mar. Chem. 34, 177-196.

Feely, R.A., Baker, E.T., Marumo, K., Urabe, T., Ishibashi, J., Gendron, J., Lebon, G.T., Okamura, K., 1996. Hydrothermal plume particles and dissolved phosphate over the superfast-spreading southern East Pacific Rise. Geochim. Cosmochim. Acta 60, 2297-2323.

Folk, R.L., 1980. Petrology of sedimentary rocks. Hemphill Publishing Company.

Francois, R., 2014. Sampling and Sample-handling Protocols for GEOTRACES Cruises 2.

Froelich, P., Klinkhammer, G.P., Bender, M.L., Luedtke, N.A., Heath, G.R., Cullen, D., Dauphin, P., Hammond, D., Hartman, B., Maynard, V., 1979. Early oxidation of organic matter in pelagic sediments of the eastern equatorial Atlantic: suboxic diagenesis. Geochim. Cosmochim. Acta 43, 1075-1090.

Froelich, P.N., 1988. Kinetic control of dissolved phosphate in natural rivers and estuaries: A primer on the phosphate buffer mechanism1. Limnol. Oceanogr. 33, 649-668. doi:10.4319/lo.1988.33.4part2.0649

Frontin-Rollet, G., 2016. The Geochemistry and Ecotoxicity of Offshore New Zealand Phosphorites (Masters in Science). Victoria University of Wellington, Wellington, New Zealand.

Fütterer, D.K., 2000. The Solid Phase of Marine Sediments, in: Schulz, H.D., Zabel, M. (Eds.), Marine Geochemistry. Springer Berlin Heidelberg, Berlin, Heidelberg, pp. 1-25. doi:10.1007/978-3-662-04242-7_1

GERM Partition Coefficient (Kd) Database [WWW Document], 2015. . Geochem. Earth Ref. Model. URL https://earthref.org/KDD/ (accessed 10.12.17).

German, C.R., Seyfried, W.E., 2014. Hydrothermal Processes, in: Treatise on Geochemistry. Elsevier, pp. 191-233.

Glasby, G.P., 2006. Manganese: Predominant Role of Nodules and Crusts, in: Schulz, H.D., Zabel, M. (Eds.), Marine Geochemistry. Springer Berlin Heidelberg, Berlin, Heidelberg, pp. 371-427.

Glasby, G.P., 1976. Manganese nodules in the South Pacific: A review. N. Z. J. Geol. Geophys. 19, 707-736. doi:10.1080/00288306.1976.10426315

Glasby, G.P., 1973. Mechanisms of enrichment of the rarer elements in marine manganese nodules. Mar. Chem. 1, 105-125. doi:10.1016/0304-4203(73)900108

Glasby, G.P., Gwozdz, R., Kunzendorf, H., Friedrich, G., Thijssen, T., 1987. The distribution of rare earth and minor elements in manganese nodules and sediments from the equatorial and S.W. Pacific. Lithos 20, 97-113. doi:10.1016/00244937(87)90001-6

Glasby, G.P., Schulz, H.D., 1999. Eh Ph diagrams for Mn, Fe, Co, Ni, Cu and as under seawater conditions: application of two new types of eh ph diagrams to the study of specific problems in marine geochemistry. Aquat. Geochem. 5, 227-248.

Glasby, G.P., Stoffers, P., Grapes, R.H., Plüger, W.L., McKnight, D.G., DeL. Main, W., 1986. Manganese nodule occurrence in the Tasman Sea. N. Z. J. Mar. Freshw. Res. 20, 489-494. doi:10.1080/00288330.1986.9516168 
Glasby, G.P., Summerhayes, C.P., 1975. Sequential deposition of authigenic marine minerals around New Zealand: Paleoenvironmental significance. N. Z. J. Geol. Geophys. 18, 477-490. doi:10.1080/00288306.1975.10421548

Goloway, F., Bender, M., 1982. Diagenetic models of interstitial nitrate profiles in deep sea suboxic sediments. Limnol. Oceanogr. 27, 624-638.

Graham, I.J., Ditchburn, R.G., Zondervan, A., Chang, S.W., Lee, S.R., Wright, I.C., 2003. Ferromanganese nodules in the vicinity of Bollons Seamount SE of the Campbell Plateau, SW Pacific Ocean Part 3, Beryllium isotope dating. Institute of Geological \& Nuclear Sciences, Lower Hutt, New Zealand. Institute of Geological \& Nuclear Sciences science report 2003/15 40p.

Guo, L., Santschi, P.H., 1997. Composition and cycling of colloids in marine environments. Rev. Geophys. 35, 17-40.

Halbach, P., Friedrich, G., von Stackelberg, U., 1988. The Manganese nodule belt of the Pacific Ocean. Enke, Stuttgart.

Halbach, P., Scherhag, C., Hebisch, U., Marchig, V., 1981. Geochemical and mineralogical control of different genetic types of deep-sea nodules from the Pacific Ocean. Miner. Deposita 16, 59-84.

Harris, D.C., 2010. Quantitative chemical analysis, 8th ed. ed. W.H. Freeman and Co, New York.

Hein, J., Koschinsky, A., Bau, M., T. Manheim, F., Kang, J.-K., Roberts, L., 2000. Cobalt-Rich Ferromanganese Crusts in the Pacific. Handbook of marine mineral deposits, 18, 239.

Hein, J.R., Koschinsky, A., 2014. Deep-Ocean Ferromanganese Crusts and Nodules, in: Treatise on Geochemistry. Elsevier, pp. 273-291. doi:10.1016/B978-0-08095975-7.01111-6

Hein, J.R., Koschinsky, A., Halbach, P., Manheim, F.T., Bau, M., Kang, J.-K., Lubick, N., 1997. Iron and manganese oxide mineralization in the Pacific. Geol. Soc. Lond. Spec. Publ. 119, 123-138.

Hein, J.R., Mizell, K., Koschinsky, A., Conrad, T.A., 2013. Deep-ocean mineral deposits as a source of critical metals for high- and green-technology applications: Comparison with land-based resources. Ore Geol. Rev. 51, 1-14.

Hein, J.R., Schulz, M.S., Dunham, R.E., Stern, R.J., Bloomer, S.H., 2008. Diffuse flow hydrothermal manganese mineralization along the active Mariana and southern Izu-Bonin arc system, western Pacific. J. Geophys. Res. 113. doi:10.1029/2007JB005432

Hein, J.R., Spinardi, F., Okamoto, N., Mizell, K., Thorburn, D., Tawake, A., 2015. Critical metals in manganese nodules from the Cook Islands EEZ, abundances and distributions. Ore Geol. Rev. 68, 97-116. doi:10.1016/j.oregeorev.2014.12.011

Homoky, W.B., Weber, T., Berelson, W.M., Conway, T.M., Henderson, G.M., van Hulten, M., Jeandel, C., Severmann, S., Tagliabue, A., 2016. Quantifying trace element and isotope fluxes at the ocean-sediment boundary: a review. Philos. Trans. R. Soc. Math. Phys. Eng. Sci. 374, 20160246. doi:10.1098/rsta.2016.0246

Hu, Z., Zhang, W., Liu, Y., Chen, H., Gaschnig, R.M., Zong, K., Li, M., Gao, S., Hu, S., 2013. Rapid bulk rock decomposition by ammonium fluoride (NH4F) in open vessels at an elevated digestion temperature. Chem. Geol. 355, 144-152. doi:10.1016/j.chemgeo.2013.06.024

Huettel, M., Webster, I.T., 2001. Porewater flow in permeable sediments. Benthic Bound. Layer Oxf. Univ. Press N. Y. 144-179.

ISA, 2010. A geological model of polymettalic nodules in the Clarion-Clipperton Zone. International Seabed Authority, Kingston, Jamaica.

ISA, 2008. Pollymetalic Nodules. Kingston, Jamaica. 
Jarvis, I., Burnett, W.C., Nathan, Y., Almbaydin, F.S.M., Attia, A.K.M., Castro, L.N., Flicoteaux, R., Hilmy, M.E., Husain, V., Qutawnah, A.A., 1994. Phosphorite geochemistry: state-of-the-art and environmental concerns. Eclogae Geol. Helvetiae 87, 643-700.

Jochum, K.P., Nohl, U., Herwig, K., Lammel, E., Stoll, B., Hofmann, A.W., 2005. GeoReM: A New Geochemical Database for Reference Materials and Isotopic Standards. Geostand. Geoanalytical Res. 29, 333-338. doi:10.1111/j.1751908X.2005.tb00904.x

Jung, H.-S., Lee, C.-B., 1999. Growth of diagenetic ferromanganese nodules in an oxic deep-sea sedimentary environment, northeast equatorial Pacific. Mar. Geol. 157, 127-144. doi:10.1016/S0025-3227(98)00154-6

Kato, Y., Fujinaga, K., Nakamura, K., Takaya, Y., Kitamura, K., Ohta, J., Toda, R., Nakashima, T., Iwamori, H., 2011. Deep-sea mud in the Pacific Ocean as a potential resource for rare-earth elements. Nat. Geosci. 4, 535-539. doi:10.1038/ngeo1185

Kennett, J.P., Watkins, N.D., 1975. Deep-sea erosion and manganese nodule development in the Southeast Indian Ocean. Science 188, 1011-1013.

Kerr, R.A., 1984. Manganese nodules grow by rain from above; the rain of plant and animal remains falling into the deep sea not only provides metals to nodules but also determines nodule growth rates and composition. Science 223, 576-578.

Key, R.M., Kozyr, A., Sabine, C.L., Lee, K., Wanninkhof, R., Bullister, J.L., Feely, R.A., Millero, F.J., Mordy, C., Peng, T.-H., 2004. A global ocean carbon climatology: Results from Global Data Analysis Project (GLODAP): GLOBAL OCEAN CARBON CLIMATOLOGY. Glob. Biogeochem. Cycles 18, n/a-n/a.

Klinkhammer, G., Heggie, D.T., Graham, D.W., 1982. Metal diagenesis in oxic marine sediments. Earth Planet. Sci. Lett. 61, 211-219.

Klinkhammer, G., Hudson, A., 1986. Dispersal patterns for hydrothermal plumes in the South Pacific using manganese as a tracer. Earth Planet. Sci. Lett. 79, 241-249.

Klinkhammer, G.P., Bender, M.L., 1980. The distribution of manganese in the Pacific Ocean. Earth Planet. Sci. Lett. 46, 361-384.

Koschinsky, A., Gaye-Haake, B., Arndt, C., Maue, G., Spitzy, A., Winkler, A., Halbach, P., 2001. Experiments on the influence of sediment disturbances on the biogeochemistry of the deep-sea environment. Deep Sea Res. Part II Top. Stud. Oceanogr. 48, 3629-3651.

Koschinsky, A., Halbach, P., 1995. Sequential leaching of marine ferromanganese precipitates: Genetic implications. Geochim. Cosmochim. Acta 59, 5113-5132.

Koschinsky, A., Hein, J.R., 2003. Uptake of elements from seawater by ferromanganese crusts: solid-phase associations and seawater speciation. Mar. Geol. 198, 331351.

Koschinsky, A., Stascheit, A., Bau, M., Halbach, P., 1997. Effects of phosphatization on the geochemical and mineralogical composition of marine ferromanganese crusts. Geochim. Cosmochim. Acta 61, 4079-4094. doi:10.1016/S0016-7037(97)002317

Kuhn, T., Wegorzewski, A., Rühlemann, C., Vink, A., 2017. Composition, Formation, and Occurrence of Polymetallic Nodules, in: Sharma, R. (Ed.), Deep-Sea Mining. Springer International Publishing, Cham, pp. 23-63. doi:10.1007/978-3-31952557-0_2

Lamy, F., Gersonde, R., Winckler, G., Esper, O., Jaeschke, A., Kuhn, G., Ullermann, J., Martinez-Garcia, A., Lambert, F., Kilian, R., 2014. Increased Dust Deposition in the Pacific Southern Ocean During Glacial Periods. Science 343, 403. doi:10.1126/science. 1245424 
Li, Y.-H., 1991. Distribution patterns of the elements in the ocean: A synthesis. Macalpine Hills Lunar Meteor. Consort. 55, 3223-3240.

Li, Y.-H., Schoonmaker, J.E., 2003. Chemical Composition and Mineralogy of Marine Sediments, in: Treatise on Geochemistry. Elsevier, pp. 1-35.

Manceau, A., Lanson, M., Takahashi Yoshio, 2014. Mineralogy and crystal chemistry of $\mathrm{Mn}, \mathrm{Fe}, \mathrm{Co}, \mathrm{Ni}$, and $\mathrm{Cu}$ in a deep-sea Pacific polymetallic nodule. Am. Mineral. 99, 2068. doi:10.2138/am-2014-4742

Manceau, A., Marcus, M.A., Grangeon, S., 2012. Determination of Mn valence states in mixed-valent manganates by XANES spectroscopy. Am. Mineral. 97, 816-827. doi:10.2138/am.2012.3903

Manheim, F.T., 1986. Marine cobalt resources. Science 232, 600-608.

Manheim, F.T., Lane-Bostwick, C.M., 1988. Cobalt in ferromanganese crusts as a monitor of hydrothermal discharge on the Pacific sea floor. Nature 335, 59-62. doi:10.1038/335059a0

Mantyla, A.W., Reid, J.L., 1983. Abyssal characteristics of the World Ocean waters. Deep Sea Res. Part Oceanogr. Res. Pap. 30, 805-833.

Margolis, S.V., Burns, R.G., 1976. Pacific deep-sea manganese nodules: Their distribution, composition, and origin. Annu. Rev. Earth Planet. Sci. 4, 229.

Martin, J.H., Knauer, G.A., Karl, D.M., Broenkow, W.W., 1987. VERTEX: carbon cycling in the northeast Pacific. Deep Sea Res. Part Oceanogr. Res. Pap. 34, $267-$ 285. doi:10.1016/0198-0149(87)90086-0

Martin, J.-M., Whitfield, M., 1983. The Significance of the River Input of Chemical Elements to the Ocean, in: Wong, C.S., Boyle, E., Bruland, K.W., Burton, J.D., Goldberg, E.D. (Eds.), Trace Metals in Sea Water. Springer US, Boston, MA, pp. 265-296.

Mawji, E., Schlitzer, R., Dodas, E.M., Abadie, C., Abouchami, W., Anderson, R.F., Baars, O., Bakker, K., Baskaran, M., Bates, N.R., Bluhm, K., Bowie, A., Bown, J., Boye, M., Boyle, E.A., Branellec, P., Bruland, K.W., Brzezinski, M.A., Bucciarelli, E., Buesseler, K., Butler, E., Cai, P., Cardinal, D., Casciotti, K., Chaves, J., Cheng, H., Chever, F., Church, T.M., Colman, A.S., Conway, T.M., Croot, P.L., Cutter, G.A., de Baar, H.J.W., de Souza, G.F., Dehairs, F., Deng, F., Dieu, H.T., Dulaquais, G., Echegoyen-Sanz, Y., Lawrence Edwards, R., Fahrbach, E., Fitzsimmons, J., Fleisher, M., Frank, M., Friedrich, J., Fripiat, F., Galer, S.J.G., Gamo, T., Solsona, E.G., Gerringa, L.J.A., Godoy, J.M., Gonzalez, S., Grossteffan, E., Hatta, M., Hayes, C.T., Heller, M.I., Henderson, G., Huang, K.-F., Jeandel, C., Jenkins, W.J., John, S., Kenna, T.C., Klunder, M., Kretschmer, S., Kumamoto, Y., Laan, P., Labatut, M., Lacan, F., Lam, P.J., Lannuzel, D., le Moigne, F., Lechtenfeld, O.J., Lohan, M.C., Lu, Y., Masqué, P., McClain, C.R., Measures, C., Middag, R., Moffett, J., Navidad, A., Nishioka, J., Noble, A., Obata, H., Ohnemus, D.C., Owens, S., Planchon, F., Pradoux, C., Puigcorbé, V., Quay, P., Radic, A., Rehkämper, M., Remenyi, T., Rijkenberg, M.J.A., Rintoul, S., Robinson, L.F., Roeske, T., Rosenberg, M., van der Loeff, M.R., Ryabenko, E., Saito, M.A., Roshan, S., Salt, L., Sarthou, G., Schauer, U., Scott, P., Sedwick, P.N., Sha, L., Shiller, A.M., Sigman, D.M., Smethie, W., Smith, G.J., Sohrin, Y., Speich, S., Stichel, T., Stutsman, J., Swift, J.H., Tagliabue, A., Thomas, A., Tsunogai, U., Twining, B.S., van Aken, H.M., van Heuven, S., van Ooijen, J., van Weerlee, E., Venchiarutti, C., Voelker, A.H.L., Wake, B., Warner, M.J., Woodward, E.M.S., Wu, J., Wyatt, N., Yoshikawa, H., Zheng, X.-Y., Xue, Z., Zieringer, M., Zimmer, L.A., 2015. The GEOTRACES Intermediate Data Product 2014. Mar. Chem. 177, 1-8. 
Maynard, J.B., 2014. 9.11 - Manganiferous Sediments, Rocks, and Ores, in: Turekian, K.K. (Ed.), Treatise on Geochemistry (Second Edition). Elsevier, Oxford, pp. 327-349. doi:10.1016/B978-0-08-095975-7.00711-7

McCave, I.N., 1986. Local and global aspects of the bottom nepheloid layers in the world ocean. Neth. J. Sea Res. 20, 167-181.

McLennan, S.M., 1989. Rare earth elements in sedimentary rocks; influence of provenance and sedimentary processes. Rev. Mineral. Geochem. 21, 169.

Mero, J.L., 1965. (Table XXIII, pages 169-171) Manganese nodule concentrations at the surface of the Pacific Ocean sea-floor as determined by coring. Suppl. Mero JL 1965 Miner. Resour. Sea Elsevier Oceanogr. Ser. 1312 Pp Httpwwwsciencedirectcomsciencebookseries042298941suppC. doi:10.1594/PANGAEA.864076

Millero, F.J., 1990. Marine solution chemistry and ionic interactions. Mar. Chem. 30, 205-229.

Mohwinkel, D., Kleint, C., Koschinsky, A., 2014. Phase associations and potential selective extraction methods for selected high-tech metals from ferromanganese nodules and crusts with siderophores. Appl. Geochem. 43, 13-21. doi:10.1016/j.apgeochem.2014.01.010

Morel, F.M.M., Milligan, A.J., Saito, M.A., 2003. Marine Bioinorganic Chemistry: The Role of Trace Metals in the Oceanic Cycles of Major Nutrients., in: Turekian, K.K. (Ed.), Treatise on Geochemistry. Pergamon, Oxford, pp. 113-143. doi:10.1016/B0-08-043751-6/06108-9

Morgan, J.J., Stumm, W., 1965. The role of multivalent metal oxides in limnological transformations as exemplified by iron and manganese, in: Jaag, O. (Ed.), Advances in Water Pollution Research. Proceedings of the Second International Conference Held in Tokyo, August 1964. Pergamon, London, pp. 103-118.

Mukhopadhyay, R., Ghosh, A.K., 2010. Dynamics of formation of ferromanganese nodules in the Indian Ocean. J. Asian Earth Sci. 37, 394-398. doi:10.1016/j.jseaes.2009.09.003

Mukhopadhyay, R., Ghosh, A.K., Iyer, S., 2008. The Indian Ocean nodule field: Geology and resource potential. Elsevier.

Muller, G., Gastner, M., 1971. The "Karbonat-Bombe", a simple device for the determination of carbonate content in sediments, soils and other materials. Neues Jahrb. Mineral. 10, 466-469.

Murray, J.W., Brewer, P.G., 1977. Mechanisms of Removal of Manganese, Iron and Other Trace Metals from Sea Water, in: G.P. Glasby (Ed.), Elsevier Oceanography Series. Elsevier, pp. 291-325. doi:10.1016/S04229894(08)71024-9

Northcote, L.C., Neil, H.L., 2005. Seasonal variations in foraminiferal flux in the Southern Ocean, Campbell Plateau, New Zealand. Mar. Micropaleontol. 56, 122 137. doi:10.1016/j.marmicro.2005.05.001

Orians, K.J., Boyle, E.A., Bruland, K.W., 1990. Dissolved titanium in the open ocean. Nature 348, 322-325. doi:10.1038/348322a0

Orians, K.J., Bruland, K.W., 1986. The biogeochemistry of aluminum in the Pacific Ocean. Earth Planet. Sci. Lett. 78, 397-410.

Orians, K.J., Bruland, K.W., 1985. Dissolved aluminium in the central North Pacific. Nature 316, 427-429. doi:10.1038/316427a0

Orsi, A., Whitworth, T., Nowlin, W., 1995. On the meridional extent and fronts of the Antarctic Circumpolar Current. Deep Sea Res. Part Oceanogr. Res. Pap. 42, 641673. 
Pante, E., Simon-Bouhet, B., 2013. marmap: A Package for Importing, Plotting and Analyzing Bathymetric and Topographic Data in R. PLOS ONE 8, e73051. doi:10.1371/journal.pone.0073051

Piper, D.Z., 1974. Rare earth elements in ferromanganese nodules and other marine phases. Geochim. Cosmochim. Acta 38, 1007-1022. doi:10.1016/00167037(74)90002-7

Plant, A., 2015. Abyssal Archives: Unravelling the Late Neogene evolution of the Pacific Deep Western Boundary Current from the New Zealand sector of the Southern Ocean (Masters in Science). Victoria University of Wellington, Wellington, New Zealand.

Post, J.E., 1999. Manganese oxide minerals: Crystal structures and economic and environmental significance. Proc. Natl. Acad. Sci. 96, 3447-3454.

Post, J.E., Bish, D.L., 1988. Rietveld refinement of the todorokite structure. Am. Mineral. $73,861$.

Puteanus, D., Halbach, P., 1988. Correlation of Co concentration and growth rate-a model for age determination of ferromanganese crusts. Chem. Geol. 69, 71-85.

Ragnarsdóttir, K.V., 2008. Rare metals getting rarer. Nat. Geosci. 1, 720-721.

Raven, J.A., 1990. Predictions of Mn and Fe use efficiencies of phototrophic growth as a function of light availability for growth and of $\mathrm{C}$ assimilation pathway. New Phytol. 116, 1-18. doi:10.1111/j.1469-8137.1990.tb00505.x

Resing, J.A., Sedwick, P.N., German, C.R., Jenkins, W.J., Moffett, J.W., Sohst, B.M., Tagliabue, A., 2015. Basin-scale transport of hydrothermal dissolved metals across the South Pacific Ocean. Nature 523, 200-203.

Rintoul, S.R., Bullister, J.L., 1999. A late winter hydrographic section from Tasmania to Antarctica. Deep Sea Res. Part Oceanogr. Res. Pap. 46, 1417-1454. doi:10.1016/S0967-0637(99)00013-8

Roshan, S., Wu, J., Jenkins, W.J., 2016. Long-range transport of hydrothermal dissolved $\mathrm{Zn}$ in the tropical South Pacific. Mar. Chem. 183, 25-32. doi:10.1016/j.marchem.2016.05.005

Rothwell, R.G., Croudace, I. w., 2015. Twenty Years of XRF Core Scanning Marine Sediments: What Do Geochemical Proxies Tell Us?, in: Croudace, I.W., Rothwell, R.G. (Eds.), Micro-XRF Studies of Sediment Cores. Springer Netherlands, Dordrecht, pp. 25-102.

Rudnick, R.L., Gao, S., 2003. Composition of the continental crust, in: Treatise on Geochemistry. Elsevier, pp. 1-64.

Sageman, B.B., Lyons, T.W., 2003. 7.06 - Geochemistry of Fine-grained Sediments and Sedimentary Rocks, in: Turekian, K.K. (Ed.), Treatise on Geochemistry. Pergamon, Oxford, pp. 115-158. doi:10.1016/B0-08-043751-6/07157-7

Sander, S.G., Koschinsky, A., 2011. Metal flux from hydrothermal vents increased by organic complexation. Nat. Geosci. 4, 145-150.

Schlitzer, R., 2015. Data Analysis and Visualization with Ocean Data View, CMOS Bulletin SCMO, 43 (1), pp. 9-13.

Schuur, C.L., Coffin, M.F., Frohlich, C., Massell, C.G., Karner, G.D., Ramsay, D., Caress, D.W., 1998. Sedimentary regimes at the Macquarie Ridge Complex: Interaction of Southern Ocean circulation and plate boundary bathymetry. Paleoceanography 13, 646-670. doi:10.1029/98PA02357

Sclater, F.R., Boyle, E., Edmond, J.M., 1976. On the marine geochemistry of nickel. Earth Planet. Sci. Lett. 31, 119-128. doi:10.1016/0012-821X(76)90103-5

Scott, S.D., 2008. Mineral deposits in the sea: second report of the Engineering Committe on Ocean Resources (ECOR) panel on marine mining (No. 2). ECOR, Cornwall, UK.

Smith, D.B., 1995. Manganese Nodule NOD-P-1. USGS, Denver, Colarado. 
Sokolov, S., Rintoul, S., 2000. Circulation and water masses of the southwest Pacific: WOCE Section P11, Papua New Guinea to Tasmania. J. Mar. Res. 58, 223-268.

Speich, S., 2008. M166 BONUS-GOODHOPE Cruise Report (Cruise Report). GEOTRACES.

Stanton, B.R., Morris, M.Y., 2004. Direct velocity measurements in the Subantarctic Front and over Campbell Plateau, southeast of New Zealand. J. Geophys. Res. Oceans 109, C01028.

Steele, J.H., Thorpe, S.A., Turekian, K.K., 2009. Marine Chemistry \& Geochemistry : A derivative of the Encyclopedia of Ocean Sciences. Elsevier Science, Burlington, UNITED STATES.

Stickley, C.E., Carter, L., Mccave, I.N., Weaver, P.P.E., 2013. Lower Circumpolar Deep Water Flow Through the SW Pacific Gateway for the Last $190 \mathrm{Ky}$ : Evidence from Antarctic Diatoms, in: The Oceans and Rapid Climate Change. American Geophysical Union, pp. 101-116. doi:10.1029/GM126p0101

Stoffers, P., Glasby, G.P., Frenzel, G., 1984. Comparison of the characteristics of manganese micronodules from the equatorial and south-west Pacific. Mineral. Petrol. 33, 1-23.

Stumm, W., Lee, G.F., 1961. Oxygenation of Ferrous Iron. Ind. Eng. Chem. 53, 143-146. doi:10.1021/ie50614a030

Stumm, W., Morgan, J.J., 1996. Aquatic Chemistry. Wiley, New York.

Summerhayes, C.P., 1967a. Marine environments of economic mineral deposition around New Zealand: A review. N. Z. J. Mar. Freshw. Res. 1, 267-282. doi:10.1080/00288330.1967.9515204

Summerhayes, C.P., 1967b. Manganese nodules from the South-Western Pacific. N. Z. J. Geol. Geophys. 10, 1372-1381. doi:10.1080/00288306.1967.10423222

Talley, L.D., Pickard, G.L., Emery, W.J., Swift, J.H., 2011a. Chapter 3 - Physical Properties of Seawater, in: Descriptive Physical Oceanography (Sixth Edition). Academic Press, Boston, pp. 29-65. doi:10.1016/B978-0-7506-4552-2.10003-4

Talley, L.D., Pickard, G.L., Emery, W.J., Swift, J.H., 2011b. Chapter 10 - Pacific Ocean, in: Descriptive Physical Oceanography (Sixth Edition). Academic Press, Boston, pp. 303-362. doi:10.1016/B978-0-7506-4552-2.10010-1

Talley, L.D., Pickard, G.L., Emery, W.J., Swift, J.H., 2011c. Chapter 13 - Southern Ocean, in: Descriptive Physical Oceanography (Sixth Edition). Academic Press, Boston, pp. 437-471. doi:10.1016/B978-0-7506-4552-2.10013-7

Tebo, B.M., Bargar, J.R., Clement, B.G., Dick, G.J., Murray, K.J., Parker, D., Verity, R., Webb, S.M., 2004. BIOGENIC MANGANESE OXIDES: Properties and Mechanisms of Formation. Annu. Rev. Earth Planet. Sci. 32, 287-328. doi:10.1146/annurev.earth.32.101802.120213

Tebo, B.M., Johnson, H.A., McCarthy, J.K., Templeton, A.S., 2005. Geomicrobiology of manganese(II) oxidation. Trends Microbiol. 13, 421-428. doi:10.1016/j.tim.2005.07.009

Terashima, S., Usui, A., Imai, N., 1995. Two new GSJ geochemical reference samples: syenite Jsy-1 and manganese nodule JMn-1. Geostand. Geoanalytical Res. 19, 221-229.

Thamdrup, B., 2000. Bacterial Manganese and Iron Reduction in Aquatic Sediments. doi:10.1007/978-1-4615-4187-5_2

Turekian, K.K., 1977. The fate of metals in the oceans. Geochim. Cosmochim. Acta 41, 1139-1144.

van Hulten, M.M.P., Middag, R., Dutay, J.-C., de Baar, H.J.W., Roy-Barman, M., Gehlen, M., Tagliabue, A., Sterl, A., 2017. Manganese in the West Atlantic Ocean in context of the first global ocean circulation model of manganese. Biogeosciences 14, 1123-1152. doi:10.5194/bg-14-1123-2017 
Vance, D., Little, S.H., de Souza, G.F., Khatiwala, S., Lohan, M.C., Middag, R., 2017. Silicon and zinc biogeochemical cycles coupled through the Southern Ocean. Nat. Geosci. 10, 202-206. doi:10.1038/ngeo2890

Verlaan, P.A., Cronan, D.S., Morgan, C.L., 2004. A comparative analysis of compositional variations in and between marine ferromanganese nodules and crusts in the South Pacific and their environmental controls. Prog. Oceanogr. 63, 125-158. doi:10.1016/j.pocean.2004.11.001

von Stackelberg, U., 2000. Manganese nodules of the Peru basin, in: Cronan, D.S. (Ed.), Handbook of Marine Mineral Deposits, CRC Marine Science Series. CRC Press, Boca Raton, pp. 197-238.

von Stackelberg, U., 1987. Growth History and Variability of Manganese Nodules of the Equatorial North Pacific, in: Teleki, P.G., Dobson, M.R., Moore, J.R., von Stackelberg, U. (Eds.), Marine Minerals: Advances in Research and Resource Assessment. Springer Netherlands, Dordrecht, pp. 189-204. doi:10.1007/978-94009-3803-8_14

Wegorzewski, A.V., Kuhn, T., 2014. The influence of suboxic diagenesis on the formation of manganese nodules in the Clarion Clipperton nodule belt of the Pacific Ocean. Mar. Geol. 357, 123-138. doi:10.1016/j.margeo.2014.07.004

Wegorzewski, A.V., Kuhn, T., Dohrmann, R., Wirth, R., Grangeon, S., 2015. Mineralogical characterization of individual growth structures of Mn-nodules with different $\mathrm{Ni}+\mathrm{Cu}$ content from the central Pacific Ocean. Am. Mineral. 100, 2497-2508.

Whitworth, T., Warren, B.A., Nowlin Jr, W.D., Rutz, S.B., Pillsbury, R.D., Moore, M.I., 1999. On the deep western-boundary current in the Southwest Pacific Basin. Prog. Oceanogr. 43, 1-54.

Wright, I.C., Graham, I.J., Chang, S.W., Choi, H., Lee, S.R., 2005. Occurrence and physical setting of ferromanganese nodules beneath the Deep Western Boundary Current, Southwest Pacific Ocean. N. Z. J. Geol. Geophys. 48, 27-41.

Wu, J., Roshan, S., Chen, G., 2014. The distribution of dissolved manganese in the tropical-subtropical North Atlantic during US GEOTRACES 2010 and 2011 cruises. Mar. Chem. 166, 9-24. doi:10.1016/j.marchem.2014.08.007 